FABIANO MORENO PERES

MÉTODOS DE MECÂNICA DA FRATURA APLICADOS A POLIETILENO DE MÉDIA DENSIDADE DESTINADO À EXTRUSÃO DE TUBOS 
FABIANO MORENO PERES

\section{MÉTODOS DE MECÂNICA DA FRATURA APLICADOS A POLIETILENO DE MÉDIA DENSIDADE DESTINADO À EXTRUSÃO DE TUBOS}

Tese apresentada à Escola Politécnica da Universidade de São Paulo para obtenção do título de Doutor em Engenharia

São Paulo 
FABIANO MORENO PERES

\section{MÉTODOS DE MECÂNICA DA FRATURA APLICADOS A POLIETILENO DE MÉDIA DENSIDADE DESTINADO À EXTRUSÃO DE TUBOS}

Tese apresentada à Escola Politécnica da Universidade de São Paulo para obtenção do título de Doutor em Engenharia Área de Concentração: Engenharia Metalúrgica e de Materiais

Orientador: Prof. Dr.Cláudio Geraldo Schön 
Este exemplar foi revisado e alterado em relação à versão original, sob responsabilidade única do autor e com a anuência de seu orientador.

São Paulo, de julho de 2009.

Assinatura do autor

Assinatura do orientador

FICHA CATALOGRÁFICA

Peres, Fabiano Moreno

Métodos de mecânica da fratura aplicados a polietileno de média densidade destinado à extrusão de tubos / F.M. Peres. -ed.rev. -- São Paulo, 2009.

$170 \mathrm{p}$.

Tese (Doutorado) - Escola Politécnica da Universidade de São Paulo. Departamento de Engenharia Metalúrgica e de Materiais.

1. Tubos 2. Distribuição de água 3. Mecânica da fratura l. Universidade de São Paulo. Escola Politécnica. Departamento de Engenharia Metalúrgica e de Materiais II. t. 
Com carinho e amor:

Aos meus pais Jordão e Aurélia À minha esposa Luciana Aos meus filhos Natália, Diego, Lívia, Fabiana e Joana Aos meus irmãos Luciana, Jordão, Laureano e Fernanda 


\section{AGRADECIMENTOS}

Agradeço a todas as pessoas que contribuíram para o desenvolvimento deste trabalho, especialmente:

Ao amigo e orientador Prof. Dr. Cláudio Geraldo Schön, pela confiança e segura orientação.

Aos professores da Escola Politécnica da Universidade de São Paulo.

Aos amigos Clélia, Vera, Gilberto, Rubens, Lívio, Danilo, Rafael, Kléber, Vinícius e demais técnicos e funcionários do Departamento de Engenharia Metalúrgica e de Materiais da Escola Politécnica da Universidade de São Paulo PMT/EPUSP, pela inestimável colaboração.

Aos amigos da pós-graduação do PMT/EPUSP pela convivência fraterna.

Às empresas Dow Brasil S.A., Braskem S.A., Ipiranga Petroquímica S.A., Solvay Indupa do Brasil S.A., pelo fornecimento de materiais.

À Coordenação de Aperfeiçoamento de Pessoal de Nível Superior - CAPES, pela bolsa concedida.

Ao meus sogros Dr. Michel e Dna. Lourdes.

Ao professor Fuad.

À minha prima Glória. 
To make brittle solids strong, we must first understand what makes them weak.

(Brian Lawn)

Omnium rerum principia parva sunt. O começo de todas as coisas é pequeno

(Marcus Tullius Cicero) 


\section{RESUMO}

O polietileno de média densidade (PEMD) é um polímero termoplástico parcialmente cristalino, cujo uso tem crescido bastante em aplicações de engenharia, como em tubos plásticos para sistemas de distribuição de água e de gás. Sob carga constante, entretanto, este material pode eventualmente apresentar fratura por fluência, por meio de um mecanismo de crescimento lento de trincas, provocando acentuadas perdas por vazamento nos sistemas. Os métodos atuais empregados pela indústria para estimar a durabilidade dos tubos são caros, demorados, pouco práticos e imprecisos. Busca-se o desenvolvimento de técnicas mais eficientes, sendo que os métodos da mecânica da fratura são promissores no sentido de descrever a etapa de propagação da trinca. Ensaios de mecânica da fratura, entretanto, requerem a introdução de pré-trincas nos corpos de prova. Sabe-se que as técnicas artificiais de introdução de pré-trincas causam algum tipo de dano na matriz polimérica, que pode ou não afetar os resultados dos ensaios, dependendo dos eventos que ocorrerem após o carregamento inicial. A principal propriedade requerida de um método de introdução de pré-trinca, portanto, é reprodutibilidade. Neste estudo foram aplicados três importantes métodos de mecânica da fratura ao PEMD e investigados os efeitos de diferentes técnicas de introdução de pré-trincas sobre os resultados dos ensaios e sobre as estruturas de deformação na matriz do material na ponta da trinca. Os ensaios de tenacidade à fratura no estado plano de deformação - $K_{l c}$ - foram realizados em condições criogênicas, em vista do comportamento dúctil do material à temperatura ambiente, sendo que a estratégia mostrou-se satisfatória. Os resultados dos ensaios de Integral-J sugerem que o método pode não ser aplicável ao PEMD, devido ao peculiar mecanismo de fratura do material. O método do trabalho essencial de fratura - EWF - se aplica bem ao PEMD. Os resultados dos ensaios de $K_{l c}$ e EWF demonstraram que diferentes técnicas de introdução de pré-trincas provocam diferentes estruturas de deformação no material na ponta da trinca e afetam os resultados de ensaios de fratura no PEMD. Os resultados de EWF demonstraram ainda que o processamento também afeta as propriedades de fratura do material. É proposta uma nova técnica para a introdução de pré-trincas, com características mais naturais, a qual requer estudos complementares para seu aperfeiçoamento. 
Palavras-chave: Polietileno. Tubos. Distribuição de água. Distribuição de gás. Mecânica da Fratura. Tenacidade à fratura no estado plano de deformação. Trabalho Essencial de Fratura. Integral-J. 


\section{ABSTRACT}

Medium density polyethylene (MDPE) is a semicrystalline thermoplastic polymer that has been increasingly used in engineering applications, as plastic pipes for water and gas distribution systems. Under constant load, however, this material may occasionally present creep failure, by means of a mechanism of slow crack growth, leading to leakage losses in the systems. Current methods used by industry to estimate durability of pipes are expensive, time consuming, non practical and inaccurate. The development of more efficient methods is a common target and fracture mechanics methods are promising in describing the crack propagation stage. Fracture mechanics testing methods, however, require the introduction of pre-cracks into the specimens. It is known that artificial methods of introducing pre-cracks produce some damage on the polymeric matrix, which may or not affect the results of tests, depending on the events that occur after the initial loading. Main propriety required of a pre-crack introducing method, therefore, is reproducibility. In this study three important fracture mechanics methods were applied to MDPE and the effects of different methods of pre-cracking over test results and over deformation structures of material matrix at the crack tip were investigated. Plane-strain fracture toughness $K_{I c}$ - tests were performed under cryogenic conditions, in view of the ductile behavior of material at room temperature and this strategy was well succeed. Results of Integral-J tests suggest that this method may not be applicable to MDPE, due to the peculiar fracture mechanism of the material. The essential work of fracture method EWF - is well suited to study MDPE. The results of $K_{I c}$ and EWF tests showed that different pre-cracking methods cause different deformation structures in the material at the crack tip and affect the fracture tests with MDPE. EWF results showed also that the processing affect the fracture properties of materials too. It is proposed a new method for introducing pre-cracks, with more natural characteristics that requires complementary studies for its improving.

Keywords: Polyethylene. Pipes. Water distribution. Gas distribution. Plane-strain fracture toughness. Essential work of fracture. J-Integral. 


\section{LISTA DE SÍMBOLOS}

\section{SÍMBOLOS LATINOS}

a comprimento de trinca

A Área

$\mathrm{A}_{\mathrm{pl}} \quad$ Área correspondente à deformação plástica, sob a curva carga-deslocamento

b ligamento do corpo de prova

B Espessura de corpo de prova (menos corpo de prova para ensaio de trabalho essencial de fratura

c Coeficiente empregado em critério para definição da região de domínio de J

C Módulo de flexibilidade (compliance)

$\mathrm{C}_{1} \quad$ Constante pré-exponencial na relação de potência para J

$\mathrm{C}_{2} \quad$ Expoente na relação de potência de $\mathrm{J}$

$\mathrm{d}_{\mathrm{m}} \quad$ Constante do material

D Diâmetro de roletes

e largura (abertura) do entalhe

E Módulo de elasticidade (ou de rigidez)

F Força; estatística de Snedecor

G Força de extensão de trinca

$\mathrm{G}_{\mathrm{c}} \quad$ Valor crítico da força de extensão de trinca

$\mathrm{G}_{\mathrm{Ic}}$ Valor crítico da força de extensão de trinca no estado plano de deformação e modo de abertura de trinca

$\mathrm{H}_{0} \quad$ Hipótese nula

$\vec{i} \quad$ Versor na direção $\mathrm{x}$

$I_{m} \quad$ Constante que depende da relação tensão-deformação

$\vec{j} \quad$ Versor na direção y

J Integral-J

$\mathrm{J}_{\mathrm{el}} \quad$ Componente elástica de $\mathrm{J}$

$\mathrm{J}_{\mathrm{Ic}} \quad$ Valor crítico da integral-J no estado plano de deformação e modo de abertura de trinca

$\mathrm{J}_{\max } \quad$ Valor máximo de $\mathrm{J}$

$\mathrm{J}_{\mathrm{pl}} \quad$ Componente plástica de $\mathrm{J}$ 
K Fator de intensidade de tensão

$\mathrm{K}_{\mathrm{c}} \quad$ Valor crítico do fator de intensidade de tensão

$\mathrm{K}_{\mathrm{Ic}} \quad$ Tenacidade à fratura no estado plano de deformação

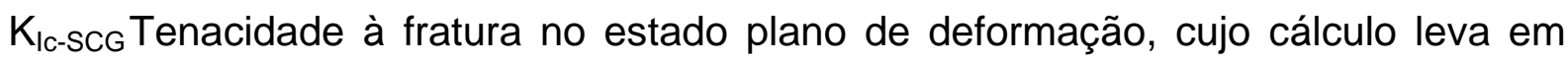
conta o crescimento estável de trinca inicial

$\mathrm{K}_{\mathrm{Q}} \quad$ Valor provisório do fator de intensidade de tensão

L Comprimento do corpo de prova

$L_{(x, y)} \quad$ Função $L_{(x, y)}$

M Momento fletor; coeficiente na inclinação de retas de exclusão

$\bar{M}_{n} \quad$ Massa molecular numérica média

$\bar{M}_{w} \quad$ Massa molecular ponderal média

$\bar{M}_{Z} \quad$ Massa molecular Z-média

$M_{(x, y)}$ Função $M_{(x, y)}$

m Inverso do expoente de endurecimento por deformação

n Expoente de endurecimento por deformação

$\mathrm{n}_{\mathrm{j}} \quad$ coseno do ângulo $\theta_{\mathrm{j}}$

$\vec{n} \quad$ Vetor normal à superfície

N Número de ciclos até ocorrência de falha por fadiga

p profundidade do entalhe

P Carga

$P_{\max }$ Carga máxima

r Raio em torna da ponta de uma trinca; coordenada polar; coeficiente de correlação linear de Pearson;

$r^{2} \quad$ Coeficiente de determinação

R Resistência da trinca

S Comprimento de arco ao longo de uma linha de integração

S Amplitude de tensão cíclica; parte de um perímetro; desvio padrão

t espessura (corpo de prova para ensaio de trabalho essencial de fratura); estatística de Student

$t_{r} \quad$ Tempo de ruptura (ou de falha)

$\vec{T} \quad$ Vetor tração

u Deslocamento

$\vec{u} \quad$ Vetor deslocamento 
U Energia

$U_{a} \quad$ Variação de energia elástica armazenada

$U_{E} \quad$ Trabalho executado por forças externas

$U_{i} \quad$ Energia de deformação antes do carregamento

$U_{p} \quad$ Energia potencial

$\cup_{\gamma} \quad$ Variação de energia elástica superficial

x Coordenada cartesiana; relação entre o comprimento da trinca inicial e a largura do corpo de prova, conforme as normas ASTM D 5045-99.

W Largura de corpo de prova; função densidade de energia de deformação

$\mathrm{W}_{\mathrm{f}} \quad$ Energia (trabalho) total absorvida no processo de fratura

$w_{e} \quad$ Trabalho essencial de fratura

$\mathrm{W}_{\mathrm{f}} \quad$ Trabalho específico de fratura

$W_{p} \quad$ Trabalho plástico não essencial por unidade de volume

y Coordenada cartesiana

\section{SÍMBOLOS GREGOS}

$\alpha \quad$ Constante do material (equação de Ramberg-Osgood)

$\beta \quad$ Fator de forma (método do trabalho essencial de fratura)

$\hat{\beta}_{i j} \quad$ Função angular

$\chi^{2} \quad$ Qui-quadrado

$\delta_{\mathrm{t}} \quad$ Abertura crítica da ponta da trinca

$\Delta \quad$ Indica uma variação (ou intervalo) de valor de uma grandeza

$\varepsilon \quad$ Deformação

$\varepsilon_{\mathrm{e}} \quad$ Deformação equivalente

$\varepsilon_{\mathrm{ij}} \quad$ Tensor deformação

$\hat{\varepsilon}_{i j} \quad$ Função angular

$\Phi \quad$ Contorno fechado

$\Gamma \quad$ Contorno arbitrário

$\eta \quad$ Fator de calibração

$v \quad$ Coeficiente de Poisson

$\theta$ Ângulo; coordenada polar 
$\sigma \quad$ Tensão

$\sigma_{\mathrm{c}} \quad$ Tensão crítica

$\sigma_{e} \quad$ Tensão equivalente de Von Mises

$\sigma_{\mathrm{e}} \quad$ Tensão equivalente de Von Mises

$\sigma_{\mathrm{m}} \quad$ Média das tensões máximas

$\sigma_{\max }$ Tensão máxima

$\sigma_{Y} \quad$ Resistência efetiva ao escoamento

$\sigma_{\mathrm{ij}}$ Tensor tensão

$\hat{\sigma}_{i j} \quad$ Função angular

$\tau \quad$ Trabalho

$\omega \quad$ Parâmetro utilizado para verificar se a extensão da trinca ocorre sob controle de J

Y Fator de forma 


\section{SUMÁRIO}

1 INTRODUÇÃO E REVISÃO BIBLIOGRÁFICA.....................................................

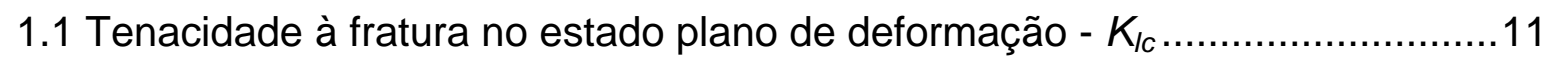

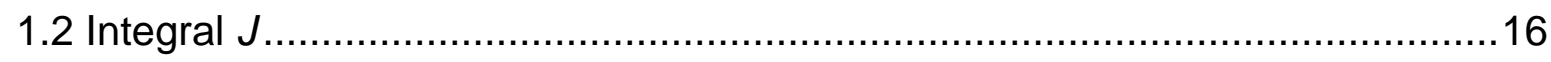

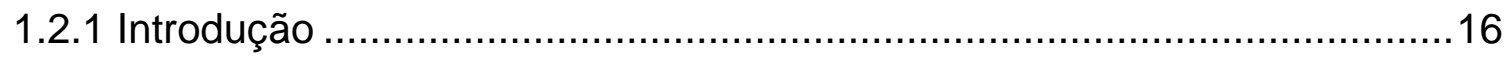

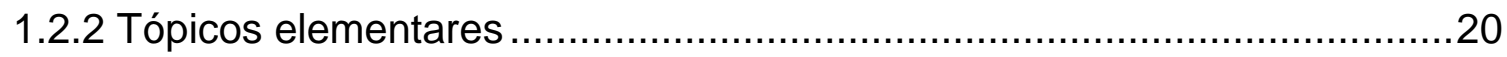

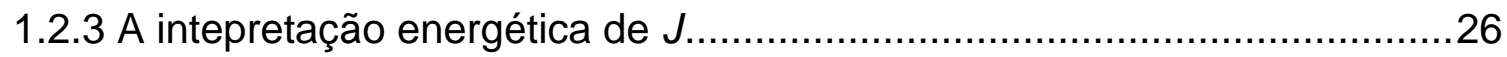

1.2.4 Definição de $J$ como uma integral de linha...............................................34

1.2.5 Aplicação de $\mathrm{J}$ em análise de corpos contendo trincas..............................36

1.2.6 J como um parâmetro de campo de tensões e deformações......................41

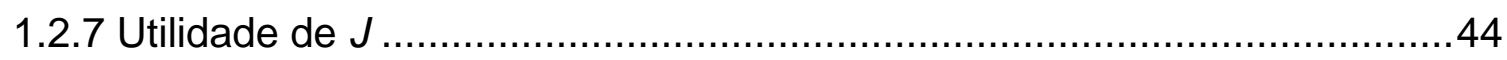

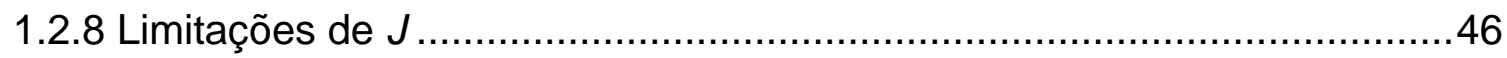

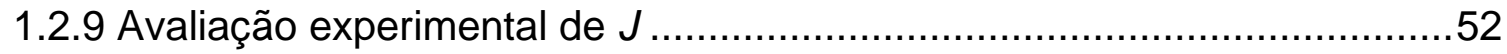

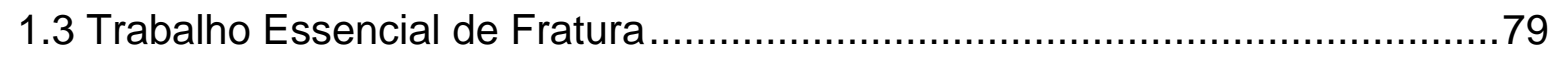

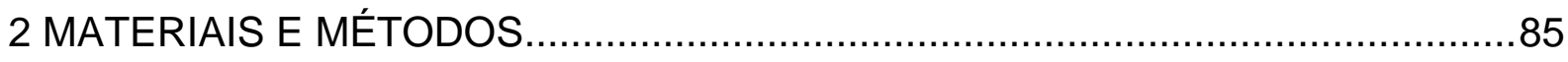

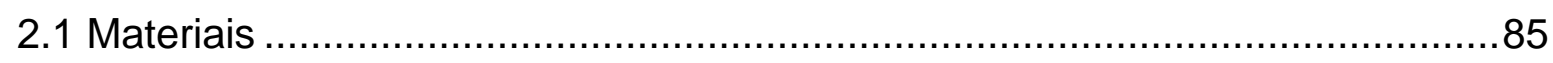

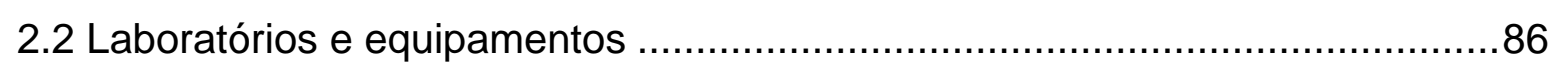

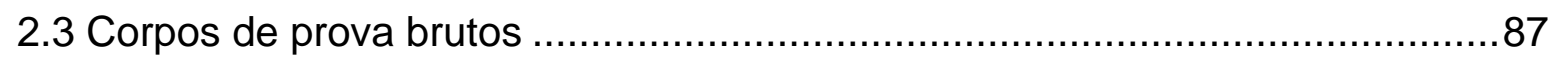

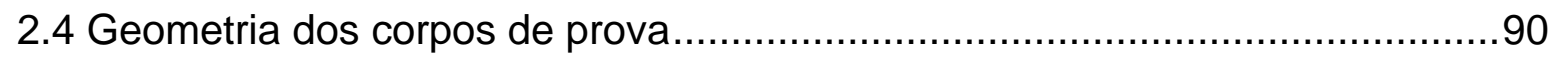

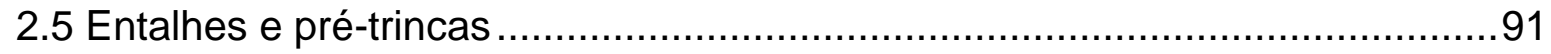

2.5.1 Corpos de prova para ensaios de $K_{l c}$ e de integral-J .............................92

2.5.2 Corpos de prova para ensaios de EWF ...............................................94

2.6 Dimensões finais e número de corpos de prova............................................96

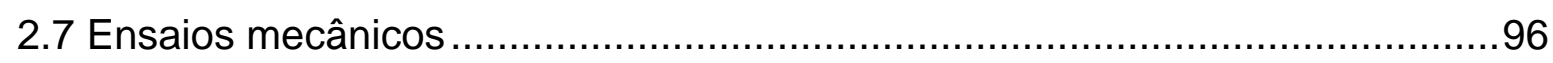

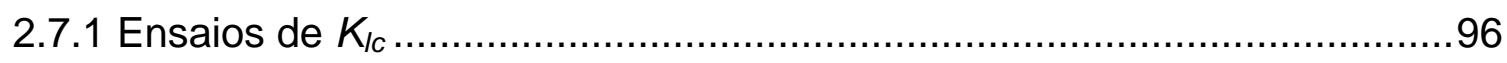

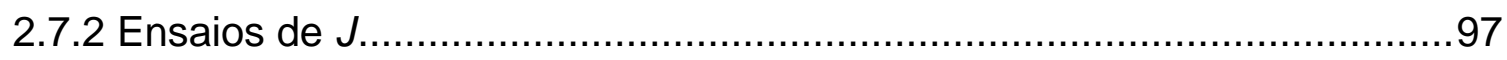

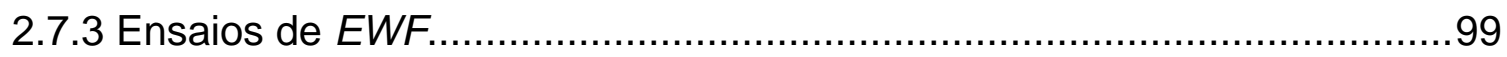

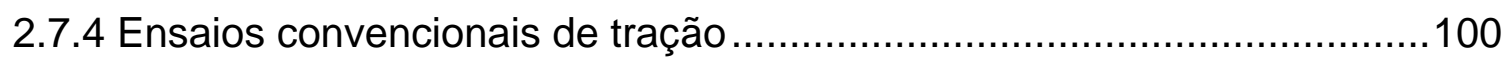

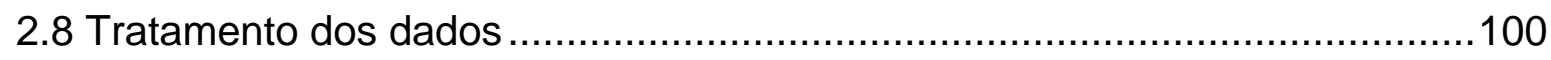

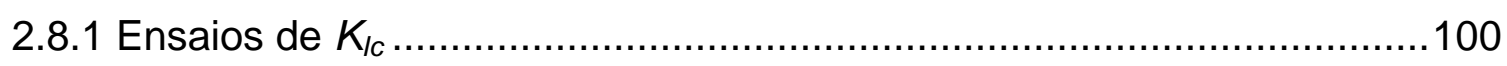

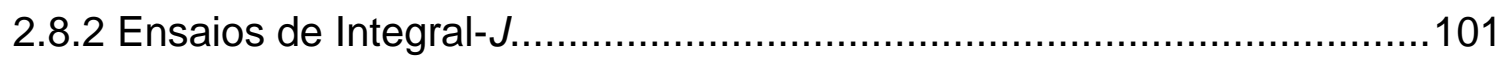

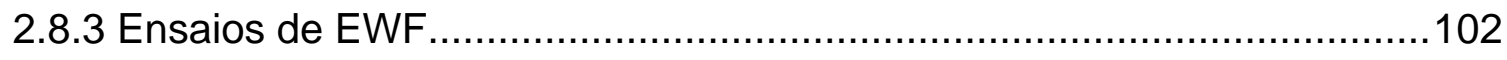




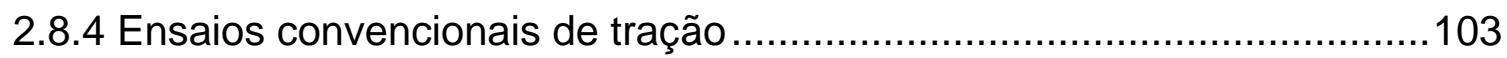

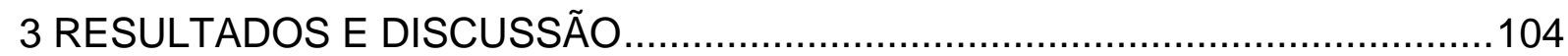

3.1 Confecção de placas de polietileno moldadas por compressão ....................104

3.2 Introdução do entalhe e da pré-trinca em corpos de prova.............................107

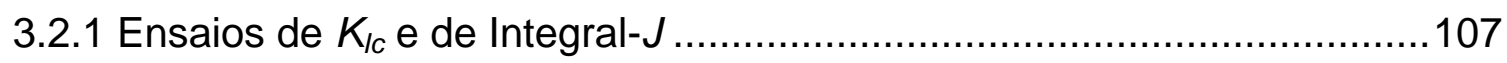

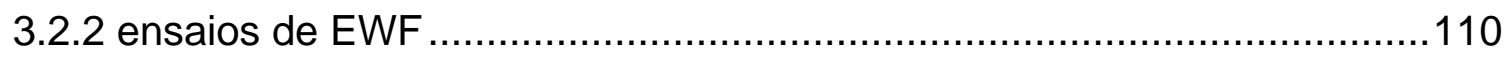

3.3 Resultados dos ensaios mecânicos......................................................114

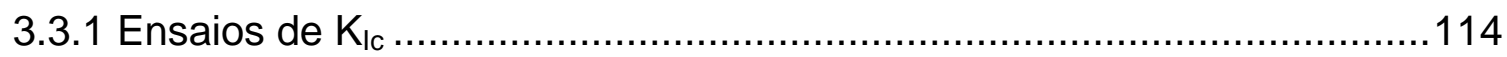

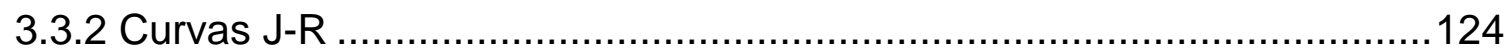

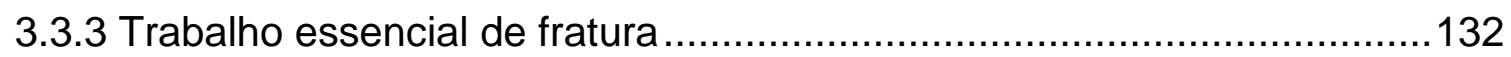

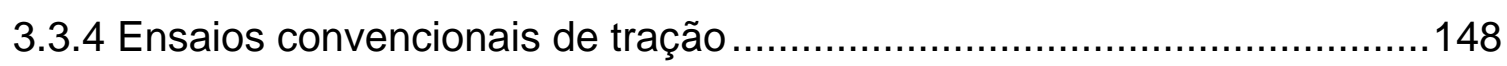

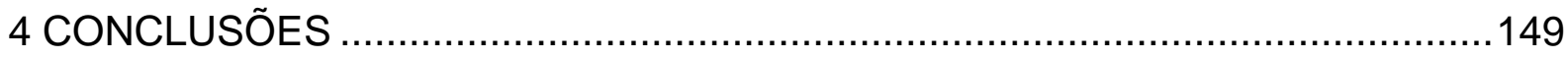

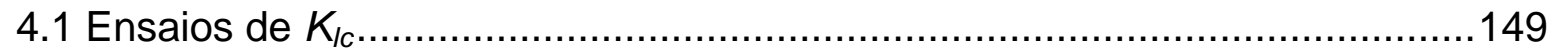

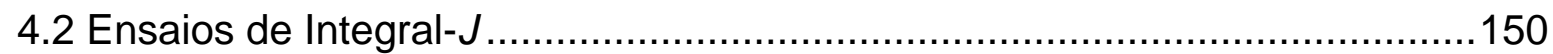

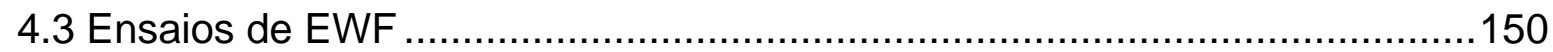

APÊNDICE A: RESULTADOS INDIVIDUAIS DOS ENSAIOS DE EWF ................151

A1 Resultados individuais de EWF da série S-0..........................................151

A2 Resultados individuais de EWF da série S-1........................................152

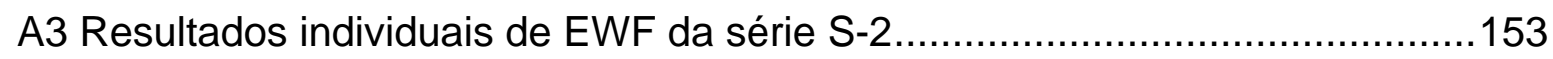

A4 Resultados individuais de EWF da série S-3..........................................154

A5 Resultados individuais de EWF da série S-4 ..........................................155

A6 Resultados individuais de EWF da série S-5........................................156

A7 Resultados individuais de EWF da série S-6 .........................................157

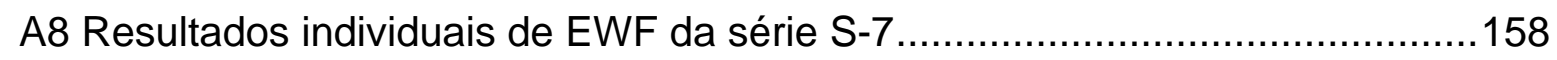

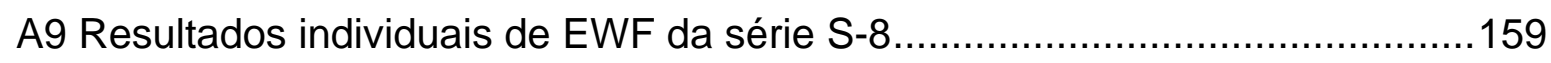

APÊNDICE B: CURVAS DE REGRESSÃO DOS MATERIAIS ............................160

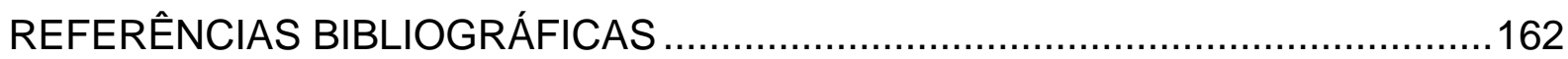




\section{INTRODUÇÃO E REVISÃO BIBLIOGRÁFICA}

Os polímeros têm sido cada vez mais utilizados como materiais de engenharia para fins mecânicos e estruturais (MANO, 2001; LJUNGBERG, 2003; WIEBECK; HARADA, 2005).

O polietileno de alta densidade (PEAD), por exemplo, é um polímero parcialmente cristalino que vem sendo muito empregado em algumas importantes aplicações de engenharia. Buscando-se resinas mais tenazes que o tipo linear convencional, a evolução deste material levou às gerações mais recentes, as quais formam uma classe de polietileno que tem sido designada por polietileno de média densidade (PEMD). São polímeros obtidos por meio de processos avançados de síntese, envolvendo técnicas de copolimerização, manipulação da distribuição de massas moleculares e controle de ramificações na cadeia principal, entre outros detalhes. Estes novos materiais têm sido utilizados em sistemas onde a integridade estrutural é crítica. Como exemplo, podemos citar a aplicação em tubos para distribuição de água e gás (MILLS, 1993; JANSON, 2003), onde o material deve resistir a tensões durante dezenas de anos. Nestas aplicações o material pode eventualmente sofrer fratura em serviço, comprometendo o desempenho do sistema e levando a acentuadas perdas por vazamento de água, riscos de incêndio e explosão e a elevados custos de manutenção. Saliente-se ainda que a água é um recurso escasso, cuja preservação constitui um dos temas centrais das preocupações ambientais da sociedade moderna. No âmbito nacional, entre outras iniciativas, as questões relativas à água e sua conservação têm provocado a aproximação entre instituições de fomento à pesquisa e a indústria de saneamento, envolvendo vultosos investimentos, na busca por melhor conhecimento científico e tecnológico para o efetivo combate às perdas de água, o que certamente inclui os materiais empregados nos sistemas de distribuição de água (A ARQUITETURA..., 2009).

Admite-se que as falhas em serviço sejam provocadas pelo desenvolvimento de um mecanismo particular conhecido como crescimento lento de trincas (slow crack growth - SCG) (LU; QIAN; BROWN, 1991a; BROWN et al, 1991; ROSE et al, 1994; HAMOUDA et al, 2001) e o problema tem demandado considerável esforço da indústria petroquímica no desenvolvimento de compostos de polietileno mais 
resistentes (FAYOLLE; VERDU, 2005; KRISHNASWAMY, 2005; KRISHNASWAMY; LAMBORN, 2005). Por enquanto, as modernas gerações de tubos têm demonstrado bom desempenho no campo e nos testes de longo prazo tradicionalmente adotados pela indústria. Entretanto, o comportamento mecânico em fratura do polietileno - e, por conseguinte dos tubos - ainda não é totalmente compreendido, de forma que a durabilidade destes e a sua integridade estrutural ao longo de toda sua vida-útil projetada não são garantidas.

A vida-útil desejada dos tubos é longa - na maior parte dos casos superior a 50 anos (JANSON, 2003), tornando-se obviamente impraticável realizar testes de desempenho dos tubos ao longo de todo esse período. Para contornar a dificuldade, a prática tem sido a realização de ensaios de menor duração, sob condições aceleradas e, a partir dos dados obtidos, empregar alguma técnica de extrapolação para estimar a durabilidade do componente.

A resistência à falha em serviço é tradicionalmente avaliada por meio de testes de resistência à pressão hidrostática interna de longa duração (long-term hydrostatic strength - LTHS), nos quais segmentos de tubos extrudados são submetidos a diferentes pressões internas, geralmente com água, em diferentes temperaturas. Nestes testes, para uma dada condição, registram-se o tempo e o tipo de falha, que pode ocorrer de dois modos principais: (i) um modo dúctil, caracterizado por extensiva deformação plástica (abaulamento da parede) seguido de ruptura, típico de altas tensões, e (ii) um modo frágil (brittle-like ${ }^{1}$ ), na forma de pequenas fissuras longitudinais, com reduzida ou nenhuma deformação plástica apreciável (slit failures), característico de tensões aplicadas moderadas ou baixas Os resultados são registrados em curvas bi-logarítmicas da tensão circunferencial (a tensão principal, de máxima intensidade na parede do tubo) contra o tempo de falha, as quais são conhecidas por "curvas de regressão" (PERES; SCHÖN, 2006; PERES; SCHÖN, 2007). O comportamento destas curvas é linear (o tempo de falha segue uma lei de potência com expoente negativo), com baixa inclinação na região inicial, correspondente às tensões mais altas, mas com uma acentuada alteração na inclinação a partir da região de transição entre os modos de falha dúctil e frágil. A

\footnotetext{
${ }^{1}$ Neste texto serão utilizadas algumas palavras em Inglês, como brittle-like e crazes, entre outras, porque elas expressam de forma mais direta e clara determinados fenômenos, além de com isso se obter maior proximidade com a literatura. Nestes casos as palavras serão grafadas sempre em itálico.
} 
Figura 1 apresenta um esquema simplificado da curva de regressão, enquanto que as curvas de regressão dos materiais estudados são apresentadas no Apêndice B. As figuras 2 e 3 apresentam respectivamente, exemplos dos tipos de falha dúctil e frágil em polietileno de alta densidade.

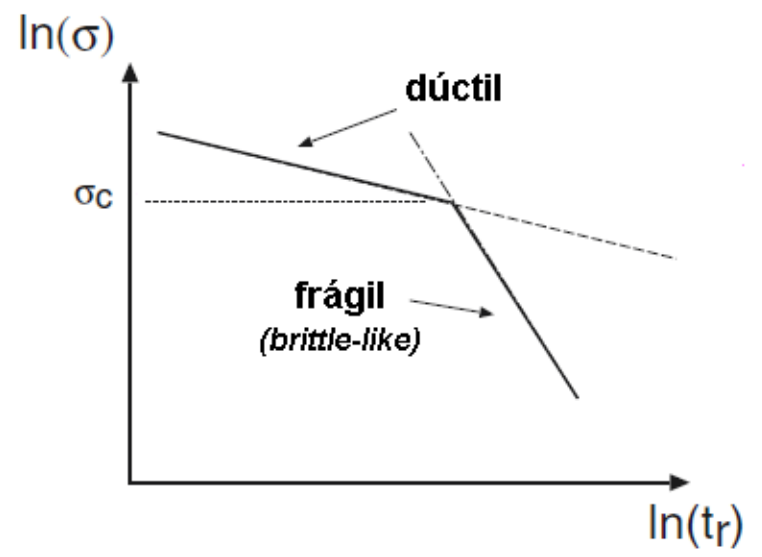

Figura 1: llustração de uma curva de regressão, como obtida em ensaios de LTHS (Adaptado de Peres e Schön, 2007).
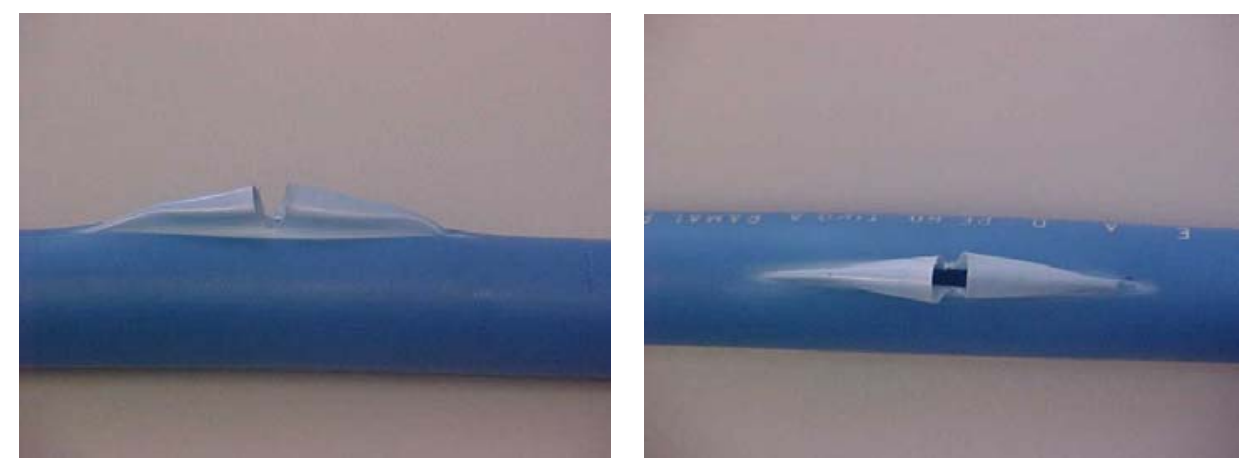

Figura 2: Falha dúctil de tubo de polietileno (abolamento seguido de ruptura dúctil)

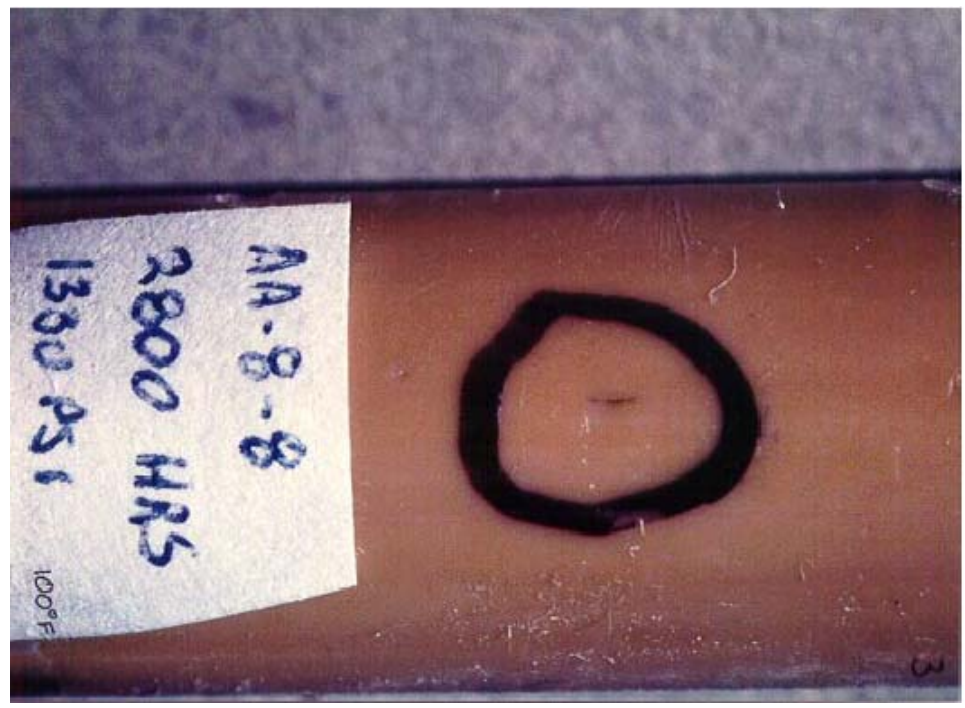

Figura 3: Falha frágil de tubo de polietileno (slit failure) (Fonte: NTSB, 1998) 
As falhas observadas em serviço são geralmente do tipo frágil, (PERES; SCHÖN, 2004; PLASTIC PIPE INSTITUTE, 2006). Por outro lado, para as resinas modernas, a inflexão que caracteriza a transição dúctil-frágil é dificilmente observada nos resultados dos ensaios de LTHS à temperatura ambiente. Para acelerar os resultados, são realizados ensaios em temperaturas mais elevadas - até $80^{\circ} \mathrm{C}$ - que se prestam para a previsão do comportamento do material à temperatura ambiente em tempos mais longos, e para garantir que a extrapolação da curva à temperatura ambiente é segura - sem inflexão - até 50 anos. Ou seja, assume-se que a linha reta construída com dados de ensaios até 10.000 horas manter-se-á reta até 100.000 horas, e que um tubo de polietileno poderá trabalhar com segurança, isto é, sem falhas, quando submetido a uma tensão circunferencial máxima igual à tensão extrapolada para 50 anos na curva de regressão, à temperatura ambiente $\left(23^{\circ} \mathrm{C}\right)$. Este processo, descrito aqui resumidamente, é conhecido como "método de extrapolação padrão" ou Standard Extrapolation Method - SEM (ISO 9080). Os resultados são utilizados para classificação do material (na forma de tubos) e para fins de projeto e dimensionamento de tubulações (PERES, 2005).

Apesar de sua ampla aceitação pela indústria, em decorrência da aparente transferibilidade direta dos resultados para a prática, uma vez que as condições de ensaio são tomadas como equivalentes àquelas sob as quais os tubos operam quando em serviço, os testes de LTHS podem ser criticados em razão de alguns aspectos importantes (LANG; STERN; DOERNER, 1997; PERES; SCHÖN, 2007).

Primeiramente, é necessário considerar que os ensaios de LTHS são realizados sob condições controladas, assumindo-se temperatura e pressão constantes, enquanto que na prática estas duas variáveis sofrem flutuações. Além disso, para acelerar os resultados, são empregadas temperaturas mais elevadas nos ensaios de LTHS. O método de extrapolação padrão envolve um processo de validação baseado na premissa de que a falha é um fenômeno termicamente ativado, podendo ser descrito por uma equação do tipo Arrhenius. Essa suposição é válida desde que o mecanismo de falha permaneça constante. Entretanto, diversos micromecanismos podem concorrer simultaneamente para a falha, sendo alguns deles especialmente sensíveis às variações de temperatura na faixa adotada nos ensaios. Podem ainda ocorrer mudanças estruturais no material nas temperaturas mais elevadas, de forma que, segundo Progelhof e Throne (1993), a extrapolação dos dados para tempos de falha mais longos deve ser feita com cuidado, não 
devendo exceder uma década (logarítmica). Outra questão diz respeito ao fato de que os resultados dos testes de LTHS são tomados como uma propriedade de uma dada composição do material. Entretanto, eventuais imperfeições internas originais do material (como resíduos de catalisadores, por exemplo) e/ou defeitos introduzidos durante os processos de fabricação e instalação dos tubos podem atuar como pontos de concentração de tensão e aumentar a propensão à iniciação local do crescimento lento de trincas, reduzindo o tempo de falha esperado. Quanto ao meio, no caso de sistemas de água potável, nos quais o líquido transportado contém cloro residual para efeitos sanitários, o material estará também sujeito ao environment assisted cracking - EAC (PERES, 2005; HASSINEN et al, 2004; DEAR; MASON; POULTON, 2006), que muitos traduzem como "corrosão sob tensão", o qual leva à abreviação da vida-útil do componente. A curva de regressão também pode levar a resultados aparentemente paradoxais. Por exemplo, Graice; Younan e Naga (2006) verificaram que um tipo de polietileno classificado como PE 80, tradicionalmente utilizado em instalações de gás, possui maior resistência à fratura frágil que um $\mathrm{PE}$ 100, tido como um material de melhor desempenho de acordo a metodologia da curva de regressão. Peres e Schön (2008) também observaram que um material com classificação superior - também um PE 100 - apresentou maior propensão à fratura frágil que outros tipos de polietileno classificados como PE 80. Por último, deve-se salientar que os testes de LTHS são muito longos, caros e pouco práticos para fins de controle de qualidade, embora algumas alternativas mais simples, que combinam ensaios de LTHS mais curtos com ensaios de tração comuns têm sido desenvolvidas para finalidades industriais (PERES; SCHÖN, 2007).

Sob o ponto de vista micromecânico polímeros termoplásticos apresentam dois mecanismos de deformação plástica competitivos: escoamento por cisalhamento (shear yielding) e microfibrilamento (crazing) (HERTZBERG, 1995; KINLOCH; YOUNG, 1995; MEYERS; CHAWLA, 1999; CANEVAROLO JÚNIOR, 2002). Considerável evidência experimental indica que a fratura dúctil do polietileno é precedida por extenso escoamento por cisalhamento (LU; BROWN, 1990a; LU \& BROWN, 1990b), mas a propagação da fratura está sempre relacionada com a nucleação e crescimento de crazes e subseqüente ruptura das fibrilas (CAWOOD; CHANNELL; CAPACCIO, 1993; LU; ZHOU; BROWN, 1994; DUAN; WILLIAMS, 1998; CHUDNOVSKY; SHULKIN, 1999). A Figura 4 ilustra o modelo de trinca associada a crazing, segundo Chudnovsky e Shulkin (1999), enquanto a Figura 5 
demonstra a ocorrência do fenômeno durante o processo de fratura do polietileno de alta densidade.

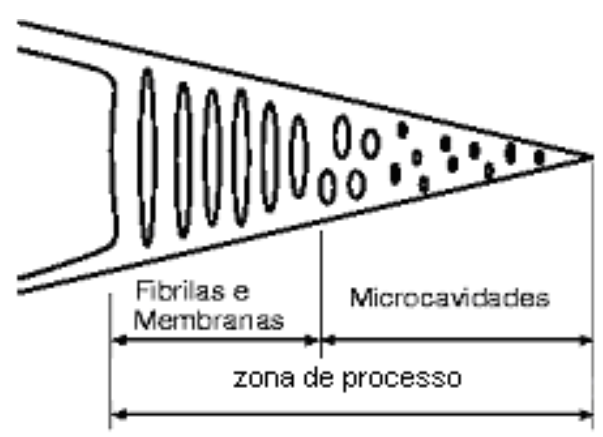

Figura 4: Desenho esquemático de craze. Chudnovsky e Shulkin (1999) idealizaram a "zona de processo" (process zone - PZ) como uma região formada por uma parte cuja estrutura é típica de crazing, como descrita acima, e uma parte composta de material com microvazios. A zona de processo integra o sistema crack layer (CL), concebido pelos autores, o qual compreende ainda a trinca. (Adaptado de CHUDNOVSKY; SHULKIN, 1999)

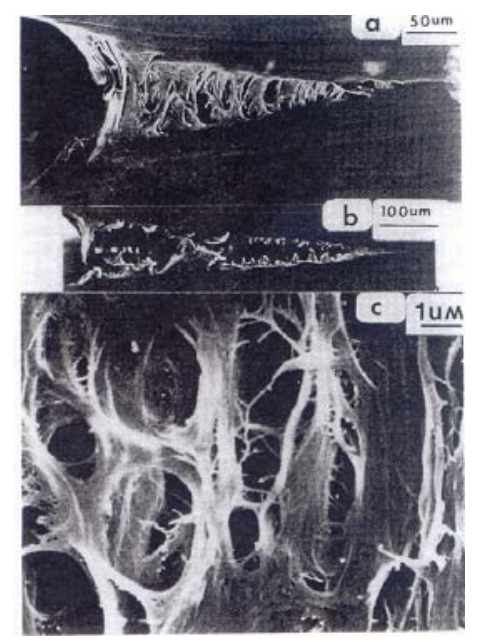

Figura 5: Morfologia da zona de processo na ponta de um entalhe em corpo de prova de polietileno de alta densidade. (a) iniciação da fratura; (b) após o crescimento da trinca; (c) estrutura detalhada das fibrilas. (Fonte: LU et al, 1994).

As considerações acima mostram que, em longo prazo, o processo de fratura do polietileno é consideravelmente complexo. Está claro, então, que uma abordagem simplista, como a das "curvas de regressão", que é um critério de tempo de falha, é sujeita a erros, já que não é hábil para manejar essa complexidade. Por exemplo, a transição dúctil-frágil observada nas "curvas de regressão" é de natureza macroscópica, mas mesmo no modo de falha frágil a observação da superfície sugere que ocorre considerável deformação plástica, indicando que o mecanismo 
microscópico é o mesmo nos dois casos (HUANG; BROWN, 1988; LU; BROWN, 1990a).

Recentemente algumas abordagens para o estudo do problema das falhas em tubos de polietileno têm sido propostas na literatura, a maioria delas baseadas em conceitos da mecânica da fratura. Por sua própria natureza esta disciplina é dedicada à descrição da propagação de trincas em um sólido, esperando-se que possa proporcionar um critério superior para o projeto de componentes estruturais de polietileno, incluindo tubos.

Dessa forma, tem se tornado cada vez mais importante a aplicação dos métodos da mecânica da fratura para a compreensão do comportamento mecânico do polietileno na presença de trincas, por meio de parâmetros como a tenacidade à fratura no estado plano de deformação - $K_{l c}$, trabalho essencial de fratura (essential work of fracture - EWF) e curvas J-R.

As análises da mecânica da fratura situam-se no nível macroscópico. Evidentemente, há uma conveniência de natureza prática no tratamento dos problemas de fratura nesta ordem de grandeza, especialmente para fins de projeto mecânico. Entretanto, as propriedades mecânicas são invariavelmente determinadas por fenômenos que ocorrem na ordem de grandeza da microestrutura do material.

O processo de fratura envolve etapas importantes, entre elas acumulação de danos, nucleação e propagação de trincas e a falha (catastrófica) final (MEYERS; CHAWLA, 1999). Cada uma dessas etapas se desenvolve numa escala característica, de forma que a modelagem do processo de fratura é, por sua própria natureza, mesoscópica.

A acumulação de danos e a nucleação da trinca estão relacionadas com estrutura molecular, com a resistência das ligações intra e intermoleculares e com a forma como essas ligações reagem ao estado de tensão aplicado. Entretanto, é muito difícil modelar integralmente o comportamento em fratura do polímero a partir de uma perspectiva molecular.

Pela abordagem da mecânica do contínuo, por outro lado, a microestrutura e a arquitetura molecular não são consideradas e o processo de fratura é descrito somente por parâmetros macroscópicos, como o conceito de fator de intensidade de tensão - K, um parâmetro da Mecânica da Fratura Elástica Linear (Linear-Elastic Fracture Mechanics - LEFM) (BARRY; DELATYCHI, 1989). Porém, este campo nos oferece a oportunidade de adotar uma nova postura em relação à estimativa da 
durabilidade de um componente, mudando do conceito "projeto seguro contra a falha" (fail-safe design), do qual a curva de regressão é um exemplo, para o de "tolerância a dano" (damage tolerance). No primeiro, considera-se que uma falha não seja esperada antes de determinado período de tempo em serviço, sendo o componente substituído ao final de sua vida útil estimada; sabe-se que há um dano crescente no material, mas ele é desconhecido e apenas o tempo de falha é considerado. Neste tipo de abordagem há certa insegurança na transferibilidade para o projeto devido à dispersão dos resultados e às incertezas intrínsecas ao processo de extrapolação de dados. No segundo caso assume-se que o componente possui um dano - uma trinca, por exemplo - que é observado, por inspeção, sendo o tempo de falha determinado a partir de sua evolução. Os critérios de projeto orientados para fadiga venceram essa mudança de postura filosófica, avançando das curvas amplitude de tensão cíclica - número de ciclos até a ocorrência da falha (também conhecidas por curvas S-N) para "ferramentas de projeto" mais modernas, como a Curva de Paris $^{2}$ (SCHÜTZ, 1996; NEWMAN JUNIOR, 1998). Espera-se que os critérios de projeto de tubos de pressão de polietileno possam também evoluir por uma trajetória semelhante. Entretanto, é necessário identificar qual (ou quais) o(s) parâmetro(s) da mecânica da fratura que melhor oriente $(\mathrm{m})$ o estudo e como avaliá-lo (s) corretamente.

No caso de materiais que apresentam comportamento elástico não linear as hipóteses da LEFM são violadas e não valem, em princípio, para materiais dúcteis e semidúcteis, como o polietileno (à temperatura ambiente), nos quais a fratura geralmente é acompanhada de significativa deformação plástica. Nestes casos as restrições para a zona plástica (small scale yielding) impõem sérias limitações para a caracterização da tenacidade por meio de parâmetros da LEFM, como K (TJONG; XU; LI, 2000; PERES; SCHÖN, 2004). Em particular, no processo de fratura do polietileno, sempre há o desenvolvimento de crazing na ponta da trinca (DUAN; WILLIAMNS, 1998) e o processo de crescimento lento (estável) de trincas não é abordado pela LEFM. Mesmo assim, apesar das limitações apontadas, importantes trabalhos foram realizados nos quais o fenômeno do crescimento lento (estável) de trincas no polietileno foi investigado com o auxílio de parâmetros da LEFM (CHAN;

\footnotetext{
${ }^{2}$ A "curva de Paris" é um gráfico em escala bi-logarítmica da taxa de crescimento da trinca sob fadiga $(d a / d N)$ versus faixa de variação do fator de intensidade de tensão $(\Delta K)$ à ponta da trinca ou defeito.
} 
WILLIAMS, 1983; QIAN; LU; BROWN, 1989; NISHIMURA; KAWAGUCHI, 2004; MOSKALA, 1998).

O estudo de polímeros com comportamento dúctil como o do polietileno é tradicionalmente desenvolvido no campo da Mecânica da Fratura Elasto-Plástica MFEP - (Elastic-Plastic Fracture Mechanics - EPFM), cujas principais abordagens são Integral-J (J-Integral), Trabalho Essencial de Fratura (Essential Work of Fracture - EWF) e abertura de ponta de trinca (crack-tip opening displacement - CTOD) (MAI; POWEL, 1991).

Os ensaios de mecânica da fratura são procedimentos relativamente complicados, exigindo, entre outros cuidados, muita atenção na confecção de corpos de prova, cuja geometria deve ser bem controlada para prevenir desvios e incertezas nos resultados.

Tipicamente, nos ensaios de mecânica da fratura são investigadas as condições críticas de carregamento que provocam o crescimento estável ou não de uma pré-trinca artificialmente introduzida na raiz de um entalhe, com dimensões e forma conhecidas, dada uma determinada geometria do corpo de prova. Na situação ideal desejada de um ensaio é reiniciada uma pré-trinca "natural" (WILLIAMS, 2001a), ou seja, um defeito semelhante a uma trinca cujo surgimento tenha ocorrido como uma resposta espontânea - natural do material - a uma solicitação mecânica controlada. Uma fissura deve satisfazer pelo menos duas exigências para ser aceita como uma trinca natural (ANDRIANOPOULOS; PIKRAKIS, 2006): não deve haver perda de massa e o raio de curvatura da ponta deve ser pequeno.

Nos materiais metálicos é amplamente reconhecido que a introdução da prétrinca por fadiga é o procedimento que proporciona os melhores resultados, tendo sido esta prática incorporada nos métodos de ensaio padronizados, como a norma ASTM E 1820. No caso dos materiais poliméricos, entretanto, a técnica de fadiga não é muito utilizada por razões práticas (WILLIAMS, 2001a). Além disso, a adoção de uma prática consensual não é tão evidente como para os metais, embora a maioria dos protocolos e métodos de ensaio padronizados preconize o uso de uma lâmina afiada (geralmente uma lâmina de barbear) para a introdução das pré-trincas, o que tem sido amplamente adotado pelos diferentes autores.

O protocolo da Sociedade Européia de Integridade Estrutural (European Structural Integrity Society - ESIS) para ensaios de tenacidade à fratura no estado plano de deformação de polímeros, por exemplo, sugere que uma trinca natural seja 
nucleada por meio de insistentes "batidinhas" (tapping on) sobre uma lâmina de barbear nova, posicionada na raiz de um entalhe previamente produzido no corpo de prova (WILLIAMS, 2001a). Se não for possível a obtenção de uma trinca natural, como é o caso de polímeros tenazes, o protocolo permite a operação da lâmina por diferentes modos, como o deslizamento (sliding), movimento de serra (sawing) ou mesmo fadiga, mas desaconselha o pressionamento da lâmina, devido ao risco de introdução de tensões residuais na ponta da trinca. A norma ASTM D 5045-99 ( $K_{l c}$, $G_{c}$ ) adota os mesmos princípios, mas não contempla a técnica de fadiga. Já a norma ASTM D 6068-96 (curvas J-R) admite também métodos de introdução de pré-trincas por fadiga ou pressionamento da lâmina como procedimentos alternativos, enquanto que o protocolo de ensaios do ESIS para construção de curvas $J-R$ não admite 0 pressionamento da lâmina.

Lu; Qian e Brown (1991b) estudaram o crescimento lento de trincas em polietileno de alta densidade e o efeito de diferentes formas de introdução de trincas artificiais nos resultados de tempo de falha e recomendam a introdução da pré-trinca por meio do pressionamento suave e controlado de uma lâmina de barbear, com auxílio de um dispositivo especialmente construído para suportar a lâmina. Em outro estudo Dapp e Rimnac (1998) compararam diferentes métodos de introdução de pré-trinca para obtenção de curvas $J-R$ de polietileno de ultra-alta massa molar e concluíram que corpos de prova cujas pré-trincas foram introduzidas por fadiga eram mais resistentes à propagação da fratura, presumidamente devido ao extenso dano introduzido na matriz polimérica, e recomendaram o pressionamento controlado da lâmina. Mais recentemente, Peres e Schön (2008) observaram uma grande dispersão nos resultados de ensaios de trabalho essencial de fratura em polietilenos de alta e média densidade destinados à fabricação de tubos de água e gás, cuja causa pode estar no método de introdução das pré-trincas adotado. Entretanto, salientaram que o dano introduzido durante a preparação da pré-trinca pode ser o fator mais relevante para a ocorrência da dispersão dos resultados, devido sua provável influência na formação da zona plástica. Souza et al (2008), utilizando condições criogênicas de ensaio, também avaliaram a tenacidade à fratura no estado plano de deformação de um polietileno de média densidade, utilizando o mesmo tipo de lâmina para introdução das pré-trincas, porém com diferentes formas de operação da ferramenta: pressionando-se suavemente a lâmina, com velocidade controlada, sobre a raiz do entalhe e por meio de "batidinhas" sobre a lâmina 
posicionada na mesma região do corpo de prova. Os resultados não foram significativamente diferentes, sob o ponto de vista estatístico, mas sugeriram que as diferentes formas de manuseio da mesma ferramenta podem provocar alguma variação nas características geométricas e/ou estruturais do material na ponta da trinca, que por sua vez pode influenciar a dispersão e os resultados dos ensaios.

Particularmente, diferentes métodos de introdução de pré-trincas podem produzir diferenças geométricas e/ou danos na matriz polimérica na região da ponta da trinca, que podem afetar os resultados de ensaios de mecânica da fratura, dependendo dos eventos que ocorrerem após o carregamento inicial. Suspeita-se ainda que, mesmo utilizando-se a mesma técnica de introdução de pré-trincas, eventos aleatórios que ocorrem na ponta da ferramenta podem determinar a formação de diferentes estruturas de deformação na região da ponta da trinca artificialmente introduzida, afetando a principal característica requerida da pré-trinca, que é a reprodutibilidade.

Neste estudo serão inspecionadas as estruturas de deformação formadas na região da ponta da trinca durante a introdução de pré-trincas em corpos de prova de polietileno de média densidade, para ensaios de tenacidade à fratura em estado plano de deformação - $K_{l c}$ (em condições criogênicas), trabalho essencial de fratura (EWF) e Curva $J-R$.

O objetivo deste trabalho é estudar a aplicação de métodos de mecânica da fratura ao polietileno de média densidade empregado na fabricação de tubos para sistemas de distribuição de água e gás e investigar o efeito do método de introdução de pré-trincas sobre os resultados de ensaios de fratura. Paralelamente buscar-se-á ainda investigar o efeito da espessura e do processamento sobre os resultados do método do trabalho essencial de fratura.

O texto é divido em capítulos, seções, subseções, itens e subitens.

\subsection{TENACIDADE À FRATURA NO ESTADO PLANO DE DEFORMAÇÃO - $K_{I C}$}

A fratura é um fenômeno mecânico caracterizado pela criação de uma ou mais novas superfícies em um corpo sólido, em decorrência da atuação de tensões, que leva eventualmente à fragmentação do sólido.

A mecânica da fratura é a disciplina que se propõe a estudar a fratura e o comportamento mecânico dos materiais na presença de trincas, estabelecendo 
quantitativamente as condições críticas para o crescimento de uma trinca, através de relações entre a tensão aplicada, as dimensões da trinca e a resistência do material.

O fator de intensidade de tensão, indicada pela letra $K$, é uma quantidade calculada a partir da teoria da elasticidade linear, que caracteriza o estado de tensão na região da ponta de uma trinca idealmente aguda (MEYERS; CHAWLA, 1999). Segundo a teoria da Mecânica da Fratura Elástica Linear, como a abordagem é conhecida, o campo de tensões na vizinhança da ponta de uma trinca, em um material isotrópico e elástico linear é dado pela eq. (1):

$$
\sigma_{i j}=\frac{K}{\sqrt{2 \pi r}} f(\theta)
$$

onde $\sigma_{i j}$ é o tensor tensão, e $r$ e $\theta$ são coordenadas polares.

Pode-se demonstrar que o fator de intensidade de tensão está relacionado com a tensão aplicada no corpo e com o comprimento da trinca através da eq. (2):

$$
K=Y \sigma \sqrt{\pi a}
$$

onde, $\sigma$ é a tensão aplicada, a é a metade do comprimento da trinca (trinca central) e $Y$ é um fator de forma que depende do modo de abertura da trinca e da geometria do corpo.

O fator de intensidade de tensão mede a severidade de uma trinca. O material é capaz de suportar forças sem sofrer fratura, dado certo comprimento de trinca e uma determinada geometria do corpo, desde que a tensão aplicada seja tal que um determinado valor crítico $K_{c}$ não seja atingido. Este valor é uma propriedade do material, para uma determinada espessura do corpo. Em particular, no estado plano de deformação e no modo de abertura (modo I) esta propriedade passa a ser independente da espessura e é conhecida por tenacidade à fratura em estado plano de deformação $-K_{l c}$.

Os ensaios de tenacidade à fratura de polímeros são disciplinados por normas técnicas, como a ASTM D 5045-99, ou protocolos de ensaio como o do 
ESIS. Nestes ensaios um corpo de prova padronizado contendo uma pré-trinca é carregado em uma máquina de ensaios mecânicos, a velocidade constante, registrando-se os valores de carga e deslocamento até a ruptura.

A Figura 6 apresenta as duas configurações de corpos de prova padronizados, incluindo as principais dimensões: flexão de três pontos (single-edgenotch bending - SENB) e compacto de tração (compact tension - CT). A figura 7 ilustra o esquema de carregamento de um ensaio em flexão de três pontos.

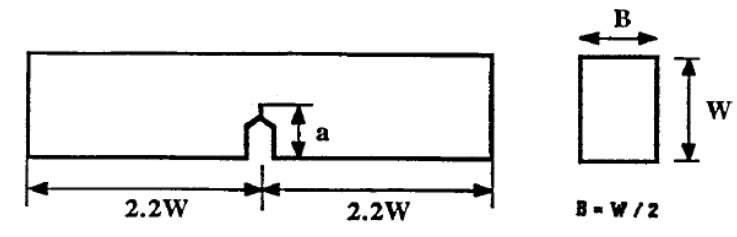

(a)

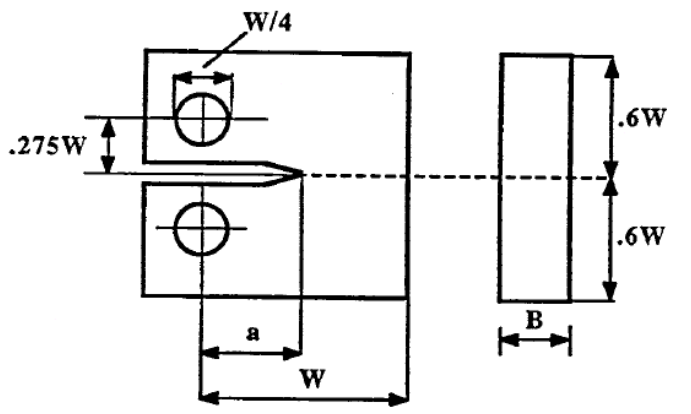

(b)

Figura 6: Configurações dos corpos de prova para ensaio de $K_{l c}$ e Integral-J de materiais poliméricos: (a) flexão de três pontos (SENB); (b) compacto de tração (CT) (Fonte: normas ASTM D 5045-99 e ASTM D 6068-96)

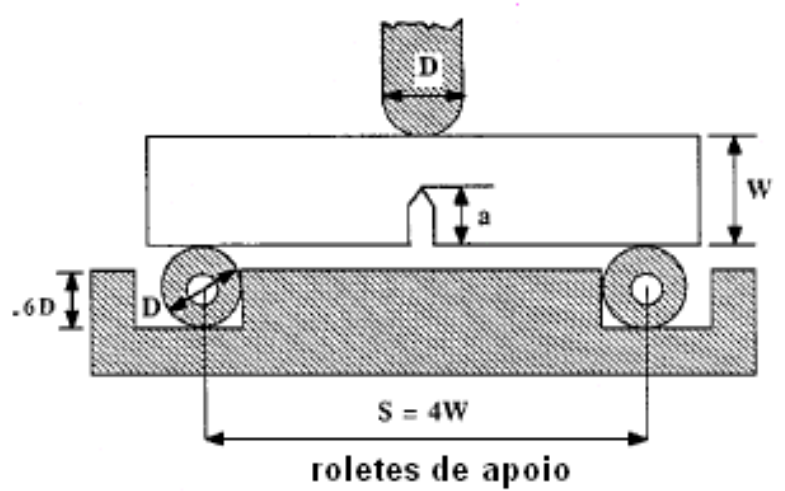

Figura 7: esquema do carregamento em flexão de três pontos, para ensaio de KIc (Adaptado da norma ASTM D 5045-99)

O avanço da trinca é acompanhado através do comportamento da curva carga $(P)$ - deslocamento $(u)$ obtida do ensaio, conforme Figura 8. No caso ideal de um corpo elástico linear, a curva de carregamento do ensaio é uma reta desde a origem até o crescimento instável final da trinca, quando ocorre a súbita e definitiva 
queda no valor da carga. Nos casos gerais, para o cálculo de $K_{l c}$ é necessário seguir um procedimento para obtenção de um valor provisório designado por $K_{Q}$, e então verificar se este valor satisfaz determinadas restrições geométricas. Primeiramente, determina-se qual a melhor reta que representa o módulo de flexibilidade (compliance) inicial do corpo de prova, indicada pela reta $A B$ na Figura 8. Uma segunda reta $A B^{\prime}$ é construída, tal que a tangente do ângulo $\theta^{\prime}$ seja $5 \%$ maior que a tangente do ângulo $\theta$. Se a máxima carga atingida no ensaio $\left(P_{\max }\right)$ estiver posicionada entre as retas $A B$ e $A B$ ', então o valor de $P_{\max }$ é utilizado diretamente no cálculo de $K_{Q}$. Se o valor de $P_{\max }$ estiver situado além da reta $A B$, é necessário obter o valor de carga $P_{Q}$, correspondente ao ponto de interseção da reta $A B^{\prime}$ com a curva de carregamento. Se o valor de $P_{\max }$ for no máximo $10 \%$ superior ao valor de $P_{Q}$, então $P_{Q}$ é utilizado no cálculo de $K_{Q}$, caso contrário o ensaio não é válido. $A$ partir do valor de $P_{\max }$ ou $P_{Q}$, conforme o caso, dos dados dimensionais do corpo de prova, do comprimento inicial da pré-trinca e considerando-se a geometria do corpo de prova calcula-se uma quantidade provisória designada por $K_{Q}$. As expressões matemáticas para os cálculos são dadas nas normas, para cada tipo de corpo de prova, enquanto que o comprimento inicial da pré-trinca pode ser medido na superfície de fratura do corpo de prova. Se o valor de $K_{Q}$ for tal que a eq. (3) seja satisfeita, onde $\sigma_{0}$ é o limite de escoamento do material e $B$, a e $(W-a)$ são as principais dimensões do corpo de prova (vide Figura 6), então $K_{Q}$ é tomado como $K_{/ c}$ do material.

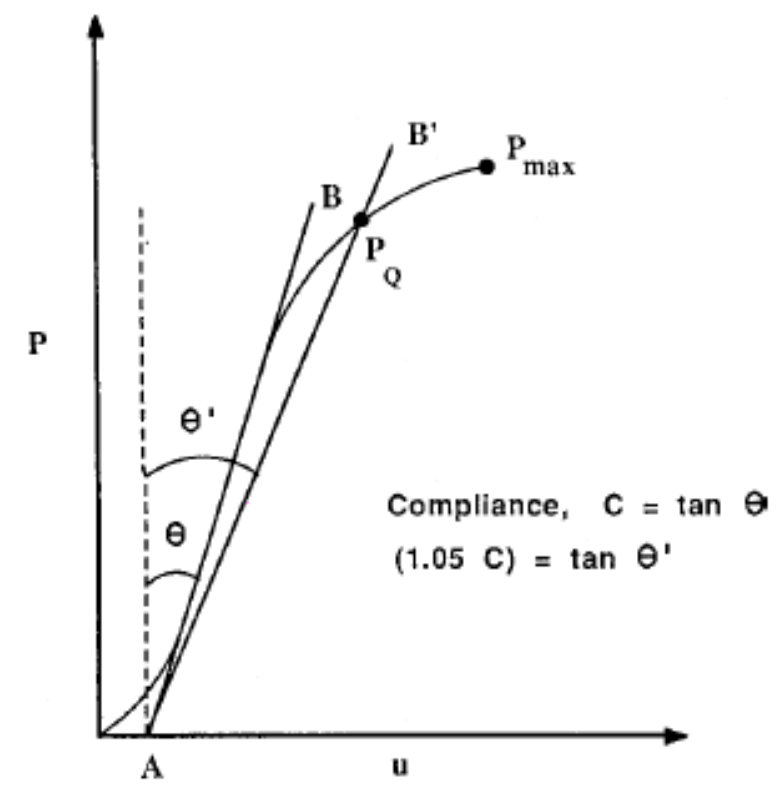

Figura 8: Determinação de $P_{Q}$ (Fonte: norma ASTM D 5045-99) 


$$
B, a,(W-a)>2,5\left(\frac{K_{Q}}{\sigma_{0}}\right)^{2}
$$

Pode-se observar na Figura 8 um certo desvio da linearidade na região inicial da curva de carregamento. Segundo Williams (2001a), este efeito pode ser devido a deformação plástica na região da ponta da trinca, fenômenos elásticos não lineares, fenômenos viscoelásticos ou algum crescimento estável inicial da trinca. De qualquer forma, as normas de polímeros, por simplicidade, desprezam esta região inicial, conforme procedimento esquematizado antes, desde que as demais exigências sejam satisfeitas. É interessante observar que, no caso dos metais, a norma ASTM E 1820 considera que algum desvio da linearidade freqüentemente ocorre no início do ensaio, mas que também deveria ser desprezado. Entretanto, a norma aconselha um carregamento preliminar controlado do corpo de prova, com limitação da carga máxima aplicada, seguido de descarregamento. As normas de polímeros não especificam procedimento semelhante.

O polietileno de média densidade é um material dúctil à temperatura ambiente e a fratura em ensaios de $K_{l c}$, quando esta ocorre, é geralmente acompanhada de extensa deformação plástica. Algumas estratégias podem ser usadas para vencer as restrições para o tamanho da zona plástica e obter valores válidos de $K_{/ c}$, como a utilização de corpos de prova maiores. Entretanto, essa opção não é geralmente prática, uma vez que as dimensões dos corpos de prova podem se tornar excessivamente grandes. Uma alternativa é reduzir a temperatura do corpo de prova, e assim elevar o limite de escoamento do material. No caso do polietileno, condições criogênicas mostraram-se satisfatórias para o comportamento linear do material (SOUZA et al, 2008) e o limite de escoamento para estas condições pode ser obtido na literatura (CHAN \& WILLIAMS, 1983b; BROOKS et al, 1998). 


\subsection{INTEGRAL $J$}

\subsubsection{INTRODUÇÃO}

O conceito da Integral $J$ surgiu numa época em que se buscava estender o sucesso da mecânica da fratura elástica linear (LEFM) aos casos de fratura elastoplástica (TARPANI, 1995), ou seja, aqueles em que a fratura ocorre com significativa deformação plástica - típico dos materiais muito dúcteis, nos quais os postulados da LEFM são violados.

Sob o ponto de vista da engenharia, procurava-se um parâmetro de fratura com a mesma utilidade, por exemplo, do fator de intensidade de tensões $-K$, que pudesse quantificar a condição crítica para a fratura ocorrer em termos de fatores indiretamente relacionados com o processo de fratura, como a carga aplicada, a geometria do corpo e o comprimento da trinca, sem abordar a região microscópica da ponta da trinca onde o dano se desenvolve, chamada zona de processo.

Saxena (1998) salienta os aspectos que tornam bem sucedida a análise dos problemas de fratura através de $K$, sob condições predominantemente elásticas lineares, que são: (i) $K$ caracteriza inequívoca e unicamente o estado de tensão na ponta da trinca, numa região que é suficientemente extensa em comparação com a zona de processo; (ii) $K$ é um parâmetro de similitude, ou seja, dois corpos submetidos ao mesmo $K$ terão as mesmas dimensões e formas da zona plástica da ponta da trinca, independentemente das respectivas dimensões e forma dos corpos, comprimento das trincas e configuração do carregamento, desde que sejam satisfeitas as exigências de domínio de $K$ ( $K$-dominance) e de mesmos níveis de restrição nas pontas das trincas; (iii) $K$ também caracteriza a taxa de liberação de energia de deformação durante o avanço da trinca, uma vez que pode ser diretamente relacionado com a força de extensão da trinca $-G$.

Como veremos ao longo desta seção, o conceito de Integral $J$ apresenta, sob certas restrições, muitas das características desejadas, o que o tornam um potencial candidato a parâmetro de fratura sob condições elasto-plásticas.

De forma a situar prontamente o leitor quanto à definição formal de $\mathrm{J}$ e proporcionar-Ihe uma idéia rápida da sua utilidade, consideremos a figura 9, que representa um corpo planar, de um material elástico não linear homogêneo e isotrópico em estado de equilíbrio estático, contendo uma trinca. 


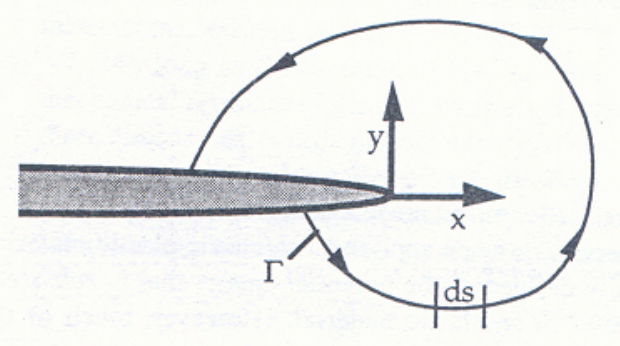

Figura 9: Contorno arbitrário em torno da ponta de uma trinca.

A idéia da Integral-J se baseia no princípio da conservação da energia, sendo que o seu senso matemático formal é o de uma integral de linha independente do caminho, cuja expressão (caso bi-dimensional) é a eq. (4):

$$
J=\int_{\Gamma} W d y-\int_{\Gamma} \vec{T} \frac{\partial \vec{u}}{\partial x} d s
$$

onde: $W$ é a função trabalho de carregamento por unidade de volume (ASTM E 1820-08), que no caso de corpos elásticos corresponde à função densidade de energia de deformação;

$\Gamma$ é um contorno arbitrário em torno da ponta da trinca, o qual se inicia na face inferior da trinca e termina na face superior, sendo positivo o sentido antihorário;

$\vec{T}$ é o vetor tração em $\Gamma$, perpendicular a $\Gamma$ e apontando para fora do contorno;

$\vec{u}$ é o vetor deslocamento;

$x$ e y são coordenadas cartesianas;

s é o comprimento do arco ao longo da linha de integração.

Por outro lado, $J$ também pode ser definido em termos da taxa de liberação da energia potencial do sistema com o avanço da trinca, conforme eq. (5):

$$
J=-\frac{\partial U_{P}}{\partial a}
$$


onde $U_{P}$ é a energia potencial do sistema por unidade de espessura e a é o comprimento da trinca.

Sob certas condições, o valor crítico $J_{c}$ pode ser usado como um critério de iniciação da fratura, ou seja, do início da propagação da trinca.

Nas subseções subseqüentes desta seção será demonstrado que os termos dominantes na descrição das singularidades de tensão e deformação na ponta da trinca também podem ser expressos em termos de $J$. Dessa forma, $J$ pode ser visto tanto como um parâmetro de campo de tensões e deformações como uma expressão da variação da energia em função do crescimento de uma trinca em um corpo elástico não linear, abrindo, a princípio, o caminho para a descrição dos problemas de fratura elástica não linear e elasto-plástica de uma forma global semelhante à abordagem dos corpos elásticos lineares pela LEFM.

$\mathrm{Na}$ prática, o valor de $\mathrm{J}$ é geralmente obtido a partir da sua interpretação energética, expressa na forma da eq. (5), e não pela integral de linha - eq. (4).

Inicialmente serão rapidamente apresentados alguns conceitos fundamentais necessários para a compreensão do conceito de J. O texto será então desenvolvido a partir de considerações iniciais de balanço de energia, levando à definição da Integral $J$ e sua relação com a variação da energia potencial. Em seguida será demonstrado que o valor de $J$ é nulo quando o contorno é fechado, resultado matemático que indicou a possibilidade de sua utilidade no estudo das trincas em materiais elásticos (não necessariamente elásticos lineares), e que ela é independente do caminho, possibilitando a escolha (arbitrária) de um contorno convenientemente afastado da ponta da trinca. Considerando-se que materiais plásticos podem ser semelhantes a materiais elásticos não lineares com as mesmas características tensão-deformação (deformation theory of plasticity) será visto que é possível estender o conceito para o comportamento elasto-plástico, desde que o carregamento ocorra em uma única direção, isto é, que seja monotônico (sem descarregamento). Será visto ainda que algumas restrições importantes de $J$, em particular a de que a trinca não pode crescer (se ela crescer ocorre o descarregamento), podem ser contornadas, sob determinadas condições, permitindo a extensão do conceito para casos especiais em que a trinca avança muito pouco e validando uma importante técnica experimental, amplamente adotada e normalizada. Serão apresentadas também algumas considerações sobre os campos de tensão e de deformação na ponta da trinca, o conceito de região de domínio de $J$ ( $J$ - 
dominance) e o conceito da curva $J-R$. Em seguida será discutida a utilidade de $J$ como parâmetro de fratura e suas limitações. Finalmente, serão rapidamente apresentadas e discutidas as técnicas experimentais utilizadas para a avaliação de $J$ e para a construção das curvas $J-R$ e as principais normas técnicas vigentes.

Nas palavras de Brian Lawn (1993) J é um "elegante e poderoso artifício matemático", o qual foi usado originalmente como uma ferramenta analítica para a determinação das tensões e deformações na ponta da trinca em fratura elastoplástica (LANDES; BEGLEY, 1977). O conceito foi introduzido no âmbito da mecânica da fratura por Rice (1968), que reconheceu que uma dada integral tinha o potencial para caracterizar a fratura em materiais elásticos não lineares e que a forma dessa integral era idêntica à componente estática do "tensor energiamomento" introduzida por Eshelby (1951) para caracterizar forças generalizadas em discordâncias e defeitos puntuais em campos elásticos, conforme citado por Rice (1968). A maior parte das referências importantes sobre o assunto cita que Cherepanov (1968), trabalhando de forma independente na antiga União das Repúblicas Socialistas Soviéticas, chegou aos mesmos resultados que Rice. Begley e Landes (1972) foram os primeiros a reconhecer experimentalmente $J$ como um parâmetro de fratura $\left(J_{I C}\right)$, tendo aberto o caminho para o desenvolvimento das técnicas experimentais atualmente adotadas. Com o desenvolvimento dos estudos reconheceu-se que $J$ está diretamente relacionado a outro moderno conceito da mecânica da fratura elasto-plástica - o trabalho essencial de fratura, que será tratado na próxima seção, enquanto que, por outro lado, existem críticas importantes sobre o assunto (BROBERG, 1995).

Pelas considerações desenvolvidas até este ponto, pode-se estabelecer como objetivo específico deste capítulo levantar e desenvolver os fundamentos principais de $J$, visando compreender os procedimentos das técnicas experimentais e de ensaio atuais e suas limitações.

As indicações de autoria mais específicas serão feitas no texto quando for oportuno, entretanto, para efeito de simplificação, os principais trabalhos e referências que orientam esta seção são: Rice (1968); Begley e Landes (1972); Landes e Begley (1972); Landes e Begley (1974); Landes e Begley (1977); Ewalds e Wanhill (1986); Meguid (1989); Broek (1991); Lawn (1993); Tarpani (1995); Anderson (1995); Broberg (1995); Hertzberg (1995); Kinlock e Young (1995); 
Cotterell e Atkins (1996); Saxena (1998); Meyers e Chawla (1999); Dowling (1999); Williams (2001b); Schön (2008).

\subsubsection{TÓPICOS ELEMENTARES}

Nesta subseção serão apresentados alguns conceitos fundamentais que tornar-se-ão muito úteis para a compreensão das demonstrações que serão desenvolvidas nas sub-seções seguintes, como a densidade de energia de deformação, o vetor tração, $\vec{T}$, e o princípio da teoria da deformação da plasticidade (deformation theory of plasticity). Também será apresentado o teorema de Green, o qual será utilizado em algumas passagens.

Iniciaremos pela notação que será adotada, indicada na Tabela 1:

Tabela 1 - Notações adotadas no desenvolvimento do conceito de Integral-J

\begin{tabular}{ccc}
\hline ENTIDADE & $\begin{array}{c}\text { NOTAÇÃO } \\
\text { MATEMÁTICA }\end{array}$ & NOTAÇÃO DE \\
ENGENHARIA
\end{tabular}

Tensor tensão (caso bi-dimensional): $\quad \sigma_{i j}=\left[\begin{array}{ll}\sigma_{11} & \sigma_{12} \\ \sigma_{21} & \sigma_{22}\end{array}\right]$

Tensor deformação (caso bi-dimensional): $\quad \varepsilon_{i j}=\left[\begin{array}{ll}\varepsilon_{11} & \varepsilon_{12} \\ \varepsilon_{21} & \varepsilon_{22}\end{array}\right]$ 
1.2.2.1 Densidade de energia de deformação

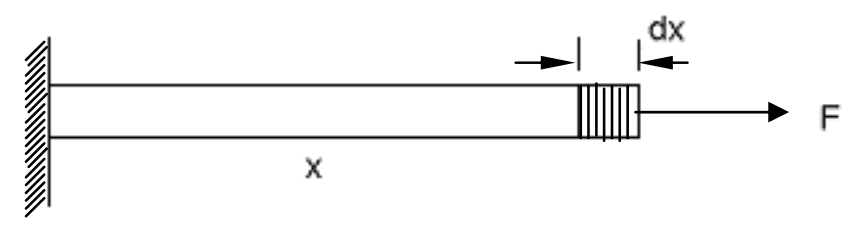

Figura 10: uma barra de comprimento $x$, submetida à ação de uma força $F$

Se uma barra de comprimento $x$ for submetida à ação de uma força $F$ (Figura 10) e se alongar por um incremento infinitesimal $d x$, o trabalho, $\tau$, realizado pela força $F$ é dado pela eq.(6):

$$
\tau=F d x
$$

Assim, o trabalho infinitesimal por unidade de volume, $d W$, é dado pela eq.(7):

$$
d W=\frac{F d x}{A x}=\sigma_{1} d \varepsilon_{1}
$$

onde $A$ é a área da seção transversal da barra.

Estendendo-se para o caso bi-dimensional, temos a eq.(8):

$d W=\sum_{i j} \sigma_{i j} d \varepsilon_{i j}=\sigma_{11} d \varepsilon_{11}+\sigma_{12} d \varepsilon_{12}+\sigma_{21} d \varepsilon_{21}+\sigma_{22} d \varepsilon_{22}=\sigma_{11} d \varepsilon_{11}+2 \sigma_{12} d \varepsilon_{12}+\sigma_{22} d \varepsilon_{22}$

Em um material elástico a energia de deformação armazenada por unidade de volume é conhecida como densidade de energia de deformação (EWALDS; WANHILL, 1986), W, cuja expressão, para o caso bi-dimensional, pode ser obtida pela integração da eq.(8). A expressão de $W$ é dada pela eq.(9), tendo-se utilizado a notação simplificada de Einstein, na qual índices repetidos implicam a soma por todos os índices e o símbolo de somatório é omitido.

$$
W=\int_{0}^{\varepsilon_{i j}} d W=\int_{0}^{\varepsilon_{i j}} \sigma_{i j} d \varepsilon_{i j}
$$




\subsubsection{Vetor Tração (caso bi-dimensional)}

O vetor tração, $\vec{T}$, que atua sobre um segmento de um corpo planar e aponta para fora da superfície, é a força resultante por unidade de área, podendo ser definido na forma da eq.(10):

$$
\vec{T}=T_{1} \vec{i}+T_{2} \vec{j}
$$

onde $\vec{i}$ e $\vec{j}$ são os versores nas direções $x$ e $y$, respectivamente.

O vetor tração difere da tensão no sentido de que é um vetor com uma direção definida. Além disso, o vetor tração atua sobre um elemento de superfície, enquanto que um tensor tensão atua sobre um elemento de volume.

Os componentes do vetor tração podem ser relacionados com as componentes de tensão, no caso bidimensional, na forma da eq.(11):

$$
\left(\begin{array}{l}
T_{1} \\
T_{2}
\end{array}\right)=\left(\begin{array}{ll}
\sigma_{11} & \sigma_{12} \\
\sigma_{21} & \sigma_{22}
\end{array}\right)\left(\begin{array}{l}
n_{1} \\
n_{2}
\end{array}\right)
$$

ou seja,

$$
\begin{aligned}
& T_{1}=\sigma_{11} n_{1}+\sigma_{12} n_{2} \\
& T_{2}=\sigma_{21} n_{1}+\sigma_{22} n_{2}
\end{aligned}
$$

onde $n_{1}$ e $n_{2}$ são os cosenos dos ângulos $\theta_{1}$ e $\theta_{2}$ que o vetor normal à superfície do corpo (e que aponta para fora do corpo), $\vec{n}$, faz com as direções positivas $x$ e $y$, respectivamente.

O vetor tração pode ser representado, em notação simplificada, pela eq.(14):

$$
T_{i}=\sigma_{i j} n_{j}
$$

onde $\sigma_{i j}$ é o tensor tensão. 
Pode-se demonstrar que se $\vec{n}$ é normal a um comprimento $d s$ da superfície, então:

$$
\begin{gathered}
d x=-n_{2} d s=-\cos \theta_{2} d s \\
d y=n_{1} d s=\cos \theta_{1} d s
\end{gathered}
$$

onde ds é um elemento infinitesimal de comprimento da superfície (contorno orientado positivamente no sentido anti-horário).

\subsubsection{Teorema de Green}

O teorema de Green estabelece uma relação entre uma integral de linha sobre um contorno fechado simples e uma integral dupla sobre a região circundada pelo contorno.

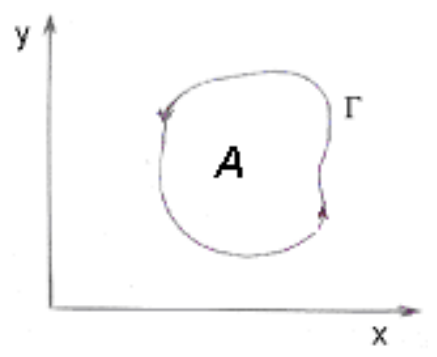

Figura 11: Um contorno fechado arbitrário $\Gamma$ circundando uma área $A$.

Seja $\Gamma$ um contorno fechado simples no plano $R^{2}$ e seja $A$ a região circundada por $\Gamma$ (Figura 11). Se $L$ e $M$ são funções de $(x, y)$ definidas numa região contendo $A$ e possuem derivadas parciais contínuas, então pode-se demonstrar que é válida a seguinte expressão (eq. (17)):

$$
\left.\int_{\Gamma} L(x, y) d x+M(x, y) d y\right)=\iint_{A}\left(\frac{\partial M(x, y)}{\partial x}-\frac{\partial L(x, y)}{\partial y}\right) d x d y
$$

Oportunamente será útil considerar isoladamente as partes da eq.(17), as quais podem ser escritas da seguinte maneira: 


$$
\begin{aligned}
& \iint_{A} \frac{\partial M(x, y)}{\partial x} d x d y=\int_{\Gamma} M(x, y) d y \\
& \iint_{A} \frac{\partial L(x, y)}{\partial y} d x d y=-\int_{\Gamma} L(x, y) d x
\end{aligned}
$$

A demonstração do teorema de Green é dispensável para os fins deste capítulo, mas o leitor interessado pode recorrer a livros-texto mais avançados de cálculo, como Kaplan \& Lewis (1974).

\subsubsection{Teoria da deformação da plasticidade (Deformation Theory of Plasticity)}

As equações constitutivas (nas direções principais) para materiais elásticos lineares sob estado tridimensional de tensões são dadas pelas seguintes expressões (eq. (20), eq.(21) e eq(22)):

$$
\begin{aligned}
& \varepsilon_{1}=\frac{1}{E}\left[\sigma_{1}-v\left(\sigma_{2}+\sigma_{3}\right)\right] \\
& \varepsilon_{2}=\frac{1}{E}\left[\sigma_{2}-v\left(\sigma_{1}+\sigma_{3}\right)\right] \\
& \varepsilon_{3}=\frac{1}{E}\left[\sigma_{3}-v\left(\sigma_{1}+\sigma_{2}\right)\right]
\end{aligned}
$$

onde $v$ é o coeficiente de Poisson.

Equações semelhantes também podem ser desenvolvidas para 0 comportamento plástico e são conhecidas como Leis de Fluxo (flow rules) (SAXENA, 1998), dadas pelas expressões abaixo (eq.(22), eq.(23) e eq(24)):

$$
\begin{aligned}
& d \varepsilon_{1}=\frac{d \varepsilon_{e}}{d \sigma_{e}}\left[\sigma_{1}-0,5\left(\sigma_{2}+\sigma_{3}\right)\right] \\
& d \varepsilon_{2}=\frac{d \varepsilon_{e}}{d \sigma_{e}}\left[\sigma_{2}-0,5\left(\sigma_{1}+\sigma_{3}\right)\right] \\
& d \varepsilon_{3}=\frac{d \varepsilon_{e}}{d \sigma_{e}}\left[\sigma_{3}-0,5\left(\sigma_{3}+\sigma_{1}\right)\right]
\end{aligned}
$$


onde $\sigma_{e}$ é a tensão equivalente de Von Mises e $\varepsilon_{e}$ é a deformação equivalente. Notese que neste caso o equivalente ao coeficiente de Poisson é 0,5 , correspondendo à conservação de volume.

As equações (23), (24) e (25) podem ser reformuladas, de forma que:

$$
d \varepsilon_{1}: d \varepsilon_{2}: d \varepsilon_{3}=\left[\sigma_{1}-0,5\left(\sigma_{2}+\sigma_{3}\right)\right]:\left[\sigma_{2}-0,5\left(\sigma_{1}+\sigma_{3}\right)\right]:\left[\sigma_{3}-0,5\left(\sigma_{3}+\sigma_{1}\right)\right]
$$

A eq.(26) mostra que se a relação entre as tensões principais se mantiver constante (carregamento proporcional), a relação entre os incrementos de deformação também serão constantes (ou vice-versa). Nestas condições os incrementos de deformação podem ser substituídos pelas deformações totais e a eq.(23) pode ser escrita pela forma da equação (27):

$$
\varepsilon_{1}=\frac{\varepsilon_{e}}{\sigma_{e}}\left[\sigma_{1}-0,5\left(\sigma_{2}+\sigma_{3}\right)\right]
$$

As expressões correspondentes para $\varepsilon_{2}$ e $\varepsilon_{3}$ podem ser obtidas por analogia.

Quando as leis de fluxo são expressas na forma da eq.(27), a teoria resultante é conhecida como teoria da deformação da plasticidade (deformation theory of plasticity). De acordo com esta teoria, as tensões e deformações são funções apenas do ponto onde são medidas e não do caminho tomado para se chegar àquele ponto (MEYERS; CHAWLA, 1999). Quando as leis de fluxo são expressas na forma das equações (23), (24) e (25), a teoria é chamada teoria incremental da plasticidade. No caso particular de carregamento proporcional, as duas teorias conduzem aos mesmos resultados.

A teoria da deformação da plasticidade é usada no desenvolvimento do conceito de $J$, assumindo-se que as condições de plasticidade na ponta da trinca se ajustam razoavelmente à suposição de carregamento proporcional (SAXENA, 1998). Entretanto, há uma importante limitação para a aplicação generalizada dessa teoria aos materiais dúcteis. Para os materiais elásticos não lineares, a relação $\frac{\varepsilon_{e}}{\sigma_{e}}$ é 
constante durante o carregamento e durante o descarregamento. Dessa forma, a teoria da deformação da plasticidade pode ser aplicada tanto no carregamento como no descarregamento do corpo. Por outro lado, no caso de materiais dúcteis, as curvas tensão-deformação no regime plástico são diferentes no carregamento e no descarregamento, o que leva a diferentes valores da relação $\frac{\varepsilon_{e}}{\sigma_{e}}$. Entretanto, se considerarmos somente o carregamento, o comportamento de um material dúctil é o mesmo de um material elástico não linear com o mesmo tipo de comportamento tensão-deformação, ou seja, materiais plásticos são semelhantes aos materiais elásticos não lineares quando o carregamento é feito somente em uma direção. Portanto, a aplicação da teoria da deformação da plasticidade neste capítulo está condicionada ao carregamento monotônico.

\subsubsection{A INTEPRETAÇÃO ENERGÉTICA DE $J$}

Uma vez que foi dito anteriormente que o conceito de $J$ é baseado num balanço de energia, vejamos como $\mathrm{J}$ pode ser definido a partir desta abordagem. Entretanto, é oportuno iniciarmos com o caso elástico linear e depois estendê-lo para os casos dos materiais elásticos não lineares e elasto-plásticos.

Considere-se inicialmente uma placa infinita, feita de um material elástico linear, de espessura unitária, contendo uma trinca passante de comprimento $2 a$ Figura 12(a). A placa é submetida a uma tensão remota (muito distante da trinca), $\sigma$, e fixada nas suas extremidades (deslocamento controlado - fixed displacement). A Figura 12(b) representa a curva carga-deslocamento correspondente. A área entre os pontos $O A B$ representa a energia elástica contida no corpo. Se o comprimento da trinca aumentar em um incremento da, haverá um relaxamento da tensão aplicada e redução da rigidez do corpo, uma vez que as extremidades do corpo estão presas (linha OC). A energia elástica armazenada diminuirá para um valor representado pela área entre os pontos OCB. Dessa forma, o crescimento da trinca de um comprimento a para um comprimento $a+d a$ resulta em uma liberação de energia elástica correspondente à área entre os pontos $O A C$. 


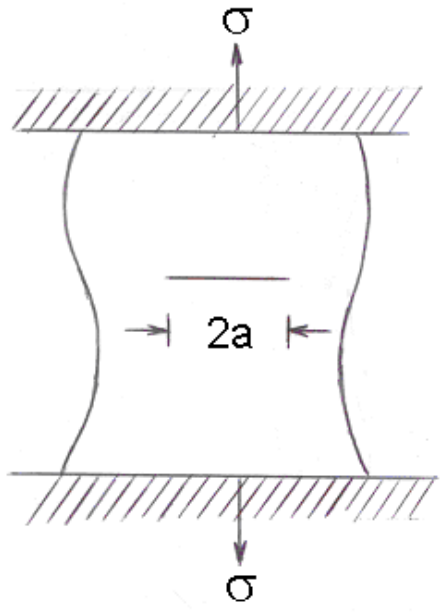

(a)

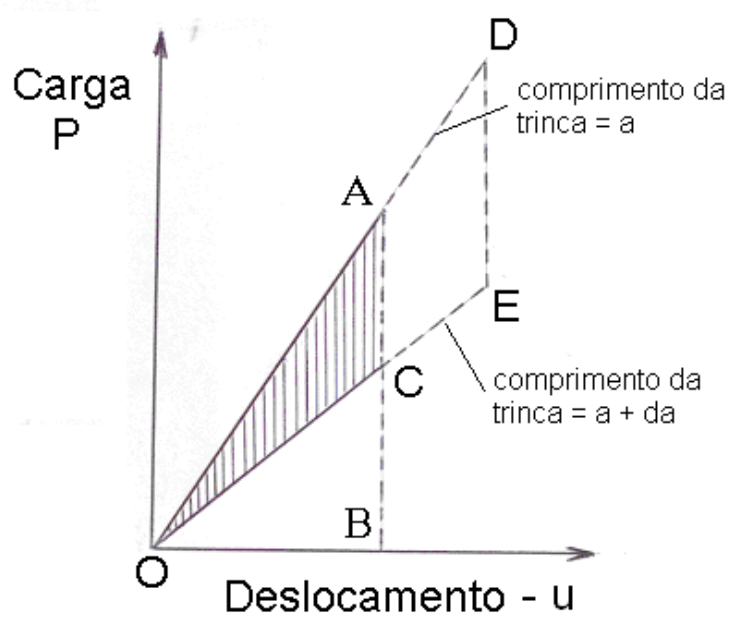

(b)

Figura 12: (a) - placa infinita de espessura unitária, contendo uma trinca de comprimento 2a, submetida a uma tensão remota $\sigma$, (b) Variação da energia elástica do corpo quando a trinca cresce de a para $a+d a$.

Se o nível da tensão atuante sobre a placa fosse maior, a quantidade de energia liberada para um crescimento da da trinca seria maior (área entre os pontos ODE na Figura 12(a). Por outro lado, somente ocorrerá o crescimento da trinca se a energia liberada no processo suprir a necessidade energética do crescimento da trinca, caso contrário a tensão deve ser aumentada. Ou seja, a trinca somente avançará se a energia requerida para estendê-la em um incremento de comprimento da puder ser liberada pelo sistema. Segundo consenso dos autores sobre o tema, esse raciocínio, introduzido por Griffith em 1921, juntamente com as contribuições de Orowan e Irwin em 1948, formam as bases fundamentais da mecânica da fratura elástica linear (linear elastic fracture mechanics - LEFM).

Na situação ilustrada na Figura 12(a) as extremidades da placa foram fixadas, ou seja, as forças externas não executam trabalho e a energia requerida para o crescimento da trinca deve ser suprida pelo próprio sistema através da liberação da energia de deformação elástica armazenada. Entretanto, se as extremidades da trinca puderem ser mover durante o crescimento da trinca, as forças externas executarão trabalho e, neste caso, a energia elástica do corpo (placa) aumenta, ao invés de diminuir (BROEK, 1991).

Considere-se novamente a situação ilustrada na Figura 12(a). Assumindo-se que a contribuição da energia cinética do corpo é desprezível, a energia total, $U$, da placa pode ser expressa da seguinte forma: 


$$
U=U_{i}+U_{a}+U \gamma-U_{E}
$$

onde $U_{i}$ é a energia de deformação contida na placa antes do carregamento (a constante), ou seja, devida a causas anteriores, $U_{a}$ é a variação da energia elástica armazenada decorrente do crescimento da trinca, $U_{\gamma}$ á e a variação da energia elástica superficial decorrente da formação de novas superfícies de trinca e $U_{E}$ é o trabalho executado pelas forças externas, que deve ser subtraído porque não faz parte da energia potencial interna da placa.

A Figura 13 ilustra como a energia total, $U$, varia em função do comprimento de trinca (não da trinca) introduzido, $\Delta a$.

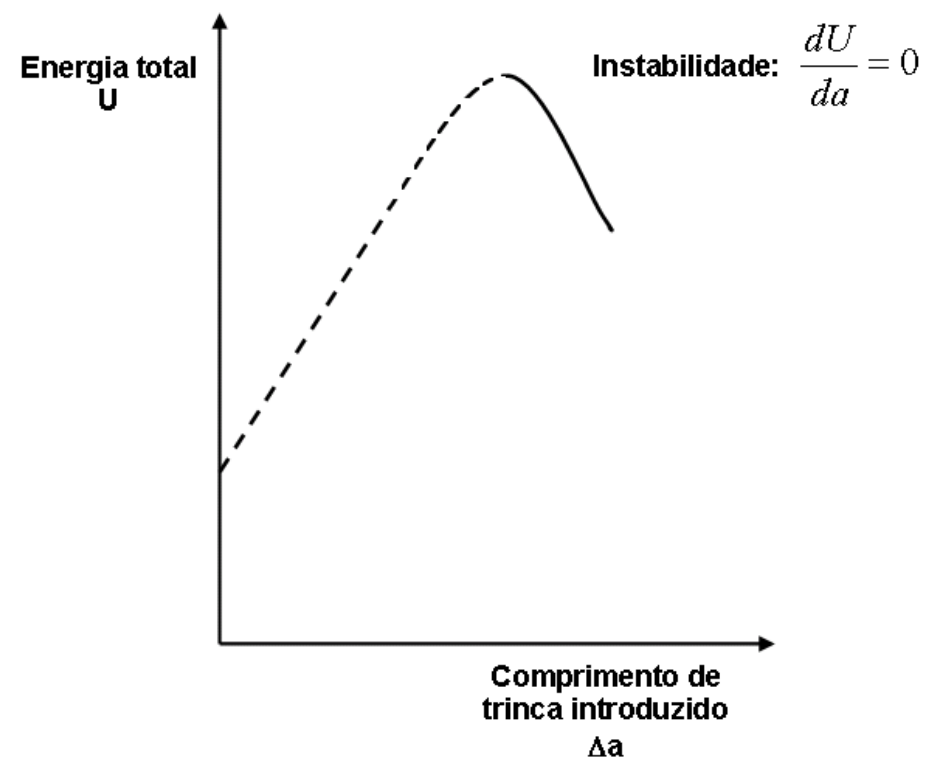

Figura 13: Energia total de uma placa infinita de espessura unitária, contendo uma trinca de comprimento $2 a$, submetida a uma tensão remota $\sigma$, tendo suas extremidades livres, em função do comprimento de trinca introduzido.

A Figura 13 representa uma "dificuldade" energética que deve ser superada para a trinca crescer. Antes de certa situação crítica ser atingida, há energia potencial suficiente para a introdução de um determinado comprimento de trinca (extensão da trinca), entretanto, a taxa de liberação da energia por unidade de comprimento de trinca é menor que a taxa de energia por unidade de comprimento de trinca demandada pelo crescimento da trinca. Ou seja, a variação da energia com o crescimento da trinca, $\frac{d U}{d a}$, é positiva e o sistema não libera (não disponibiliza) energia para a trinca crescer, permanecendo a mesma armazenada na placa na 
forma de energia potencial elástica. Na Figura 13 o trecho inicial tracejado é imaginário, virtual, uma vez que o crescimento da trinca não é admitido antes do ponto de instabilidade.

A condição crítica ou de instabilidade da trinca ocorrerá quando houver energia potencial elástica armazenada no corpo suficiente para a trinca crescer e a taxa de liberação de energia por unidade de comprimento de trinca for maior ou igual à taxa de consumo de energia por unidade de comprimento da trinca. Nesta situação o sistema está apto a fazer uso eficiente da energia disponível no processo de fratura (a não ser que o fluxo de energia para a ponta da trinca seja prejudicado). A condição de instabilidade é expressa pela eq. (29):

$$
\frac{d U}{d a} \leq 0
$$

Substituindo-se a eq.(28) na eq.(29) e considerando-se que $U_{i}$ é constante, temos:

$$
\frac{d\left(U_{a}+U_{\gamma}-U_{E}\right)}{d a} \leq 0
$$

A equação (30) pode ser escrita da seguinte forma:

$$
\frac{d\left(U_{E}-U_{a}\right)}{d a} \geq \frac{d U_{\gamma}}{d a}
$$

O lado esquerdo da eq.(31) é conhecido como taxa de liberação de energia ou "força" de extensão de trinca, designada por $G$, e representa a energia elástica por unidade de superfície de trinca que está disponível para o crescimento infinitesimal da trinca. Assim:

$$
G=\frac{d\left(U_{E}-U_{a}\right)}{d a}
$$

O lado direito da eq.(31) expressa a resistência da trinca, designada por $R$. Assim, a condição de instabilidade pode ser escrita da seguinte forma: 
Considerando-se, a princípio, que $R$ é constante, isto é, que a energia necessária para produzir uma trinca é sempre a mesma para cada incremento da, de acordo com a eq.(33) o valor da grandeza $G$ deve ser maior que um certo valor crítico $G_{c}$ para que a fratura ocorra.

A partir das análises de Inglis (1913) sobre uma trinca elíptica, Griffith estabeleceu a seguinte expressão para $G$ (estado plano de tensão):

$$
G=\frac{\pi \sigma^{2} a}{E}
$$

de onde

$$
G_{c}=\frac{\pi \sigma_{c}^{2} a}{E}
$$

e

$$
\sigma_{c}=\sqrt{\frac{E G_{c}}{\pi a}}
$$

O valor de $G_{c}$ pode ser calculado a partir de ensaios mecânicos, medindo-se a tensão crítica para a fratura do corpo, $\sigma_{c}$.

No estado plano de deformação e no modo de abertura de trinca, o valor de $G_{c}$ é designado por $G_{l c}$, sendo esta grandeza considerada uma propriedade do material.

A eq.(36) possui o formato geral de um critério de engenharia para a falha por fratura, na qual a tensão aplicada se iguala à resistência do corpo, no caso, a placa considerada. Entretanto, o mesmo princípio pode ser estendido para outras geometrias e configurações de carregamento de componentes feitos com materiais que apresentem comportamento elástico linear, ou predominantemente frágil, como o vidro estudado por Griffith. 
Considere-se novamente a situação representada na Figura 12(a). Entretanto, a placa agora é feita de um material elástico não linear. O comportamento cargadeslocamento de um corpo com estas características, sem a trinca (ou com uma trinca estacionária) é representado na Figura 14:

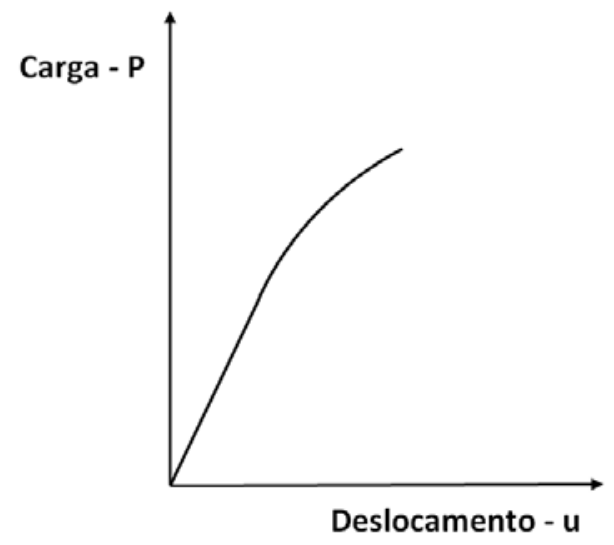

Figura 14: Comportamento de um sólido elástico não linear

$\mathrm{Na}$ medida em que o corpo continua elástico (não necessariamente linear), o balanço de energia, representado pela eq.(28) e a condição de instabilidade expressa pela equação (31) permanecem válidos.

Define-se, então, a grandeza J pela seguinte expressão:

$$
J=\frac{d\left(U_{E}-U_{a}\right)}{d a}
$$

No caso particular de o corpo ser de um material elástico linear, $J=G$, possuindo o mesmo significado físico da grandeza definida na eq.(31).

A partir da eq.(28), podemos isolar os termos energéticos responsáveis pelo comportamento elástico não linear e definir a energia potencial, $U_{P}$, através da seguinte expressão:

$$
U_{P}=U_{i}+U_{a}-U_{E}
$$

Derivando-se a eq.(38) em relação ao comprimento da trinca, da, e lembrando-se que $U_{i}$ é constante, obtém-se: 


$$
\frac{d U_{P}}{d a}=\frac{d\left(U_{a}-U_{E}\right)}{d a}=\frac{-d\left(U_{E}-U_{a}\right)}{d a}
$$

Comparando-se a eq.(39) com a eq.(37) verifica-se que:

$$
J=-\frac{d U_{P}}{d a}
$$

lembrando-se que a placa possui espessura unitária.

A equação (40) é a definição de $J$ sob o ponto de vista energético, apresentada na introdução desta seção - eq.(5), sem demonstração. Um decréscimo na energia armazenada,$-\frac{d U_{P}}{d a}$, significa uma liberação da energia de extensão da trinca, $J$, de forma a suprir a energia necessária, $-\frac{d U_{\gamma}}{d a}$, para um incremento da na superfície da trinca.

Fisicamente, a integral-J representa a diferença em energia potencial de dois corpos idênticos contendo trincas com comprimentos a e a + da, respectivamente. Essa interpretação energética de $J$ é representada pela área hachurada na Figura 15, para o caso particular de deslocamento controlado (fixed displacement).

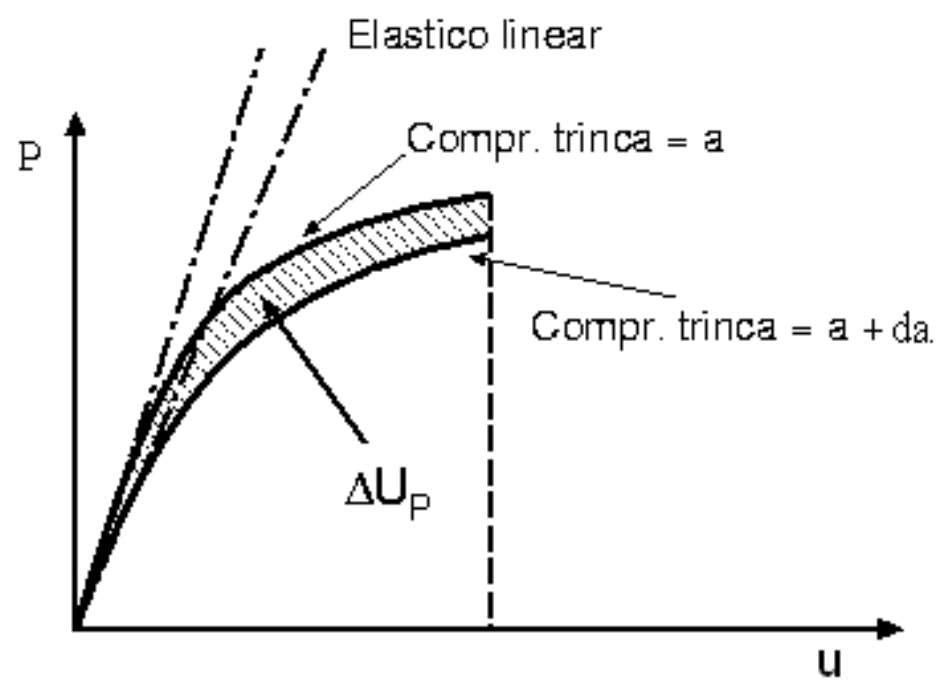

Figura 15: Interpretação energética da integral $J$ 
A interpretação de $\mathrm{J}$ a partir da abordagem energética é particularmente importante porque os métodos atuais de avaliação de $J$ se baseiam nesta definição.

Se considerarmos agora que o material do corpo da placa que estamos analisando apresenta comportamento elasto-plástico e que as condições de plasticidade na ponta da trinca são coerentes com a assunção de carregamento proporcional, então é válida a aplicação da teoria da deformação da plasticidade (item 1.2.2.4), desde que não ocorra o descarregamento em qualquer parte do corpo. Este raciocínio permite estender a análise de $\mathrm{J}$ para os problemas de fratura envolvendo materiais elasto-plásticos, respeitando-se a limitação quanto ao descarregamento.

Devemos observar ainda que até este ponto consideramos apenas a situação onde as extremidades do corpo são fixadas. Entretanto, como será visto posteriormente, pode-se demonstrar que as seguintes igualdades são válidas (EWALDS; WANHILL, 1986; BROEK, 1991; SAXENA, 1998):

$$
J=-\left(\frac{d U_{P}}{d a}\right)_{u}=-\int_{0}^{u}\left(\frac{d P}{d a}\right)_{u} d u
$$

e

$$
J=\left(\frac{d U_{P}}{d a}\right)_{P}=\int_{0}^{P}\left(\frac{d u}{d a}\right)_{P} d P
$$

Portanto:

$$
J=\left(\frac{d U_{p}}{d a}\right)_{P}=-\left(\frac{d U_{P}}{d a}\right)_{u}
$$

Dessa forma, os mesmo resultados são obtidos, independentemente se as condições forem de deslocamento controlado (fixed displacement or displacement control) ou de carga controlada (constant load). 
O próximo passo é desenvolver uma expressão para a variação da energia potencial com o crescimento da trinca, $\frac{d U_{P}}{d a}$.

\subsubsection{DEFINIÇÃO DE J COMO UMA INTEGRAL DE LINHA}

Consideremos a situação ilustrada na Figura 16, na qual um corpo planar homogêneo, de espessura unitária, com perímetro $\Gamma$ e área $A$, livre de forças internas, contendo uma trinca de comprimento a,sofre a tração $\vec{T}$, que atua em uma parte $S$ do perímetro e executa um trabalho externo, $U_{E}$. $O$ trecho $S_{u}$ sofre, então, um deslocamento representado por um vetor deslocamento $\vec{u}$. Assume-se que as trações e os deslocamentos são independentes do comprimento da trinca. $x$ e y são coordenadas cartesianas.

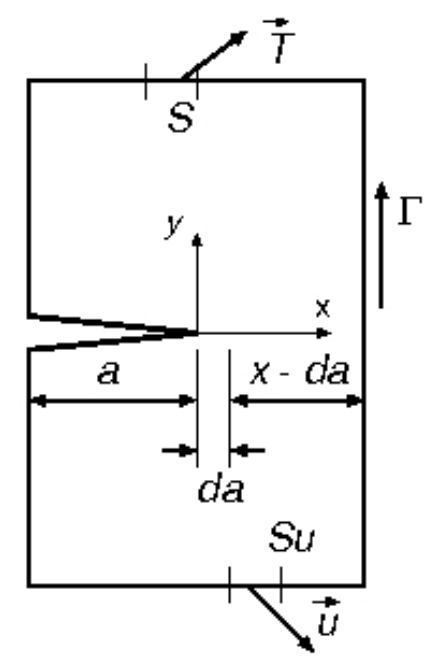

Figura 16: corpo de espessura unitária, contendo uma trinca, carregado por uma tração Erro! Não é possível criar objetos a partir de códigos de campo de edição..

A energia potencial do corpo é dada por uma expressão equivalente àquela anteriormente definida (eq.(38)), onde a soma dos fatores $U_{a}$ e $U_{i}$ constitui a energia total de deformação contida no corpo e a parcela $U_{E}$ o trabalho das forças externas, que podem ser dadas respectivamente, pelas seguintes expressões:

$$
\begin{gathered}
U_{a}+U_{i}=\iint_{A} W d x d y \\
U_{E}=\int_{S} \vec{T} d s \vec{u}
\end{gathered}
$$


onde $d s$ é um elemento infinitesimal do contorno $\Gamma$.

Substituindo-se a eq.(44) e a eq.(45) na eq.(38), temos a seguinte expressão da energia potencial:

$$
U_{P}=\iint_{A} W d x d y-\int_{S} \vec{T} d s \vec{u}
$$

Supondo-se que o vetor tração seja constante, a derivação da eq.(46) em relação ao comprimento da trinca leva à seguinte expressão:

$$
\frac{d U_{P}}{d a}=\iint_{A} \frac{\partial W}{\partial a} d x d y-\int_{\Gamma} \vec{T} \frac{\partial \vec{u}}{\partial a} d s
$$

na qual o segundo termo foi estendido para todo o contorno, uma vez que $\frac{\partial \vec{u}}{\partial a}=0$ ao longo de $S_{u}$ e porque nas superfícies da trinca e no restante do contorno (além de $S$ e $S_{u}$ ) não há tração.

Tomando-se a ponta da trinca como a origem do sistema de coordenadas (vide Figura 16) e considerando-se que o perímetro $\Gamma$ é fixo, então:

$$
d a=-d x \Rightarrow \frac{d}{d a}=-\frac{d}{d x}
$$

Dessa forma, a eq.(47) pode ser reescrita da seguinte maneira:

$$
\frac{d U_{P}}{d a}=-\iint_{A} \frac{\partial W}{\partial x} d x d y+\int_{\Gamma} \vec{T} \frac{\partial \vec{u}}{\partial x} d s
$$

Com auxílio do teorema de Green (item 1.2.2.3), o primeiro termo da eq.(49) pode ser reescrito em termos de uma integral de linha ao longo do contorno $\Gamma$, ou seja: 


$$
\frac{d U_{P}}{d a}=-\int_{\Gamma} W d y+\int_{\Gamma} \vec{T} \frac{\partial \vec{u}}{\partial x} d s
$$

Substituindo-se a eq.(50) na eq.(40), temos:

$$
J=\int_{\Gamma} W d y-\int_{\Gamma} \vec{T} \frac{\partial \vec{u}}{\partial x} d s
$$

ou

$$
J=\int_{\Gamma} W d y-\int_{\Gamma} T_{i} \frac{\partial u_{i}}{\partial x} d s
$$

As equações (51) e (52) definem a Integral J, apresentada anteriormente, sem demonstração, na introdução deste capítulo - eq.(4).

\subsubsection{APLICAÇÃO DE J EM ANÁLISE DE CORPOS CONTENDO TRINCAS}

Até este ponto foi introduzido o conceito de $J$, bem como sua definição a partir de uma interpretação energética e na forma de uma integral de linha. Para verificar sua utilidade na análise de um corpo contendo uma trinca é preciso primeiro reconhecer um resultado matemático importante: o valor de $\mathrm{J}$ ao longo de um contorno fechado, $\Phi$, em um corpo homogêneo, é igual a zero. Em seguida, é preciso verificar que em torno da ponta de uma trinca pode-se definir um contorno, $\Gamma$. Por fim, é preciso demonstrar a mais notável propriedade de $\mathrm{J}$ : seu valor ao longo de $\Gamma$ independe do trajeto escolhido, ou seja, não se altera se ele começar em qualquer ponto ao longo de um dos flancos da trinca, passar por trás da ponta da trinca e terminar em qualquer ponto do flanco oposto, seguindo em sentido antihorário. Esta propriedade permite que a escolha da posição e do traçado do contorno $\Gamma$ seja arbitrária e possa ser definida por conveniência.

Consideremos um caminho de integração fechado, $\Phi$, circundando uma região A ocupada por um corpo planar homogêneo, conforme a Figura 17, onde $x$ e 
y são coordenadas cartesianas. Como anteriormente, o corpo sofre a ação de uma tração $\vec{T}$.

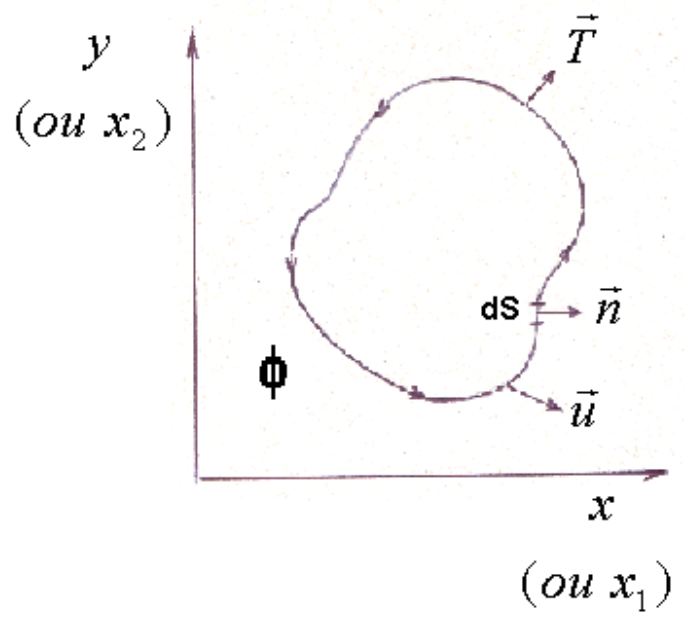

Figura 17: Um contorno fechado $\Phi$, orientado positivamente no sentido anti-horário.

Para reconhecermos que o valor de $\mathrm{J}$ é nulo ao longo do contorno da Figura 17, devemos demonstrar que as duas parcelas da eq.(52) são iguais, ou seja, que:

$$
\int_{\Phi} W d y=\int_{\Phi} T_{i} \frac{\partial u_{i}}{\partial x} d s
$$

Com auxílio do teorema de Green (item 1.2.2.3), o lado esquerdo da eq.(53) pode ser reescrito da seguinte forma:

$$
\int_{\Phi} W d y=\iint_{A} \frac{\partial W}{\partial x} d x d y
$$

A expressão para $\frac{\partial W}{\partial x}$ pode ser obtida a partir da eq.(8):

$$
\frac{\partial W}{\partial x}=\sigma_{11} \frac{\partial \varepsilon_{11}}{\partial x}+2 \sigma_{12} \frac{\partial \varepsilon_{12}}{\partial x}+\sigma_{22} \frac{\partial \varepsilon_{22}}{\partial x}
$$


A relação $\frac{\partial W}{\partial x}$ pode ainda ser representada em termos de $u_{1}$ e $u_{2}$. Para tanto, é preciso observar que:

$$
\begin{gathered}
\frac{\partial \varepsilon_{11}}{\partial x}=\frac{\partial}{\partial x}\left(\frac{\partial u_{1}}{\partial x}\right) \\
2 \frac{\partial \varepsilon_{12}}{\partial x}=\frac{\partial}{\partial x}\left(\frac{\partial u_{1}}{\partial y}+\frac{\partial u_{2}}{\partial x}\right) \\
\frac{\partial \varepsilon_{22}}{\partial x}=\frac{\partial}{\partial x}\left(\frac{\partial u_{2}}{\partial y}\right)
\end{gathered}
$$

Substituindo as equações (56), (57) e (58) na eq.(55), temos:

$$
\frac{\partial W}{\partial x}=\sigma_{11} \frac{\partial}{\partial x}\left(\frac{\partial u_{1}}{\partial x}\right)+\sigma_{12} \frac{\partial}{\partial x}\left(\frac{\partial u_{1}}{\partial y}+\frac{\partial u_{2}}{\partial x}\right)+\sigma_{22} \frac{\partial}{\partial x}\left(\frac{\partial u_{2}}{\partial y}\right)
$$

Ou, em termos genéricos:

$$
\frac{\partial W}{\partial x}=\frac{\partial}{\partial x_{j}}\left[\sigma_{i j}\left(\frac{\partial u_{i}}{\partial x}\right)\right]
$$

Substituindo a eq.(60) na eq. (54), temos:

$$
\int_{\Phi} W d y=\iint_{A} \frac{\partial}{\partial x_{j}}\left[\sigma_{i j}\left(\frac{\partial u_{i}}{\partial x}\right)\right] d x d y
$$

Com auxílio das equações (12) e (13), o lado direito da equação (53) pode ser reescrito da seguinte forma: 


$$
\begin{aligned}
& \int_{\Phi} T i \frac{\partial u_{i}}{\partial x} d s=\int_{\Phi}\left[\left(\sigma_{11} n_{1}+\sigma_{12} n_{2}\right) \frac{\partial u_{1}}{\partial x}+\left(\sigma_{21} n_{1}+\sigma_{22} n_{2}\right) \frac{\partial u_{2}}{\partial x}\right] d s= \\
& =\int_{\Phi}\left(\sigma_{11} \frac{\partial u_{1}}{\partial x}+\sigma_{21} \frac{\partial u_{2}}{\partial x}\right) n_{1} d s+\int_{\Phi}\left(\sigma_{12} \frac{\partial u_{1}}{\partial x}+\sigma_{22} \frac{\partial u_{2}}{\partial x}\right) n_{2} d s
\end{aligned}
$$

Substituindo as equações (15) e (16) na eq.(62), temos:

$$
\int_{\Phi} T i \frac{\partial u_{i}}{\partial x} d s=\int_{\Phi}\left(\sigma_{11} \frac{\partial u_{1}}{\partial x}+\sigma_{21} \frac{\partial u_{2}}{\partial x}\right) d y-\left(\sigma_{12} \frac{\partial u_{1}}{\partial x}+\sigma_{22} \frac{\partial u_{2}}{\partial x}\right) d x
$$

Com auxílio novamente do teorema de Green:

$$
\int_{\Phi} T i \frac{\partial u_{i}}{\partial x} d s=\iint_{A} \frac{\partial}{\partial x}\left(\sigma_{11} \frac{\partial u_{1}}{\partial x}+\sigma_{21} \frac{\partial u_{2}}{\partial x}\right) d x d y+\iint_{A} \frac{\partial}{\partial y}\left(\sigma_{12} \frac{\partial u_{1}}{\partial x}+\sigma_{22} \frac{\partial u_{2}}{\partial x}\right) d x d y
$$

Em termos genéricos, a eq. (64) fica:

$$
\int_{\Phi} T i \frac{\partial u_{i}}{\partial x} d s=\iint_{A} \frac{\partial}{\partial x_{j}}\left[\sigma_{i j}\left(\frac{\partial u_{i}}{\partial x}\right)\right] d x d y
$$

Por comparação, verifica-se que os segundos termos das equações (61) e (65) são iguais, ou seja, chega-se à eq.(53). Dessa forma,

$$
J=\int_{\Phi} W d y-\int_{\Phi} T i \frac{\partial u_{i}}{\partial x} d s=0 \quad \text { c.q.d. }
$$

O resultado obtido na eq.(66) demonstra que o valor de $J$ é zero para qualquer contorno fechado em um corpo planar homogêneo, desde que não haja dissipação de energia na área circunscrita por $\Phi$. Ou seja, qualquer trabalho externo aplicado é armazenado elasticamente no material (HALE; RAMSTEINER, 2001).

Consideremos agora a situação em que o corpo possui uma trinca (Figura 18). Em torno da ponta da trinca é adotado um contorno (arbitrário), $\Gamma$, com orientação positiva no sentido anti-horário, e que se inicia em um ponto qualquer do 
plano inferior da trinca e termina em um ponto qualquer do flanco superior. Supõe-se que os flancos da trinca estejam sobre o eixo $x$.

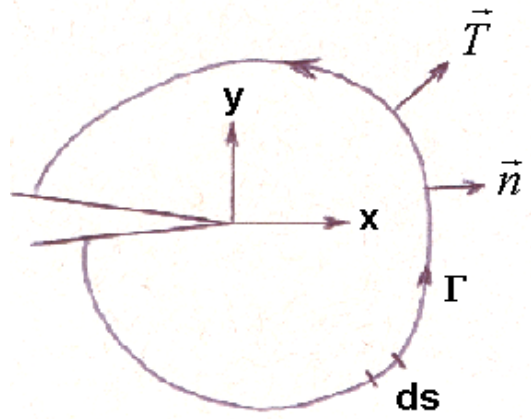

Figura 18: Corpo homogêneo planar, contendo uma trinca, sob ação da tração $\vec{T}$, e um contorno $\Gamma$ em torno da ponta da trinca.

Em torno da ponta da trinca da Figura 18, podemos ainda adotar um contorno fechado, $\Phi$, representado na Figura 19 pelo traçado $A B C D E F A$. O contorno $\Phi$ é formado por quatro segmentos: pelo segmento $\Gamma_{1}(A B C)$, pelo segmento $\Gamma_{2}(D E F)$ e pelos trechos $C D$ e $F A$. Observe-se que $\Gamma_{1}$ e $\Gamma_{2}$ possuem orientações contrárias.

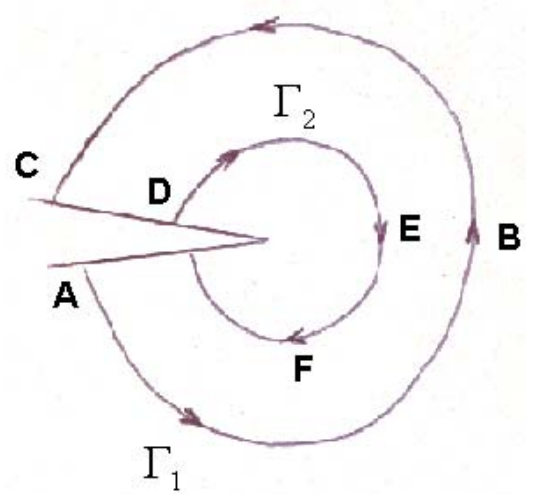

Figura 19: contorno fechado em torno da ponta de uma trinca

Sabendo-se que o valor de $J$ ao longo de um contorno fechado é zero (eq.(66)), podemos escrever, a partir da Figura 19:

$$
J_{\Phi}=J_{\Gamma_{1}}+J_{\Gamma_{2}}+J_{C D}+J_{F A}=0
$$

Em uma superfície a tração é nula, enquanto que nos flancos da trinca $d y=0$. Portanto, $J_{C D}=J_{F A}=0$. Dessa forma, podemos escrever: 


$$
J_{\Gamma_{1}}=-J_{\Gamma_{2}}
$$

Esse resultado demonstra que o valor de $J$ é o mesmo ao longo de qualquer contorno orientado positivamente (sentido anti-horário) ao redor da ponta de uma trinca, iniciando na superfície de um dos flancos da trinca e terminando na superfície do outro flanco. Portanto, o valor de $\mathrm{J}$ ao longo do contorno $\Gamma$ da Figura 18 é independente do caminho (path independent).

A propriedade de independência do caminho é importante porque permite que J seja calculado ao longo de um caminho suficientemente distante da ponta da trinca. Esta região é complicada porque nela as soluções numéricas dos campos de tensão e deformação são imprecisas (SAXENA, 1998). Por outro lado, G é uma medida (indireta) do campo de tensão na ponta da trinca, uma vez que esta grandeza é diretamente relacionada ao fator de intensidade, $K$, através do módulo de rigidez, E. Espera-se que, devido à analogia com $G, J$ desempenhe um papel semelhante nos corpos elásticos não lineares. Na verdade, como será visto adiante, J também é um parâmetro de campo de tensão e deformação e pode ser calculado sobre um contorno convenientemente escolhido, afastado da ponta da trinca, contendo somente cargas e deslocamentos elásticos (EWALDS; WANHILL, 1986). Dessa forma, assumindo-se que seja aplicável a teoria da deformação da plasticidade e a conseqüente restrição para o descarregamento, uma análise compreendendo fenômenos elasto-plásticos pode ser realizada a partir de um contorno para o qual as cargas e deslocamentos elásticos são conhecidos.

\subsubsection{J COMO UM PARÂMETRO DE CAMPO DE TENSÕES E DEFORMAÇÕES}

Consideremos um material elasto-plástico cuja curva tensão-deformação possa ser representada pela equação de Ramberg-Osgood (BROEK, 1991; SAXENA, 1998; DOWLING, 1999):

$$
\frac{\varepsilon}{\varepsilon_{0}}=\frac{\sigma}{\sigma_{0}}+\alpha\left(\frac{\sigma}{\sigma_{0}}\right)^{\frac{1}{n}}
$$


onde $\sigma_{0}$ é o limite de escoamento do material, $n$ é o expoente de endurecimento por deformação e $\alpha$ também é uma constante do material.

Se considerarmos que a deformação é grande, podemos desprezar o primeiro termo da eq.(69) (que representa a porção elástica) e, chamando $\frac{1}{n}=m$, temos:

$$
\frac{\varepsilon}{\varepsilon_{0}}=\alpha\left(\frac{\sigma}{\sigma_{0}}\right)^{m}
$$

Uma vez que $\mathrm{J}$ é independente do caminho, podemos arbitrariamente adotar um contorno circular de raio $r$, cujo centro está posicionado na ponta da trinca, conforme a Figura 20:

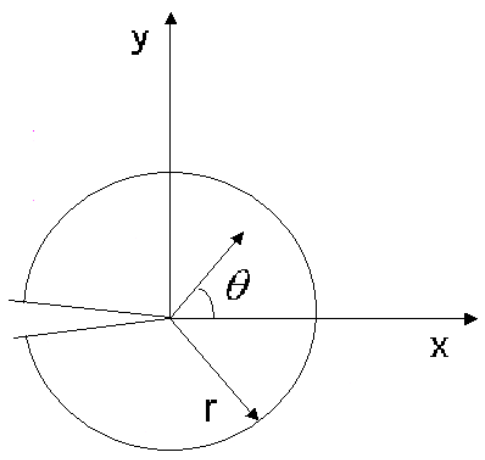

Figura 20: Contorno circular de raio $r$, com centro na ponta de uma trinca.

Considerando-se que $y=r \operatorname{sen} \theta, \quad d y=r \cos \theta d \theta \quad$ e $d s=r d \theta$, podemos reescrever a eq.(52) da seguinte maneira:

$$
J=r \int_{-\pi}^{\pi}\left(W \cos \theta-T_{i} \frac{\partial u_{i}}{\partial x}\right) d \theta
$$

ou

$$
\frac{J}{r}=\int_{-\pi}^{\pi}\left(W \cos \theta-T_{i} \frac{\partial u_{i}}{\partial x}\right) d \theta
$$


onde $W, T_{i}$ e $\frac{\partial u_{i}}{\partial x}$ são funções de $r$ e $\theta$.

A integral é independente do caminho e terá o mesmo valor qualquer que seja o valor de $r$. Por este motivo, a variável $r$ ficou de fora da integral.

W é expressa em termos de produtos de tensão e deformação (eq.(9)). Por outro lado, a tração $T_{i}$ tem dimensão de tensão, enquanto que $\frac{\partial u}{\partial x}$ tem dimensão de deformação. Dessa forma, todos os termos no integrando da equação (72) possuem a dimensão de produto de tensão e deformação, e podemos escrever:

$$
\sigma_{i j} \varepsilon_{i j} f_{i j}(\theta, m) \propto\left(\frac{J}{r}\right)
$$

e

$$
\sigma_{i j} \varepsilon_{i j} \propto\left(\frac{J}{r}\right) g_{i j}(\theta, m)
$$

Manipulando-se as equações (70) e (74), pode-se demonstrar que (SAXENA, 1998):

$$
\begin{gathered}
\sigma_{i j}=\sigma_{0}\left(\frac{J}{\alpha \sigma_{0} \varepsilon_{0} I_{m} r}\right)^{\frac{1}{1+m}} \hat{\sigma}_{i j}(\theta, m) \\
\varepsilon_{i j}=\alpha \varepsilon_{0} \sigma_{0}\left(\frac{J}{\alpha \sigma_{0} \varepsilon_{0} I_{m} r}\right)^{\frac{m}{1+m}} \hat{\varepsilon}_{i j}(\theta, m)
\end{gathered}
$$

Nas equações (75) e (76), $I_{m}$ é uma constante que depende da relação tensão-deformação (BROEK, 1991). Os valores de $I_{m}$ para estados planos de tensão ou plano de deformação podem ser encontrados em bons livros-texto sobre o assunto, como Saxena (1998), ou podem ser obtidos, aproximadamente, através das seguintes relações: 
Estado plano de tensão:

$$
I_{m}=4,546-0,2827 m+0,0175 m^{2}-0,45816.10^{-4} m^{3}
$$

Estado pano de deformação:

$$
I_{m}=6,658-0,4744 m+0,0404 m^{2}-0,01262 m^{3}
$$

As funções angulares $\hat{\sigma}_{i j}$ e $\hat{\varepsilon}_{i j}$ podem ser obtidas em livros-texto especializados no assunto, como Saxena (1998), para diferentes valores de $m$ e $\theta$.

As equações (75) e (76) demonstram que $J$ é também um parâmetro de campo de tensão e deformação. Elas são análogas às expressões dos campos de tensão na ponta da trinca da mecânica da fratura elástica linear (LEFM), com a ressalva que $J$ não é um parâmetro de campo tão geral como $K$, uma vez que as equações (75) e (76) dependem do material (através de $m$ ).

A existência de uma relação particular entre $J$ e os campos de tensão e deformação na ponta da trinca em materiais elásticos não lineares foi demonstrada, em trabalhos separados, por Hutchinson (1968) e por Rice e Rosengren (1968), conforme citado por Saxena (1998). Na literatura de mecânica da fratura, estes campos são conhecidos como campos de tensão HRR (HRR stress fieds) ou singularidades HRR (HRR singularities), em referência às iniciais dos nomes dos pesquisadores.

A existência dos campos HRR é fundamental para a integral-J porque, segundo Begley e Landes (1972), sob escoamento generalizado (large scale yielding), deve existir uma singularidade tensão-deformação na ponta da trinca para que $J$ seja válido como um critério de falha.

\subsubsection{UTILIDADE DE $J$}

Como visto nas seções anteriores, sob certas restrições, o conceito de integral-J pode ser entendido como uma taxa de liberação de energia em corpos de materiais elásticos não lineares contendo trincas, análoga a G na LEFM. Além disso, J pode ser visto como um parâmetro de campo, na medida em que está unicamente relacionado ao campo de tensões na região da ponta da trinca e, por ser um parâmetro de campo, um critério de fratura baseado em $J$ é compatível com 
qualquer critério baseado em características específicas da região da ponta da trinca (BEGLEY e LANDES, 1972). Uma vez que o campo de tensões na ponta da trinca é determinado completamente por $J$, pode-se presumir que os fenômenos que ocorrem naquela região sejam controlados por $\mathrm{J}$ e que duas trincas submetidas ao mesmo $J$ comportam-se da mesma maneira. Ou seja, a princípio, $J$ seria um parâmetro de similitude, como K. Conforme observado por Saxena (1998) verifica-se que importantes propriedades de $J$ a tornam muito semelhante aos bens sucedidos parâmetros da LEFM.

Pelas considerações acima, é bastante razoável esperar-se que $J$ tenha igualmente potencial para ser um parâmetro de fratura, útil na análise de problemas de fratura de corpos elásticos não lineares. Em princípio, deve existir um valor crítico, $J_{c}$, característico do material, que estabelece a condição para o crescimento da trinca. Dessa forma, o valor calculado de $J$ para um corpo contendo um trinca pode ser comparado com $J_{c}$, estabelecendo a base para um critério de falha, que pode ser escrito da seguinte maneira:

$$
J \geq J_{c}
$$

ou seja, se $J$ atingir o valor crítico $J_{c}$ a trinca avançará.

Em particular, em estado plano de deformação e no modo de abertura de trinca, o valor crítico de $J$ é designado por $J_{I c}$.

Como vantagem especial dos métodos de $J$, e por razões que ainda serão vistas neste texto, valores de $J_{l c}$ para materiais elasto-plásticos podem ser obtidos a partir de corpos de prova significativamente menores, quando comparados às dimensões exigidas para validar as medições de $K_{l c}\left(\mathrm{ou} G_{l c}\right.$ ) de materiais que apresentam excessiva deformação plástica.

A tenacidade de um material, tomada pelo valor de $J_{c}$, pode ser um parâmetro particularmente útil nos casos em que o início do crescimento estável de trincas constitui a situação crítica de projeto, ao invés da carga máxima de falha. Além disso, $J_{c}$ e a curva $J-R$ (esta será discutida ainda nesta seção) podem servir de base para comparação, seleção e garantia de qualidade de materiais com limites de escoamento similares (ASTM E 1820-08). 


\subsubsection{LIMITAÇÕES DE $J$}

Apesar de atraente, a aplicação de $J$ na análise de problemas de fratura deve ser feita com cautela. Algumas hipóteses são explicita ou implicitamente assumidas no desenvolvimento das condições que sustentam os argumentos apresentados na seção anterior, as quais impõem severas restrições ao conceito e limitações aos métodos experimentais.

Embora se tendo a pretensão de apresentar um conceito efetivo para o tratamento de problemas de fratura elasto-plástica, a verdade é que ao longo do capítulo importantes passagens foram desenvolvidas assumindo-se que o material apresentava comportamento elástico, embora não necessariamente linear, portanto, reversível. Nestes casos a curva tensão-deformação segue o mesmo trajeto tanto no carregamento como no descarregamento (Figura 21(a)). A prova da independência do caminho - principal propriedade de $J$, e as equações de campo HRR - equações (75) e (76), cuja derivação decorre da independência do caminho, são válidas com a assunção de comportamento elástico. Entretanto, se a trinca crescer haverá algum descarregamento ao longo dos flancos da trinca e num material real (elasto-plástico) este descarregamento é elástico linear, de forma que o processo não é mais reversível (Figura 21(b)). Por outro lado, a aplicação da teoria da deformação da plasticidade, fundamental para a extensão do conceito para o comportamento elasto-plástico, somente é válida em carregamento monotônico. Por estes argumentos, conclui-se que o conceito de $J$ é válido desde que não ocorra qualquer descarregamento; a princípio ele somente pode ser aplicado até o início do crescimento da trinca, ou seja, a trincas estacionárias.

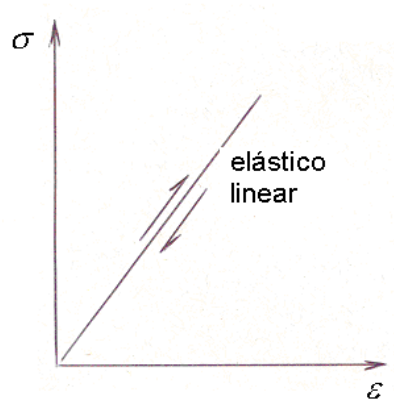

(a)

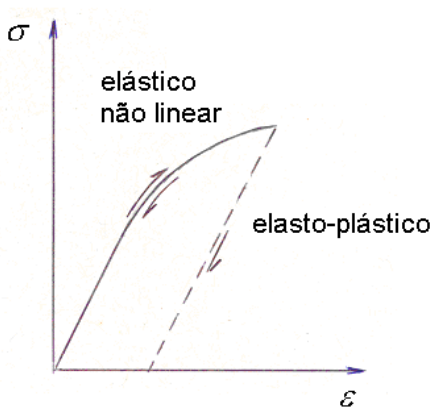

(b)

Figura 21: Curvas tensão-deformação para materiais elásticos (a), elásticos não lineares e elasto-plásticos (b). 
O comportamento elasto-plástico implica ainda em uma questão energética, uma vez que a energia dissipada não pode ser transformada em outras formas de energia (no sistema). Nesse sentido, havendo deformação plástica real, segundo Ewalds e Wanhill (1986), algumas transformações de termos de energia em importantes passagens não são legítimas, especialmente na análise do balanço de energia e na prova de que o valor de $J$ é nulo em um contorno fechado. Para materiais elasto-plásticos, $J$ perde sua interpretação física relacionada à energia potencial, mas conserva seu significado como uma medida da intensidade dos campos de tensão e deformação elasto-plástica ao redor da ponta da trinca (BEGLEY e LANDES, 1972; MEGUID, 1989; DOWLING, 1999). Dessa forma, J não pode ser identificado como a energia disponível para a extensão da trinca nestes materiais, entretanto, segundo Begley e Landes (1972), J ainda é igual à variação da energia potencial por unidade de crescimento de trinca $\left(-\frac{d U_{P}}{d a}\right)$.

Por outro lado, na demonstração da independência de $J$ do caminho, na interpretação energética de $J$ (relação entre $J$ e a energia potencial) e no desenvolvimento das relações entre $J$ e os campos de tensão e deformação na ponta da trinca é usada a teoria das pequenas deformações (small-deformation theory) (SAXENA, 1998). Essa teoria busca a descrição da deformação de materiais mais rígidos (comparativamente à teoria da deformação finita (finite-deformation theory) que busca a descrição de deformações arbitrariamente grandes) e não leva em conta a mudança (alongamento, cisalhamento, área e elementos de volume) em objetos geométricos durante a deformação (GUZ, 2001). Entretanto, as deformações que ocorrem na zona de processo de materiais dúcteis são realmente plásticas e não podem mais ser consideradas pequenas. Como conseqüência, há uma pequena região inelástica em torno da ponta da trinca que não pode ser controlada por $\mathrm{J}$. Como veremos adiante, essa região deve ser suficientemente pequena em relação às dimensões da região na qual o campo de tensão é controlado por $\mathrm{J}$ para que a análise através desse parâmetro seja válida.

Buscando novamente uma útil analogia com a mecânica da fratura elástica linear, é oportuno resgatar o conceito de região de domínio de $K$ (region of $K$ dominance or K-field).

Excessiva plasticidade viola as hipóteses sobre as quais se fundamenta a LEFM. Entretanto, se a zona plástica na região da ponta da trinca for 
suficientemente pequena em relação às dimensões do corpo e da trinca, pode-se definir uma região que engloba a primeira, onde as equações dos campos de tensão elástica ainda se aplicam. Essa região, conhecida como "região de domínio de K", circunda e controla o comportamento da zona plástica e da ponta da trinca, sendo que sua existência é necessária para garantir que a LEFM seja aplicável. Mesmo valor de $K$ significa mesma zona plástica e mesmo campo de tensão, ao que se dá o nome de princípio de similitude. Em outras palavras, espera-se que duas trincas se comportem da mesma maneira quando estiverem submetidas ao mesmo $K$, independentemente da geometria, tipo de carregamento e comprimento da trinca. $\mathrm{O}$ princípio da região de domínio de $K$ é ilustrado na Figura 22:

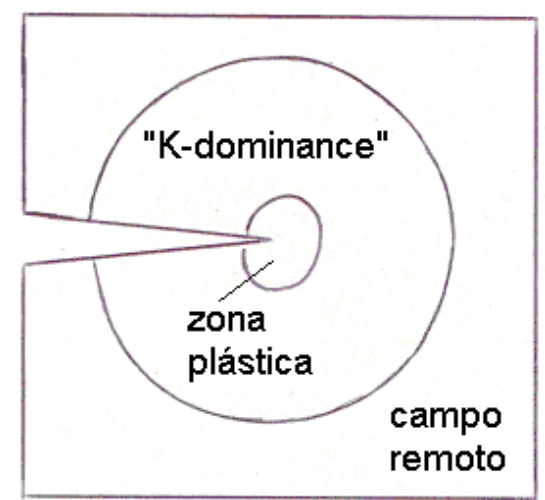

Figura 22: Região de domínio de K.

Verifica-se que a exigência de similitude é satisfeita se a relação entre o fator de intensidade de tensão e o limite de escoamento - $\left(\frac{K}{\sigma_{0}}\right)^{2}$ - for pequena em relação a qualquer dimensão do corpo. Dessa forma, tem-se admitido que a aplicação da LEFM obedece ao critério estabelecido pela eq.(80) (DOWLING, 1999):

$$
a,(W-a), B \geq \frac{4}{\pi}\left(\frac{K}{\sigma_{0}}\right)^{2}
$$

onde a é o comprimento da trinca, $(W-a)$ é o comprimento do ligamento e $B$ é a espessura do corpo.

Um raciocínio semelhante pode ser desenvolvido para superar as dificuldades da aplicação de $J$, decorrentes da plasticidade na região da ponta da trinca, 
definindo-se uma região de domínio de $\mathrm{J}$ (region of J-dominance) onde permanecem válidos os campos HRR - equações (75) e (76). Igualmente, exigem-se condições de similitude, ou seja, é necessário que as condições da zona plástica e da frente da trinca sejam as mesmas para diferentes geometrias e que elas sejam controladas pelo valor de $\mathrm{J}$ aplicado. Consideremos a Figura 23:

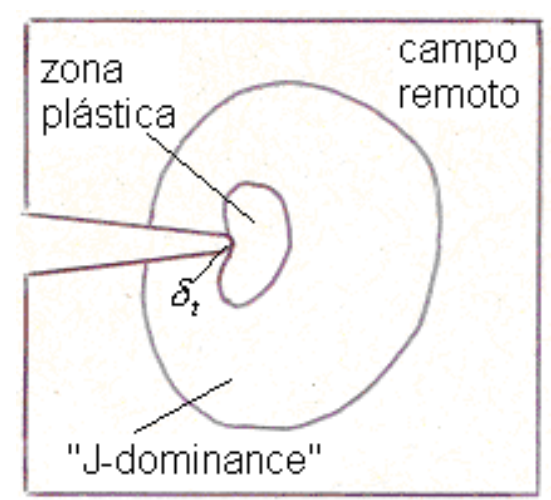

Figura 23: Região de domínio de J

Vamos supor que a extensão da zona plástica na frente da trinca possa ser definida em termos de múltiplos da abertura crítica da ponta da trinca (crack tip opening displacement - CTOD), $\delta_{t}$. Dessa forma, para que $J$ seja um parâmetro válido de similitude, deve-se determinar que as dimensões importantes do corpo (a, $W$-a, B) também sejam múltiplos de $\delta_{t}$. Considerando-se o modelo de Dugdale (1960), pode-se demonstrar a seguinte expressão (RICE, 1968):

$$
J=\sigma_{0} \delta_{t}
$$

A equação (81) é válida para materiais perfeitamente plásticos, para os quais $m \rightarrow \infty$. Uma expressão mais geral é a seguinte (SAXENA, 1998):

$$
\delta_{t}=d_{m} \frac{J}{\sigma_{0}}
$$

onde $d_{m}$ é uma constante do material, que depende de $m$.

É possível, então, estabelecer um critério geral para a definição da região de domínio de $\mathrm{J}$, da seguinte forma: 


$$
a,(W-a), B \geq c\left(\frac{J}{\sigma_{0}}\right)
$$

McClintock (1971), citado por Saxena (1998), observou que, para materiais perfeitamente plásticos, os campos das linhas de escorregamento (slip line fields) de corpos de diferentes geometrias contendo trincas podem ser bastante diferentes, e que, portanto, os campos de tensão e deformação na frente da trinca deveriam ser dependentes da geometria. Segundo Saxena (1998), pode-se argumentar que o endurecimento por deformação é necessário para que se tenha uma nítida região de domínio de $\mathrm{J}$ e, mesmo com endurecimento por deformação, a extensão da região de domínio de J será dependente da geometria. Conforme citado por Broek (1991) e por Saxena (1998), os resultados de McMecking e Parks (1979), confirmados por Shih e German (1979), sugerem que há uma região de domínio de $J$ se forem satisfeitas as exigências das seguintes expressões:

Corpo de prova com trinca central (center crack tension):

$$
(W-a), \geq 200\left(\frac{J}{\sigma_{0}}\right)
$$

Corpos de prova do tipo de flexão de três pontos (SENB ou SE(B)):

$$
(W-a), \geq 30\left(\frac{J}{\sigma_{0}}\right)
$$

As equações (84) e (85) são obviamente muito importantes para a definição das dimensões de corpos de provas em ensaios de J. Aliás, já adentrando o campo da prática experimental, que será tratado de forma mais detalhada na próxima subseção, surge uma importante questão relacionada ao crescimento da trinca. Os métodos modernos para a construção da curva $J-R$ e para a avaliação de $J_{l c}$ se baseiam em associações entre o valor aplicado de $J$ e uma certa quantidade de crescimento estável de trinca correspondente, $\Delta a$. Assim sendo, deve haver algum crescimento da trinca nos métodos de J. Entretanto, a teoria da deformação da plasticidade impõe uma severa restrição ao descarregamento, que fatalmente ocorre nos flancos de um trinca em crescimento, surgindo a questão se e até que ponto $J$ 
efetivamente ainda controla um crescimento estável da trinca. A própria norma ASTM E 1820-08 reconhece que o valor de $\mathrm{J}$ em campo remoto (far-field J) pode não representar adequadamente o campo tensão-deformação local para uma trinca em crescimento. Então, torna-se necessário contornar a restrição ao crescimento da trinca, de forma a viabilizar aspectos operacionais das medições, particularmente no que diz respeito à determinação do início da propagação estável da trinca.

Uma idéia para superar o problema é impor a condição de que extensões muito limitadas da trinca ocorram numa região muito pequena, onde apenas ali não se aplique a assunção de carregamento proporcional, permanecendo esta válida no restante do corpo. Hutchinson e Paris (1979), citados por Broek (1991) e por Saxena (1998) estabeleceram um critério para verificar se a extensão da trinca, $\Delta a$, é suficientemente pequena em relação às dimensões da região de domínio de $J$, para que o crescimento da trinca seja ainda controlado por J. A partir da eq.(76) e após alguma manipulação matemática, examina-se um incremento de deformação em um elemento do material, que originalmente estava a uma distância $(r+d a)$ da posição atual da ponta da trinca, e que agora está a uma distância r (SAXENA, 1998). Dessa forma:

$$
\frac{d \varepsilon_{i j}}{\varepsilon_{i j}}=\frac{m}{m+1} \frac{d J}{J}+\frac{d a}{r} \frac{\hat{\beta}_{i j}(\theta)}{\hat{\varepsilon}_{i j}(\theta)}
$$

onde: $\hat{\beta}_{i j}(\theta)=\frac{m}{m+1} \cos \theta \hat{\varepsilon}_{i j}(\theta)+\operatorname{sen} \theta \frac{\partial}{\partial \theta} \hat{\varepsilon}_{i j}(\theta)$

O primeiro termo da eq.(86) é o termo proporcional (o incremento na deformação é diretamente proporcional ao incremento em J), enquanto que o segundo termo é não proporcional. Dessa forma, a condição que se impõe para que o crescimento da trinca seja controlado por $J$ é que o segundo termo da eq.(86) seja muito pequeno (desprezível) em relação ao primeiro. Se considerarmos que o valor de $\frac{m}{m+1}$ e dos termos angulares são próximos da unidade, o requerimento exigido pode ser traduzido da seguinte maneira: 


$$
\frac{d J}{J}>>\frac{d a}{r}
$$

Fisicamente, a eq.(87) significa que se o valor de $\left[J /\left(\frac{d J}{d a)}\right)\right]$ for pequeno quando comparado com as dimensões da região de domínio de $\mathrm{J}$, o crescimento da trinca será controlado por J. Tomando-se o comprimento do ligamento, $(W-a)$, como a extensão da região de domínio de $\mathrm{J}$, tem-se:

$$
\frac{(W-a)}{J} \frac{d J}{d a}=\omega>>1
$$

Pelo exposto, verifica-se que a extensão da trinca que ocorre sob controle de $J$ depende da geometria e das dimensões do corpo, e do expoente de endurecimento por deformação do material.

$\mathrm{Na}$ eq.(88), tem sido sugerido que o valor de $\omega$ seja da ordem de 40 (ou maior) (BROEK 1991).

Verifica-se ainda que $J$ controla o crescimento da trinca apenas se a curva $J x$ $\Delta a$ apresentar alta inclinação e desde que a quantidade de extensão da trinca seja muito pequena.

Por fim, é importante observar que, por simplicidade, no desenvolvimento do conceito de $\mathrm{J}$ foram usados modelos planares (biaxiais), com espessura unitária, de forma que deformações na direção da espessura não foram consideradas. Assim sendo, a validade de $J$ restringe-se aos casos de estado plano de deformação, onde uma das deformações é nula (neste caso, na direção da espessura) ou ao caso hipotético de estado plano de tensão em um corpo com espessura unitária. Segundo Ewalds \& Wanhill (1986) essa restrição não é tão importante para efeitos práticos, uma vez que $J$ é útil principalmente no estudo de corpos espessos, onde o estado de tensões predominante é idealmente o estado plano de deformação.

\subsubsection{AVALIAÇÃO EXPERIMENTAL DE J}

Begley e Landes (1972) foram os primeiros a reconhecer e a demonstrar experimentalmente o potencial de $J\left(J_{I c}\right)$ como um parâmetro de fatura para 
materiais com comportamento elasto-plástico. Begley e Landes (1972) usaram a abordagem energética (relação entre $J$ e a energia potencial) nas suas avaliações. Esta abordagem permanece como via experimental mais prática, embora $\mathrm{J}$ possa ser calculada analiticamente, a partir da sua definição como uma integral independente do caminho. O leitor interessado poderá recorrer à bibliografia, como Rice (1968) e Saxena (1998) para verificar o desenvolvimento de soluções analíticas, mas este texto manter-se-á restrito às abordagens energéticas.

\subsubsection{O método original de $\mathrm{J}$}

O método original de Begley e Landes (1972) se baseia na definição de J como taxa de decréscimo da energia potencial $\left(-\frac{d U_{P}}{d a}\right)$ por unidade de espessura do material e guarda analogia com o método da compliance (SAXENA, 1998) para medição de $K(G)$. O procedimento emprega diversos corpos de prova nominalmente iguais e requer a avaliação gráfica de $-\frac{d U}{d a}$. O método será rapidamente descrito com auxílio da Figura 24.

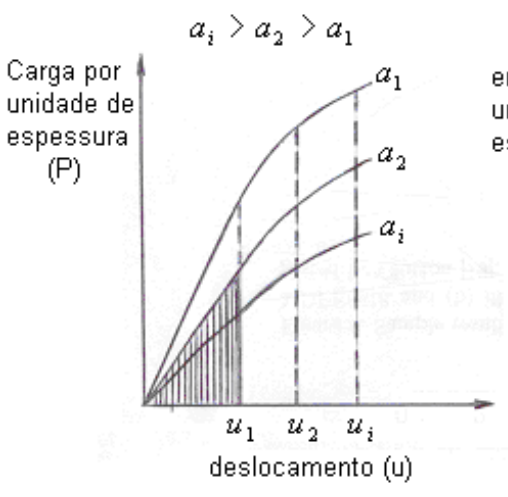

(a)

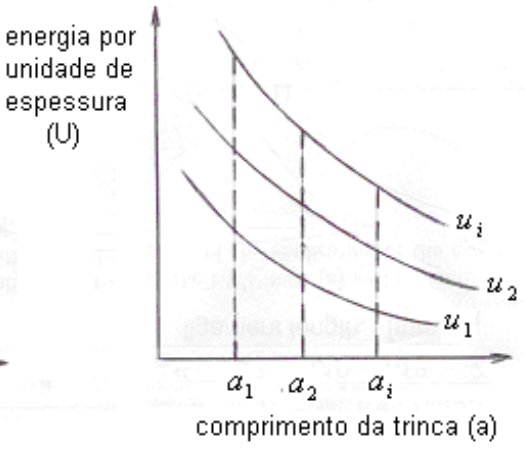

(b)

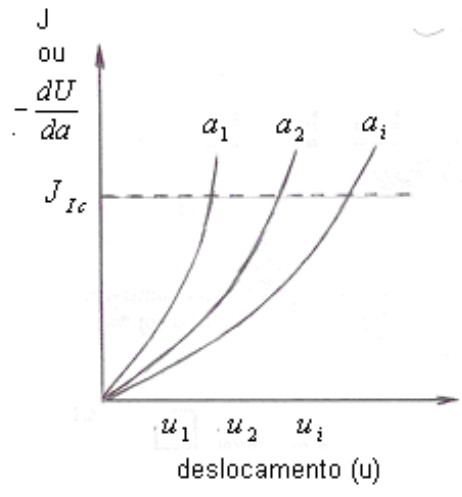

(c)

Figura 24: Ilustração do método original para estimativa de $J_{I c}$, desenvolvido por Begley e Landes (1972)

Primeiramente, diversos corpos de prova contendo diferentes comprimentos de trinca $\left(a_{1}, a_{2}, \ldots, a_{i}\right)$ são carregados até níveis de carregamento que não permitam o crescimento da trinca, obtendo-se uma série de curvas carga $(P) \times$ deslocamento (u) (Figura 24(a)). A área sob cada curva $P$ x u representa a energia aplicada a cada 
corpo de prova, $U$, que pode ser tomada até determinados deslocamentos $\left(u_{1}, u_{2}, \ldots\right.$, $u_{j}$ ), obtendo-se uma série de valores $U_{i j}$, onde o índice $i$ refere-se ao comprimento da trinca e o índice $j$ ao deslocamento. Por exemplo, a área indicada na Figura 24(a), designada por $U_{21}$, representa a energia aplicada no corpo de prova com trinca de comprimento $a_{2}$ até o deslocamento $u_{1}$. Caso as espessuras dos corpos de prova sejam diferentes da unidade, os valores devem ser divididos pela espessura.

Em seguida, para cada valor de deslocamento, $u_{j}$, é construído um gráfico de $U_{i j}$ em função de $a_{i}$, formando uma família de curvas $U \times$ a para diferentes deslocamentos, como ilustrado na Figura 24(b). A inclinação (negativa) de cada curva , $\frac{d U}{d a}$, é medida em diferentes pontos, obtendo-se uma série de valores de $\mathrm{J}$.

Por fim, é construído um gráfico dos diferentes valores de $\mathrm{J}$ em função do deslocamento, para cada comprimento de trinca. Esta família de curvas está ilustrada na Figura 24(c), onde também está representado o valor de $J_{l c}$. Conhecendo-se o valor do deslocamento no início da propagação da trinca pode-se obter o valor de $J_{I c}$ a partir de cada curva de calibração, $J \times u$, correspondente a cada comprimento de trinca inicial. Se $J_{l c}$ for realmente um critério apropriado de fratura, seu valor deveria ser o mesmo para todas as curvas.

O método original desenvolvido por Begley e Landes (1972) é elegante e faz uso direto da interpretação energética de J. Entretanto, o procedimento é trabalhoso, na medida em que envolve muitos corpos de prova, a manipulação de muitos dados e a construção de uma série de gráficos. Além disso, segundo os próprios autores (1972b), a determinação do início do crescimento da trinca é muito difícil.

Segundo os autores originais, levando-se em conta a variação experimental dos resultados, o método não depende da geometria. Entretanto, outros autores consideram que as curvas $\mathrm{J} \times u$ dependem do material e da geometria do corpo de prova (SAXENA, 1998).

1.2.9.2 A evolução dos métodos de avaliação de J: Métodos semi-empíricos com um corpo de prova único

É possível estimar $\mathrm{J}$ a partir de procedimentos mais simples, utilizando registros de carga-deslocamento de um único corpo de prova, com auxílio de algumas expressões que foram desenvolvidas para determinados tipos de corpos de 
prova. Para compreender estas expressões, entretanto, é necessário considerar a definição de $J$ sob outra forma.

Considere a Figura 25, que ilustra uma situação de carregamento a deslocamento constante, de dois corpos elásticos não lineares idênticos, de espessura unitária, contendo trincas com comprimento a e a $+\Delta a$, respectivamente:

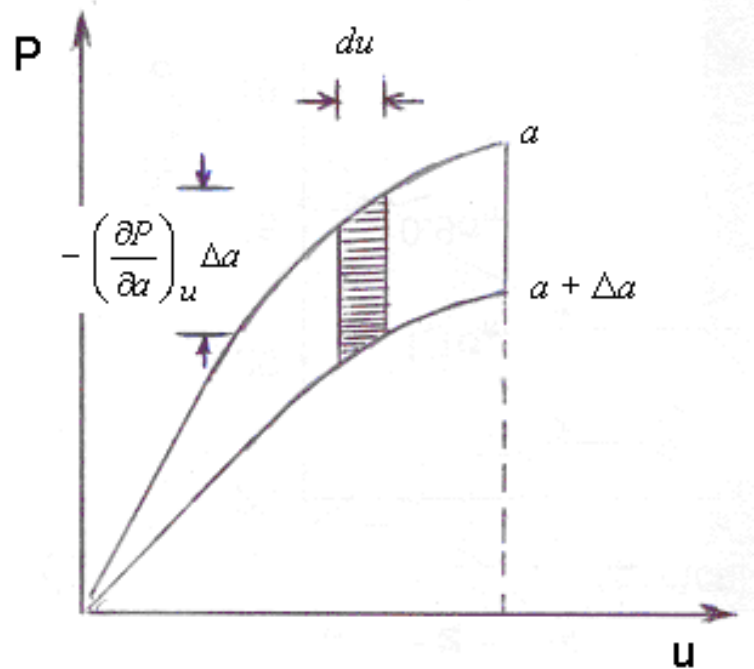

Figura 25: Curva carga-deslocamento de dois corpos elásticos não lineares idênticos, contendo trincas de comprimento a e a $+\Delta a$, carregados até o mesmo deslocamento.

Considerando-se que as forças externas não realizam trabalho sob condição de deslocamento constante, a diferença de energia potencial decorrente da extensão da trinca por $\Delta a$, que corresponde à área entre as duas curvas, é dada pela seguinte expressão:

$$
-\Delta U_{P}=-\int_{0}^{u}\left(\frac{\partial P}{\partial a}\right)_{u} \Delta a d u
$$

Considerando-se o limite, quando $\Delta a \rightarrow 0$ e a definição de $J$, dada pela eq.(40), temos:

$$
J=-\frac{d U_{P}}{d a}=-\int_{0}^{u}\left(\frac{\partial P}{\partial a}\right)_{u} d u
$$


Considere-se, agora, o caso de carregamento a carga constante, ilustrado na Figura 26:

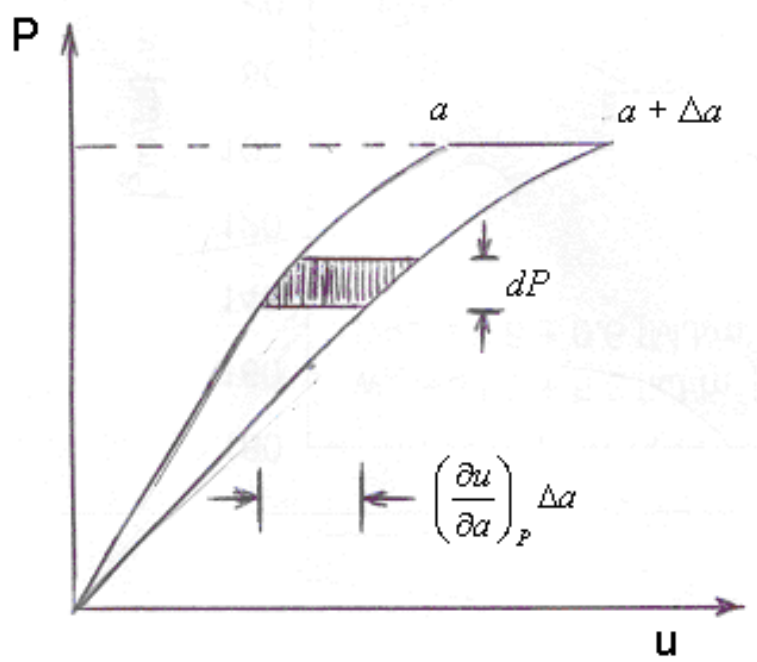

Figura 26: Curva carga-deslocamento de dois corpos elásticos não lineares idênticos, contendo trincas de comprimento a e $a+\Delta a$, carregados até carga constante.

Novamente, a diferença de energia potencial decorrente da extensão da trinca por $\Delta a$, que corresponde à área entre as duas curvas, é dada pela seguinte expressão:

$$
-\Delta U_{P}=\int_{0}^{P}\left(\frac{\partial u}{\partial a}\right)_{P} \Delta a d P
$$

Considerando-se o limite, quando $\Delta a \rightarrow 0$ e a definição de $J$, dada pela eq.(40), temos:

$$
J=-\frac{d U_{P}}{d a}=\int_{0}^{P}\left(\frac{\partial u}{\partial a}\right)_{P} d P
$$

Comparando-se as equações (90) e (92), temos as seguintes expressões alternativas para a definição de $\mathrm{J}$ :

$$
J=-\int_{0}^{u}\left(\frac{\partial P}{\partial a}\right)_{u} d u=\int_{0}^{P}\left(\frac{\partial u}{\partial a}\right)_{P} d P
$$


ou

$$
J=-\frac{1}{B} \int_{0}^{u}\left(\frac{\partial P}{\partial a}\right)_{u} d u=\frac{1}{B} \int_{0}^{P}\left(\frac{\partial u}{\partial a}\right)_{P} d P
$$

para um corpo com espessura $B$.

A equação 93 é equivalente à equação 43 .

Foram Rice e colaboradores (1973), citados por Ewalds e Wanhill (1986) e por Saxena (1998), quem forneceram a principal contribuição para a simplificação do método, ao desenvolverem expressões que permitiam a estimativa de $\mathrm{J}$ a partir de um único corpo de prova do tipo flexão de três pontos (SENB), contendo um entalhe profundo. Considere a Figura 27, que ilustra um corpo de prova do tipo SENB e o mesmo corpo submetido a uma flexão pura. A Figura 28 representa a curva de carregamento do corpo.

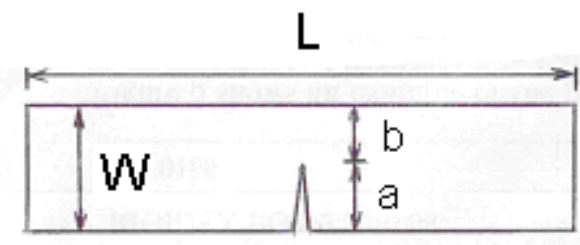

(a)

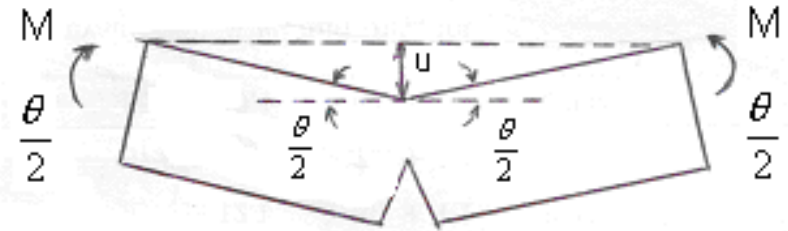

(b)

Figura 27: (a) corpo de prova do tipo SENB contendo uma trinca profunda e suas dimensões principais; (b) o mesmo corpo em flexão pura.

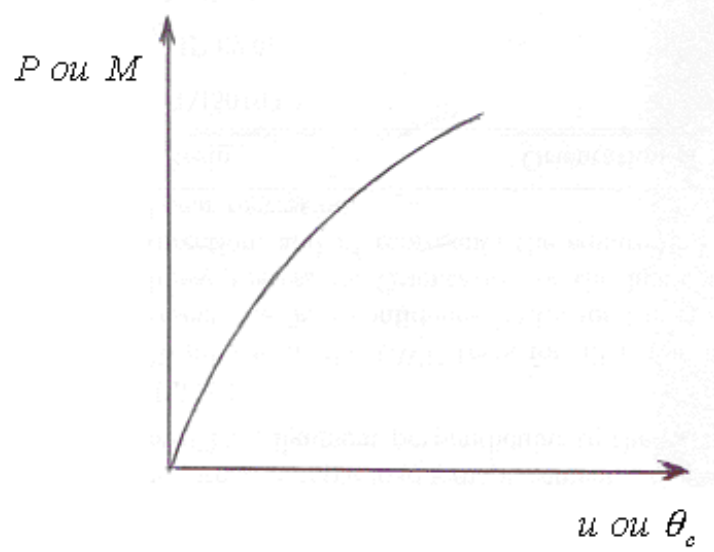

Figura 28: Curva de carregamento de um corpo de prova do tipo SENB contendo uma trinca profunda. 
Assumindo-se que toda a deformação plástica ocorra somente no ligamento do corpo, $b$, e que este é dado por $b=W-a$, temos:

$$
\frac{\partial}{\partial b}=-\frac{\partial}{\partial a}
$$

O ângulo total de rotação, $\theta_{t}$, é dado por:

$$
\theta_{t}=\theta_{n c}+\theta_{c}
$$

onde $\theta_{n c}$ é o ângulo de rotação (flexão) correspondente ao corpo sem a presença da trinca (portanto, independente de a) e $\theta_{c}$ é o ângulo de rotação adicional devido à presença da trinca, ou seja, é a contribuição da trinca introduzida para o ângulo total de rotação.

A eq.(94) pode ser escrita da seguinte maneira:

$$
J=\frac{1}{B} \int_{0}^{P}\left(\frac{\partial u}{\partial a}\right)_{P} d P=\frac{1}{B} \int_{0}^{M}\left(\frac{\partial \theta_{t}}{\partial a}\right)_{M} d M=-\frac{1}{B} \int_{0}^{M}\left(\frac{\partial \theta t}{\partial b}\right)_{M} d M
$$

onde $M$ é o momento fletor aplicado.

Com base em uma análise dimensional, é razoável supor que $\theta_{c}$ é uma função do momento aplicado, da resistência do material, $\sigma_{0}$, do comprimento do ligamento, $b$, e da espessura do corpo, $B$, que depende somente de propriedades do material, como o módulo de rigidez, $E$, o limite de escoamento, $\sigma_{0}$, e o expoente de endurecimento por deformação, $n$. $\theta_{c}$ pode ser expresso da seguinte maneira:

$$
\theta_{c}=f\left(\frac{M}{B b^{2}}\right)
$$

Deve-se observar que $\sigma_{0}$ possui dimensões de tensão e, a rigor, deveria ser incluída no denominador da eq.(98). Entretanto, trata-se de uma constante que não altera os resultados das passagens seguintes e, portanto, foi omitida. 
Para um corpo de prova com entalhe profundo, $\theta_{n c} \ll \theta_{c}$, podendo-se assumir que $\theta_{t} \approx \theta_{c}$. Dessa forma:

$$
-\left(\frac{\partial \theta_{t}}{\partial b}\right)_{M} \cong-\left(\frac{\partial \theta_{c}}{\partial b}\right)_{M}=-\left[\frac{\partial}{\partial b} f\left(\frac{M}{B b^{2}}\right)\right]_{M}=\frac{2 M}{B b^{3}} f^{\prime}\left(\frac{M}{B b^{2}}\right)
$$

A função $f^{\prime}\left(\frac{M}{B b^{2}}\right)$ pode ser obtida através de um artifício matemático: derivando-se a eq.(98) em relação à M, temos:

$$
\left[\frac{\partial}{\partial M} f\left(\frac{M}{B b^{2}}\right)\right]_{b}=\frac{1}{B b^{2}} f^{\prime}\left(\frac{M}{B b^{2}}\right)
$$

Rearranjando a eq.(100), temos:

$$
f^{\prime}\left(\frac{M}{B b^{2}}\right)=B b^{2}\left[\frac{\partial}{\partial M} f\left(\frac{M}{B b^{2}}\right)\right]_{b}=B b^{2}\left(\frac{\partial \theta_{c}}{\partial M}\right)_{b}
$$

Substituindo a eq.(101) na eq.(99), temos:

$$
-\left(\frac{\partial \theta_{c}}{\partial b}\right)_{M}=\frac{2 M}{b}\left(\frac{\partial \theta_{c}}{\partial M}\right)_{b}
$$

Substituindo a equação (102) na equação (97), temos:

$$
J=\frac{1}{B} \int_{0}^{M} \frac{2 M}{b}\left(\frac{\partial \theta_{c}}{\partial M}\right)_{b} d M
$$

Entretanto,

$$
d \theta_{c}=f^{\prime}\left(\frac{M}{B b^{2}}\right) \frac{d M}{B b^{2}}
$$


ou,

$$
d M=\frac{B b^{2}}{f^{\prime}\left(\frac{M}{B b^{2}}\right)} d \theta_{c}
$$

Substituindo as equações (101) e (105) na equação (103), temos:

$$
J=\frac{2}{B b} \int_{0}^{\theta_{c}} M d \theta_{c}
$$

A expressão $\int_{0}^{\theta_{c}} M d \theta_{c}$ é a área sob a curva $M-\theta_{c}$ (Figura 28), de forma que, em princípio, um teste de $J$ pode ser realizado medindo-se o momento, $M$, em função de $\theta_{c}$ em um único corpo de prova do tipo SENB. Entretanto, a construção de uma curva $M-\theta_{c}$ não é ainda muito prática, embora seja menos trabalhosa que o método original de Begley e Landes (1972). Por outro lado, lembrando que estamos assumindo que $\theta_{c} \approx \theta_{t}$ (que é efetivamente medido) e que a deformação plástica está restrita ao ligamento, a eq.(106) pode ser modificada, com uma pequena margem de erro, segundo Rice e colaboradores (1973), citados por Ewalds e Wanhill (1986). Assumindo-se que $b \ll W$, podem-se considerar como válidas as seguintes relações:

$$
\begin{gathered}
P=\frac{4 M}{L} \\
u=\frac{\theta_{t} L}{4} \Rightarrow d u=\frac{L}{4} d \theta_{t}
\end{gathered}
$$

Substituindo-se as equações (107) e (108) na eq.(106), temos:

$$
J=\frac{2}{B b} \int_{0}^{u} P d u
$$


Para a estimativa precisa de $J$ empregando-se a eq.(109) é necessário que $\frac{a}{W} \geq 0,5$ (SAXENA, 1998), caso em que também $u_{t}$ (ou simplesmente $u$ ) $\approx u_{c}$ (deslocamento adicional em decorrência da trinca).

Através da eq.(109) o valor de $J$ pode ser calculado a partir da curva cargadeslocamento de um único corpo de prova do tipo SENB contendo uma trinca profunda. Particularmente, o valor de $J_{l c}$ pode ser obtido à partir da área sob a curva, até o ponto imediato em que a trinca começa a crescer. Entretanto, este não é o procedimento normalmente adotado porque é difícil a identificação exata do instante em que a trinca começa a avançar. Alternativamente, duas técnicas podem ser adotadas: o método da compliance e a técnica dos múltiplos corpos de prova. $\mathrm{Na}$ primeira, que utiliza um único corpo de prova, o comprimento da trinca é calculado em intervalos regulares durante o ensaio, através do descarregamento parcial do corpo de prova e da medição do módulo de flexibilidade (compliance). Esta técnica será rapidamente descrita no próximo item, mas não será adotada neste trabalho. $\mathrm{Na}$ técnica dos múltiplos corpos de prova, vários corpos de prova nominalmente idênticos podem ser carregados de forma que cada um apresente uma certa extensão limitada (mas definida) da trinca, $\Delta a$. A extensão da trinca é medida diretamente na superfície de fratura por meios óticos. Com os dados obtidos é construída uma curva $J-\Delta a$, denominada curva $J-R$, cuja extrapolação para $\Delta a=0$ fornece o valor de $J_{c}$, ou $J_{l c}$, se as condições para o estado plano de deformação forem satisfeitas. Vistos desta forma simplificada, estes procedimentos podem ser duvidosos devido às restrições para o crescimento da trinca impostas pelos fundamentos de J. Por outro lado, sob determinadas condições, eles podem ser aceitáveis, desde que a curva $J-R$ apresente alta inclinação, que a quantidade de extensão de trinca seja muito pequena, como visto anteriormente, e que os resultados sejam corrigidos. Esta questão será mais detalhada no próximo item.

O corpo de prova do tipo compacto (compact tension - CT) (Figura 6(b)) é outra configuração importante em ensaios de mecânica da fratura. Pode-se demonstrar que a expressão de $J$ para este tipo de corpo de prova é a seguinte (SAXENA, 1998): 


$$
J=\frac{U\left(2+0,522 \frac{b}{W}\right)}{B b}
$$

onde $U$ é a área sob a curva carga-deslocamento.

De forma genérica, pode-se expressar $\mathrm{J}$ para um único corpo de prova, da seguinte maneira:

$$
J=\frac{\eta U}{B b}
$$

onde o fator de calibração, $\eta$, depende da geometria do corpo de prova adotado.

1.2.9.3 O desenvolvimento dos métodos atuais para avaliação da tenacidade através de $\mathrm{J}$ em materiais metálicos

As bases metodológicas para as técnicas modernas de avaliação de $J_{l c}$ e de construção das curvas J-R foram desenvolvidas por Landes e Begley $(1974,1977)$, a partir dos avanços proporcionados pelos trabalhos de Rice e colaboradores (1973).

A primeira técnica a ser desenvolvida foi a dos múltiplos corpos de prova, à qual a maior parte desta seção está dedicada, tendo-se em vista que o presente trabalho está focado em um material polimérico. Em linhas gerais, o procedimento básico contempla as seguintes etapas:

(i) Seleção do tipo e dimensões do corpo de prova: geralmente as configurações SENB e CT são as mais comumente usadas em função de se dispor de expressões para o cálculo de $J$ e da experiência já acumulada com estas geometrias. Lande e Begley (1974) usaram os tipos SENB e CT, mas neste trabalho a configuração adotada é SENB;

(ii) Confecção dos corpos de prova: são utilizados múltiplos corpos de prova com dimensões nominalmente idênticas, incluindo os entalhes e as pré-trincas, com o objetivo de reproduzir tanto quanto possível a parte inicial das curvas cargadeslocamento; 
(iii) Introdução do entalhe e da pré-trinca: os métodos de $J$ baseiam-se na ativação controlada de uma pré-trinca artificialmente introduzida na raiz de um entalhe previamente usinado no corpo de prova. Em metais as pré-trincas são introduzidas por fadiga, enquanto que em polímeros outras técnicas são utilizadas, as quais serão posteriormente discutidas com mais detalhes;

(iv) Preparação do equipamento para os ensaios: requer-se uma máquina universal de ensaios, bases e acessórios para apoio e fixação dos corpos de prova e dispositivos para registro das medições de carga e deslocamento aplicados. É essencial que o deslocamento seja medido ao longo da linha de carregamento do corpo de prova;

(v) Execução dos ensaios: cada corpo de prova é submetido a um carregamento com deslocamento controlado, de forma que cada um apresente uma certa quantidade de crescimento estável da pré-trinca. É importante observar que a configuração do carregamento nos métodos de J é no modo I (de abertura);

(vi) Ruptura dos corpos de prova: após a extensão controlada da pré-trinca, o corpo de prova deve ser rompido para expor a superfície de fratura;

(vii) Medição do comprimento inicial e da extensão da pré-trinca: estes valores são medidos por meios óticos diretamente na superfície de fratura. A superfície de fratura deve apresentar, naturalmente ou por meios artificiais, diferentes nuances entre os diferentes estágios de forma a permitir a distinção da quantidade de crescimento estável da trinca;

(viii) Análise das curvas carga-deslocamento;

(ix) Construção da curva J-R e cálculo de $J_{I c}$ condicional (ou $J_{Q}$ ): o valor condicional de $J_{I C}$ é um valor provisório, designado por $J_{Q}$, cuja validação decorre da satisfação de determinadas exigências, sendo a mais importante a do estado plano de deformação

(x) Validação de $J_{l c}$.

A análise e as medições na superfície de fratura são críticas. As frentes da pré-trinca, tanto inicialmente como após o crescimento estável, não são geralmente retas devido à diferença de estado de tensão entre a superfície lateral do corpo de prova (sob estado plano de tensão) e o núcleo (sob estado plano de deformação ou de transição). Esta questão, que complica as medições da trinca inicial e da extensão da trinca, é ilustrada na Figura 29. A prática normalmente adotada é 
calcular um único valor médio de uma série de medidas, realizadas através da espessura do corpo de prova. A introdução de entalhes laterais (side grooves), prática recomendável nas normas, tende a diminuir a curvatura da frente da trinca.

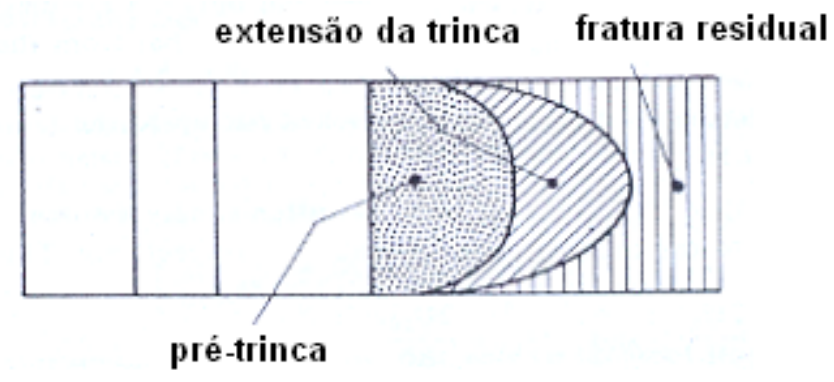

Figura 29: llustração da superfície de fratura final de um corpo de prova para ensaio de $J$ (Adaptado de Ewalds e Walhill, 1986)

Através da análise das curvas de carregamento, é obtida a energia aplicada a cada corpo de prova, $U_{i}$ (a partir da área sob a curva), para provocar um determinado crescimento estável de trinca, $\Delta a_{i}$. Os dados de cada corpo de prova são substituídos na eq.(111), obtendo-se o valor correspondente de $J\left(J_{i}\right)$. Com os pares $\left(J_{i}, \Delta a_{i}\right)$ é construído um gráfico, conhecido como curva $J-R$, cuja extrapolação para um crescimento nulo da trinca $(\Delta a)$ forneceria, em tese, o valor de $J_{c}$ (ou $J_{l c}$ ). Entretanto, no caso de materiais dúcteis o crescimento da trinca não ocorre imediatamente com o carregamento inicial. Na verdade, pós o início do carregamento ocorre primeiramente um arredondamento da ponta da trinca, antes do crescimento verdadeiro da ponta da trinca. Este fenômeno é ilustrado na Figura 30:

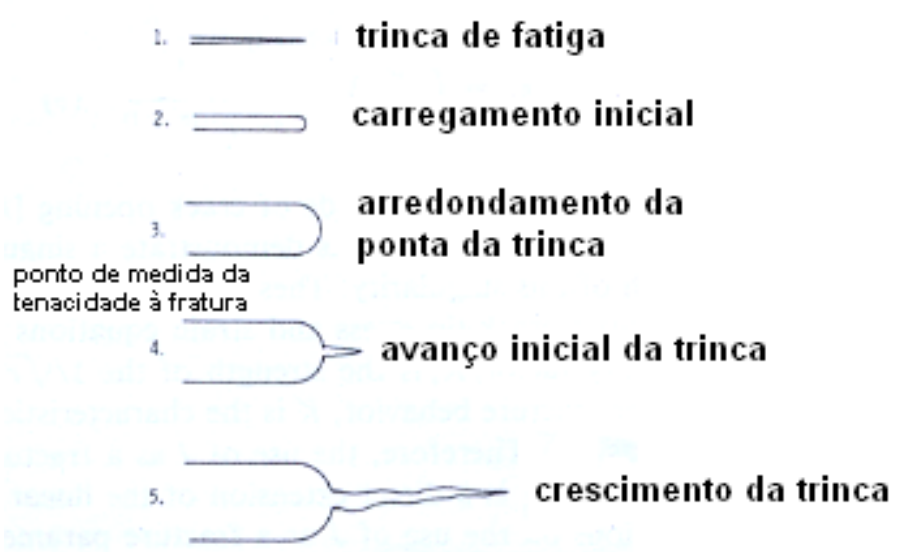

Figura 30: llustração dos fenômenos que ocorrem na ponta da trinca, no processo de fratura de um material dúctil (Adaptado de Landes e Begley, 1977). 
O arredondamento da ponta da trinca provoca um aparente crescimento estável da trinca (Figura 31), o qual precisa ser corrigido. Nesse sentido, supõe-se arbitrariamente que esta aparente extensão da trinca deve ser menor ou igual ao raio da ponta da trinca arredondada, que por sua vez, é igual à metade da abertura da ponta da trinca (crack tip opening displacement - CTOD), $\delta_{t}$. Considerando-se um material perfeitamente plástico e a eq.(80), pode-se escrever a seguinte expressão:

$$
J=2 \sigma_{0} \Delta a
$$

Para o caso de materiais que apresentam alto expoente de endurecimento por deformação, Landes e Begley (1974) propuseram a seguinte expressão:

$$
J=2 \sigma_{Y} \Delta a
$$

onde $\sigma_{Y}$ é resistência efetiva ao escoamento (effective yield strength), que corresponde à média entre a tensão de escoamento e a resistência máxima à tração do material.

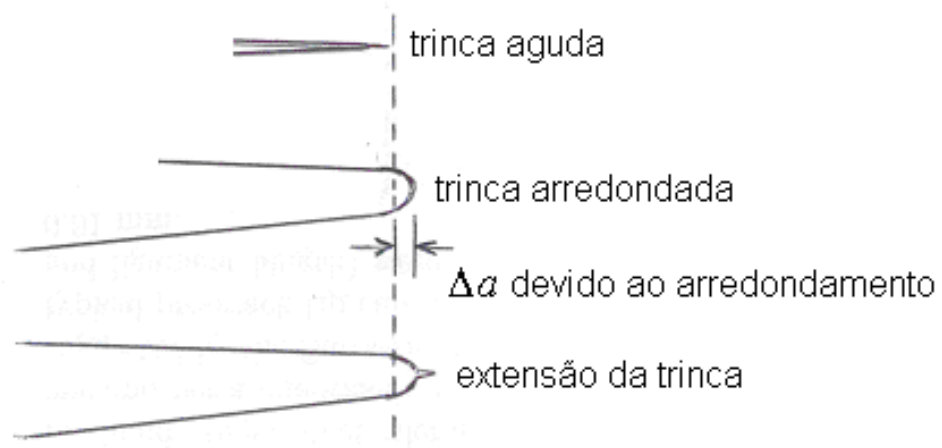

Figura 31: Ilustração do crescimento aparente da trinca, decorrente do arredondamento da ponta da trinca. (Adaptado de Broek, 1991)

A reta dada pela eq.(113), denominada "linha de arredondamento" (blunting line), é construída no mesmo sistema cartesiano que a curva J-R. Originalmente, a curva $J-R$ também era uma reta, obtida por análise de regressão linear simples pelo método dos mínimos quadrados através dos pontos válidos (ou aceitáveis). Este termo surge do fato de alguns pontos $\left(J_{i}, \Delta a_{i}\right)$ não serem aceitáveis, dependendo da 
quantidade de extensão de trinca. Considera-se que as medições de extensão de trinca menores que $0,15 \mathrm{~mm}(\Delta a<15 \mathrm{~mm})$ não são suficientemente precisas, enquanto que, por outro lado, assume-se que até valores de $\Delta a$ iguais a $1,5 \mathrm{~mm}$ as suposições básicas da teoria de $J$ não são violadas. Para se determinar graficamente estes limites, são traçadas duas retas de exclusão, com a mesma inclinação da "linha de arredondamento" $\left(2 \sigma_{Y}\right)$, a partir das extensões de trinca 0,15 $\mathrm{mm}$ e $1,5 \mathrm{~mm}$. Apenas os pontos situados entre estas duas linhas de exclusão são aceitáveis para a análise de regressão da curva J-R. O valor condicional de $J_{I c}\left(J_{Q}\right)$ é obtido na interseção da "linha de arredondamento" com a curva J-R. Duas linhas verticais adicionais, denominadas linhas de mínima e máxima extensão aparente de trinca, que passam sobre o ponto de interseção da curva J-R com as duas linhas de exclusão, completam o esquema. A Figura 32 ilustra o resultado gráfico do procedimento descrito.

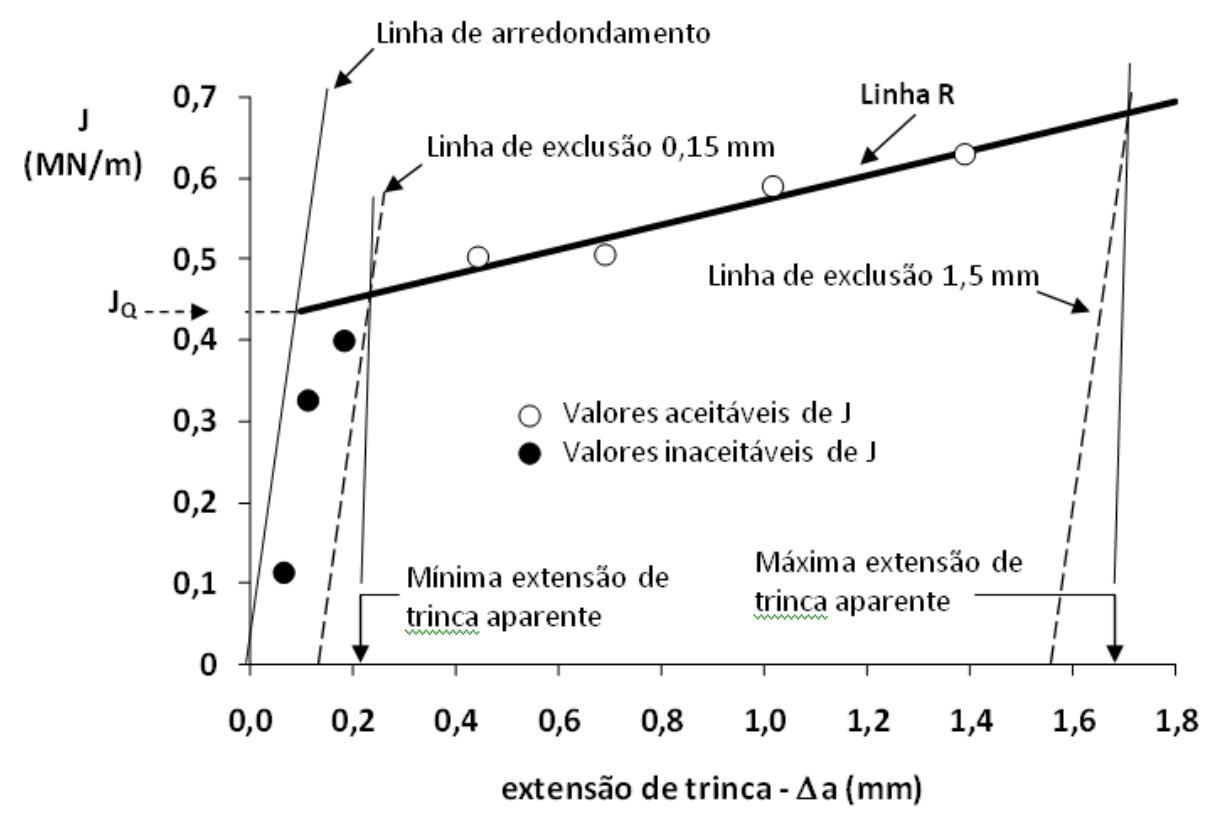

Figura 32: llustração da construção gráfica para determinação de $J_{l c}$, incluindo a linha de arredondamento, a curva (linha) $J-R$ e as linhas de exclusão que delimitam a região de validação dos dados (Adaptado de Ewalds e Wanhill, 1986).

É oportuno, em função da natureza do material em foco neste trabalho, salientar que a descrição sugerida na Figura 30 dos fenômenos que ocorrem na frente da trinca é particularmente útil no caso dos materiais metálicos. Em polímeros podem ocorrer determinados mecanismos de deformação na ponta da trinca, em especial crazing, que alteram significativamente a descrição proposta. Entretanto, esta característica especial e suas implicações serão tratadas posteriormente. 
A "linha de arredondamento", como definida pela eq.(112), é válida para materiais perfeitamente plásticos. Considerando-se um material real, que pode apresentar significativo endurecimento por deformação, a inclinação da "curva de arredondamento" poderia diminuir consideravelmente, conforme eq.(82), dependendo do expoente de endurecimento por deformação. Por outro lado, de acordo com Ewalds e Wanhill (1986), a curva $J-R$, até aqui considerada na forma linear, também sofre uma alteração na inclinação, só que neste caso para um valor maior. Estes efeitos levariam a uma superestimativa de $J_{Q}$ e a uma maior variação nos resultados, como pode ser observado na Figura 33:
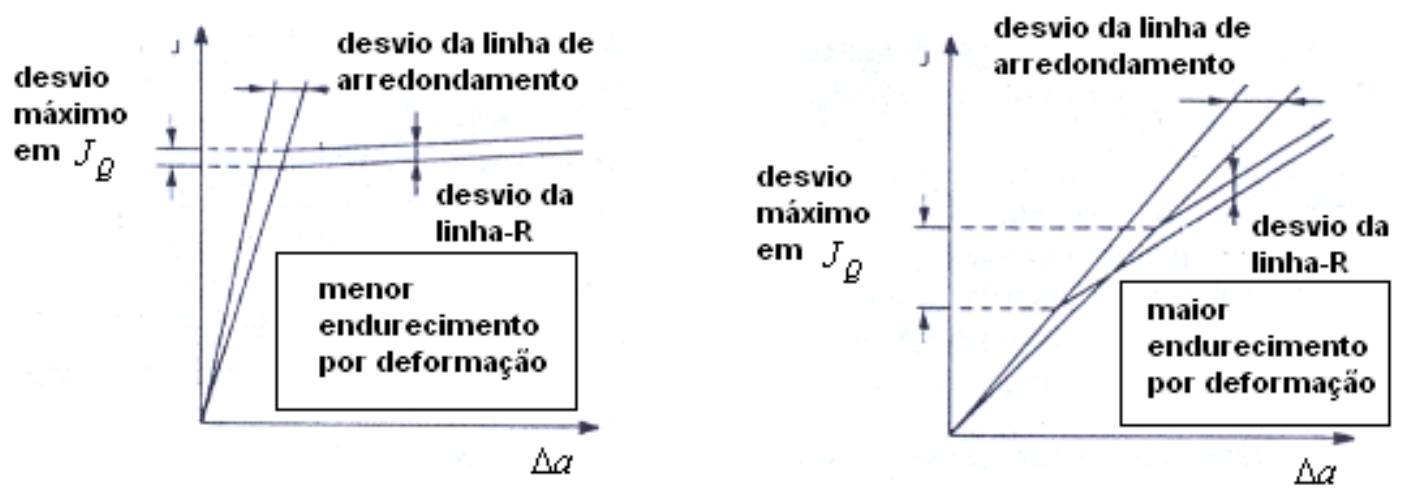

Figura 33: Influência do endurecimento por deformação na estimativa de $J_{Q}$ (Adaptado de Ewalds e Wanhill, 1986)

A inclinação da curva $J-R$, dada certa extensão da trinca, fornece uma noção da relativa estabilidade do crescimento da trinca. Um material cuja inclinação é mais acentuada é menos suscetível a uma propagação instável da trinca (ANDERSON, 1995), enquanto que para materiais muito frágeis a curva tem inclinação praticamente nula (WILLIAMS, 2001b).

A Figura 34 ilustra os principais passos adotados nos primeiros métodos para se estimar $J_{I c}$ através da técnica dos múltiplos corpos de prova, a partir da expressões desenvolvidos pelo método de Rice e colaboradores (1973).

A idéia da curva $J-R$ linear foi logo abandonada e, ao invés de uma reta, a curva passou a ser descrita através de uma relação de potência do tipo:

$$
J=C_{1}(\Delta a)^{C_{2}}
$$


que, por sua vez, pode ser obtida determinando-se uma reta de regressão linear pelo método dos mínimos quadrados, da seguinte forma:

$$
\ln J=\ln C_{1}+C_{2} \ln (\Delta a)
$$

onde $C_{1}$ e $C_{2}$ são as constantes da regressão.

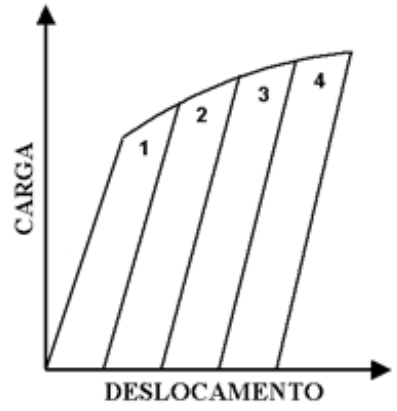

(a) Carregamento de corpos de prova idênticos a diferentes deslocamentos

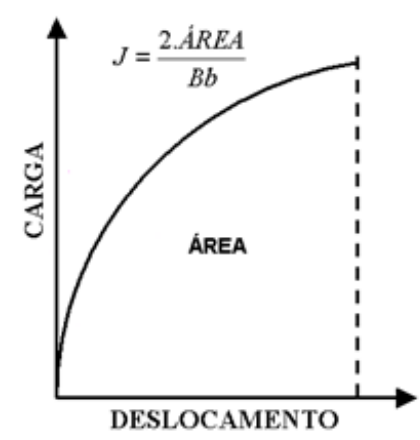

(c) Cálculo de J para cada corpo de prova

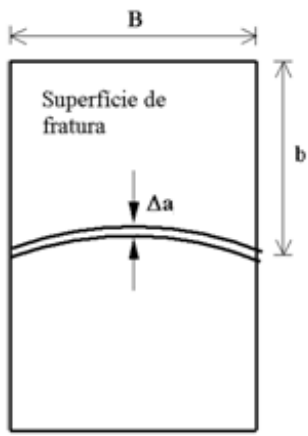

(b) Marcação da superfície e medição da extensão média de trinca

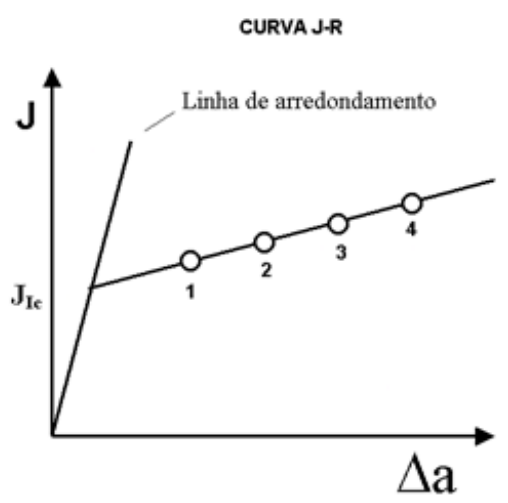

(d) Construção de gráfico $\mathbf{J}$ - extensão de trinca

Figura 34: Procedimento experimental para avaliação de $J_{I c}$ e construção da curva $J-R$ (Adaptado de Landes e Begley, 1977).

Com o novo formato da curva $J-R$, a definição de $J_{I c}$ condicional $\left(J_{Q}\right)$ também foi alterada. Nesse sentido, uma nova reta, com a mesma inclinação da "linha de arredondamento", é construída a partir do ponto de extensão de trinca igual a 0,2 $\mathrm{mm}(\Delta \mathrm{a}=0,2 \mathrm{~mm})$ (offset line). O valor condicional de $J_{I c}\left(J_{Q}\right)$ é obtido na interseção entre essa reta e a curva $J-R$ definida pela relação de potência - eq.(114). Também foi definida a distribuição dos pontos válidos ao longo da curva J-R.

Outro importante aperfeiçoamento no método foi a definição da capacidade de medição do corpo de prova, expressa em termos de um valor máximo de $J, J_{\max }$, 
de forma a garantir que o crescimento (estável) da trinca seja controlado por $\mathrm{J}$ (SAXENA, 1998). J $J_{\max }$ é dado pela seguinte expressão (ASTM E 813-89):

$$
\text { mínimo } \quad\left(J_{\max }=b \sigma_{Y} / 15 \text { ou } \quad J_{\max }=B \sigma_{Y} / 15\right)
$$

Com as alterações discutidas nos parágrafos anteriores, o método ilustrado nas Figuras 32 e 34 evoluiu para o esquema representado na Figura 35, o qual serviu de base para norma ASTM E 813, que disciplinou inicialmente as medições de $J_{I c}$ para materiais metálicos.

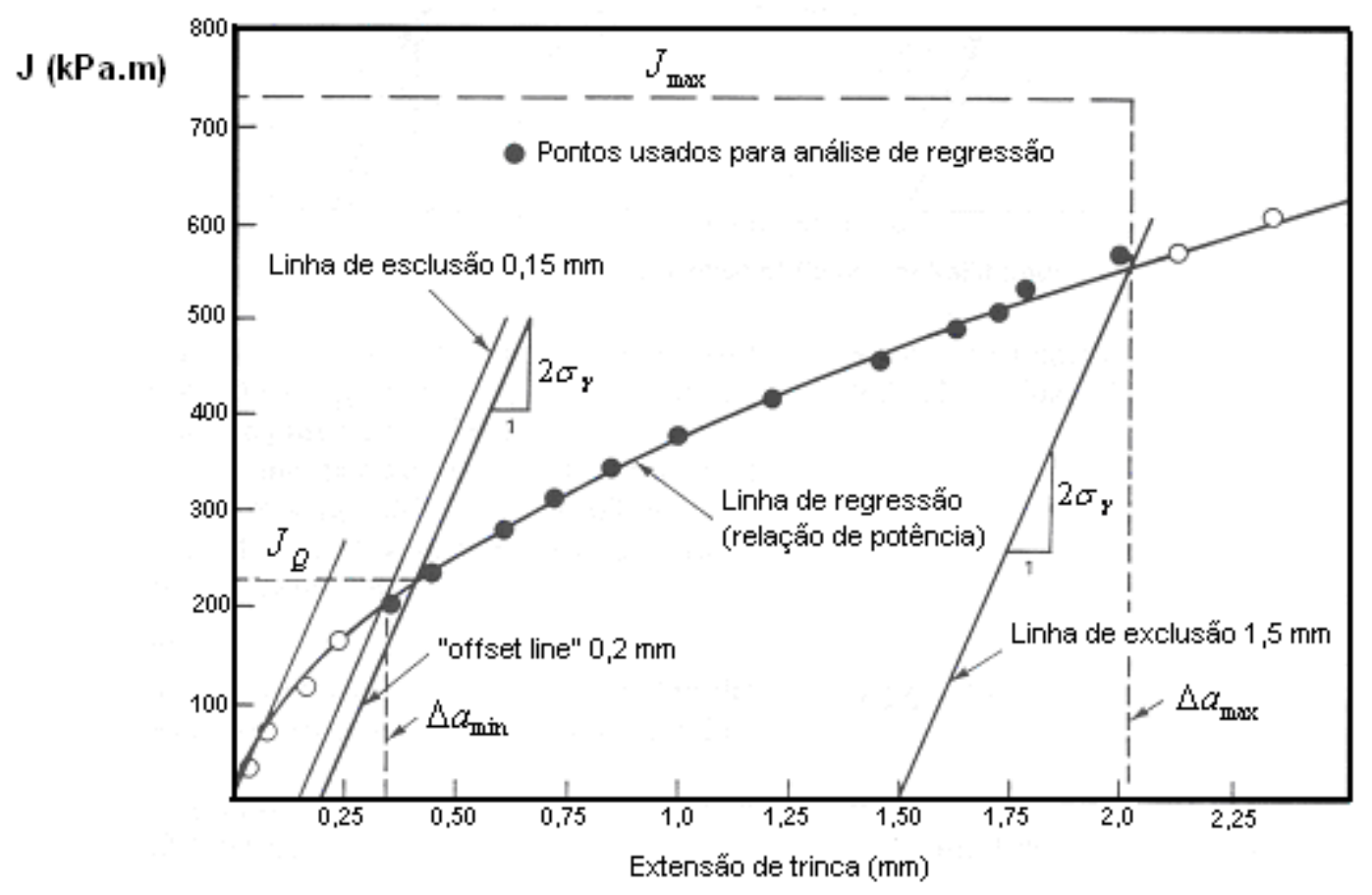

Figura 35: Construção gráfica para determinação de $J_{I c}$ (Adaptado da norma ASTM E 813-89).

O valor de $J_{Q}$ obtido pelo método ilustrado na Figura 35 é validado como $J_{I c}$ se a inclinação da curva $J-R(d J / d a)$ no ponto $\left(J_{Q}, \Delta a_{Q}\right)$ for menor que o valor de $\sigma_{Y}$ e se as exigências da eq. (117) forem satisfeitas.

$$
B, b>25 \frac{J_{Q}}{\sigma_{Y}}
$$


Verifica-se que as exigências impostas pela eq.(117) são menos restritivas para as dimensões do corpo de prova em relação às de $K_{l c}$, o que pode ser visto como uma vantagem do método de $J$.

A norma para medição de $\mathrm{J}$ em materiais metálicos evoluiu através dos anos. A norma ASTM E 813 foi substituída pela norma ASTM E 1737 e esta, por sua vez, foi substituída em 1999 pela atual norma ASTM E 1820. Por outro lado, para os casos em que a tenacidade do material é caracterizada por toda a curva $J-R$, ao invés de apenas o valor de $J_{I c}$, surgiu a norma ASTM E 1152, cujo escopo também é contemplado atualmente na norma ASTM E 1820. Entre outras importantes modificações que foram feitas, a restrição para o máximo valor admissível de $J$ é menos severa, tendo-se adotado o número 10 no denominador da eq.(116). Com as mais recentes alterações o método pode ser representado pelo esquema da Figura 36:

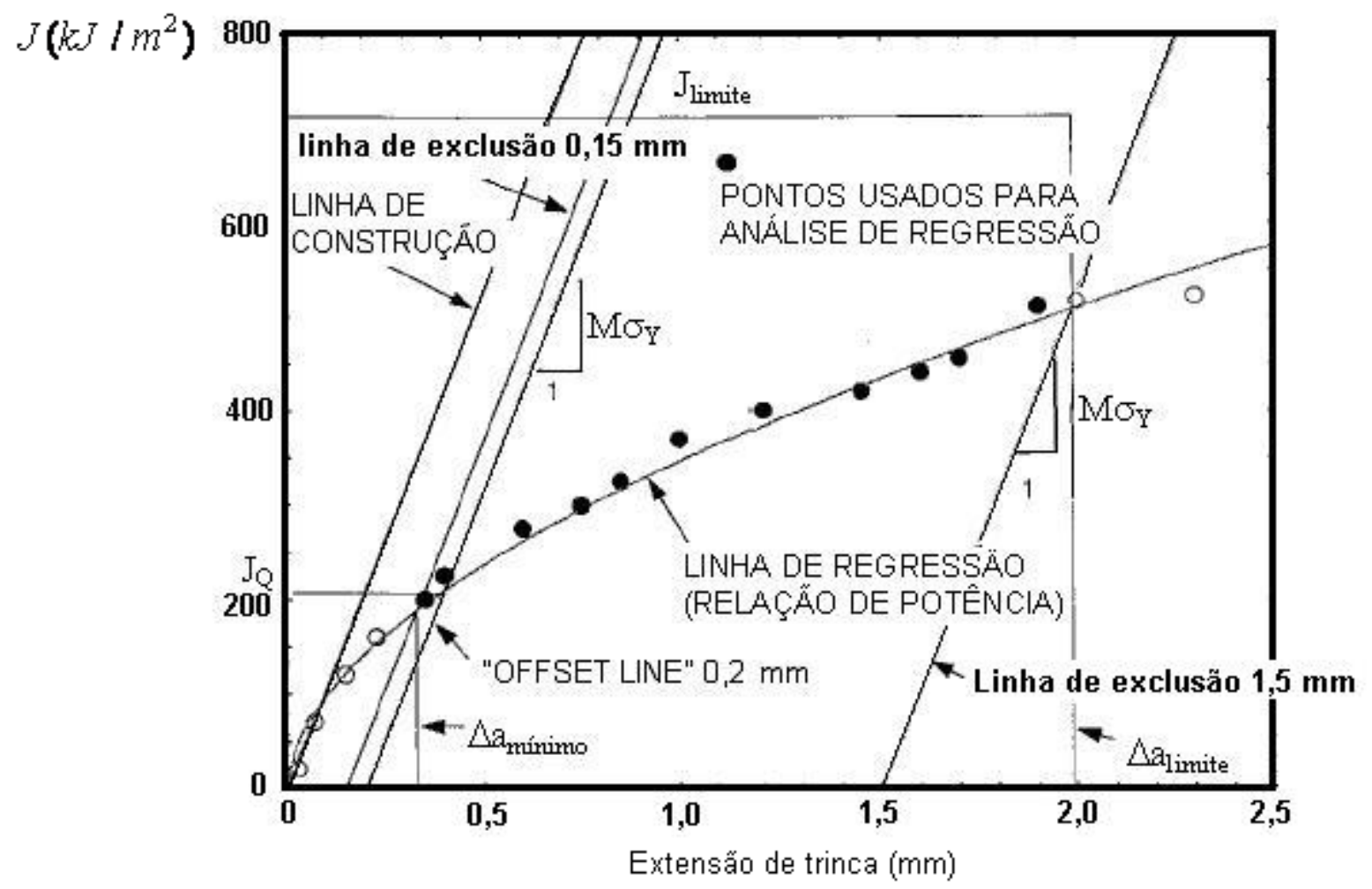

Figura 36: Construção gráfica para determinação de $J_{I c}$ (Adaptado da norma ASTM E 1820-08).

O esquema da Figura 36 contempla algumas novas exigências e alterações importantes, como:

(i) Necessidade de validação do comprimento inicial da trinca, $a_{0 i}$; 
(ii) Definição do coeficiente $M$ na inclinação das retas de exclusão. $O$ valor de $M$ não deve ser menor que 2, sob risco de superestimar o valor de $J_{l c}$, segundo Ewalds e Wanhill (1986);

(iii) Exigência que a constante $C_{2}$ nas equações (114) e (115) seja menor que 1.;

(iv) Restrições menos severas para o maior valor de $J$ admissível e para as dimensões do corpo de prova no cálculo de $J_{I c}$, traduzidas nas equações (118) e (119), respectivamente.

$$
\begin{gathered}
J_{\operatorname{limit}}=\frac{b \sigma_{Y}}{7,5} \\
B, b>10 \frac{J_{Q}}{\sigma_{Y}}
\end{gathered}
$$

De acordo com norma atual para os materiais metálicos (ASTM 1820-08), a avaliação da tenacidade depende do comportamento do corpo de prova durante 0 ensaio. Dessa forma, a tenacidade pode ser avaliada na forma de uma curva $R$ ( $R$ curve), ou na forma de um valor pontual dos parâmetros de fratura adotados ( $K, \mathrm{~J}$ ou CTOD). No caso de $J$, se a fratura ocorre sem crescimento estável da trinca a tenacidade pode ser estimada através de um valor pontual designado na norma por $J_{c}$. Este parâmetro não deve ser confundido com a noção de $J_{l c}$, que é uma medida da resistência à extensão da trinca no início do crescimento estável, sob condição de estado plano de deformação. Assume-se que $J_{c}$ é um parâmetro independente das dimensões planares (in plane dimensions) do corpo de prova (embora possa ser dependente da espessura), se as seguintes condições forem obedecidas:

$$
\begin{gathered}
B, b>100 \frac{J_{Q}}{\sigma_{Y}} \\
\Delta a_{p}<0,2 m m+\frac{J_{Q}}{M \sigma_{Y}}
\end{gathered}
$$

onde $\Delta a_{p}$ é a extensão física (média) da trinca. 
Outra modificação importante que foi feita nas normas para materiais metálicos diz respeito ao valor do fator $\eta$ na eq.(111), que era originalmente igual a 2, para o corpo de prova do tipo SENB (ASTM E 813-89), mas que foi alterado para 1,9 (ASTM E 1820-08), no caso em que o deslocamento ao longo da linha de carregamento serve de base para o cálculo da energia aplicada.

Nos parágrafos anteriores foram apresentadas várias modificações que foram sendo introduzidas à medida que o conhecimento e as técnicas de ensaio evoluíam. Entretanto, talvez o mais significativo avanço trazido pelas técnicas atualmente vigentes para o ensaio de $\mathrm{J}$ em materiais metálicos seja a correção para 0 crescimento da trinca.

A eq.(111) foi desenvolvida assumindo-se o comprimento constante da trinca, onde a única contribuição para o comportamento não linear da curva cargadeslocamento provém da deformação plástica. Em outras palavras, a eq.(111) é válida para trincas estacionárias, ou seja, baseia-se somente no comprimento inicial da trinca, sem levar em conta o crescimento dela, que efetivamente ocorre durante os ensaios.

Deve-se notar que $J_{I c}$ não estabelece necessariamente um critério para o processo instável de fratura. Na verdade, a fratura final dos materiais dúcteis ocorre em níveis maiores de $J$, de forma que, nestes casos, $J_{I c}$ serve apenas como uma medida das condições para o início do crescimento estável da trinca, ou seja, é apenas um ponto na curva J-R. Entretanto, o início do desenvolvimento dos ensaios de tenacidade através de $J$ foi marcado justamente pela busca da caracterização de $J_{I c}$ como um parâmetro de fratura. Dessa forma, embora se tenha logo reconhecido que a região da curva $J-R$ além do ponto correspondente a $J_{l c}$ poderia não ser adequadamente caracterizado por $J$, assumiu-se que ela prestava-se apenas para efeito de extrapolação (BEGLEY e LANDES, 1972; LANDES e BEGLEY, 1974; BEGLEY e LANDES, 1977). Isso não traria prejuízo ao método, uma vez que até o ponto da curva $J-R$ onde $J_{l c}$ é medido o crescimento da trinca é tido como insignificante (ANDERSON, 1995).

O comportamento típico da curva J-R medida por Landes e Begley (1974) foi o de uma parábola com concavidade ligeiramente orientada para cima. Reconhecendo que a eq.(111) não vale para uma trinca em crescimento, Landes e Begley (1974) argumentaram que o valor de $J$ seria superestimado e que o 
comportamento da curva $J-R$ real esperado seria o de uma curva achatada, com concavidade ligeiramente orientada para baixo. Entretanto, segundo os autores, essa diferença não prejudicava a estimativa de $J_{l c}$, como pode ser verificado na Figura 37.

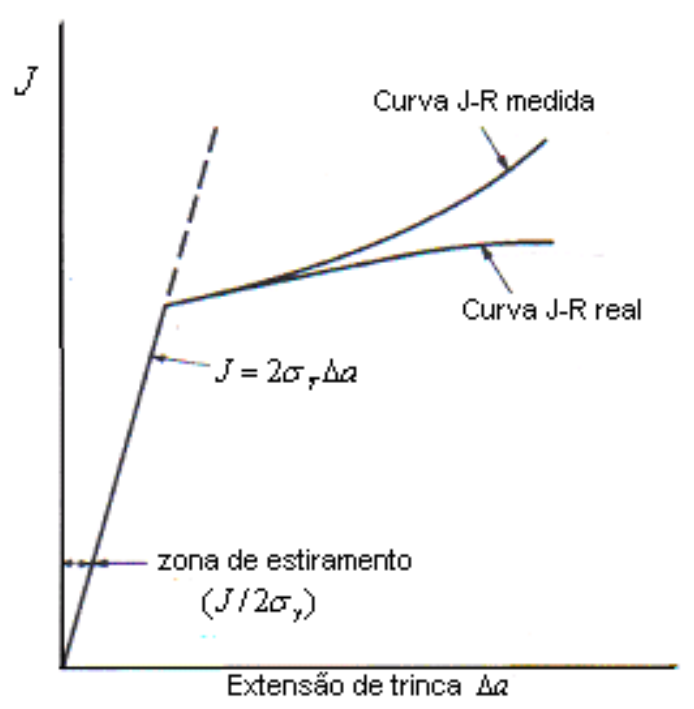

Figura 37: Efeito do crescimento da trinca sobre o comportamento da curva J-R (Adaptado de Begley e Landes, 1974)

A norma atual para materiais metálicos contempla um procedimento mais elaborado para correção dos valores de $\mathrm{J}$ para o crescimento da trinca, no qual a avaliação de $J$ é um processo incremental que leva em conta o comprimento atualizado da trinca e do ligamento $O$ leitor interessado no entendimento dessas correções pode recorrer à bibliografia, como Anderson (1995) e Saxena (1998), e diretamente à norma ASTM E 1820.

Até este ponto da seção a atenção foi concentrada na técnica dos corpos de prova múltiplos. Uma técnica alternativa é o método da compliance, o qual utiliza realmente um único corpo de prova, e que foi inicialmente proposto para materiais metálicos por Clarke et al (1976), citados por Landes e Begley (1977). Neste método o corpo de prova é carregado até que ocorra uma pequena quantidade de crescimento de trinca e então sofre um descarregamento controlado (uma redução de carga de aproximadamente 10\%). Assume-se que este ligeiro descarregamento não altera o processo de fratura, mas é suficiente para proporcionar uma recuperação elástica linear, a partir de cuja inclinação (relacionada à compliance) é possível estimar o comprimento da trinca e em seguida o crescimento da trinca. $O$ carregamento do corpo de prova é retomado até que ocorra um novo crescimento 
estável da trinca e assim, sucessivamente, o processo é periodicamente repetido. Dessa forma obtém-se um conjunto de valores de a, $\Delta a$ e $P$, a partir dos quais, quando bem escolhidos os pontos de descarregamento, pode-se construir a curva J$R$. a Figura 38 ilustra o método da compliance. O método requer grande precisão na medição da compliance e, portanto, equipamentos sofisticados e grande experiência prática. Apesar de integrar as normas para materiais metálicos, o método não é muito utilizado. Para materiais poliméricos, há uma limitação importante decorrente da natureza viscoelástica destes materiais, de forma que a recuperação elástica não é linear. Como alternativa para materiais (metálicos) que apresentam relaxação da carga antes da medição da compliance e, portanto, uma não linearidade dependente do tempo, a norma ASTM 1820-08 sugere um "tempo de estabilização", durante o qual se aguarda que a carga estabilize, antes do carregamento seguinte.

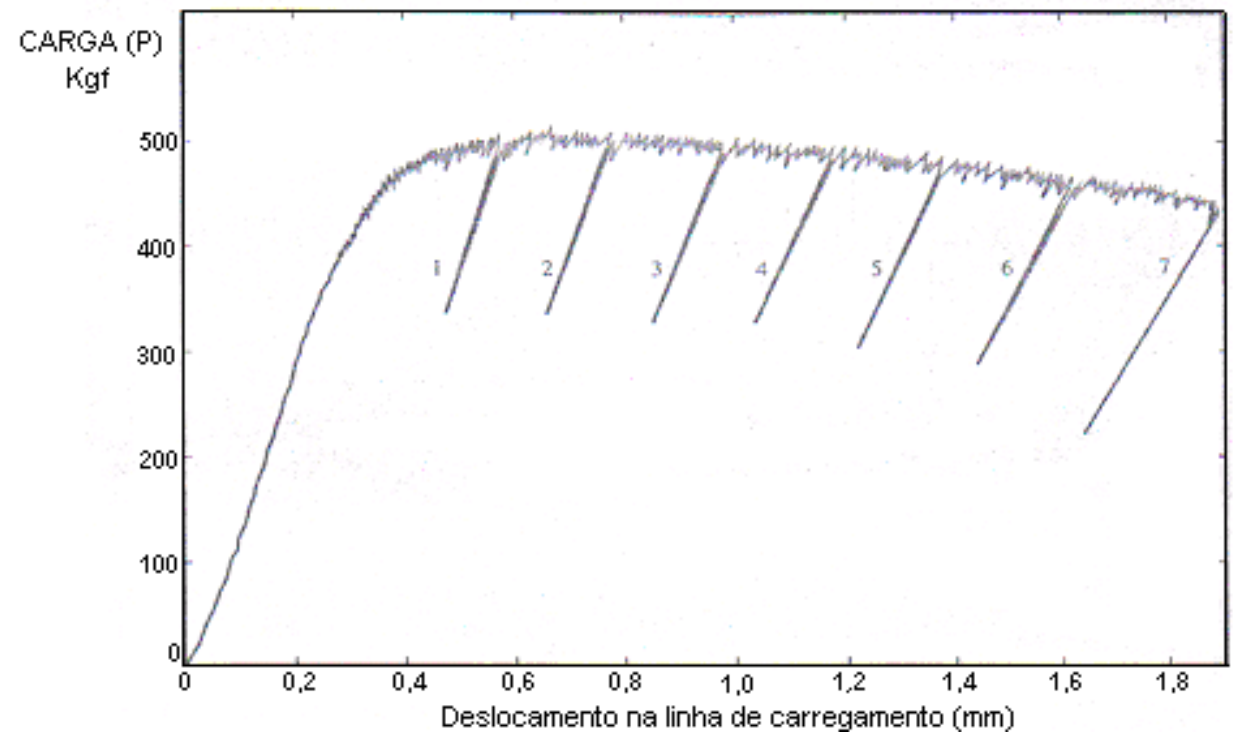

Figura 38: Curva carga-deslocamento do método da compliance elástica (Adaptado de Saxena, 1998)

Finalmente, deve-se observar que nas normas para materiais metálicos é usual dividir o valor total de $J$ em duas componentes, uma elástica, $J_{e l}$, e outra plástica, $J_{p l}$, ou seja:

$$
J=J_{e l}+J_{p l}
$$

As contribuições elástica e plástica são dadas, respectivamente pelas equações (123) e (124) (ASTM E 1820-08): 


$$
J_{e l}=\frac{K^{2}(1-v)}{E}
$$

onde, $K$ é o fator de intensidade de tensões, $v$ é o coeficiente de Poisson e $E$ é o módulo de rigidez do material.

$$
J_{p l}=\frac{\eta A_{p l}}{B b}
$$

$\mathrm{Na}$ eq.(124), derivada da eq.(111), $A_{p l}$ é a área sob a curva cargadeslocamento, definida conforme esquema da Figura 39:

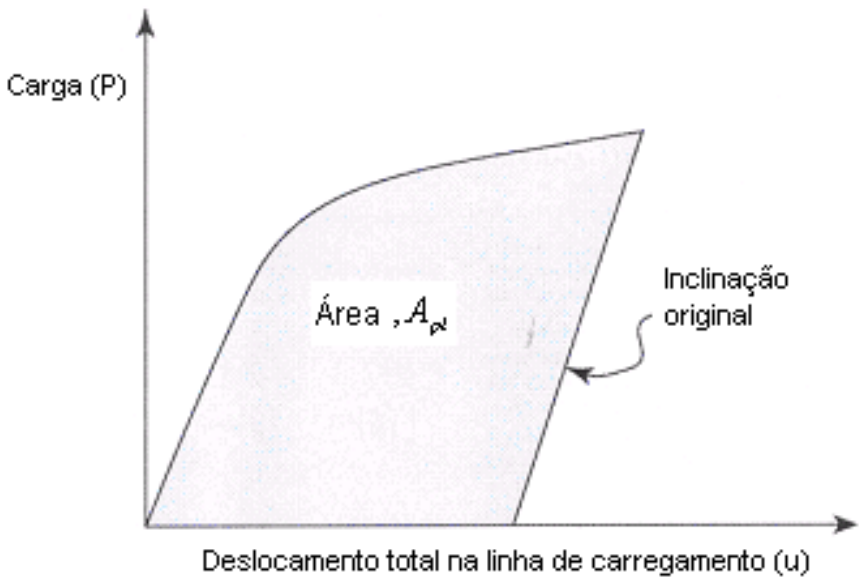

Figura 39: Definição da área "plástica", $A_{p l}$, usada nos cálculos de $\mathrm{J}$ de materiais metálicos (Fonte: norma ASTM E 1820-08)

Nos materiais poliméricos, a divisão proposta pela eq.(122) não é conveniente devido à natureza viscoelástica desses materiais, o que leva a um comportamento não linear, como citado anteriormente.

Ao longo desta subseção foram discutidas as orientações gerais e os aspectos mais importantes dos métodos de ensaio de J. As normas técnicas contêm numerosas especificações, cuja discussão pormenorizada foge, por ora, ao escopo do presente trabalho. Por exemplo, a determinação de $J_{Q}$ é um processo interativo minucioso. 


\subsubsection{Os métodos de J para polímeros}

A ASTM não possui uma norma específica para a avaliação de $J_{l c}$ em materiais poliméricos, enquanto que, por outro lado, a norma ASTM D 6068-96 disciplina a técnica para construção da curva $J-R$ de materiais plásticos. O ESIS possui um protocolo de ensaio (HALE e RAMSTEINER, 2001) que contempla a construção da curva $J-R$ e a determinação do parâmetro $J_{c}$ de iniciação da propagação estável de trinca, de maneira semelhante ao procedimento definido na norma ASTM E 813. Em termos gerais, a prática comum tem sido adotar o método de Landes e Begley (1974), contemplado nas normas de materiais metálicos, e estender os princípios gerais, com algumas modificações, para os polímeros. Isso é o que foi feito, por exemplo, no protocolo de ensaios do ESIS e na norma ASTM D 6068-96. Uma vez que os métodos de $J$ para polímeros foram desenvolvidos a partir daqueles aplicados aos materiais metálicos, requer-se, portanto, atenção e adequação aos mecanismos de deformação e de fratura, os quais são muito diferentes nos polímeros em relação aos metais. Alguns autores, por exemplo, chamam a atenção para o fato de não haver ainda suficiente evidência experimental para garantir que os limites para validação dos pontos da curva J-R em plásticos possam ser definidos da mesma forma que os de metais (HALE e HAMSTEINER, 2001). Isso equivale a dizer que não há ainda suficiente conhecimento para definir os limites da região de crescimento estável de trinca controlado por $J$.

Também a natureza viscoelástica dos materiais poliméricos deve ser respeitada, de forma que fatores como a temperatura e a velocidade de ensaio são mais relevantes do que no caso dos metais. Segundo Hale e Ramsteiner (2001), a interpretação de $\mathrm{J}$ como a taxa de decréscimo da energia potencial com 0 crescimento da trinca - eq.(43) - só é válida se a temperatura do material permanecer constante durante o ensaio, uma vez que a teoria de Rice (1968) é baseada somente em considerações de energia mecânica e não leva em conta variações de energia térmica.

Examinando outra questão, os plásticos podem apresentar anisotropia, decorrente da orientação das macromoléculas poliméricas durante 0 processamento, o que requer atenção quanto à orientação da trinca inicial no corpo de prova. Uma alternativa, adotada neste trabalho, é o emprego de corpos de prova extraídos de placas moldadas por compressão simples, nas quais se espera que os 
efeitos de orientação sejam muito reduzidos. O procedimento para a confecção de placas será detalhado no capítulo referente aos materiais e métodos.

Os aspectos acima mencionados estão contemplados nas normas. Entretanto, não é objetivo deste item discutir todas as orientações técnicas para execução dos ensaios. Detalhes práticos para os ensaios de $J$ serão apresentados no capítulo referente aos materiais e métodos, mas o leitor interessado nas especificações mais detalhadas pode recorrer às normas e protocolos de ensaios citados neste trabalho. Entretanto, algumas considerações importantes são aqui levantadas com o objetivo de situar as normas para polímeros em relação às dos materiais metálicos e, no que couber, salientar pontos importantes específicos relacionados ao material em estudo.

Em termos gerais, os métodos de $J$ para polímeros utilizam a técnica dos corpos de prova múltiplos e a medição do comprimento da trinca diretamente na superfície de fratura. Em resumo, vários corpos de prova nominalmente idênticos são carregados para apresentarem diferentes quantidades de crescimento estável de trinca, $\Delta a$. A energia absorvida em cada caso é medida através do cálculo da área sob a curva carga $(P)$ - deslocamento $(u)$, e $J$ é determinado conforme a eq.(111). Com os dados calculados de $J$, constrói-se então uma curva $J$ x $\Delta a$, (curva $J-R$ ). Também há critérios para validação e distribuição (espaçamento) dos dados, entretanto, os valores de extensão de trinca correspondentes às linhas de exclusão e o máximo valor de J admissível são diferentes.

Podem ser utilizados os corpos de prova do tipo compacto (CT) ou de flexão de três pontos (SENB), semelhantes aos utilizados em ensaios de $K$, devendo-se observar que o fator de calibração na eq.(111), $\eta$, permanece igual a 2, enquanto que na norma atual da ASTM para materiais metálicos esse valor é 1,9.

Para a construção da "linha de arredondamento" e na definição do valor de $J_{\max }$, segundo o protocolo do ESIS (HALE; RAMSTEINER, 2001), o valor de $\sigma_{Y}$ não é a média entre o limite de escoamento e resistência máxima à tração do material, como definido na eq.(112), mas sim o limite de escoamento com a definição própria para os materiais poliméricos.

Nos materiais metálicos a pré-trinca é geralmente introduzida por fadiga. Este procedimento é aceito para polímeros pelas normas da ASTM e pelo protocolo de ensaios do ESIS. Entretanto, o objetivo do procedimento para introdução da pré- 
trinca é obter uma trinca inicial tão aguda quanto possível, com o mínimo dano no material na frente da trinca, enquanto que, conforme discutido anteriormente, 0 método por fadiga pode introduzir deformações que modificam o processo de fratura. Dessa forma, a prática mais comum tem sido a utilização de lâminas de barbear, as quais podem ser manuseadas de diferentes maneiras, segundo as normas (por pressionamento, por corte, através de batidinhas). Não há ainda um consenso quanto à melhor forma de introdução de pré-trincas em polímeros com auxílio de lâminas de barbear.

Há dois fatores principais que controlam a consistência das medições de $\mathrm{J}$ : a interpretação correta da curva de carregamento, considerando-se que ocorre um efetivo crescimento da trinca durante o ensaio, e a precisão na medição do comprimento da trinca. É importante observar que nem a norma ASTM D 6068-96 nem o protocolo de ensaio do ESIS fazem qualquer correção dos valores de $\mathrm{J}$ para o crescimento da trinca, o que pode implicar em valores superestimados, como visto anteriormente. Por outro lado, os dois procedimentos especificam que o valor do expoente $C_{2}$ na eq.(114) deve ser menor do que 1 . Deve-se ainda considerar que a energia total aplicada sobre o corpo de prova inclui parcelas de efeitos de indentação e de compliance dos dispositivos de apoio e fixação dos corpos de prova, que devem ser corrigidos. Estas correções estão previstas nas normas citadas.

Da experiência acumulada no âmbito do ESIS (HALE \& RAMSTEINER, 2001) pode-se apreender que as medições na superfície de fratura de materiais como o polietileno de média densidade pode ser bastante complicada. Enquanto parece não haver dificuldade para a obtenção do comprimento inicial da pré-trinca, a definição da frente da trinca após o crescimento estável depende totalmente da correta interpretação da superfície de fratura. Entretanto, espera-se que a superfície de fratura do MDPE seja muito confusa devido aos diferentes micro-mecanismos de deformação que atuam durante o processo de fratura, especialmente escoamento por cisalhamento (shear yielding) e micro-fibrilamento (crazing). Primeiramente, deve-se esperar que no MDPE a ponta da trinca arredonde significativamente durante o processo de fratura. Como ilustração e para efeito de comparação, a Figura 40 mostra os efeitos na ponta da trinca em polietileno de alta densidade, que é menos dúctil do que o MDPE. Em particular, no fenômeno de micro-fibrilamento, pode-se esperar que a frente do craze (do dano total) seja bem definida na 
superfície de fratura, dependendo, evidentemente, do método empregado para a ruptura final do corpo de prova, porque à frente só há material da matriz durante a fratura final. Portanto, na superfície final de fratura pode-se esperar certo contraste entre as regiões separadas pela frente do craze. Por outro lado, a frente da trinca verdadeira pode ser muito difícil de ser identificada porque a ponta da trinca caminha através de fibrilas que se rompem durante a fratura final, com possibilidade de deixar uma superfície de fratura com características muito próximas da superfície correspondente ao crescimento estável, ou seja, com tocos de fibrilas.
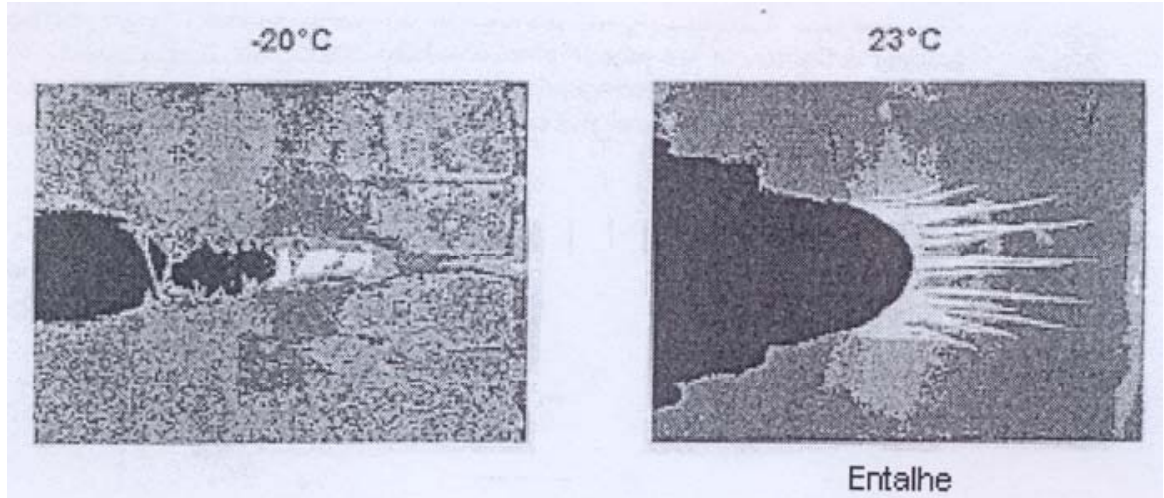

Figura 40: Ponta da trinca em um corpo de prova compacto de tração de polietileno de alta densidade (vista lateral) após deformação a $-20^{\circ} \mathrm{C}$ (crazing) e $23^{\circ} \mathrm{C}$ (blunting) (Adaptado de HALE e RAMSTEINER, 2001).

É oportuno ressaltar que tanto a norma ASTM D 6068-96 como o protocolo de ensaios do ESIS advertem que os métodos prescritos não são recomendados para materiais cuja frente de trinca não pode ser distinguida de processo de deformação que ocorre à frente da ponta da trinca, cuja superfície de fratura apresente características muito confusas ou irregulares ou cuja falha final seja mais decorrente de escoamento generalizado (colapso plástico) do que de propagação de uma trinca.

Por fim, deve-se observar que alguns autores reconhecem que a curva $J-R$ é dependente da geometria e, portanto, não representa propriedades fundamentais do material (WILLIAMS, 2001b), enquanto que outros entendem que a curva J-R é uma propriedade do material, indicativa da sua tenacidade (SAXENA, 1998).

\subsection{TRABALHO ESSENCIAL DE FRATURA}

O trabalho essencial de fratura (Essential Work of Fracture - EWF) é outro conceito da mecânica da fratura elasto-plástica que tem despertado muito atenção 
na avaliação das propriedades de fratura do polietileno (KARGER-KOKSIS; CZIGÁNY; MOSKALA, 1997).

O método EWF é particularmente atraente porque propõe um parâmetro fundamental de fratura, mas é simples e fácil de ser executado (PARDOEN; MARCHAL; DELANNAY, 2002; LACH et al, 2005; WILLIAMS; RINK, 2007).

O método EWF é normalmente empregado para caracterizar o comportamento em fratura de materiais na forma de filmes ou chapas finas (CLUTTON, 2001; WILLIAMS; RINK, 2007), como aqueles empregados pela indústria de embalagens (HASHEMI, 1997), nos quais se pode considerar que o estado de tensão predominante é plano. Assumindo-se que as paredes dos tubos de sistemas de distribuição de água e gás estejam sob estado plano de tensão durante sua operação (GERE; TIMOCHENKO, 1991), pode ser instrutivo e útil a avaliação da resistência à fratura dos materiais empregados na sua produção através de parâmetros de EWF. Nesse sentido, já se verificou que o método EWF pode proporcionar uma maneira simples de categorizar resinas e compostos para a produção de tubos de pressão em termos de sua resistência à fratura (PERES \& SCHÖN, 2008).

O princípio do método EWF, originalmente sugerido por Broberg $(1968,1975)$ baseia-se na idéia que a energia relacionada à fratura de um material elasto-plástico pode ser dividida em duas componentes: o trabalho essencial de fratura e uma parte não essencial. A primeira parte se desenvolve em uma região em torno da ponta da trinca, a qual Broberg chamou de "end-region", e é específica do processo de fratura, supondo-se, portanto, que seja uma propriedade do material (PERES; SCHÖN, 2008). O restante da energia total de fratura, controlado pelo comprimento do segmento não fraturado do corpo de prova e dependente da geometria (CLUTTON, 2001), é relacionado à deformação plástica generalizada e difusa que ocorre numa região externa à ponta da trinca. Essa região, conhecida por "outer region" envolve a anterior e é necessária para acomodar as largas deformações que ocorrem na "end region" (COTTERELL; REDDEL, 1977; CHAN; WILLIAMS, 1994).

O conceito foi aplicado a metais por Cotterell e Reddel (1977) e estendido para polímeros dúcteis por vários pesquisadores (MAI; COTTERELL, 1986; MAI et al, 1987); SALEEMI; NAIRN, 1990; MAI; POWELL, 1991; CHAN; WILLIAMS, 1994; WU; MAI, 1996; HASHEMI, 1997; KARGER-KOCSIS; CZIGÁNY; MOSKALA, 1997; MARCHAL; WALHIN; DELANNAY, 1997; TJONG; XU; LI, 2000; CLUTTON, 2001; 
PARDOEN; MARCHAL; DELANNAY, 2002; FAYOLE; VERDU, 2005; LACH et al, 2005; WILLIAMS; RINK, 2007; PERES; SCHÖN, 2008).

A idéia básica do método EWF é tomar a energia a partir da área sob a curva carga $(P)$ - deslocamento $(\Delta x)$, obtida em vários ensaios de corpos de prova contendo diferentes comprimentos de ligamento, garantindo-se que todo o ligamento tenha apresentado escoamento. A Figura 41 apresenta um esquema do tipo de corpo de prova comumente empregado (Double Edge Notch Tensile - DENT) e suas restrições geométricas, bem como uma representação gráfica do princípio do método EWF.

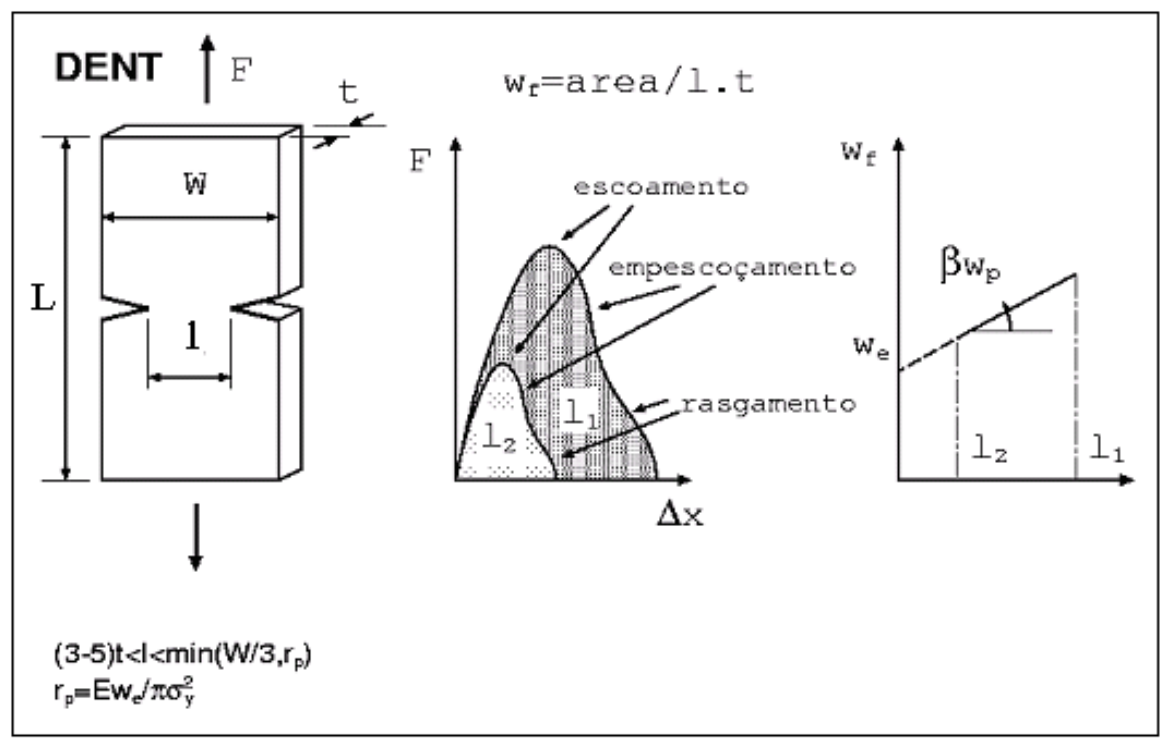

Figura 41: Esquema básico do método EWF e as restrições geométricas para o corpo de prova do tipo DENT

É possível dividir a energia total de fratura em uma parte que é consumida ao longo da linha de fratura e outra que é consumida em determinado volume do material que circunda a trinca. Assume-se que a primeira é proporcional à superfície de fratura, enquanto que a segunda é proporcional ao volume da região circunvizinha. Tanto para metais como para plásticos, tem sido observado que o volume da "outer region" é proporcional ao quadrado do comprimento do ligamento (CHAN; WILLIAMS, 1994). Dessa forma, a energia total absorvida no processo de fratura, $W_{f}$, pode ser dada pela seguinte expressão:

$$
W_{f}=\int F \Delta x=w_{e} l t+\beta w_{p} l^{2} t
$$


onde $w_{e}$ é o trabalho essencial de fratura, $\beta$ é um fator de forma relacionado com a dimensão da zona plástica normal à linha da trinca, $w_{p}$ é o trabalho plástico não essencial, dissipado por unidade de volume de material, I é o comprimento do ligamento e $t$ é a espessura da chapa (CLUTTON, 2001). Normalizando-se a eq.(125) por It obtém-se:

$$
w_{f}=w_{e}+\beta w_{p} l
$$

onde $w_{f}$ é o trabalho específico de fratura.

Se o ligamento estiver sob estado plano de tensão puro, $w_{e}, w_{p}$ e $\beta$ são independentes do comprimento do ligamento, de forma que a eq.(126) se torna a equação de uma reta, cuja inclinação é $\beta w_{p}$ (MAI; POWELI, 1991; SALEEMI; NAIRN, 1990; PEGORETTI; MARCHI; RICCÒ, 1997). De forma a garantir que os ligamentos de todos os corpos de prova estejam globalmente sob o mesmo estado de tensão, algumas restrições geométricas devem ser obedecidas (WU; MAI, 1996; CLUTTON, 2001; PARDOEN; MARCHAL; DELANNAYI, 2002; LACH, 2005). Estas restrições estão ilustradas na Figura 41.

O valor de $w_{e}$ pode ser determinado por meio de análise de regressão linear simples, calculando-se o intercepto da função linear de $w_{f}$ em $I(I=0)$. Um exemplo típico de uma curva $w_{f}-I$, que será chamada reta de regressão, é apresentado na Figura 42.

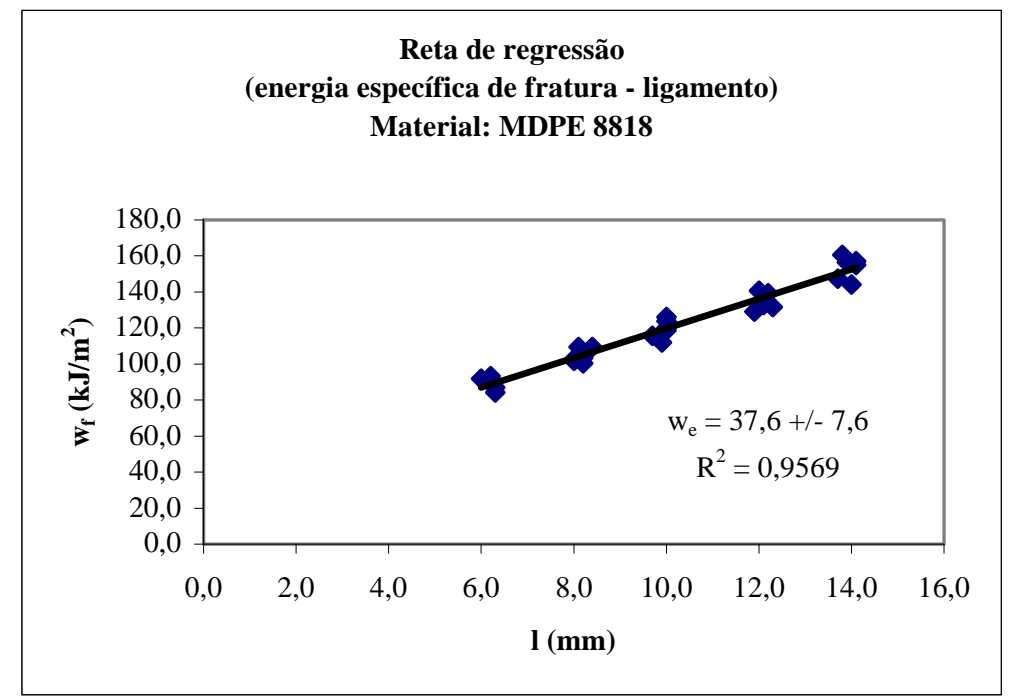

Figura 42: Reta de regressão do método EWF - Material: MDPE 8818 (Fonte: Peres, 2005) 
De acordo com Williams e Rink (2007) e Clutton (2001) é aconselhável a adoção de um critério de tensão aos resultados do método EWF de forma a se garantir que a fratura tenha ocorrido sob estado plano de tensão e para excluir dados referentes às situações em que fratura tenha ocorrido antes do completo escoamento do ligamento. Esse critério consiste no cálculo da média $\left(\sigma_{m}\right)$ das tensões máximas $\left(\sigma_{\max }\right)$ suportadas pelos corpos de prova de uma série e dispensar aqueles resultados cuja tensão máxima tenha sido maior que $1,1 \sigma_{m}$ ou menor $0,90 \sigma_{m}$. Ou seja, estabelece-se uma faixa de validade dos resultados em torno de 10\% da tensão máxima e os pontos que se situarem fora desta faixa são excluídos. O critério da tensão máxima é ilustrado na Figura 43.

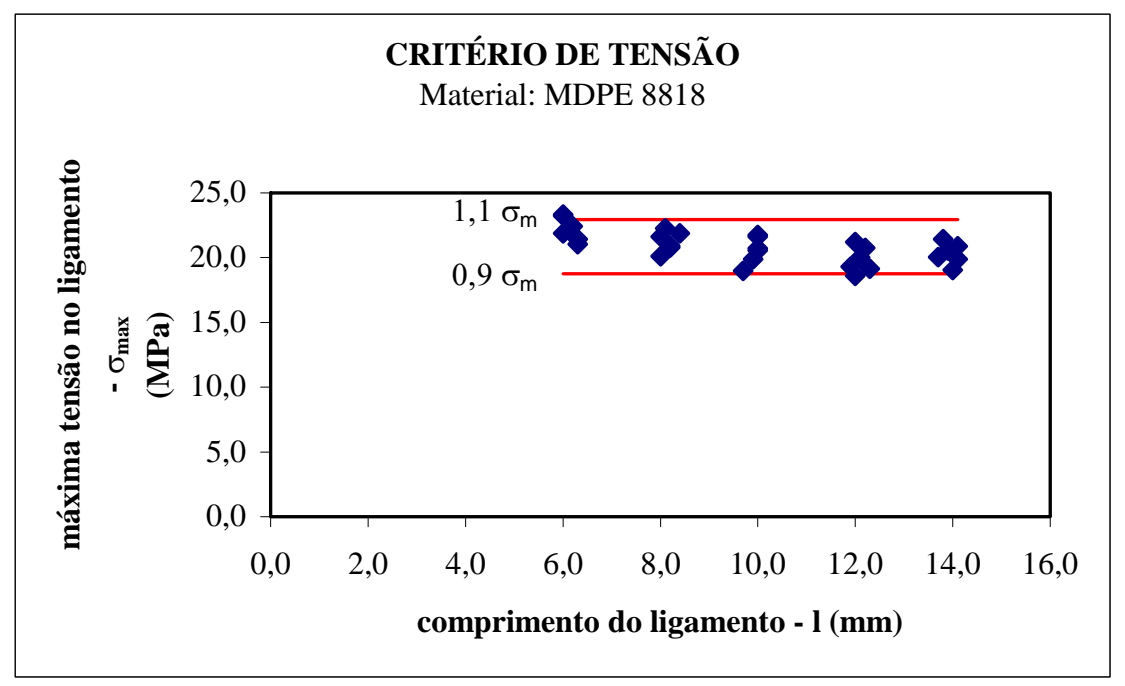

Figura 43: Critério de tensão. Material: MDPE 8818 (Fonte: PERES, 2005)

Conforme se pode observar na Figura 41, é necessário introduzir entalhes e/ou pré-trincas nos corpos de prova para ensaios de EWF, como nos métodos de mecânica da fratura em geral. Novamente emerge a questão da possível influência do método de introdução de pré-trincas, discutida anteriormente em relação aos ensaios de $K_{l c}$ e Integral-J, com a diferença que os ensaios de EWF são normalmente realizados em estado plano de tensão.

Geralmente, se recomenda que as raízes dos entalhes nos corpos de prova para ensaio de EWF sejam agudas, mas na prática diferentes ferramentas e métodos têm sido utilizados (CLUTTON, 2001). 
Já se observou anteriormente (PERES, 2005) que em ensaios de EWF de polietilenos de média densidade, sob estado plano de tensão, ocorre acentuado arredondamento da ponta do entalhe antes do início da fratura, como se pode observar na Figura 44. A princípio, este fato pode sugerir que não seja necessário adotar muito rigor na escolha da afiação da ferramenta e mesmo da técnica de introdução de entalhes e pré-trincas, uma vez que a ordem de grandeza do raio de curvatura se altera significativamente durante o ensaio. Por outro lado, já foi mostrado que a questão da técnica de introdução do entalhe pode ser relevante no ensaio de EWF, dependendo da sensibilidade da tenacidade do material ao entalhe (YAMAKAWA et al, 2004). Desta forma, neste trabalho será verificado se a técnica de introdução de entalhes e pré-trincas afeta os resultados de ensaios de EWF no polietileno de média densidade.

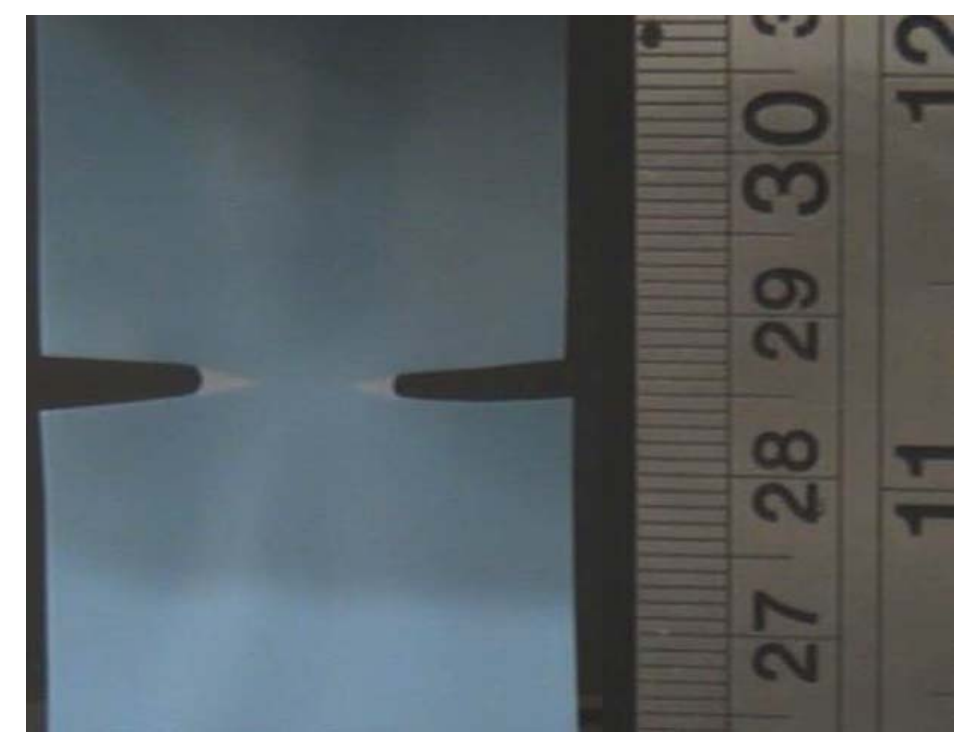

Figura 44: Corpo de prova em ensaio de EWF, apresentando acentuado arredondamento da ponta da pré-trinca. Escala em mm. Material: Rigidex PC 002-50R968

Outra vantagem oferecida pelo método EWF é a estreita relação entre o trabalho essencial de fratura, $w_{e}$, e o valor crítico da Integral-J, $J_{c}$ (MAl; COTTERELL, 1986; SALEEMI; NAIRN, 1990; MAI; POWELL, 1991; PARDOEN, MARCHAL; DELANNAY, 2002). Neste sentido, o método EWF pode constituir uma rota mais simples para a obtenção de $J_{c}$. 


\section{MATERIAIS E MÉTODOS}

\subsection{MATERIAIS}

- Resina MDPE 8818: composto de polietileno sem pigmentos, de cor natural, fabricado pela PBBPolisur S.A. (Dow Latin America), lote 1085B857, classificado como PE 80 conforme ISO 12162, destinado, após pigmentação, à fabricação por extrusão de tubos de pressão de água e gás natural. 0 material tem densidade de $0,940 \mathrm{~g} / \mathrm{cm}^{3}$ e índice de fluidez de 0,77 $\mathrm{g} \mathrm{a}$ $190^{\circ} \mathrm{C} / 5 \mathrm{~kg} / 10$ minutos, conforme norma ASTM D 1238. Dados extraídos da "curva de regressão" de um composto da mesma resina na cor amarela MDPE 8818 YW (apêndice B - Figura 96), conforme norma ISO 9080, indicam os seguintes valores: LTHS/LCL $\left(50\right.$ anos $\left./ 23^{\circ} \mathrm{C}\right)=8,03 \mathrm{MPa}(\mathrm{MRS}=8,0$ MPa). Este material foi utilizado nos ensaios de $K_{\text {Ic }}$ e nas séries de ensaios principais de Integral-J.

- Resina GM 5010 T2: composto de polietileno, de cor preta, com teor de negro-de-fumo 2,2\%, lote 1263, fabricado pela Ipiranga Petroquímica S.A, classificado como PE 80 conforme ISO 12162, destinado à fabricação por extrusão de tubos de pressão de água. É um polietileno bimodal, com densidade de $0,954 \mathrm{~g} / \mathrm{cm}^{3}$ e índice de fluidez $0,53 \mathrm{~g}$ a $190^{\circ} \mathrm{C} / 5 \mathrm{~kg} / 10$ minutos, conforme norma ISO 1133. Segundo o fabricante a resina apresenta os seguintes valores típicos de distribuição de massa molar e polidispersão, obtidos conforme norma ASTM D 3593: $\bar{M}_{n}=12 \mathrm{~kg} / \mathrm{mol}, \bar{M}_{w}=176 \mathrm{~kg} / \mathrm{mol}$, $\bar{M}_{z}=653 \mathrm{~kg} / \mathrm{mol}$, polidispersão $\left(\bar{M}_{w} / \bar{M}_{n}\right)=15$. Dados extraídos da "curva de regressão" (Figura 97), conforme norma ISO 9080, indicam os seguintes valores: LTHS $\left(50\right.$ anos $\left./ 20^{\circ} \mathrm{C}\right)=10,232 \mathrm{MPa}, \mathrm{LTHS} / \mathrm{LCL}=9,901 \mathrm{MPa}(\mathrm{MRS}=$ 8,0 MPa). Este material foi utilizado nos ensaios preliminares de Integral-J.

- Resina Rigidex PC 002-50R968: composto de polietileno pigmentado, com cor azul claro, fabricado pela Solvay Indupa do Brasil S.A., classificado como PE 80 conforme ISO 12162, destinado à fabricação por extrusão de tubos de pressão de água. O material tem densidade de $0,944 \mathrm{~g} / \mathrm{cm}^{3}\left(23^{\circ}\right)$ e índice de 
fluidez de $0,85 \mathrm{~g}$ a $190^{\circ} \mathrm{C} / 5 \mathrm{~kg} / 10$ minutos, conforme norma ISO 1133. Dados extraídos da "curva de regressão" (Figura 98), conforme norma ISO 9080, indicam o seguintes valores: LTHS $\left(50\right.$ anos $\left./ 20^{\circ} \mathrm{C}\right)=9,38 \mathrm{MPa}, \mathrm{LTHS} / \mathrm{LCL}$ $\left(50\right.$ anos $\left./ 20^{\circ} \mathrm{C}\right)=8,64 \mathrm{MPa}(\mathrm{MRS}=8,0 \mathrm{MPa})$. Este material foi utilizado nos ensaios de EWF.

Por composto de polietileno entende-se a resina base de polietileno acrescida de antioxidantes e outros aditivos, entre os quais, quando for o caso, pigmentos.

Os materiais foram recebidos dos fabricantes na forma de grânulos (pellets) e mantidos em suas embalagens originais em sala com temperatura ambiente amena e sem umidade.

\subsection{LABORATÓRIOS E EQUIPAMENTOS}

Os trabalhos experimentais deste projeto foram desenvolvidos nos laboratórios do Departamento de Engenharia Metalúrgica (PMT), da Escola Politécnica da USP (EPUSP), que possuem os seguintes equipamentos:

- máquina universal de ensaios mecânicos marca Kratos, modelo K 2000 MP, devidamente calibrada, equipada com sistema eletrônico computadorizado para aquisição de dados de carga e deslocamento da travessa móvel. As células de carga disponíveis possuem capacidade de 50kgf, 500 kgf, 2.000 kgf.

- microscópio eletrônico de varredura (MEV) marca Philips, modelo XL 30, com tensão de aceleração 20 kV e corrente no filamento entre 60 e $80 \mu \mathrm{A}$.

- Máquina de sputtering, para recobrimento de superfícies poliméricas com ouro, marca Balzers, modelo Sputter Cpater SCD 050.

- microscópio de força atômica marca Shimadzu, modelo STM 9500J

- ultramicrótomo criogênico Leica, modelo Em UC6.

- microscópio ótico marca Olympus, modelo BX60M

- microscópio ótico viajante, marca Gaertner, com divisões de 0,01mm.

- prensa hidráulica marca Sirma, modelo HB-E, do PMT/EPUSP, com controle automático da temperatura das placas e divisão de $1^{\circ} \mathrm{C}$. 
- serra de fita, lixadeira circular, furadeira coordenada, ferramentas manuais diversas e outros equipamentos e dispositivos próprios de oficinas mecânicas.

\subsection{CORPOS DE PROVA BRUTOS}

Os corpos de prova dos ensaios mecânicos foram confeccionados em diversas espessuras, para atender diferentes finalidades. No caso dos ensaios de $K_{1 c}$ e Integral-J as espessuras nominais foram de $14 \mathrm{~mm}$, sendo esta a maior espessura final possível de ser conseguida com as ferramentas atualmente disponíveis no PMT. Para os ensaios de EWF foram adotadas três espessuras: 0,2 mm, $1 \mathrm{~mm}$ e 3 $\mathrm{mm}$. Os corpos de prova foram extraídos de placas moldadas por compressão simples, obtidas diretamente a partir do material granulado fornecido pelo fabricante, exceto os corpos de prova para ensaios de EWF com espessura nominal de 0,2 mm, os quais foram extraídos de filmes obtidos por extrusão e sopro.

As placas foram moldadas conforme orientações gerais estabelecidas pela norma ASTM D 4703 - 03, com ligeiras modificações de forma contemplar a experiência já adquirida no PMT na confecção de placas de polietileno moldadas por compressão simples.

Para a confecção das placas mais finas, com espessura nominal de $1 \mathrm{~mm}$ e 3 $\mathrm{mm}$, foi utilizado um molde constituído por duas placas de aço lisas, com dimensões de $200 \times 200 \mathrm{~mm}$, intercaladas por uma moldura de aço de $1 \mathrm{~mm}$ ou $3 \mathrm{~mm}$ de espessura, conforme o caso, e largura de aproximadamente $10 \mathrm{~mm}$. As placas de aço foram revestidas com folhas de alumínio, com espessura de $0,1 \mathrm{~mm}^{3}$. O material granulado, em quantidade suficiente para preencher a cavidade do molde mais um excesso de $10 \%$, era colocado entre as placas de aço e o conjunto era posicionado entre as placas da prensa, estas previamente aquecidas a $190^{\circ} \mathrm{C}$. Após um período de estabilização de 5 minutos aplicava-se uma pressão hidráulica de cerca de 200 $\mathrm{kg} / \mathrm{cm}^{2}$, durante 3 minutos. Após esse período a pressão era brevemente aliviada (1 ou 2 segundos) e em seguida o molde era novamente comprimido por mais 2 minutos, totalizando 5 minutos de tempo total de prensagem. Após o período total de compressão as placas da prensa eram afastadas e o conjunto do molde era afastado, sendo resfriado naturalmente no ambiente do laboratório (em torno de

\footnotetext{
${ }^{3}$ Foram testadas outras alternativas de revestimento - vide capítulo resultados e discussão.
} 
$25^{\circ} \mathrm{C}$ ) por cerca de 30 minutos. Em seguida as chapas de aço do molde eram separadas, destacando-se as placas de polietileno, as quais eram posicionadas entre chapas de aço frias, sobre uma bancada plana, até o seu completo resfriamento. As placas obtidas dessa forma eram lisas, planas e apresentavam bom aspecto geral, sem defeitos ou bolhas internas aparentes. O processo de preparação para moldagem por compressão das placas com espessura de $1 \mathrm{~mm}$ e 3 mm é ilustrado na Figura 45(a).

Para a confecção das placas mais espessas foi utilizada outra configuração de molde e um procedimento de prensagem diferente. Foi construída uma base de aço, contendo uma cavidade usinada de $180 \mathrm{~mm} \times 180 \mathrm{~mm}$ e profundidade de 20 $\mathrm{mm}$, totalmente aberta na parte superior. $\mathrm{O}$ fundo da cavidade era coberto com uma folha de tecido teflonado (lençol de "Armalon") para facilitar a extração da placa. Colocava-se inicialmente no molde cerca de $80 \%$ em peso da quantidade calculada para o preenchimento da cavidade. Uma chapa de aço lisa era disposta sobre o material e o conjunto era posicionado entre as placas da prensa, pré-aquecidas a $190^{\circ} \mathrm{C}$, permanecendo nesta condição por 30 minutos, para estabilização. Após este período o conjunto era pressionado durante 10 minutos, sob pressão hidráulica de cerca de $200 \mathrm{kgf} / \mathrm{cm}^{2}$. A seguir, o molde era retirado da prensa e aberto, sendo adicionado o material restante. Depois de montado o molde era posicionado novamente entre as placas da prensa, sendo que o conjunto permanecia nesta posição durante 10 minutos, para estabilização. Novamente o molde era pressionado a $200 \mathrm{kgf} / \mathrm{cm}^{2}$ e o sistema de aquecimento das placas da prensa era então desligado, iniciando-se um período lento de resfriamento, sob pressão, que duraria cerca de 15 horas. Após este período de tempo, as placas da prensa eram afastadas, o molde era aberto e a placa de polietileno era retirada. Geralmente a placa final apresenta-se empenada, requerendo retificação. Após a usinagem mecânica obtinham-se placas de boa qualidade, planas e isentas de defeitos externos ou internos aparentes, sendo que a espessura final era de aproximadamente $14 \mathrm{~mm}$. O processo de prensagem das placas mais espessas é ilustrado na Figura 45(b). 

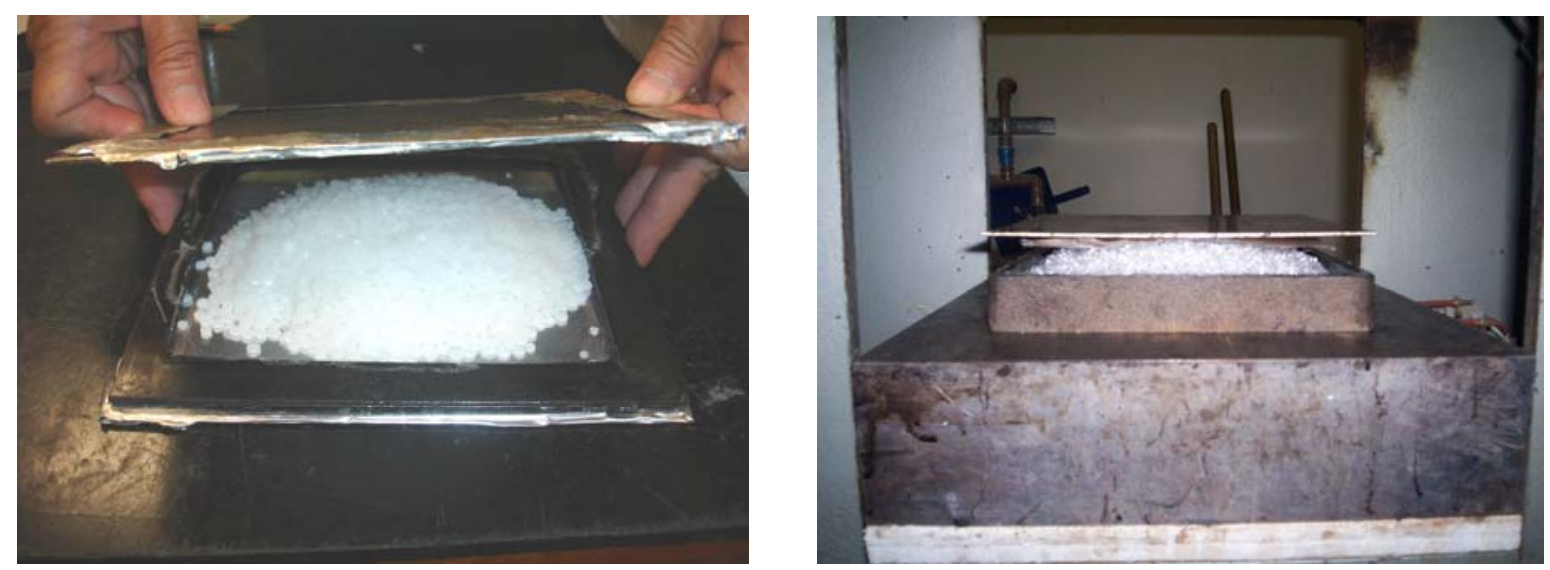

Figura 45: processo de moldagem por compressão dos grânulos de polietileno: (a) preparação para moldagem de placas de 1 ou $3 \mathrm{~mm}$ de espessura; (b) prensagem de placas de $20 \mathrm{~mm}$ de espessura.

Os corpos de prova para ensaios de tração foram obtidos diretamente a partir de placas com espessura de $3 \mathrm{~mm}$, por meio de estampagem em prensa pneumática e com auxílio de um estampo de aço com a geometria desejada.

Para a obtenção dos corpos de prova para ensaios de $K_{l c}$ e Integral $J$ as placas de polietileno com espessuras nominais de $14 \mathrm{~mm}$ eram cortadas em serra de fita, em peças com dimensões próximas das desejadas. Estas peças eram posteriormente lixadas com lixas de grão 100 e 600, sucessivamente, até as dimensões finais dos corpos de prova brutos. Os corpos de prova brutos com espessura de $3 \mathrm{~mm}$ para ensaios de EWF foram obtidos da mesma forma.

Os corpos de prova brutos com espessura de $1 \mathrm{~mm}$ para ensaios de EWF foram recortadas nas dimensões finais, diretamente a partir da placa moldada, com auxílio de estilete de aço.

Os corpos de prova de menor espessura para ensaios de EWF foram recortados de filmes com espessura nominal de 0,2 $\mathrm{mm}$, com auxílio de um estilete de aço. Os filmes foram previamente obtidos a partir de balões com diâmetro médio de $90 \mathrm{~mm}$, produzidos por sopro em uma extrusora de laboratório pertencente à empresa Cromex S/A. Trata-se de uma máquina que foi montada internamente, utilizando-se uma matriz com diâmetro de $60 \mathrm{~mm}$ e abertura de 0,8 mm (relação de suflamento $\cong 1,5: 1$ e relação de estiragem $\cong 4: 1$ ), regulada para temperatura do canhão $190^{\circ} \mathrm{C}$ e produção aproximada de $5,8 \mathrm{~kg} / \mathrm{hora}$. Na operação de corte dos corpos de prova levou-se em conta a direção principal de extrusão, tendo-se o cuidado de indicá-la em cada peça cortada. 
As dimensões finais nominais dos corpos de prova de fratura brutos são indicados na Tabela 2.

Tabela 2: Dimensões nominais dos corpos de prova brutos para os ensaios mecânicos

\begin{tabular}{cccc}
\hline TIPO DE ENSAIO & COMPRIMENTO $(\mathrm{mm})$ & LARGURA $(\mathrm{mm})$ & ESPESSURA $(\mathrm{mm})$ \\
\hline$K_{\text {Ic }}$ & 130 & 28 & 14 \\
Integral-J & 130 & 28 & 14 \\
EWF & 75 & 38 & 0,2 \\
EWF & 75 & 38 & 1 \\
EWF & 75 & 38 & 3
\end{tabular}

\subsection{GEOMETRIA DOS CORPOS DE PROVA}

Para os ensaios de $K_{l c}$ e Integral-J foi adotada a geometria dos corpos de prova do tipo SENB (ou SE(B)), conforme Figura 46, enquanto que para os ensaios de EWF foi adotada a geometria do tipo DENT, conforme Figura 41. Em todos os casos requereu-se a introdução de entalhes e pré-trincas, sendo que, no caso dos ensaios de $J$, foi necessária ainda a introdução de entalhes laterais (side grooves).
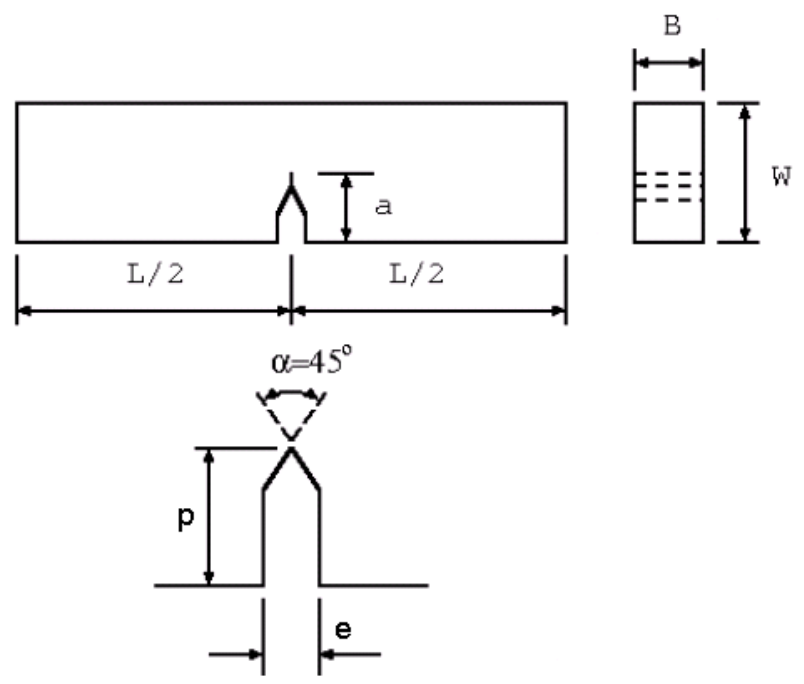

Figura 46: esquema do corpo de prova do tipo SENB, para ensaios de $K_{l c}$ e Integral-J, com a indicação das principais dimensões.

Para os ensaios convencionais de tração adotou-se o corpo de prova do tipo IV, conforme a norma ASTM D 638. 


\subsection{ENTALHES E PRÉ-TRINCAS}

Embora a questão da introdução das pré-trincas em corpos de prova para ensaios de fratura já tenha sido discutida anteriormente, ela será rapidamente retomada na introdução desta seção.

O objetivo do entalhamento e pré-trincamento do corpo de prova em ensaios de fratura é introduzir artificialmente um defeito ou trinca idealmente semelhante a uma trinca natural, com o mínimo de dano ao material na frente da ponta da trinca, de maneira reprodutível, de forma que durante os ensaios possam ser verificadas as condições críticas de carregamento para a sua ativação e propagação. Em metais as pré-trincas são introduzidas por fadiga. Entretanto, em materiais poliméricos verificou-se que a técnica não é satisfatória, adotando-se, alternativamente, a utilização de lâminas afiadas. No caso de polímeros frágeis à temperatura ambiente, como o poli(metacrilato de metila) (PMMA), uma trinca natural pode ser introduzida aplicando-se cuidadosamente "batidinhas" sobre uma lâmina de aço posicionada na raiz de um entalhe. Um exemplo de pré-trinca produzida com esta técnica é mostrado na Figura 47. É difícil se obter o mesmo resultado (uma pré-trinca natural) por meio desta técnica no polietileno em virtude da ductilidade e da opacidade do material. Desta forma, neste estudo adotou-se o uso de diferentes ferramentas e técnicas, dependendo do tipo de ensaio, as quais são apresentadas a seguir.

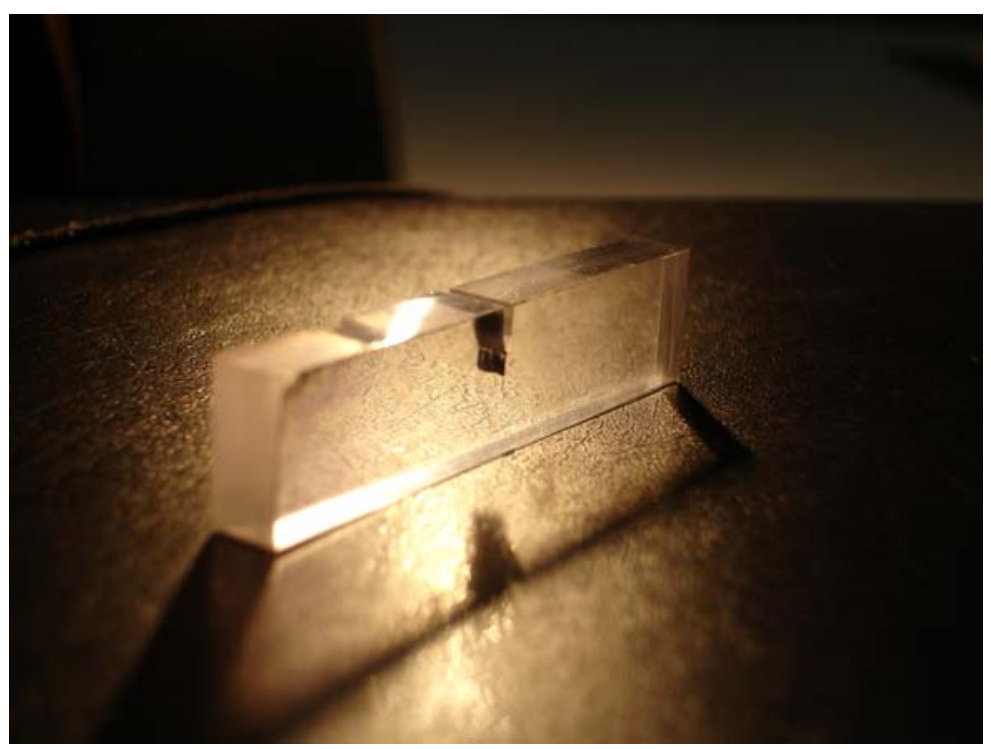

Figura 47: Pré-trinca natural introduzida por meio de "batidinhas" sobre uma lâmina de aço posicionada na raiz do entalhe de um corpo de prova de PMMA. 


\subsubsection{CORPOS DE PROVA PARA ENSAIOS DE $K_{l C}$ E DE INTEGRAL-J}

Para a introdução dos entalhes principais e dos entalhes laterais (ensaios de J) foi confeccionado um disco de aço serrilhado, com $1 \mathrm{~mm}$ de espessura e diâmetro de $92 \mathrm{~mm}$, com 100 dentes de $1 \mathrm{~mm}$ de altura, afiados a 45․ As pontas dos dentes eram bastante agudas, mas o raio de curvatura exato não foi determinado. O disco era instalado em uma furadeira coordenada e os entalhes eram produzidos a 3.600 rotações por minuto, passando-se o corpo de prova (fixado à mesa móvel da máquina) contra o disco. A profundidade dos entalhes foi fixada entre 12 e $14 \mathrm{~mm}$. O disco de corte é mostrado na Figura 48(a), enquanto que a Figura 48(b) ilustra 0 procedimento de introdução dos entalhes.

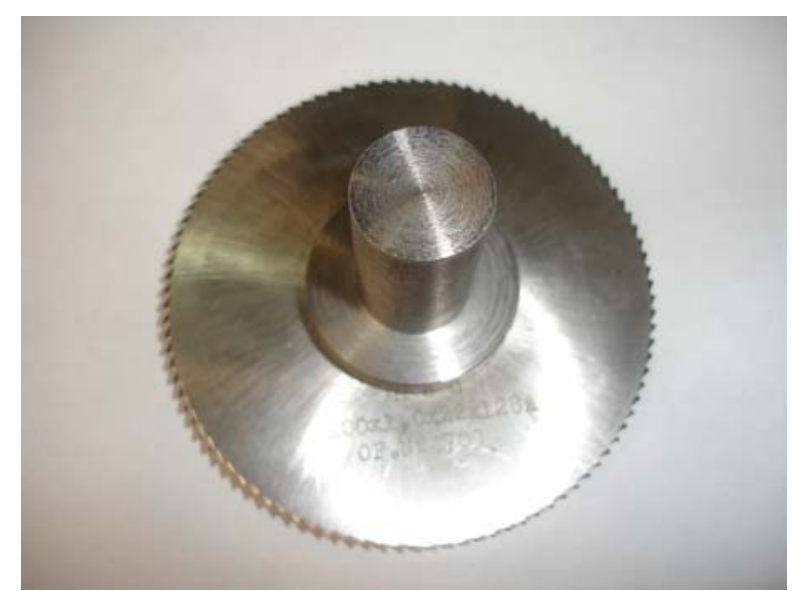

(a)

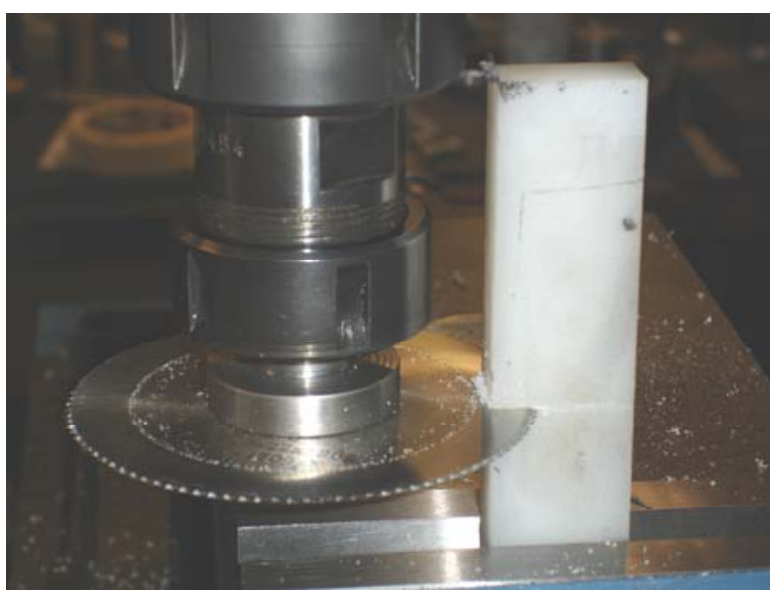

(b)

Figura 48: (a) Disco de corte serrilhado para introdução de entalhes em corpos de prova para ensaios de $K_{l c}$ e Integral-J. (b) Operação de introdução de entalhe em corpo de prova. Material: MDPE 8818.

Para os ensaios de $K_{l c}$ as pré-trincas foram introduzidas com auxílio de lâminas de barbear novas, posicionadas nas raízes dos entalhes, de duas maneiras diferentes. Na primeira, a lâmina penetrava sob efeito de "batidinhas" no topo de um dispositivo de fixação que a suportava, conferidas manualmente por um pequeno martelo, até que a profundidade de penetração atingisse entre 1,5 e $2 \mathrm{~mm}$, tendo como limitador de curso um batente de plástico. No procedimento alternativo a lâmina era lentamente pressionada na raiz do entalhe em uma máquina universal de ensaios mecânicos, a uma velocidade de $0,05 \mathrm{~mm} / \mathrm{min}$, até uma profundidade de penetração de cerca de $2 \mathrm{~mm}$. Nos dois casos foi utilizado um dispositivo de aço especialmente projetado e construído para suportar a lâmina de barbear e permitir 
sua fixação à travessa móvel da máquina de ensaio, bem como para receber os golpes do pequeno martelo. O dispositivo é apresentado na Figura 49, enquanto que a Figura 50 ilustra os dois procedimentos adotados.

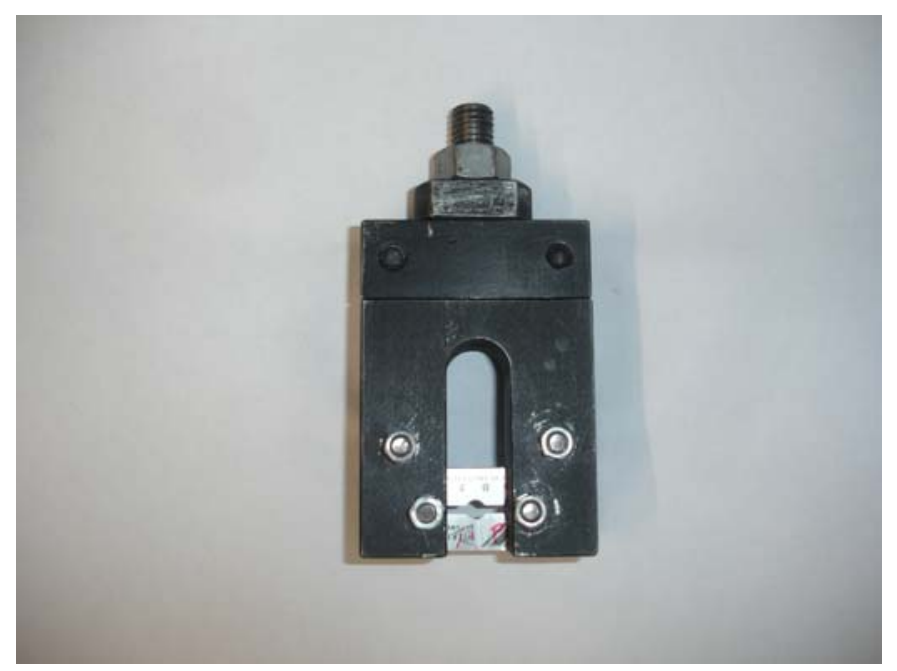

Figura 49: Dispositivo para suporte da lâmina de barbear

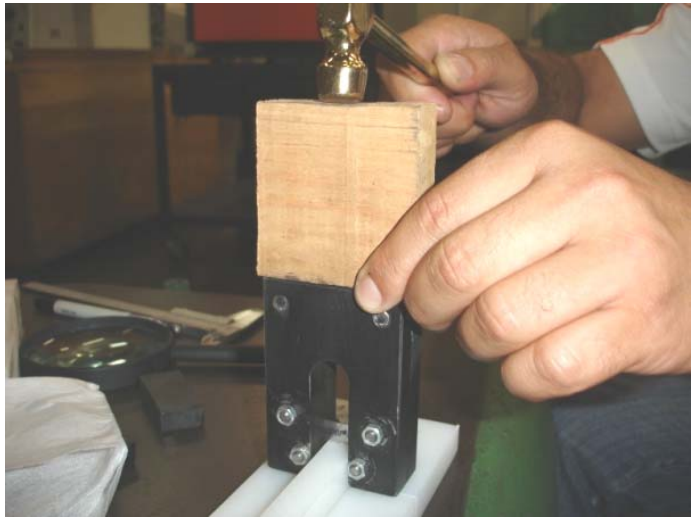

(a)

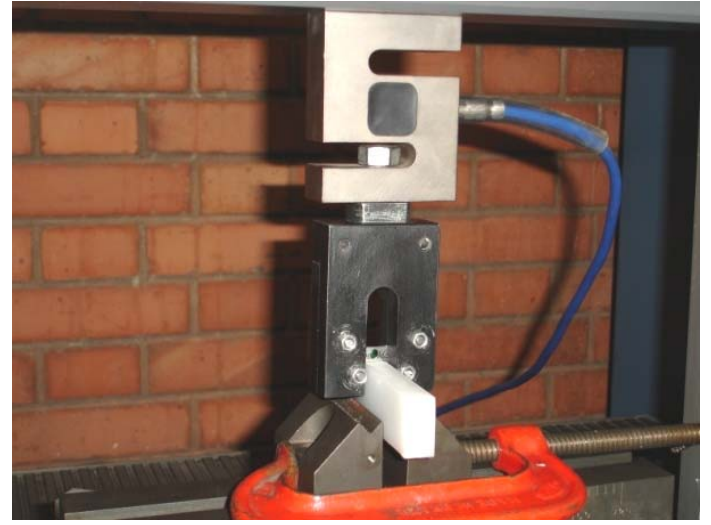

(b)

Figura 50: introdução de pré-trincas em corpos de prova. (a) Método das "batidinhas"; (b) pressionamento lento e controlado da lâmina. Material: MDPE 8818.

Nos corpos de prova para os ensaios de Integral-J foi adotado somente 0 pressionamento lento e controlado da lâmina para introdução das pré-trincas, como descrito acima.

A região da ponta da pré-trinca, em cada caso, foi inspecionada em microscópio eletrônico de varredura, visando a comparar as estruturas de deformação provocadas no material durante a introdução das pré-trincas.

As duas técnicas de introdução de pré-trincas adotadas neste estudo estão previstas genericamente nas normas. Contudo, saliente-se que as normas 
geralmente se referem a "batidinhas" conferidas diretamente contra o topo da lâmina (tapping on), enquanto que pela baixa rigidez da lâmina e pelas características do material, preferiu-se neste estudo adotar um método de transferência indireta das batidas, por meio do dispositivo. Por outro lado, as normas também não prescrevem, especificamente, condições controladas de pressionamento da lâmina.

Durante a execução dos ensaios vislumbrou-se uma nova abordagem para a introdução de pré-trincas, com características mais "naturais", a qual será discutida com mais detalhes no capítulo resultados e discussão.

\subsubsection{CORPOS DE PROVA PARA ENSAIOS DE EWF}

Os entalhes nos corpos de prova com espessura de $3 \mathrm{~mm}$ foram produzidos de duas maneiras. Na primeira foram utilizados o mesmo disco de corte e o mesmo procedimento do entalhamento dos corpos de prova para os ensaios de $K_{l c}$ e de Integral-J, sem qualquer pré-trinca adicional. A profundidade da penetração do disco, em cada caso, foi definida diretamente pelo comprimento do ligamento desejado. Na segunda forma, após a introdução de um entalhe por meio do disco de corte, era introduzida uma pré-trinca adicional de cerca de $2 \mathrm{~mm}$ de profundidade na raiz do entalhe. Para este fim era utilizada uma lâmina de barbear nova, pressionada a $1 \mathrm{~mm} / \mathrm{min}$ de velocidade, em máquina de ensaios. Neste caso a profundidade do entalhe era definida de forma que o ligamento tivesse o comprimento final desejado, considerando-se a existência da pré-trinca.

Os entalhes nos corpos de prova com espessuras nominais de $1 \mathrm{~mm}$ e de 0,2 $\mathrm{mm}$ foram introduzidos por meio de um estilete comum de aço, apoiado contra uma régua também de aço, pungindo-se a superfície do material com a ponta da lâmina em um ponto distante cerca de 2 milímetros da região destinada ao ligamento, arrastando-a em seguida no sentido da borda. Desta forma, obtinha-se uma aproximação do comprimento final desejado do ligamento. Na raiz do entalhe foi introduzida uma pré-trinca adicional de comprimento de cerca de $2 \mathrm{~mm}$, com auxílio de duas alternativas de tipos de lâmina: lâmina de barbear nova ou estilete de aço comum. Em cada caso, a lâmina era lenta e cuidadosamente forçada contra o material, em corte reto, até a profundidade correspondente ao comprimento final desejado do ligamento. Antes disso, o corpo de prova era posicionado e fixado entre duas placas de acrílico esquadrejadas, firmemente presas por um grampo de aço, 
levando-se em conta o alinhamento do entalhe previamente produzido. A operação da lâmina era manual, mas seu deslocamento era guiado por dois batentes constituídos de barras esquadrejadas de acrílico. Este dispositivo proporcionou o apoio necessário para o avanço reto da lâmina. O procedimento de introdução das pré-trincas está ilustrado na Figura 51.

Em todos os casos, os entalhes e pré-trincas eram produzidos acompanhando marcas finas, retas e esquadrejadas, previamente produzidas a tinta sobre a superfície do corpo de prova, de forma a se garantir o alinhamento e a correta posição dos entalhes, centralizados em relação às bordas.

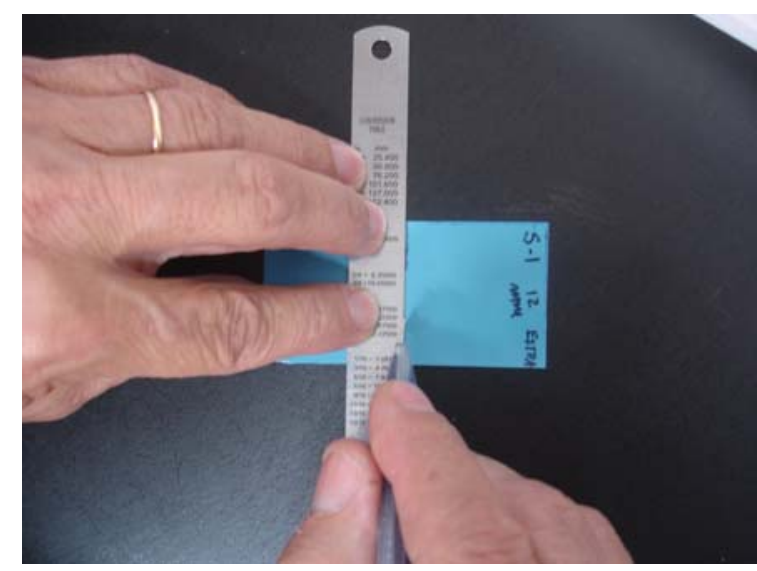

(a)

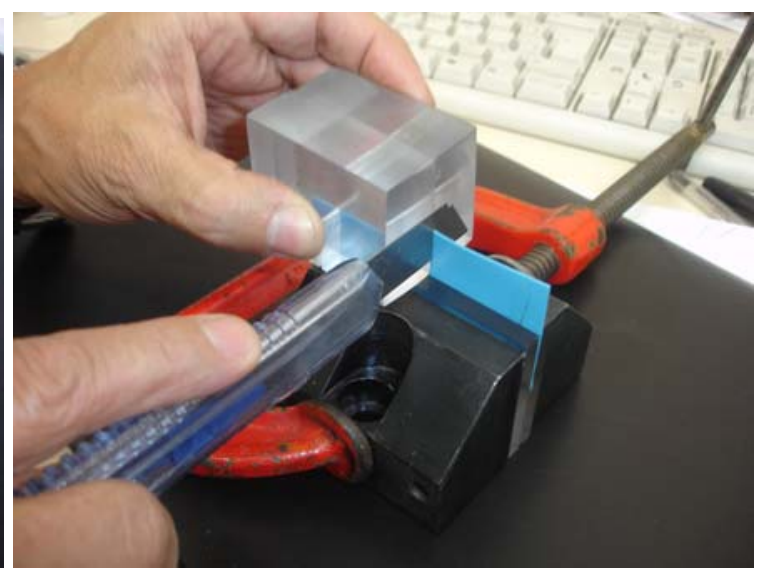

(b)

Figura 51: Método de introdução de pré-trincas em corpos de prova para ensaios de EWF, adotado para as espessuras de $1 \mathrm{~mm}$ e $3 \mathrm{~mm}$ : (a) Introdução do entalhe, com auxílio de estilete de aço; (b) Introdução de pré-trinca na raiz do entalhe, com auxílio de uma lâmina de aço (estilete comum, como na figura, ou lâmina de barbear).

Além das técnicas descritas, para efeito de comparação de resultados, foram aproveitados neste estudo os resultados de uma série de corpos de prova anteriormente produzidos (PERES, 2005). Nesta série, os entalhes/pré-trincas foram introduzidos em uma única operação, por pungimento e arraste da ponta de lâmina de estilete, conforme procedimento ilustrado na Figura 51(a).

As regiões da ponta dos entalhes e pré-trincas de alguns exemplares aleatoriamente escolhidos, contemplando cada caso, foram inspecionadas em microscópio eletrônico de varredura, visando a caracterizar as estruturas de deformação provocadas no material durante a introdução das pré-trincas. 


\subsection{DIMENSÕES FINAIS E NÚMERO DE CORPOS DE PROVA}

As dimensões principais ( $B$ e $W$ ) finais dos corpos de prova para os ensaios de $K_{l c}$ e Integral $J$ foram medidas com paquímetro, com precisão de 0,01 mm. Os comprimentos de trinca iniciais (a) nos mesmos ensaios, bem como avanços de frentes de trincas $(\Delta a)$, foram realizados nas superfícies de fratura, em um microscópio ótico viajante, com precisão de 0,01 $\mathrm{mm}$. Quando aplicável, foram adotados os valores médios, conforme instruções das normas ASTM D 5045-99 e D 6068-96. O número de corpos de prova para os ensaios de $K_{l c}$ variou entre 5 e 8 , enquanto que nos ensaios de Integral-J foram utilizados 3 corpos de prova para os ensaios preliminares e 7 a 8 nas séries principais.

Os ligamentos dos corpos de prova para ensaios de EWF foram agrupados nas seguintes classes de comprimentos nominais: $6 \mathrm{~mm}, 8 \mathrm{~mm}, 10 \mathrm{~mm}, 12 \mathrm{~mm}, 14$ $\mathrm{mm}$ e $16 \mathrm{~mm}$. O comprimento do ligamento de cada corpo de prova foi medido no microscópio ótico viajante, com precisão de 0,01 $\mathrm{mm}$, enquanto que a espessura foi medido com micrômetro, com precisão de 0,001 mm. Cada classe de ligamento continha inicialmente 5 corpos de prova, totalizando 30 corpos de prova em cada série.

As dimensões finais dos corpos de prova de tração são aquelas determinadas na norma ASTM D 638, tendo sido medidas com paquímtero, com precisão de 0,01 $\mathrm{mm}$. Foram ensaiados 3 corpos de prova em cada série.

\subsection{ENSAIOS MECÂNICOS}

Todos os ensaios mecânicos foram realizados em máquina universal de ensaios mecânicos do PMT/EPUSP, em temperatura de $23 \pm 2^{\circ} \mathrm{C}$.

\subsubsection{ENSAIOS DE $K_{I C}$}

Os ensaios de $K_{l c}$ foram realizados conforme a norma ASTM D 5045-99, contemplando-se também as orientações indicadas no protocolo de ensaio do ESIS (WILLIAMS, 2001a). A configuração de carregamento foi a de flexão de três pontos, com distância entre apoios de $112 \mathrm{~mm}$, determinada pelas dimensões nominais dos corpos de prova, conforme esquema mostrado na Figura 7. A velocidade de ensaio 
adotada foi $10 \mathrm{~mm} / \mathrm{min}$. Foi utilizada uma célula de carga de $500 \mathrm{kgf}$ de capacidade e os dados dos ensaios foram coletados e registrados eletronicamente. Os corpos de prova foram previamente imersos em nitrogênio líquido por um período de duas a quatro horas e ensaiados imediatamente após a retirada do banho. As superfícies de fratura foram revestidas com uma fina camada de ouro (pela técnica de sputtering) para facilitar a observação em microscópio ótico viajante, no qual foram feitas as medições do comprimento das pré-trincas. As superfícies de fratura também foram examinadas em microscópio eletrônico de varredura.

Uma série adicional de corpos de prova foi testada para investigar o efeito do crescimento estável de trinca observado nos ensaios. Nesse sentido, os corpos de prova previamente congelados foram submetidos a um carregamento realizado a 10 $\mathrm{mm} / \mathrm{min}$, até que uma carga máxima definida (250N) fosse atingida. Em seguida os corpos de prova foram descarregados e novamente imersos em nitrogênio líquido por um período de 2 a 4 horas. Após esse tempo os corpos de prova foram ensaiados conforme procedimento anterior. Nesta série, o método de introdução das pré-trincas iniciais adotado foi o pressionamento controlado, em máquina de ensaio, a $0,05 \mathrm{~mm} / \mathrm{min}$.

\subsubsection{ENSAIOS DE J}

Os ensaios para construção da curva $J-R$ foram realizados a deslocamento controlado, à temperatura ambiente $\left(25^{\circ} \mathrm{C}\right)$, conforme a norma ASTM D 6068-96, contemplando-se também as orientações indicadas no protocolo de ensaio do ESIS (HALE; RAMSTEINER, 2001). A configuração de carregamento foi a de flexão de três pontos, com distância entre apoios de $112 \mathrm{~mm}$, determinada pelas dimensões nominais dos corpos de prova, conforme esquema mostrado na Figura 7. A velocidade de ensaio adotada nos ensaios principais foi $1 \mathrm{~mm} / \mathrm{min}$. Foi utilizada uma célula de carga de $500 \mathrm{kgf}$ de capacidade e os dados dos ensaios foram coletados e registrados eletronicamente. As medidas de deslocamento ao longo da linha de carregamento foram feitas a partir do deslocamento da travessa da máquina de ensaio. Para corrigir efeitos estranhos, como os de indentação e aqueles decorrentes da rigidez do sistema mecânico, foi realizado um ensaio de calibração, no qual um corpo de prova sem entalhe foi carregado, nas mesmas condições de ensaio adotadas, conforme configuração de carregamento mostrada na Figura 52. 
Após o carregamento a deslocamento controlado, os corpos de prova eram congelados por imersão em nitrogênio líquido e rompidos por impacto ou em alta velocidade na mesma base de apoio utilizada nos ensaios. As medições do comprimento da pré-trinca e do avanço da frente de trinca $(\Delta a)$ foram feitas diretamente nas superfícies de fratura, com auxílio de um microscópio ótico viajante (Figura 53). Para facilitar a observação, as superfícies de fratura foram revestidas com uma fina camada de ouro, por meio de sputtering. As superfícies de fratura foram ainda observadas em microscópio eletrônico de varredura.

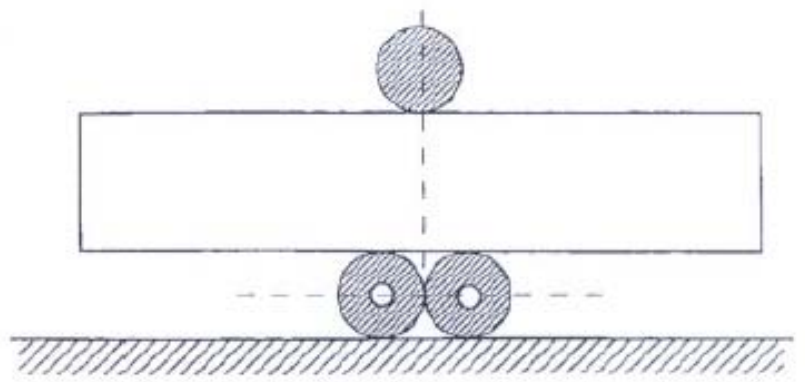

Figura 52: configuração do ensaio de calibração do sistema mecânico (Fonte: norma ASTM D 6068-96)

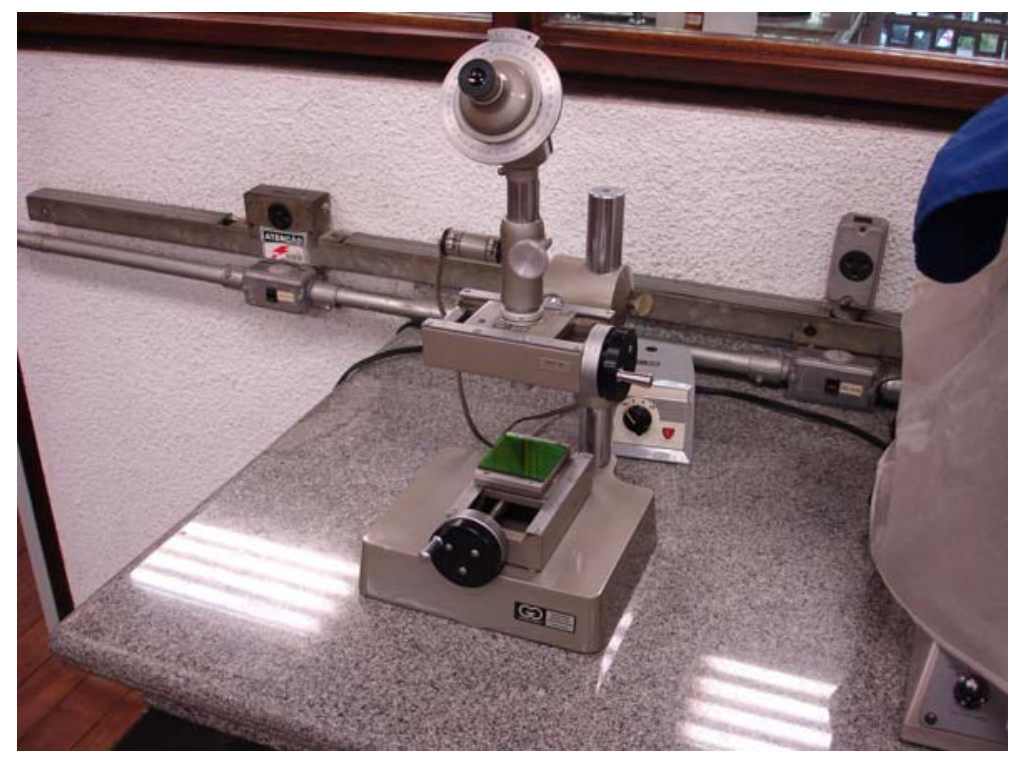

Figura 53: Microscópio ótico viajante, utilizado para a medição de comprimentos de trincas e avanços de frente de trinca em superfícies de fratura. 


\subsubsection{ENSAIOS DE EWF}

Ainda não há uma norma internacionalmente aceita para a realização de ensaios de EWF. Neste estudo os ensaios foram conduzidos conforme o protocolo de ensaio sugerido pelo ESIS (CLUTTON, 2001) e a experiência já adquirida no PMT (PERES, 2005), além de outras recomendações propostas na literatura (WILLIAMS; RINK, 2007).

Os ensaios de tração foram realizados à velocidade de $5 \mathrm{~mm} / \mathrm{min}$, cuidandose para que os corpos de prova ficassem alinhados em relação à linha de carregamento da máquina. Utilizou-se uma célula de carga de 50 kgf de capacidade para os ensaios dos corpos de prova com espessuras nominais de 0,2 $\mathrm{mm}$ e $1 \mathrm{~mm}$, e uma célula de carga de 500 kgf de capacidade para os ensaios dos corpos de prova com $3 \mathrm{~mm}$ de espessura. Os dados dos ensaios foram coletados e registrados eletronicamente.

Para melhor organização dos dados, cada série de corpos de prova recebeu uma designação própria, conforme tabela 3.

Tabela 3: Classificação das séries nos ensaios de EWF

\begin{tabular}{cccc}
\hline Série & $\begin{array}{c}\text { Espessura } \\
\text { Nominal } \\
(\mathbf{m m})\end{array}$ & Tipo de pré-trinca & $\begin{array}{c}\text { Orientação do ligamento } \\
\text { em relação à principal } \\
\text { direção de extrusão }\end{array}$ \\
\hline S-0 & 0,2 & pungimento c/ ponta de estilete & paralelo \\
S-1 & 0,2 & corte reto c/ lâmina de barbear & perpendicular \\
S-2 & 0,2 & corte reto c/ lâmina de barbear & paralelo \\
S-3 & 0,2 & corte reto com estilete de aço & perpendicular \\
S-4 & 0,2 & corte reto com estilete de aço & $\begin{array}{c}\text { paralelo } \\
\text { S-5 }\end{array}$ \\
S-6 & 1,0 & corte reto c/ lâmina de barbear & indeterminado \\
S-7 & 3,0 & corte reto com estilete de aço & indeterminado \\
S-8 & 3,0 & lâmina de barbear, a 1 mm/min & indeterminado \\
& 3,0 & corte com disco de corte afiado & indeterminado \\
\hline
\end{tabular}

Na tabela 3, a série S-0 corresponde aos dados aproveitados de trabalhos anteriores (PERES, 2005). 


\subsubsection{ENSAIOS CONVENCIONAIS DE TRAÇÃO}

Os ensaios convencionais de tração foram realizados conforme a norma ASTM D 638, à velocidade de $5 \mathrm{~mm} / \mathrm{min}$ da travessa móvel da máquina, utilizandose uma célula de carga de 500 kgf de capacidade. Os dados dos ensaios foram coletados e registrados eletronicamente.

\subsection{TRATAMENTO DOS DADOS}

\subsubsection{ENSAIOS DE $K_{I C}$}

A partir da análise da curva de carregamento e do valor máximo de carga registrado de cada corpo de prova, conforme procedimento já apresentado na seção 1.1, foram calculados os respectivos valores de $K_{Q}$. Os cálculos foram realizados conforme as expressões a seguir (equações (127), (128) e (129)), válidas para o tipo de corpo de prova adotado e definidas na norma ASTM D 5045-99:

$$
K_{Q}=\left(\frac{P_{Q}}{B W^{\frac{1}{2}}}\right) f(x)
$$

onde

$$
f(x)=6 x^{\frac{1}{2}} \frac{\left[1,99-x(1-x)\left(2,15-3,93 x+2,7 x^{2}\right)\right]}{(1+2 x)(1-x)^{\frac{3}{2}}}
$$

e

$$
x=\frac{a}{W}
$$

Para cada série de ensaios foram calculados a média e o desvio padrão, da forma convencional (COSTA NETO, 1977), e as séries foram comparadas por meio da realização de alguns testes estatísticos específicos, assumindo-se que os resultados de ensaios de $K_{l c}$ são normalmente distribuídos e independentes.

Os testes para comparação de duas variâncias foram baseados na distribuição $F$ de Snedecor (COSTA NETO, 1977). Adotando-se como hipótese nula a igualdade das variâncias, utilizou-se como variável de teste a estatística $F_{\text {teste, }}$ 
definida como a razão entre a maior e a menor variância. A hipótese nula era rejeitada quando o valor de $F_{\text {teste }}$ fosse maior que um determinado valor crítico $F_{c}$, encontrado em tabelas estatísticas, dado o grau de significância desejado para o teste e os graus de liberdade de cada série. Dependendo da situação analisada foram realizados testes unilaterais e bilaterais.

Os testes para comparação de duas médias foram baseados na distribuição $t$ de Student. Nesse sentido, os dados foram tomados como não-emparelhados (nãocorrelacionados), podendo surgir duas situações.

$\mathrm{Na}$ primeira os desvios-padrão das populações eram tidos como desconhecidos, mas podia-se admitir que fossem iguais, dependendo do teste das variâncias. Neste caso, era testada a hipótese nula de igualdade das médias, utilizando-se como variável de teste a estatística $t_{\text {teste }}$ calculada com base em uma média ponderada das variâncias amostrais, usando-se como pesos os graus de liberdade de cada série (COSTA NETO, 1977). A hipótese nula era rejeitada quando o valor de $t_{\text {teste }}$ fosse maior que um determinado valor crítico $t_{c}$, encontrado em tabelas estatísticas, dado o grau de significância desejado para o teste e o número de graus de liberdade, este último sendo o resultado da soma do número de elementos de cada série subtraído de 2 . Os testes realizados foram bilaterais.

$\mathrm{Na}$ segunda situação os desvios-padrão das populações eram tidos como desconhecidos e supostamente diferentes, também dependendo do teste das variâncias. Neste caso adotou-se o método aproximado de Aspin-Welch (COSTA NETO, 1977), em que para a determinação de $t_{c}$ é considerada uma conveniente correção do número de graus de liberdade. Com esta correção, o valor de $t_{c}$ pode ser encontrado em tabelas, como no caso anterior, rejeitando-se a hipótese nula quando $t_{\text {teste }}>t_{c}$.

\subsubsection{ENSAIOS DE INTEGRAL-J}

O trabalho aplicado em cada corpo de prova foi calculado a partir da área total sob as curvas de carregamento, através da aplicação do algoritmo do trapézio (BARROS, 1972). Em cada ensaio, descontou-se do trabalho total realizado a energia (trabalho aplicado) correspondente à área sob a curva de carregamento do ensaio de calibração, até a correspondente carga máxima atingida no carregamento do corpo de prova em questão. Com esta correção, o valor de $J$ foi calculado 
conforme a eq(111), considerando-se o fator de forma, $\eta$, igual a 2 para o tipo de corpo de prova adotado, conforme a norma ASTM D 6068-96.

As curvas J-R foram construídas a partir do conjunto de pares $(J, \Delta a)$ obtidos, considerando-se os critérios de validação especificados na norma ASTM D 6068-96.

Para a obtenção das relações de potência do tipo da eq(114) entre $J$ e $\Delta a$ que melhor se justavam aos dados de cada série, buscou-se inicialmente a linearização da relação entre os valores das variáveis. Para isso, cada conjunto de pontos $(J, \Delta a)$ foi transformado em um conjunto correspondente (InJ,In $\Delta a$ ) e sobre este novo conjunto efetuou-se uma análise de regressão linear pelo método dos mínimos quadrados, obtendo-se a equação da reta que melhor se ajustava aos pontos. A partir dos coeficientes linear e angular da reta se obtinham respectivamente os parâmetros $\mathrm{C}_{1}$ e $\mathrm{C}_{2}$ da eq(114).

\subsubsection{ENSAIOS DE EWF}

Para cada corpo de prova, em cada série, foram obtidos o trabalho total aplicado até a ruptura do ligamento e a carga máxima registrada durante o ensaio. $\mathrm{O}$ trabalho aplicado para romper o ligamento $\left(W_{f}\right)$ foi calculado a partir da área sob a curva carga-deslocamento, empregando-se o algoritmo do trapézio (BARROS, 1972). Os resultados de $W_{f}$ foram normalizados pela área da seção no ligamento (comprimento do ligamento $x$ espessura do corpo de prova), obtendo-se os valores de trabalho específico $\left(w_{f}\right)$. A tensão máxima em cada corpo de prova foi determinada dividindo-se a carga máxima observada pela área da seção do ligamento. Para cada série calculou-se a média das tensões máximas $\left(\sigma_{m}\right)$ e os resultados individuais foram submetidos ao critério de tensão, eliminando-se os registros dos corpos de prova cujas tensões máximas estavam situadas fora dos limites de validade estabelecidos. Ou seja, forma eliminados os pontos com tensão máxima menor que $0,9 \sigma_{m}$ ou maior que $1,1 \sigma_{m}$. Sobre os resultados validados pelo critério da tensão aplicou-se uma análise de regressão linear pelo método dos mínimos quadrados, eliminando-se os registros cujas diferenças entre resíduos e seus correspondentes valores previstos pela regressão fossem maiores que \pm duas vezes o desvio padrão dos resíduos. Sobre os dados restantes aplicou-se a análise de regressão linear definitiva, cujos valores dos coeficientes linear e angular 
correspondem, respectivamente, à média estimada dos parâmetros $w_{e}$ e $\beta w_{p}$ do método do trabalho essencial de fratura. A análise de regressão fornece ainda meios para se obter, por meio da variância residual, as variâncias dos estimadores da regressão (COSTA NETO, 1977), com as quais foram construídos os intervalos de 95\% de confiança, sendo ainda úteis na realização dos testes estatísticos aplicados. Por fim, o valor do coeficiente de determinação $\left(r^{2}\right)$, onde $r$ é o coeficiente de correlação linear de Pearson, é uma medida do grau de relacionamento linear entre as variáveis, no caso, entre $w_{f}$ e $I$. Valores de $r$ próximos da unidade indicam que a reta de regressão é bem determinada pela correlação entre os pontos experimentais.

Para verificar os efeitos das variações estudadas, as séries foram comparadas por meio da realização de alguns testes estatísticos específicos, assumindo-se que os resíduos das regressões são normalmente distribuídos. Desta assunção resulta que as distribuições dos estimadores dos parâmetros das regressões podem ser tomados como normais.

A metodologia para a comparação de duas séries foi a mesma descrita na subseção 2.8.1 e os testes foram bilaterais.

Para a comparação de mais de duas variâncias utilizou-se o Teste de Bartlett (COSTA NETO, 1977). Este teste se baseia no cálculo de uma estatística de teste $\chi_{k-1}^{2}$, onde $k$ é o número de séries comparadas, a qual, sob a hipótese de igualdade das variâncias, tem aproximadamente distribuição de qui-quadrado com $k-1$ graus de liberdade. A hipótese nula é rejeitada quando o valor da estatística de teste é maior que um valor crítico para o mesmo número de graus de liberdade, geralmente obtido em tabelas, dado o nível de significância desejado. O teste é unilateral à direita.

\subsubsection{ENSAIOS CONVENCIONAIS DE TRAÇÃO}

Nos ensaios convencionais de tração, para cada corpo de prova foi obtido o valor da máxima carga registrado no ensaio. A partir dos valores de carga máxima e das dimensões dos corpos de prova foram calculas as tensões (de engenharia) de escoamento de cada material, indicando-se a média e o desvio padrão dos resultados. 


\section{RESULTADOS E DISCUSSÃO}

\subsection{CONFECÇÃO DE PLACAS DE POLIETILENO MOLDADAS POR COMPRESSÃO}

A confecção de placas de polietileno moldadas por compressão requer atenção a uma série de fatores, dentre os quais se destacam:

- As características do material a ser moldado

- Preparação do molde

- Temperatura de processamento

- Tempo de aquecimento

- Tempo de moldagem

- Condição de resfriamento

Os materiais estudados neste projeto são polímeros que evoluíram das primeiras gerações de polietilenos lineares de alta densidade aplicados a tubos de pressão (pressure pipes). As gerações mais modernas, às quais pertencem os materiais deste trabalho, são resinas projetadas para apresentarem melhor desempenho quanto à fratura por fluência, por meio de emaranhamento molecular (entanglements) mais eficiente. Por outro lado, espera-se que isto leve a uma maior viscosidade extensional, o que por sua vez pode dificultar processos de moldagem. Assim, já foi notado anteriormente (PERES, 2005) que estes materiais não se comportam bem no processo de injeção, apresentando dificuldades para o preenchimento das cavidades do molde. Este efeito também foi notado quando se tentou adotar o mesmo procedimento utilizado para a obtenção das placas de $3 \mathrm{~mm}$ de espessura por compressão (PERES, 2005) para a confecção das placas de $1 \mathrm{~mm}$ de espessura. Como resultado, as placas apresentavam muitas deformações e variações de espessura. Além disso, as folhas de alumínio comuns utilizadas para revestir as placas de aço do molde se dobram facilmente durante a moldagem das placas de $1 \mathrm{~mm}$, provocando muitos veios e marcas superficiais. Neste trabalho as placas necessitavam ter ótimo acabamento e ser isentas de defeitos grosseiros 
porque o efeito da deformação na região da ponta das pré-trincas sobre os ensaios de fratura é justamente o foco deste estudo.

Assim, no caso das placas de $1 \mathrm{~mm}$ de espessura foi necessário alterar as condições de preparação do molde, uma vez que as demais condições de processamento anteriormente adotadas nas placas de $3 \mathrm{~mm}$ de espessura (PERES, 2005), como temperatura e tempos de prensagem, mostraram-se adequadas. Foram testadas seis alternativas de revestimento das placas de aço do molde: sem revestimento, papel (folha) alumínio comercial comum (PERES, 2005), tecido teflonado, tecido teflonado auto-aderente, lâmina de alumínio de 0,1 mm de espessura e um filme de poliimida $\left(\right.$ Kapton $\left.^{\circledR}\right)$. Os melhores resultados foram conseguidos com lâmina de alumínio de 0,1 mm de espessura e com o filme de poliimida, tendo-se obtido placas sem defeitos internos ou externos visíveis. O filme de poliimida proporciona a obtenção de placas com melhor acabamento superficial que a lâmina de alumínio, além da desmoldagem da placa ser mais fácil. Entretanto, optou-se pela lâmina de alumínio de 0,1 $\mathrm{mm}$ de espessura por questão de disponibilidade e custo do material, uma vez que os resultados com esta opção também foram satisfatórios. As demais alternativas apresentaram problemas diversos, como bolhas, veios e marcas grosseiras superficiais, decorrentes de agarramento do material, dobradura do material do revestimento, impressão da textura do tecido do revestimento e contaminação com agentes químicos. Na Figura 54 são mostrados exemplos das placas de $1 \mathrm{~mm}$ e $3 \mathrm{~mm}$ de espessura, obtidas com revestimento das placas do molde com lâmina de alumínio de 0,1 mm de espessura.

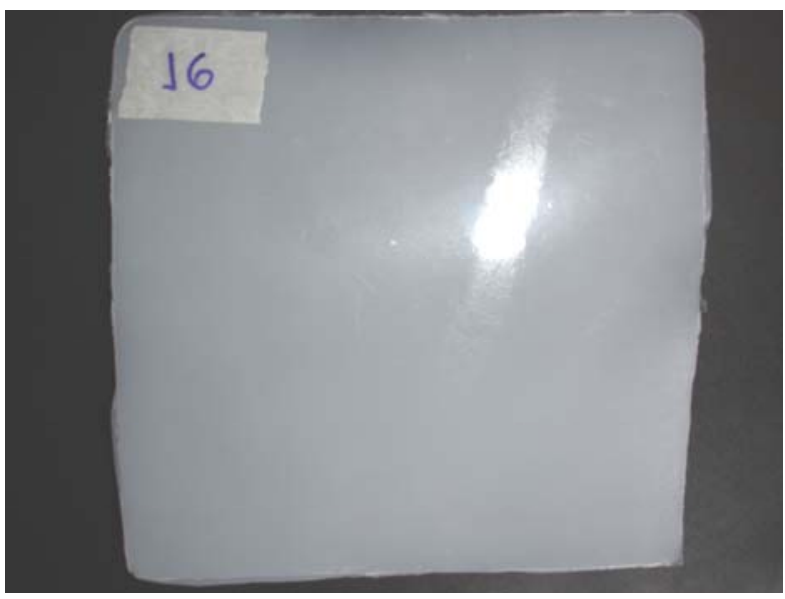

(a)

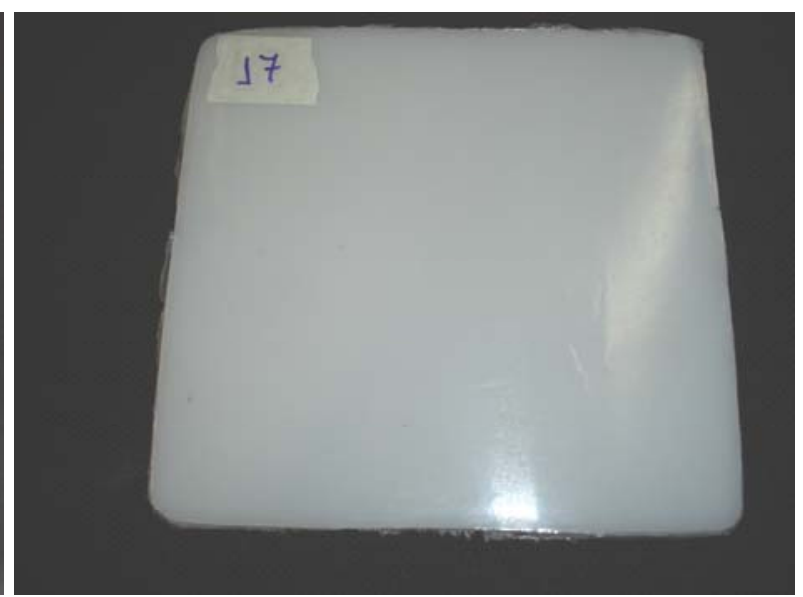

(b)

Figura 54: Placas de PEMD moldadas por compressão, com espessuras de $1 \mathrm{~mm}$ (a) e $3 \mathrm{~mm}$ (b). Placas de aço do molde revestidas com lâmina de alumínio com 0,1 mm de espessura. 
Não havia experiência prévia no PMT para a confecção das placas de espessura maior. Uma vez determinados os melhores tempos de processamento, as condições de resfriamento e mantida a temperatura de $190^{\circ} \mathrm{C}$, a questão do revestimento do molde tornou-se irrelevante para o aspecto final das placas porque, em virtude da contração e do conseqüentemente empenamento, as placas requereram usinagem posterior. Entretanto, alguma proteção contra o agarramento às paredes metálicas do molde é aconselhável para facilitar a desmoldagem, tendo o tecido teflonado se mostrado uma boa opção. Na Figura 55 são mostrados exemplos de placas espessas brutas e após usinagem.
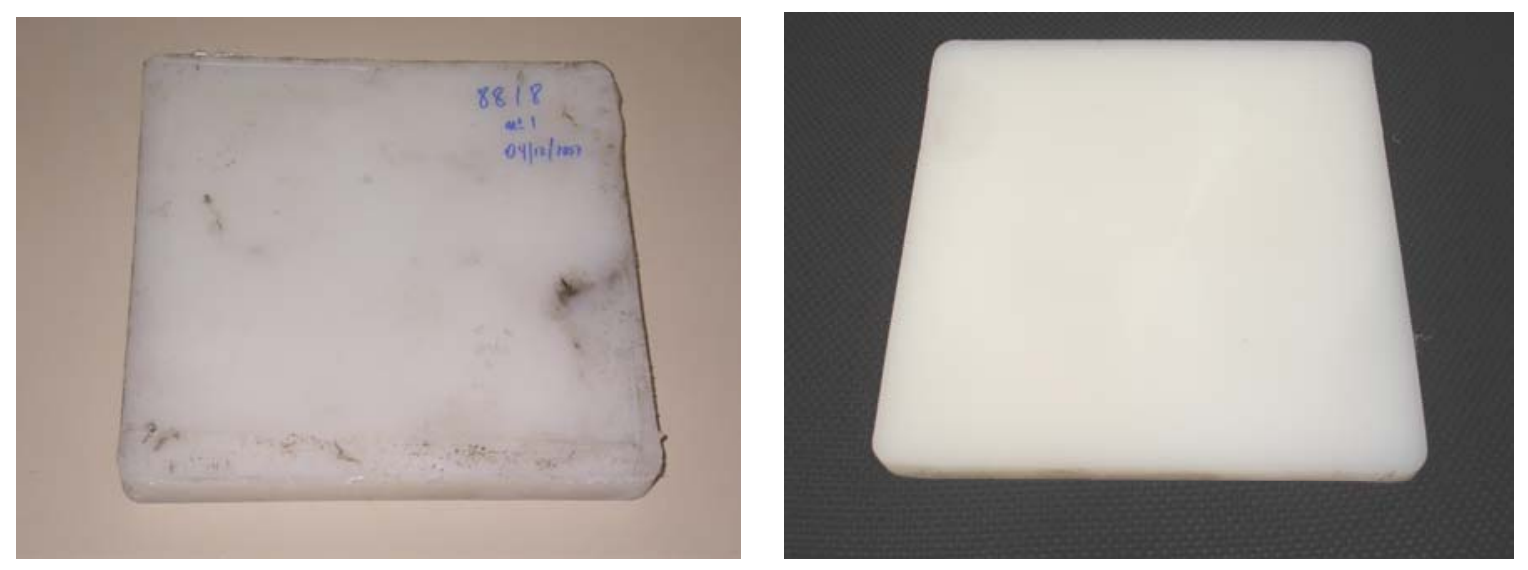

Figura 55: Placa bruta de MDPE 8818 (a), com cerca de $20 \mathrm{~mm}$ de espessura, e após usinagem mecânica (b), com espessura final de $14 \mathrm{~mm}$.

Materiais contendo negro-de-fumo podem apresentar problemas em processos lentos de resfriamento após moldagem por compressão (ASTM D 470303). De fato, isto foi observado na confecção de placas espessas do composto GM 5010 T2, cujas placas apresentaram bolhas internas e superficiais. Por este motivo, este material foi descartado para os ensaios mecânicos principais. De qualquer maneira, alguns corpos de prova isentos de defeitos com este material foram muito úteis e serviram para os primeiros testes de Integral-J. Estes testes foram importantes para a realização de alguns ajustes importantes nos ensaios principais, como a definição da quantidade de deflexão aplicada, poupando corpos de prova. 


\subsection{INTRODUÇÃO DO ENTALHE E DA PRÉ-TRINCA EM CORPOS DE PROVA}

\subsubsection{ENSAIOS DE $K_{I C}$ E DE INTEGRAL-J}

Inicialmente tentou-se produzir entalhes com auxílio de uma serra de fita (Figura 56). Entretanto, a forma reta da raiz do entalhe produzido e a excessiva deformação provocada pelos dentes da serra dificultavam o posicionamento da lâmina de barbear, podendo prejudicar a reprodutibilidade da técnica. Desta forma, foi utilizado o disco de corte especialmente afiado para a produção dos entalhes, instalado em uma furadeira coordenada (Figura 48). Na figura 57 são mostrados exemplos dos entalhes produzidos com a serra de fita e com o disco de corte.

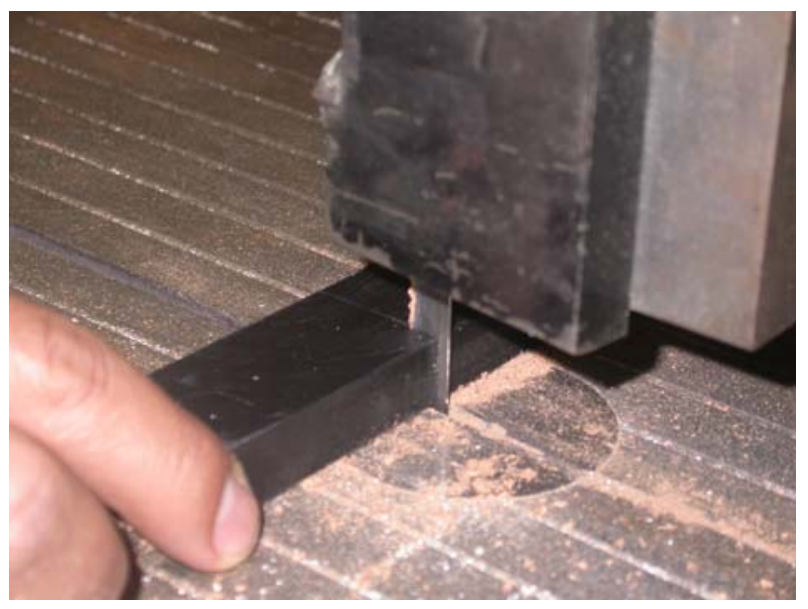

Figura 56: Introdução de entalhe com auxílio de serra de fita (material: GM 5010 T2)

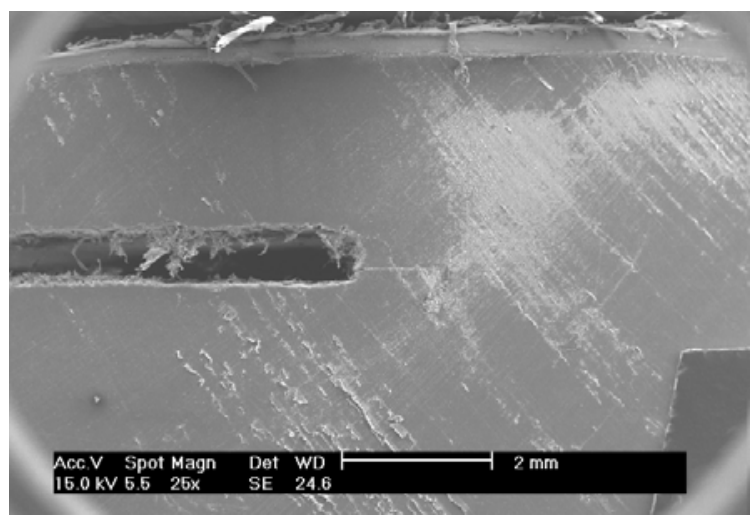

(a)

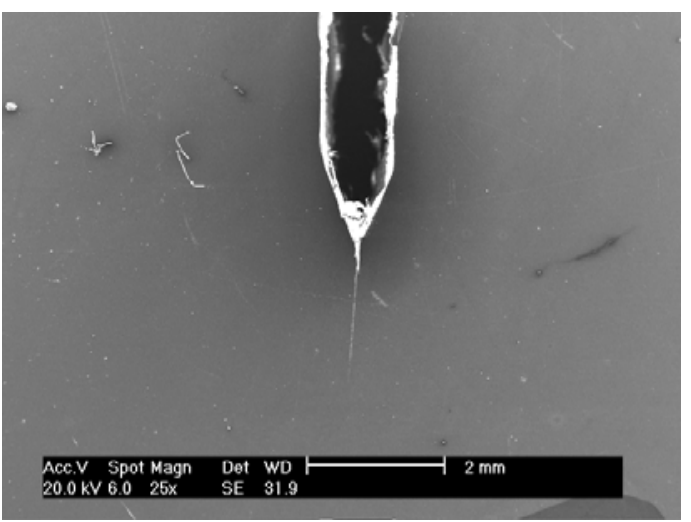

(b)

Figura 57: Raízes de entalhes produzidos com serra de fita (a) e com disco de corte afiado (b)

$\mathrm{Na}$ Figura 58 são mostradas, com diferentes ampliações, as pontas das prétrincas produzidas com lâminas de barbear novas, conforme as duas técnicas 
apresentadas na subseção 2.5.1, observadas a partir da superfície da face lateral do corpo de prova. A partir desta perspectiva, não se notam diferenças significativas de forma, dimensões e estruturas de deformação no entorno das pontas das prétrincas, indicadas com setas.

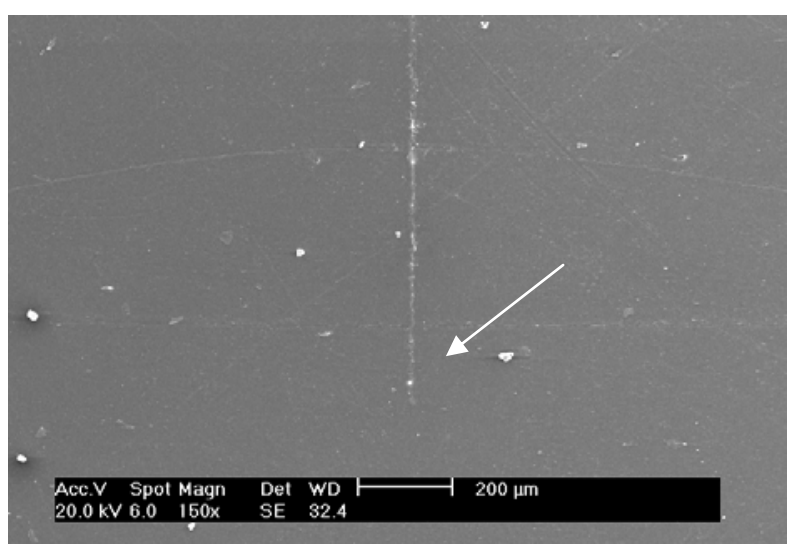

(a)

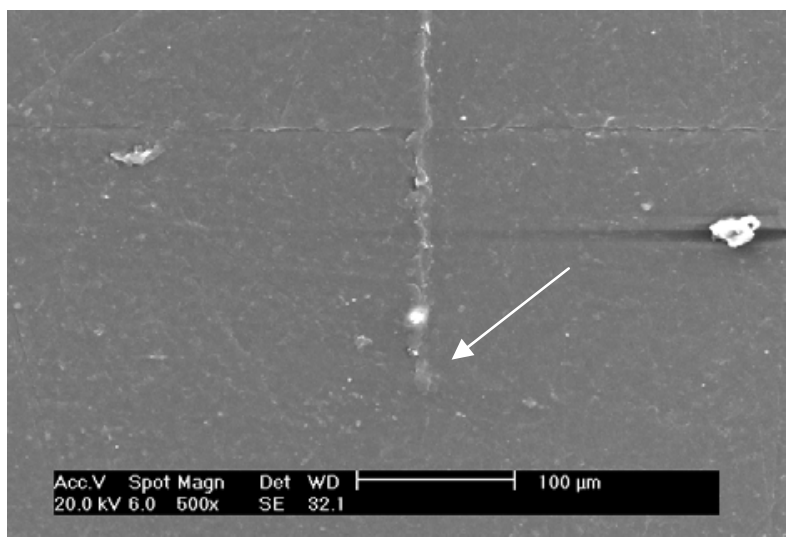

(b)

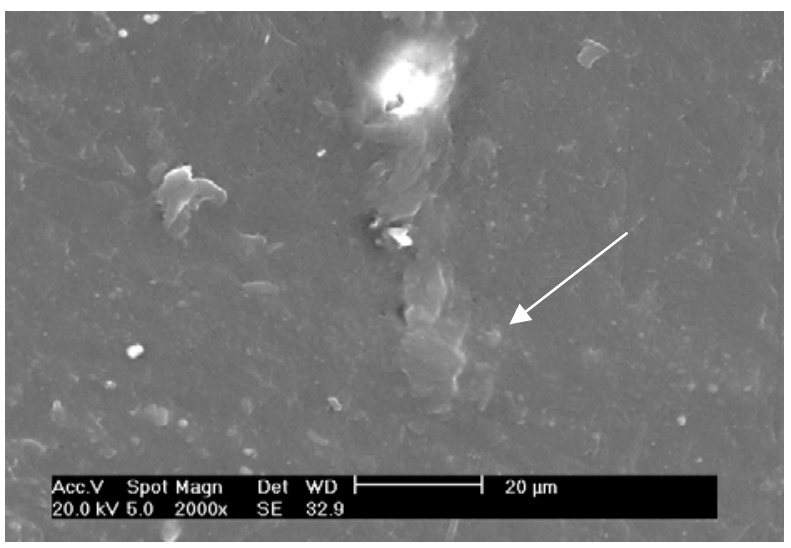

(c)

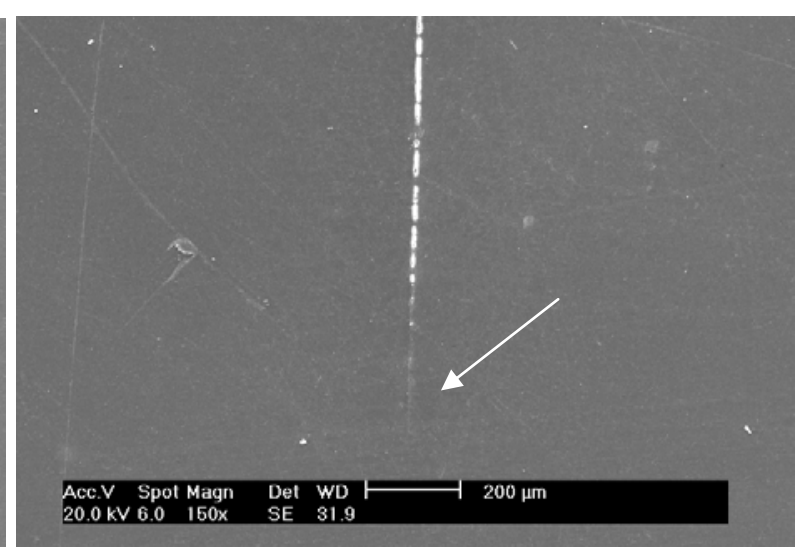

(d)

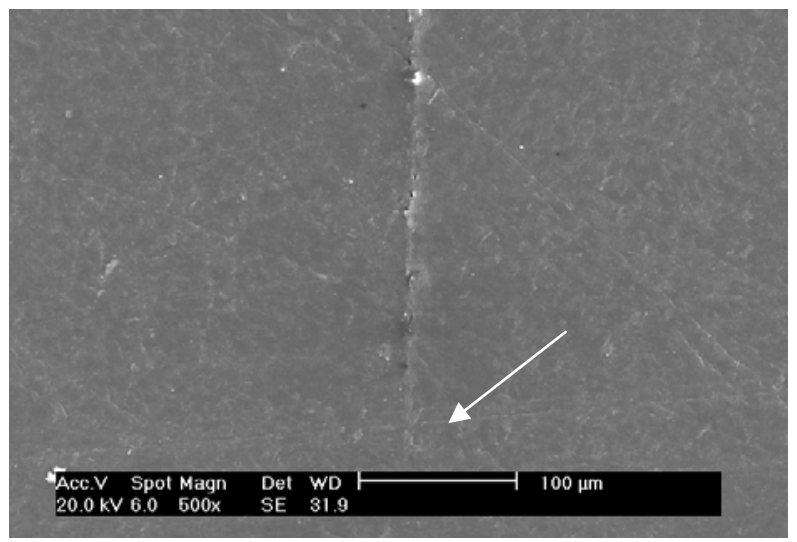

(e)

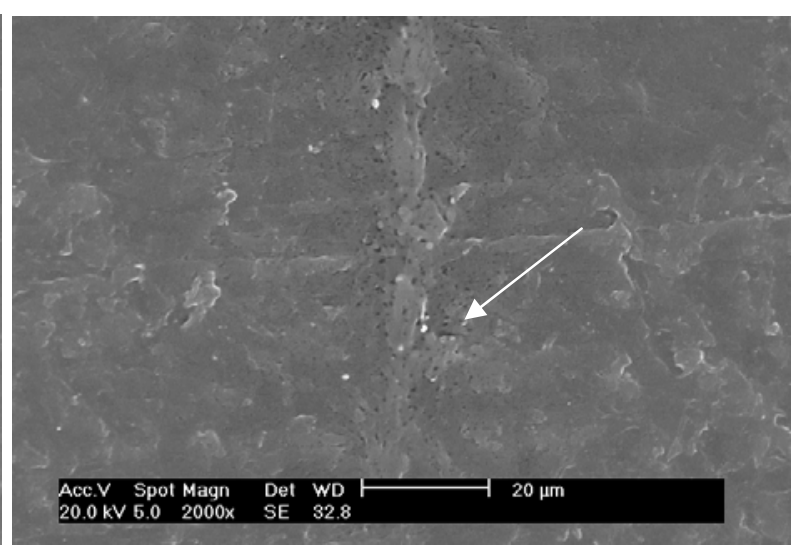

(f)

Figura 58: Pontas das pré-trincas produzidas por meio de pressionamento controlado - (a) a (c) e de "batidinhas" - (d) a (f). As setas indicam a ponta da pré-trinca. Imagens obtidas em MEV, com superfícies revestidas com ouro. 
Por outro lado, as diferentes técnicas de introdução das pré-trincas deixam marcas diferentes na superfície formada pelo avanço da lâmina. Na Figura 59 são apresentadas imagens das superfícies e das raízes das pré-trincas produzidas pelas diferentes técnicas, observadas em microscópio ótico, a partir da superfície de fratura revestida com ouro, após ensaio de $K_{l c}$ de corpos de prova congelados em nitrogênio líquido. As estrias presentes na região próxima da ponta da pré-trinca (Figura 59(b)) são provavelmente decorrentes da penetração descontínua da lâmina, na técnica das "batidinhas".
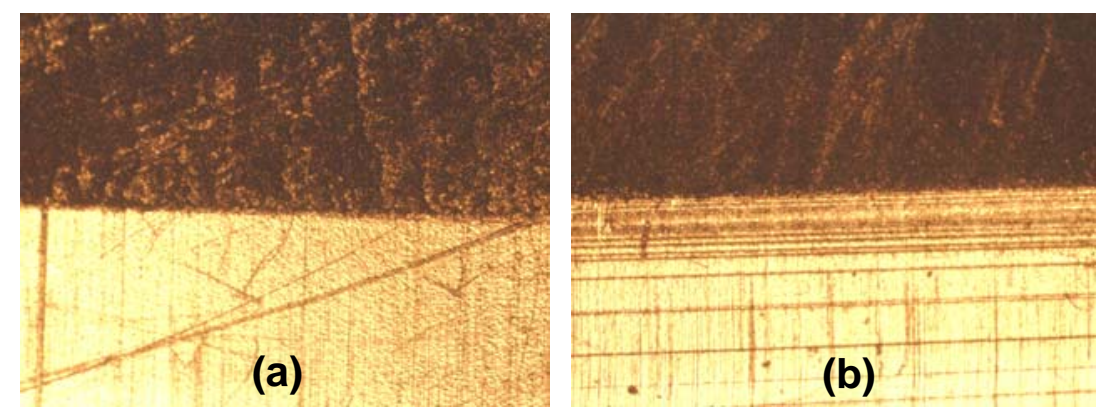

Figura 59: Região da ponta da pré-trinca produzida por pressionamento controlado (a) e por meio de "batidinhas" (b). Superfícies de fratura revestidas com ouro, observadas em microscópio ótico - aumento 50x.

A Figura 60 mostra, com mais detalhes, a zona de transição entre a ponta da pré-trinca e a zona de fratura propriamente dita, na região central do corpo de prova, tornando-se evidentes os diferentes graus de deformação do material decorrentes dos diferentes métodos de introdução das pré-trincas.

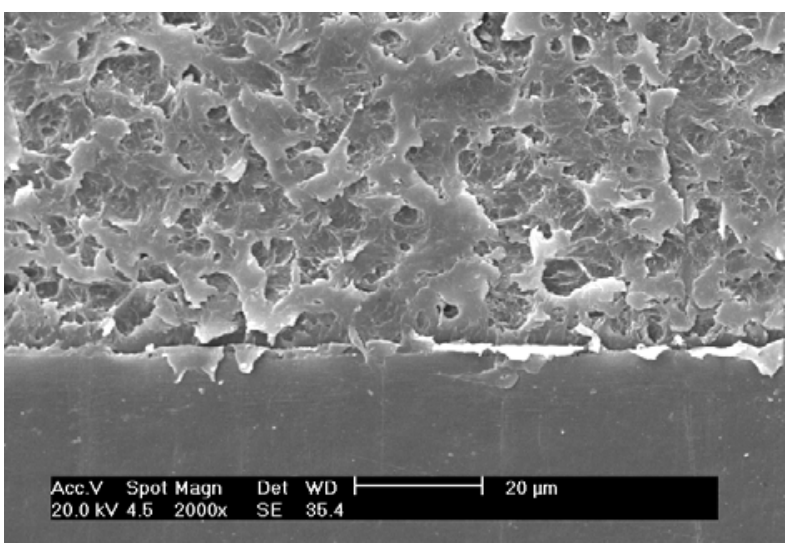

(a)

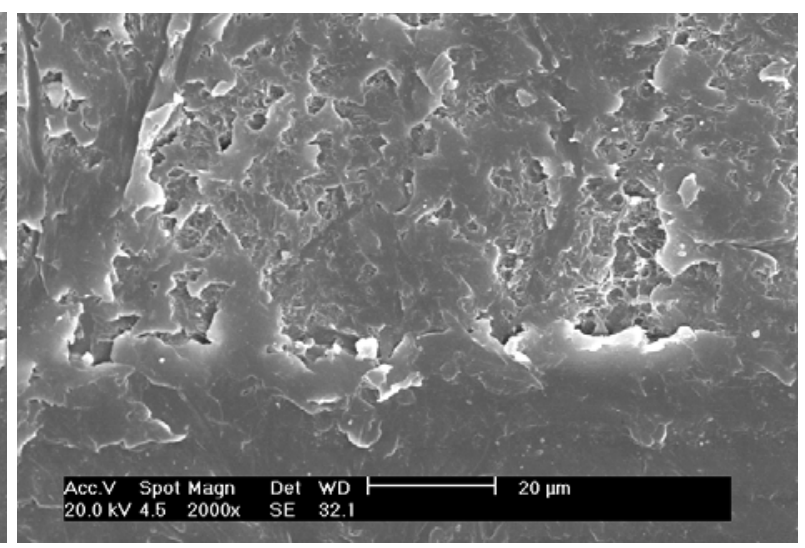

(b)

Figura 60: Região de transição da ponta da pré-trinca para a superfície de fratura produzida: (a) pré-trinca introduzida por meio de pressionamento lento de controlado de lâmina de barbear; (b) pré-trinca introduzida por meio de "batidinhas". Imagem obtida em MEV; superfícies revestidas com ouro. 
A propósito da observação da superfície de fratura em microscópios óticos, as características superficiais em ensaios de $K_{l c}$ e de Integral-J de polietileno de média densidade, em particular a raiz da pré-trinca e a frente da trinca, ficam melhor definidas quando a superfície original (natural) é revestida com ouro. Essa providência não é absolutamente necessária, mas sem o revestimento a precisão das medições na superfície de fratura no microscópio ótico viajante requer acuidade visual apurada. O benefício do revestimento da superfície com ouro pode ser verificada ao se comparar a superfície natural e a superfície revestida de um corpo de prova que sofreu um crescimento estável de trinca em ensaio de Integral-J, à temperatura ambiente, seguido de resfriamento em nitrogênio líquido e subseqüente ruptura por impacto, cujas imagens são mostradas na Figura 61. A pré-trinca foi introduzida por meio de pressionamento lento e controlado da lâmina.

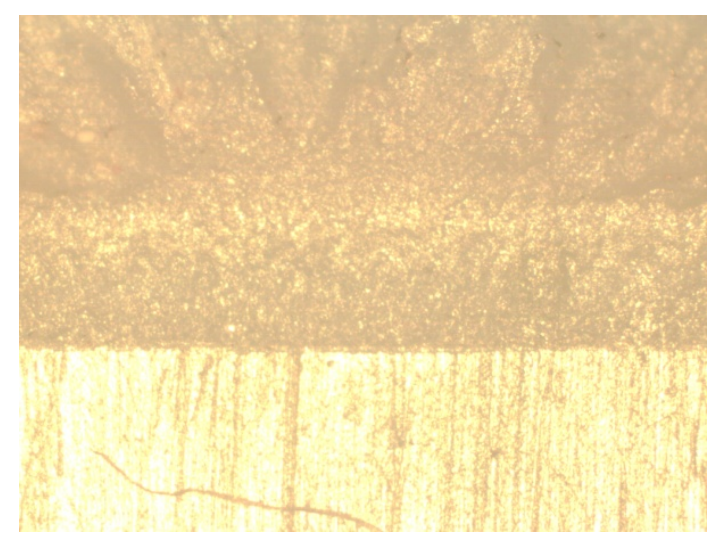

(a)

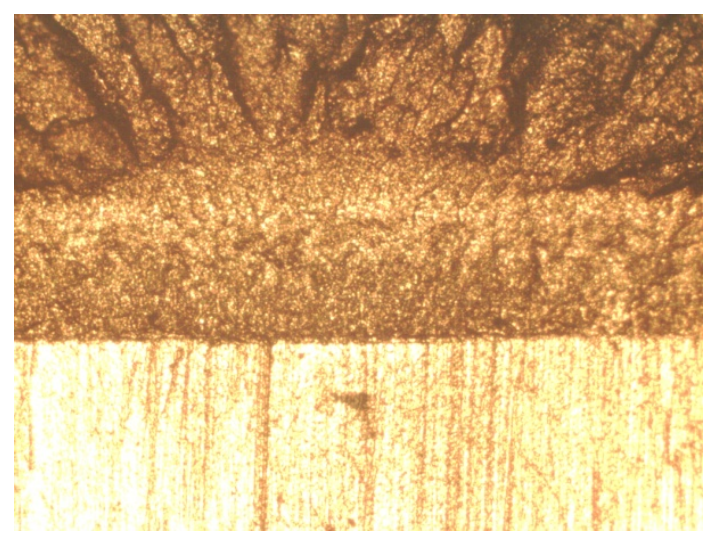

(b)

Figura 61: Imagens de superfície de fratura após crescimento estável de trinca, seguido de ruptura por impacto após resfriamento em nitrogênio líquido. (a) sem revestimento; (b) superfície revestida com ouro. Imagens obtidas em microscópio ótico, com aumento de 50x. Material: MDPE 8818.

\subsubsection{ENSAIOS DE EWF}

A Figura 62 mostra, com diferentes ampliações (25X, 200X e 2.000X), a região da ponta da pré-trinca em corpos de prova para ensaios de EWF, com espessura nominal de 0,2 mm. As pré-trincas foram introduzidas por meio de (a) corte reto com lâmina de barbear (S-1), (b) corte reto com estilete (S-3) e (c) pungimento da ponta de um estilete (série $\mathrm{S}-0$ ). As setas nas imagens com aumento de $25 \mathrm{X}$ indicam as pontas verdadeiras das pré-trincas, para efeito de distinção da ponta do entalhe, esta última localizada cerca de $2 \mathrm{~mm}$ antes. Nas demais imagens 
esta distinção não é necessária porque as pontas dos entalhes não aprecem nas ampliações subseqüentes ou porque não houve a introdução prévia de um entalhe $(\mathrm{S}-0)$.
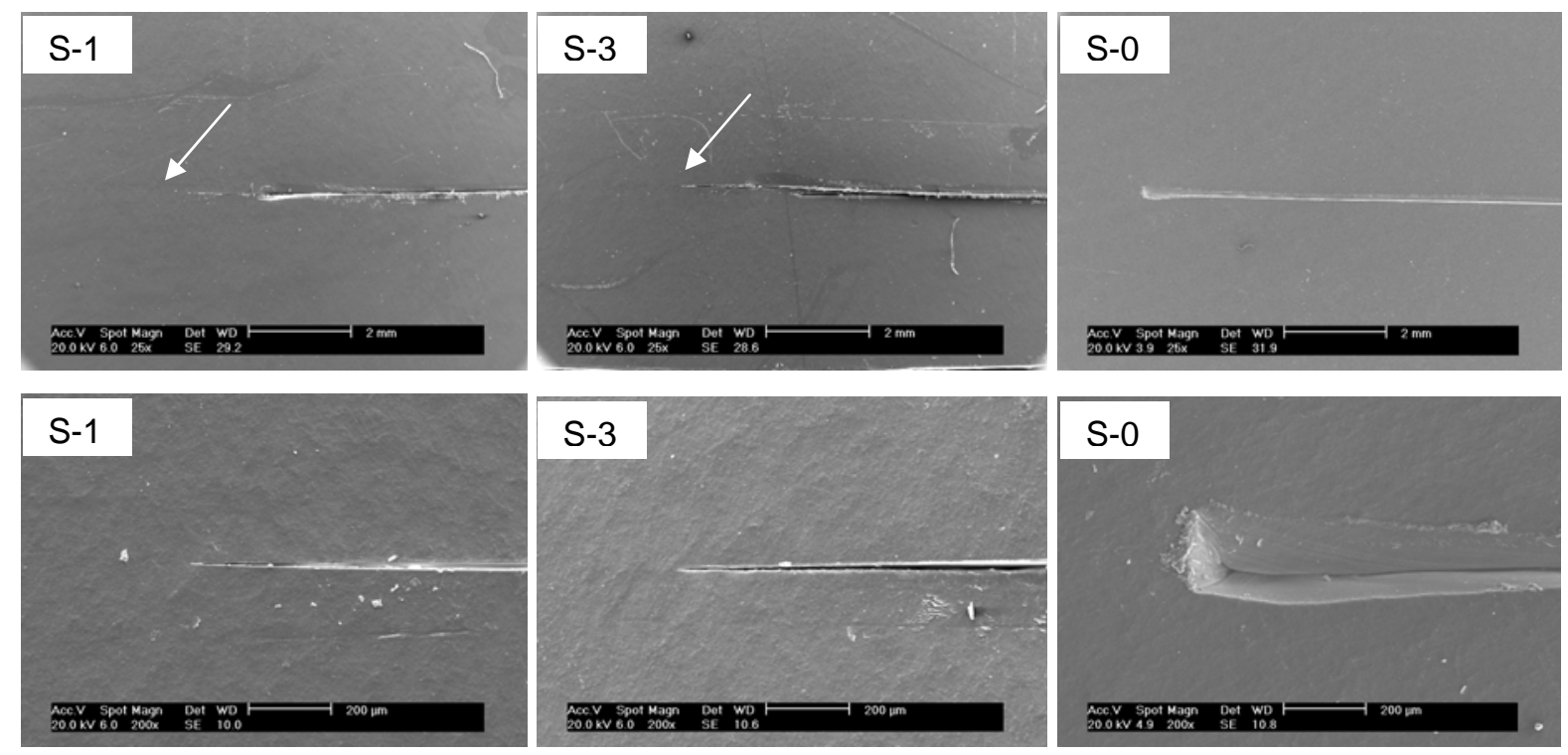

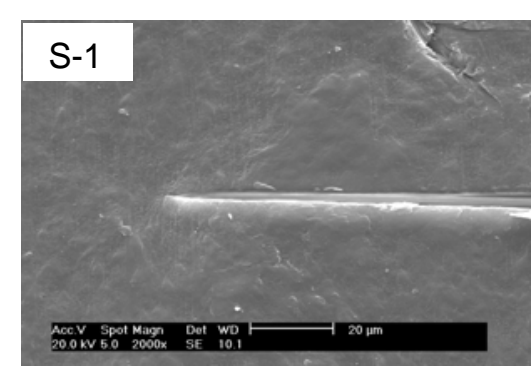

(a)

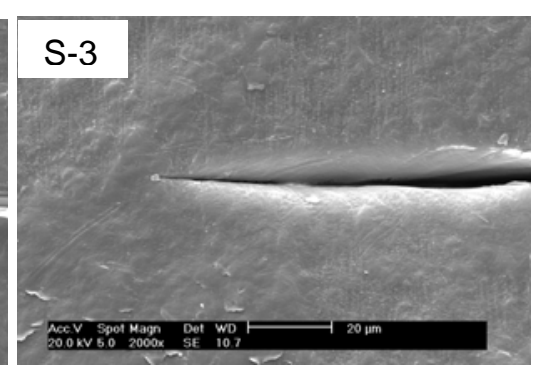

(b)

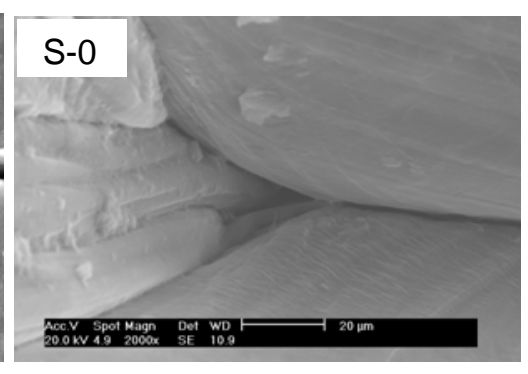

(c)

Figura 62: Região da ponta da pré-trinca em corpos de prova EWF com espessura de 0,2 $\mathbf{m m}$. Pré-trincas introduzidas por (a) corte reto com lâmina de barbear (S-1); (b) corte reto com estilete (S-3); (c) pungimento com ponta de estilete (S-0). Ampliações de 25X (topo), 200X (centro) e 2.000X (baixo). Imagens obtidas em MEV; superfícies revestidas com ouro.

Pode-se observar na Figura 62 que as diferentes ferramentas utilizadas para introdução das pré-trincas produzem diferentes estruturas de deformação na região da ponta da trinca.

A Figura 63 mostra, com diferentes ampliações (25X, 200X e 2.000X), a região da ponta da pré-trinca em corpos de prova para ensaios de EWF, com espessura nominal de $1 \mathrm{~mm}$. As pré-trincas foram introduzidas por meio de (a) corte reto com lâmina de barbear (S-5) e (b) corte reto com estilete (S-6). As setas nas imagens com aumento de $25 \mathrm{X}$ indicam as pontas verdadeiras das pré-trincas, para efeito de distinção da ponta do entalhe, esta última localizada cerca de 1 a $2 \mathrm{~mm}$ 
antes. Nas demais imagens esta distinção não é necessária porque as pontas dos entalhes não aprecem nas ampliações subseqüentes.
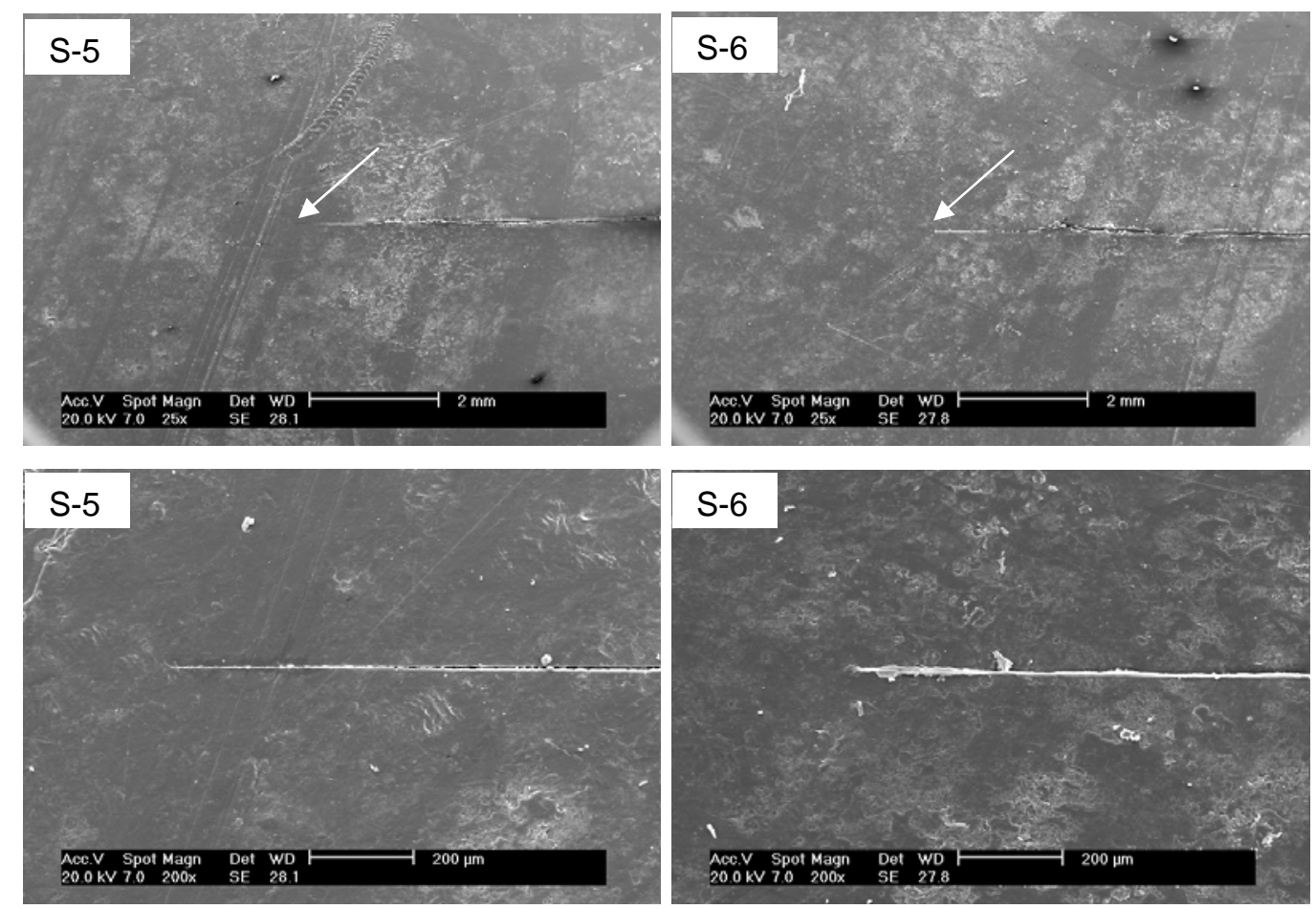

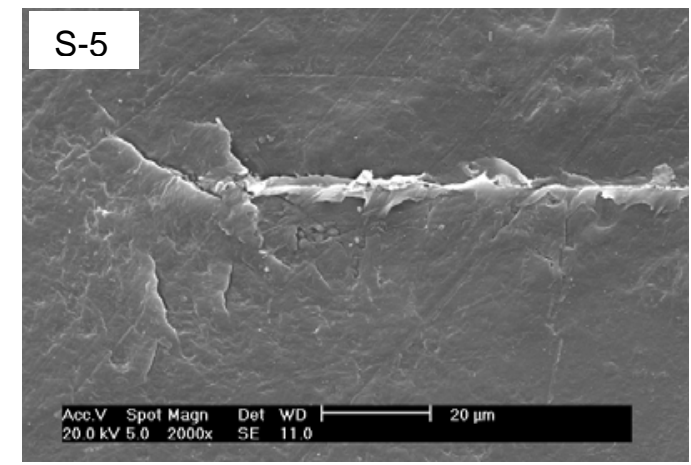

(a)

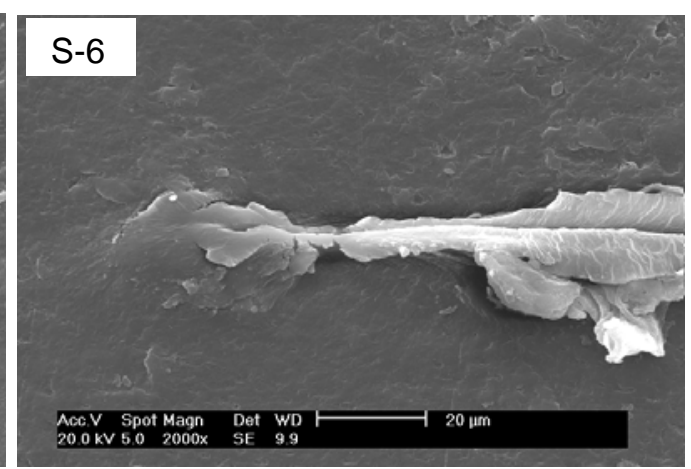

(b)

Figura 63: Região da ponta da pré-trinca em corpos de prova EWF com espessura de $1 \mathrm{~mm}$. Pré-trincas introduzidas por (a) corte reto com lâmina de barbear (S-5); (b) corte reto com estilete (S-6). Ampliações de 25X (topo), 200X (centro) e 2.000X (baixo). Imagens obtidas em MEV; superfícies revestidas com ouro.

Novamente, pode-se observar na Figura 63 que as diferentes ferramentas utilizadas para introdução das pré-trincas produzem diferentes estruturas de deformação na região da ponta da trinca.

A Figura 64 mostra, com diferentes ampliações (25X, 200X e 2.000X), a região da ponta da pré-trinca em corpos de prova para ensaios de EWF, com espessura nominal de $3 \mathrm{~mm}$. A pré-trinca na Figura 64(a) foi introduzida por meio de pressionamento controlado de lâmina de barbear (S-7), na raiz de um entalhe feito 
com disco de corte, enquanto que na Figura 64(b) a ponta da pré-trinca corresponde à própria ponta do entalhe feito com disco de corte, em cuja raiz não foi introduzido qualquer corte adicional (S-8). A seta na imagem com aumento de $25 \mathrm{X}$ indica a ponta verdadeira da pré-trinca, para efeito de distinção da ponta do entalhe, esta última localizada cerca de $2 \mathrm{~mm}$ antes. Nas demais imagens esta distinção não é necessária.
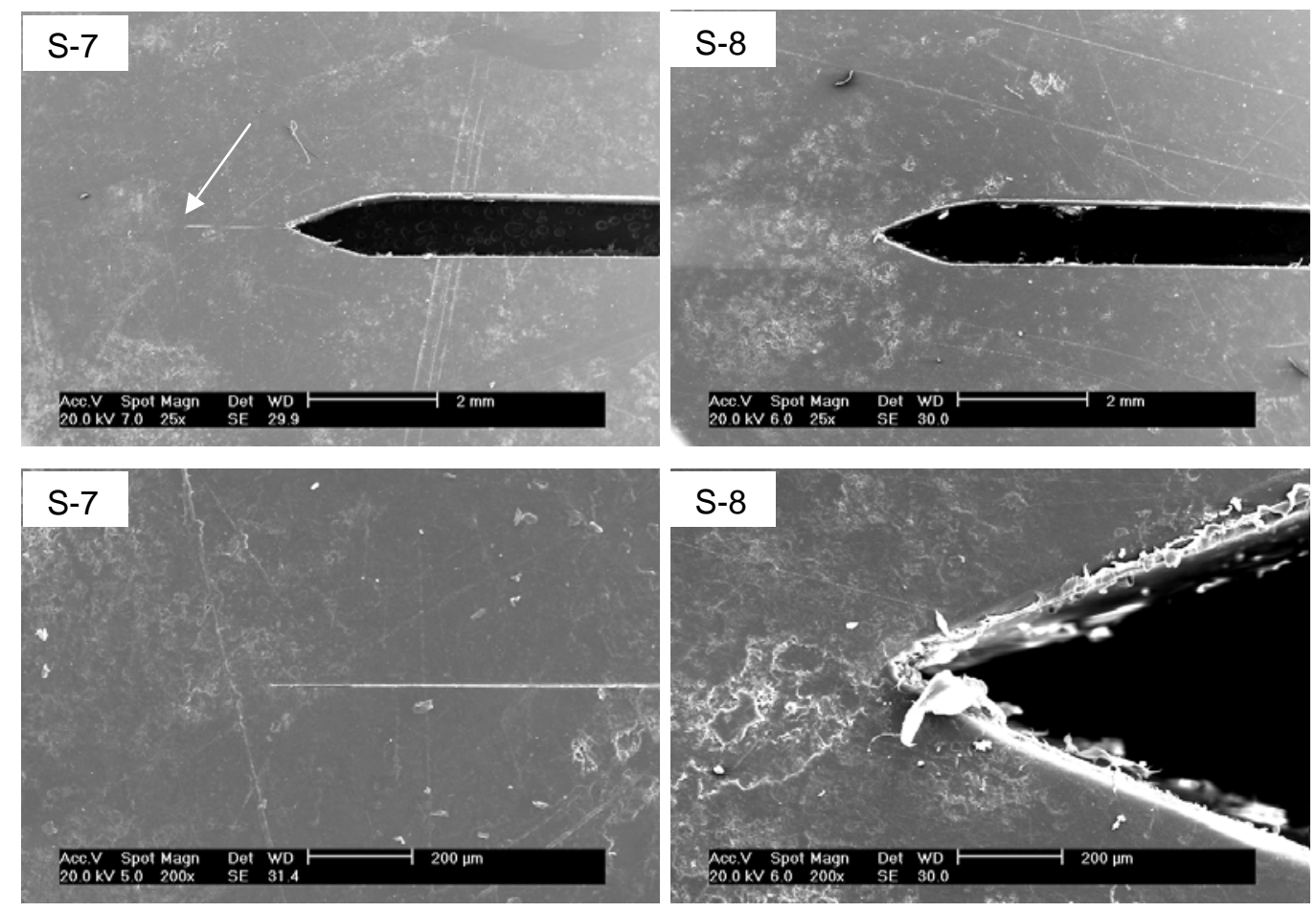

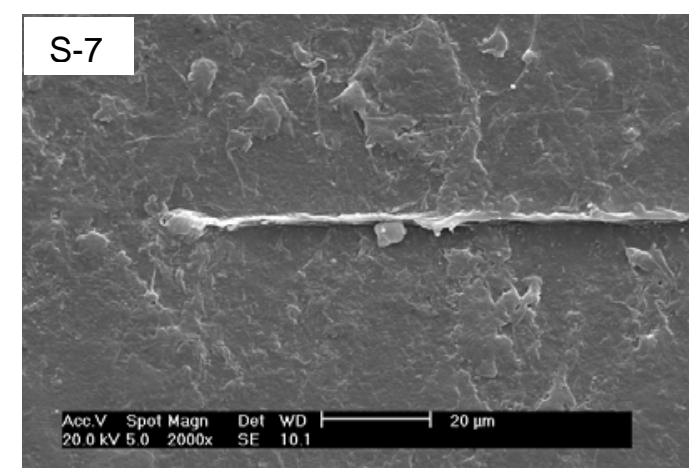

(a)

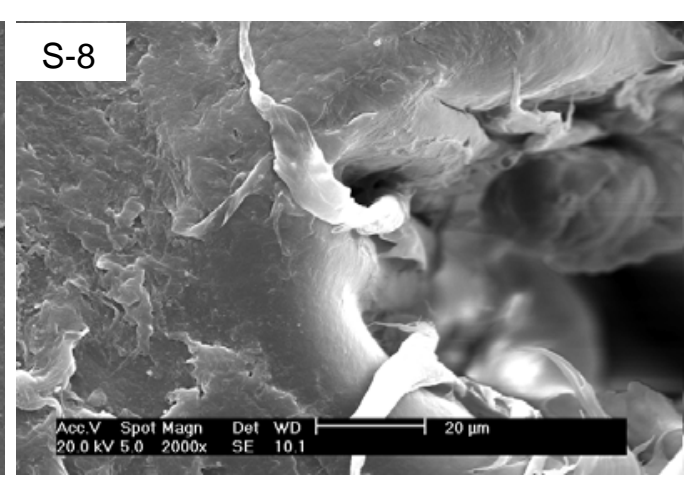

(b)

Figura 64: Região da ponta da pré-trinca em corpos de prova EWF com espessura de $3 \mathbf{m m}$. (a): pré-trinca introduzida por meio de pressionamento controlado de lâmina de barbear (S-7); (b): a ponta da pré-trinca é a própria ponta do entalhe (S-8). Ampliações de $25 \mathrm{X}$ (topo), 200X (centro) e 2.000X (baixo). Imagens obtidas em MEV; superfícies revestidas com ouro.

Pode-se observar na Figura 64 que a situação na ponta da pré-trinca introduzida por meio da lâmina de barbear é totalmente diferente da ponta do entalhe feito com disco de corte, tanto em termos geométricos como em termos das 
estruturas de deformação impostas na matriz do material pelas diferentes técnicas. Analisando-se as imagens das Figuras 62 a 64 verifica-se que pode haver importante diferença na deformação do material na região da ponta da pré-trinca de corpos de prova de EWF, dependendo da técnica e da ferramenta utilizada.

\subsection{RESULTADOS DOS ENSAIOS MECÂNICOS}

\subsubsection{ENSAIOS DE K}

A Figura 65 mostra uma típica curva carga x deslocamento obtida nos ensaios de $K_{l c}$ previamente congelados em nitrogênio líquido, onde se pode notar um comportamento predominantemente linear, após discreto desvio da linearidade no início do carregamento. O desvio inicial da linearidade foi observado em todos os corpos de prova, em maior ou menor extensão, entretanto, observou-se que a partir de determinado nível de carga a curva de carregamento é linear até a ruptura. Houve alguma variação de corpo de prova para corpo de prova no nível de carga da transição para o regime linear, mas verificou-se que a partir de $250 \mathrm{~N}$, aproximadamente, o comportamento das curvas de carregamento de todos os corpos de prova apresentaram comportamento linear.

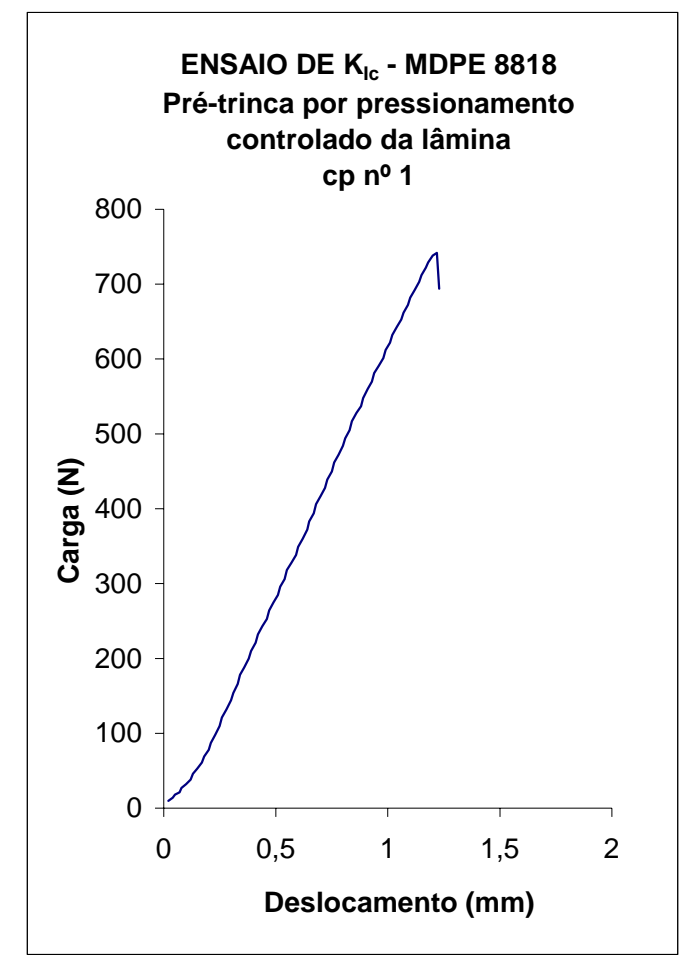

Figura 65: curva carga $x$ deslocamento em ensaio de $K_{l c}$ de um corpo de prova de MDPE 8818 sob condições criogênicas. 
As tabelas 4 e 5 apresentam os resultados individuais dos ensaios de tenacidade à fratura do composto MDPE 8818 (em condições criogênicas), com os dois métodos de introdução de pré-trincas adotados, bem como as dimensões de cada corpo de prova e os valores da média de $K_{l c}$ e do desvio padrão. Os cálculos foram realizados conforme a norma ASTM D 5045-99, sendo que as condições de validação dos ensaios foram satisfeitas. Considerando-se um valor estimado do limite de escoamento do material em baixas temperaturas (> $70 \mathrm{MPa}$ ), a partir de dados disponíveis na literatura (CHAN; WILLIAMS, 1983b) (BROOKS; DUCKETT; WARD, 1998), pode-se verificar que as dimensões principais dos corpos de prova obedecem ao critério de validação do regime da LEFM, conforme eq. (80), e que são satisfeitas as exigências geométricas para o estado plano de deformação, conforme eq. (3). Desta forma, de acordo com a norma, os valores de tenacidade à fratura obtidos podem ser tomados como $K_{l c}$ do material, sob condições criogênicas.

Tabela 4: Resultados dos ensaios de $\mathrm{K}_{\mathrm{lc}}$ - pré-trincas introduzidas através de "batidinhas" sobre a lâmina. Material: MDPE 8818

\begin{tabular}{ccccccccc}
\hline $\begin{array}{c}\text { Corpo } \\
\text { de prova }\end{array}$ & $\begin{array}{c}\mathrm{W} \\
(\mathrm{mm})\end{array}$ & $\begin{array}{c}\mathrm{B} \\
(\mathrm{mm})\end{array}$ & $\begin{array}{c}\mathrm{a} \\
(\mathrm{mm})\end{array}$ & $\begin{array}{c}\mathrm{P}_{\mathrm{Q}} \\
(\mathrm{N})\end{array}$ & $\begin{array}{c}\mathrm{K}_{\mathrm{Q}} \\
\left(\mathrm{MPa} \mathrm{m}^{1 / 2}\right)\end{array}$ & $\begin{array}{c}2,5\left(\mathrm{~K}_{\mathrm{Q}} / \sigma_{\mathrm{y}}\right)^{2} \\
(\mathrm{~mm})\end{array}$ & $\begin{array}{c}\mathrm{K}_{\mathrm{lc}} \text { - média } \\
\left(\mathrm{MPa} \mathrm{m}^{1 / 2}\right)\end{array}$ & $\begin{array}{c}\text { Desvio } \\
\text { padrão }\end{array}$ \\
\hline 1 & 28,4 & 14,1 & 15,48 & 811,5 & 4,19 & $<8,96$ & & \\
2 & 28,4 & 14,1 & 15,54 & 840,9 & 4,38 & $<9,79$ & & \\
3 & 28,5 & 14,0 & 15,50 & 806,6 & 4,21 & $<9,04$ & & \\
4 & 28,4 & 14,2 & 15,52 & 926,7 & 4,82 & $<11,85$ & & \\
5 & 28,5 & 14,1 & 15,55 & 711,0 & 3,68 & $<6,91$ & & \\
6 & 28,2 & 13,8 & 13,48 & 900,3 & 3,86 & $<7,60$ & & \\
7 & 28,0 & 13,9 & 13,67 & 886,5 & 3,91 & $<7,80$ & & \\
8 & 28,1 & 13,8 & 12,88 & $1.178,8$ & 4,77 & $<11,6$ & & \\
\hline
\end{tabular}

Tabela 5: Resultados dos ensaios de $\mathrm{K}_{\mathrm{lc}}$ - pré-trinca introduzidas pressionando-se lentamente a lâmina. Material: MDPE 8818

\begin{tabular}{ccccccccc}
\hline $\begin{array}{c}\text { Corpo } \\
\text { de prova }\end{array}$ & $\begin{array}{c}\mathrm{W} \\
(\mathrm{mm})\end{array}$ & $\begin{array}{c}\mathrm{B} \\
(\mathrm{mm})\end{array}$ & $\begin{array}{c}\mathrm{a} \\
(\mathrm{mm})\end{array}$ & $\begin{array}{c}\mathrm{P}_{\mathrm{Q}} \\
(\mathrm{N})\end{array}$ & $\begin{array}{c}\mathrm{K}_{\mathrm{Q}} \\
\left.(\mathrm{MPa} \mathrm{m})^{1 / 2}\right)\end{array}$ & $\begin{array}{c}2,5\left(\mathrm{~K}_{\mathrm{Q}} / \sigma_{\mathrm{y}}\right)^{2} \\
(\mathrm{~mm})\end{array}$ & $\begin{array}{c}\mathrm{K}_{\mathrm{lc}}-\text { média } \\
\left.(\mathrm{MPa} \mathrm{m})^{1 / 2}\right)\end{array}$ & $\begin{array}{c}\text { Desvio } \\
\text { padrão }\end{array}$ \\
\hline 1 & 28,5 & 14,0 & 15,73 & 711,0 & 3,80 & $<7,37$ & & \\
2 & 28,3 & 14,2 & 15,70 & 681,6 & 3,64 & $<6,76$ & & \\
3 & 28,3 & 14,1 & 15,80 & 630,1 & 3,44 & $<6,04$ & & \\
4 & 28,4 & 14,2 & 15,62 & 720,8 & 3,77 & $<7,25$ & & \\
5 & 28,3 & 14,0 & 15,18 & 764,9 & 3,88 & $<7,68$ & & \\
6 & 28,0 & 14,1 & 14,67 & 727,7 & 3,53 & $<6,36$ & & \\
7 & 27,9 & 14,1 & 14,31 & 846,3 & 3,99 & $<8,12$ & & \\
8 & 27,9 & 14,1 & 14,19 & 835,5 & 3,88 & $<7,68$ & & \\
\hline
\end{tabular}


Assumindo-se que os resultados de ensaios de $K_{l c}$ sejam normalmente distribuídos e independentes, a estatística $F$ de Snedecor (COSTA NETO, 1977) nos permite realizar um teste de igualdade das variâncias correspondentes aos dados das tabelas 4 e 5. Dessa forma, considerando-se o nível de significância de 5\%, não se pode rejeitar a hipótese de que as variâncias sejam iguais, uma vez que o valor da estatística-teste $\left(F_{\text {teste }}=4,66\right)$ é inferior ao valor da variável $F\left(F_{7,7 ; 2,5 \%}=4,99\right)$ para o teste bi-caudal, ou seja, está dentro da região de aceitação da hipótese nula (de que as variâncias são iguais). Posto de outra forma, não existem evidências suficientes de que as variâncias sejam diferentes, ao nível de significância de 5\%.

Com base no resultado do teste de hipótese anterior, podemos testar se os resultados das duas formas de introdução de pré-trincas adotadas, representados pelas médias das duas séries, são diferentes. Neste sentido, assume-se que não há variação no grau de dispersão dos resultados (as variâncias são iguais), que as populações são normalmente distribuídas e que estamos tratando dados nãoemparelhados (populações não-correlacionadas). Usaremos uma variância estimada com base em uma média das variâncias amostrais, ponderada pelos graus de liberdade de cada uma, e a estatística $t$ de Student (COSTA NETO, 1977), com 14 graus de liberdade. Dessa forma, considerando-se o nível de significância de 5\%, pode-se rejeitar a hipótese nula (de que as médias dos valores de $K_{l c}$ são iguais) porque o valor da estatística-teste $\left(t_{\text {treste }}=3,063\right.$ ) é maior que o valor da variável $t$ $\left(t_{14 ; 2,5}=2,145\right)$ para o teste bi-caudal, ou seja, está dentro da região de rejeição da hipótese nula (de que as médias são iguais). Pode-se assumir, então, que há evidências suficientes, ao nível de significância de $5 \%$, de que os valores de tenacidade à fratura no estado plano de deformação, obtidos quando a introdução das pré-trincas se dá por meio de "batidinhas" sobre uma lâmina de barbear, são superiores (cerca de 13\%) àqueles que são obtidos quando as pré-trincas são introduzidas por meio de pressionamento lento e controlado da lâmina.

Por outro lado, é razoável supor que os resultados obtidos a partir do pressionamento lento e controlado como método de introdução de pré-trincas sejam mais homogêneos que aqueles obtidos por meio de uma técnica manual, como a das "batidinhas". Essa suposição sugere a realização de um teste mono-caudal das variâncias e a verificação de eventuais reflexos na comparação das médias. Neste sentido, considerando-se o nível de significância de 5\%, pode-se rejeitar a hipótese de que as variâncias sejam iguais, uma vez que o valor da estatística-teste $\left(F_{\text {teste }}=\right.$ 
$4,66)$ é superior ao valor da variável $F\left(F_{7,7 ; 5 \%}=3,79\right)$ para o teste mono-caudal, ou seja, está dentro da região de rejeição da hipótese nula (de que as variâncias são iguais).

Com a nova conclusão da comparação das variâncias, para a comparação das médias dos valores de $K_{l c}$, deve-se assumir que os desvios-padrão das população são desconhecidos (só se dispõe dos valores das amostras) e que eles são supostamente diferentes. Como o número de dados é relativamente pequeno, e ainda que se considere que os dados tenham sido extraídos de populações normalmente distribuídas, deve-se recorrer a métodos aproximados, como o de Aspin-Welch (COSTA NETO, 1977) em que o número de graus de liberdade da estatística $t$ é convenientemente corrigido. Seguindo este método, a estatística-teste para a comparação das médias é superior ( $t_{\text {teste }}=3,067$ ) ao valor da variável $t$ corrigida $\left(t_{11 ; 2,5 \%}=2,201\right)$ para o teste bi-caudal, ou seja, está dentro da região de rejeição da hipótese nula (de que as médias são iguais). Novamente, há evidências suficientes, ao nível de significância de 5\%, de que as diferentes técnicas de introdução de pré-trincas adotadas conduzem a resultados diferentes.

Os resultados obtidos sustentam a suspeita de que diferentes métodos de introdução de pré-trinca produzem diferentes estruturas de deformação no material na região da ponta da trinca, conforme se pode observar na Figura 60, e que técnicas que produzem danos mais severos produzem valores mais elevados em ensaios de tenacidade à fratura de polietileno. Além disso, pode-se verificar que uma técnica mais controlada e refinada de introdução de pré-trincas, como o pressionamento lento de uma lâmina de barbear, promove a obtenção de resultados mais homogêneos. Essa verificação pode ser facilmente feita comparando-se os valores dos coeficientes de variação de Pearson ${ }^{4}$ correspondentes aos dados das tabelas 4 e 5 , respectivamente iguais a $9,7 \%$ e 5,0\%.

A Figura 66 apresenta imagens típicas das superfícies de fratura dos corpos de prova cujas pré-trincas foram introduzidas através de "batidinhas" (a) e através de pressionamento lento da lâmina (b). Nos dois casos, a maior extensão da superfície de fratura apresenta características típicas de fratura frágil. Entretanto, em todos os

\footnotetext{
${ }^{4}$ Coeficiente de variação de Pearson: uma medida da variabilidade dos dados em relação ao seu valor médio (razão entre o desvio padrão e a média referentes a dados de uma mesma série, expresso em termos percentuais) (MARTINS, 2002).
} 
corpos de prova observou-se uma pequena região próxima ao núcleo e imediatamente à frente da pré-trinca, com formato curvilíneo e características típicas de crescimento estável de um defeito, que pode ser uma trinca natural ou um craze - tomaremos como uma trinca. Esta região, cujo desenvolvimento é o provável responsável principal pelo desvio inicial da linearidade na curva de carregamento durante o ensaio mecânico, não se estende até a borda do corpo de prova. $\mathrm{Na}$ verdade, ela parece refletir uma acomodação inicial do material às diferenças de tenacidade entre o estado plano de tensão predominante na superfície e próxima desta e o estado plano de deformação no núcleo do corpo de prova. Desta forma, a tenacidade à fratura do material, genericamente designada por $K_{c}$, é vencida primeiramente na região do núcleo, onde seu valor é menor e supostamente corresponde ao valor da tenacidade à fratura no estado plano de deformação - $K_{l c}$, e a fratura começa a se propagar neste ponto. Entretanto, a propagação instável da fratura é contida pelo material adjacente, que se encontra em transição para o estado plano de tensão, sob o qual o valor da tenacidade à fratura é superior, e pela resistência das fibrilas de uma eventual zona de crazing nucleada no início do carregamento na região central do corpo de prova. Além de determinado ponto, a situação torna-se insustentável e a fratura catastrófica frágil ocorre.

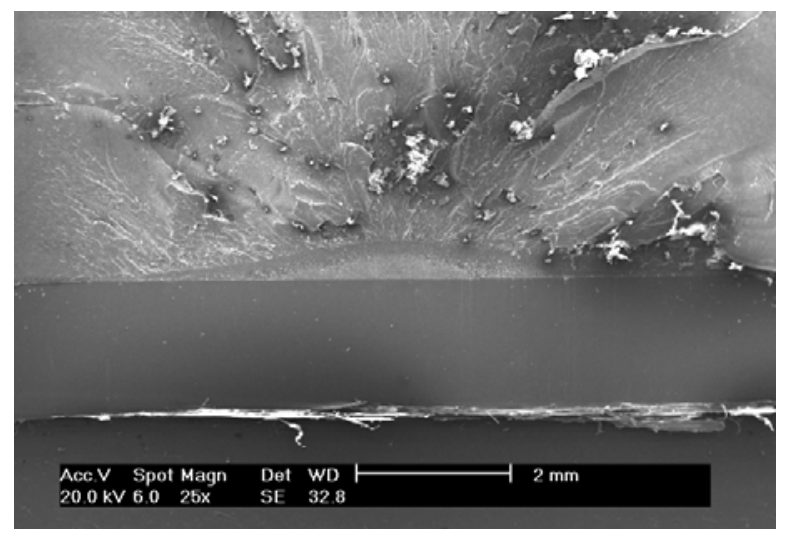

(a)

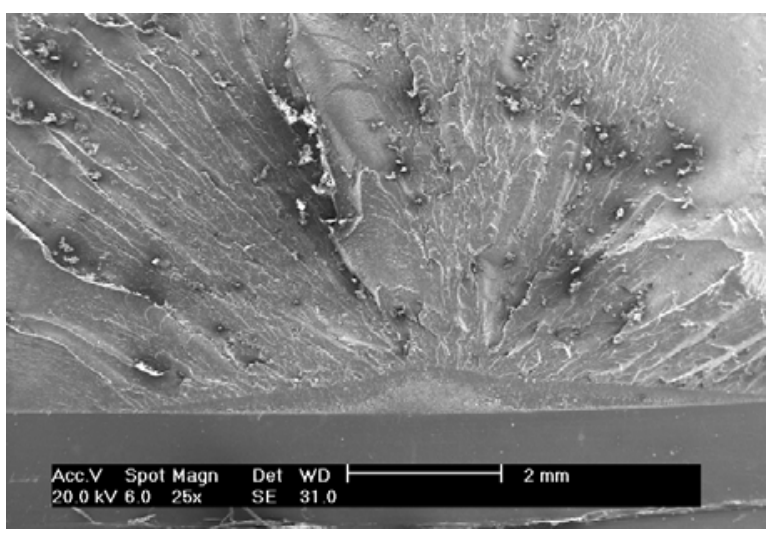

(b)

Figura 66: Superfícies de fratura de corpos de prova de ensaios de $K_{I c}$, sob condições criogênicas, com pré-trincas introduzidas por meio de (a) "batidinhas" e (b) por meio de pressionamento lento da lâmina. Imagens obtidas em microscópio eletrônico de varredura (elétrons secundários - superfícies revestidas com ouro).

A existência da pequena região de crescimento estável de trinca, além da qual a fratura é efetivamente frágil, incentiva a realização de um novo cálculo de $K_{/ c}$ dos ensaios realizados, considerando na medição da trinca inicial a frente de trinca 
que efetivamente antecede a fratura frágil. Nesse sentido, a trinca inicial foi tomada como a distância da borda do corpo de prova até a fronteira entre a região de crescimento estável (ou ponta da pré-trinca, caso não tenha ocorrido crescimento estável no ponto) e a região de propagação instável da trinca, e não somente a frente reta da pré-trinca introduzida por meio da lâmina. Para obtenção do comprimento da trinca inicial a ser utilizado nos cálculos, adotou-se arbitrariamente a sugestão da norma ASTM D 6068-96: mediu-se o comprimento da trinca inicial em cinco pontos eqüidistantes entre si, distribuídos ao longo da distância entre dois pontos situados a 0,005W (cinco milésimos da profundidade do corpo de prova) de cada borda lateral; a média dos dois valores mais próximos das bordas foi combinada com os valores das três medições restantes e a média dos quatro últimos valores foi tomada como o comprimento inicial da pré-trinca. Os resultados dos cálculos realizados conforme este procedimento, considerando-se apenas os cinco primeiros corpos de prova de cada série, são apresentados nas tabelas 6 e 7, nas quais os novos valores de tenacidade à fratura em estado plano de deformação são designados por $K_{I C \text {-SCG }}$.

Tabela 6: Resultados dos ensaios de $K_{I c-S C G}$ - pré-trincas introduzidas através de "batidinhas" sobre a lâmina. Material: MDPE 8818

\begin{tabular}{ccccccccc}
\hline $\begin{array}{c}\text { Corpo } \\
\text { de prova }\end{array}$ & $\begin{array}{c}\mathrm{W} \\
(\mathrm{mm})\end{array}$ & $\begin{array}{c}\mathrm{B} \\
(\mathrm{mm})\end{array}$ & $\begin{array}{c}\mathrm{a} \\
(\mathrm{mm})\end{array}$ & $\begin{array}{c}\mathrm{P}_{\mathrm{Q}} \\
(\mathrm{N})\end{array}$ & $\begin{array}{c}\mathrm{K}_{\mathrm{Q}} \\
\left(\mathrm{MPa} \mathrm{m}^{1 / 2}\right)\end{array}$ & $\begin{array}{c}2,5\left(\mathrm{~K}_{\mathrm{Q}} / \sigma_{\mathrm{y}}\right)^{2} \\
(\mathrm{~mm})\end{array}$ & $\begin{array}{c}\mathrm{K}_{\mathrm{lc}-\mathrm{ScG}}-\text { média } \\
\left(\mathrm{MPa} \mathrm{m}^{1 / 2}\right)\end{array}$ & $\begin{array}{c}\text { Desvio } \\
\text { padrão }\end{array}$ \\
\hline 1 & 28,4 & 14,1 & 15,64 & 811,5 & 4,28 & $<9,35$ & & \\
2 & 28,4 & 14,1 & 15,79 & 840,9 & 4,52 & $<10,42$ & & \\
3 & 28,5 & 14,0 & 15,71 & 806,6 & 4,32 & $<9,52$ & 4,36 & 0,43 \\
4 & 28,4 & 14,2 & 15,71 & 926,7 & 4,93 & $<12,40$ & & \\
5 & 28,5 & 14,1 & 15,71 & 711,0 & 3,75 & $<7,17$ & & \\
\hline
\end{tabular}

Tabela 7: Resultados dos ensaios de $K_{I c-s c G}$ - pré-trincas introduzidas pressionando-se lentamente a lâmina. Material: MDPE 8818

\begin{tabular}{ccccccccc}
\hline $\begin{array}{c}\text { Corpo } \\
\text { de prova }\end{array}$ & $\begin{array}{c}\mathrm{W} \\
(\mathrm{mm})\end{array}$ & $\begin{array}{c}\mathrm{B} \\
(\mathrm{mm})\end{array}$ & $\begin{array}{c}\mathrm{a} \\
(\mathrm{mm})\end{array}$ & $\begin{array}{c}\mathrm{P}_{\mathrm{Q}} \\
(\mathrm{N})\end{array}$ & $\begin{array}{c}\mathrm{K}_{\mathrm{Q}} \\
\left(\mathrm{MPa} \mathrm{m}^{1 / 2}\right)\end{array}$ & $\begin{array}{c}2,5\left(\mathrm{~K}_{\mathrm{Q}} / \sigma_{\mathrm{y}}\right)^{2} \\
(\mathrm{~mm})\end{array}$ & $\begin{array}{c}\mathrm{K}_{\mathrm{lc}-\mathrm{scG}}-\text { média } \\
\left.(\mathrm{MPa} \mathrm{m})^{1 / 2}\right)\end{array}$ & $\begin{array}{c}\text { Desvio } \\
\text { padrão }\end{array}$ \\
\hline 1 & 28,5 & 14,0 & 15,87 & 711,0 & 3,87 & $<7,63$ & & \\
2 & 28,3 & 14,2 & 15,94 & 681,6 & 3,75 & $<7,17$ & & \\
3 & 28,3 & 14,1 & 16,72 & 630,1 & 3,87 & $<7,62$ & 3,89 & 0,12 \\
4 & 28,4 & 14,2 & 15,83 & 720,8 & 3,87 & $<7,64$ & & \\
5 & 28,3 & 14,0 & 15,60 & 764,9 & 4,09 & $<8,53$ & & \\
\hline
\end{tabular}


Os valores de tenacidade à fratura apresentados nas tabelas 6 e 7, os quais também satisfazem aos critérios de validação da norma ASTM D 5045-99, são, respectivamente, $3 \%$ e $4 \%$ superiores àqueles apresentados nas tabelas 4 e 5 . A realização de um teste estatístico das médias resultará que não se pode rejeitar a hipótese nula ao nível de significância de 5\%. Entretanto, o teste é dispensável sob o argumento de que a única diferença nos cálculos está no comprimento da trinca inicial, enquanto se espera que um valor de a maior, ainda que apenas ligeiramente, leve a um valor maior de $K_{l c}$, mantidos os demais valores dimensionais e de carga. Portanto, as observações experimentais e os resultados obtidos neste trabalho indicam que, para o polietileno de média densidade estudado, nas condições de ensaio adotadas, a metodologia de obtenção de $K_{1 c}$ segundo a norma ASTM D 504599 pode proporcionar valores subestimados, embora discretamente.

A análise anterior enseja uma nova perspectiva do problema da introdução da pré-trinca, uma vez que a região de crescimento estável observada é decorrente de uma resposta natural do material e, portanto, introduz um defeito natural no corpo de prova. A Figura 67 mostra que a transição entre a frente do defeito natural, tomada como a frente da região de crescimento estável, e a superfície de fratura imediata é sensivelmente diferente (mais suave) do caso da frente da pré-trinca artificialmente introduzida com a lâmina. Dessa forma, resolveu-se investigar o efeito de uma técnica de introdução de pré-trinca que contemplasse a formação de um defeito natural como aquele provocado pela região de crescimento estável no início do carregamento do corpo de prova.

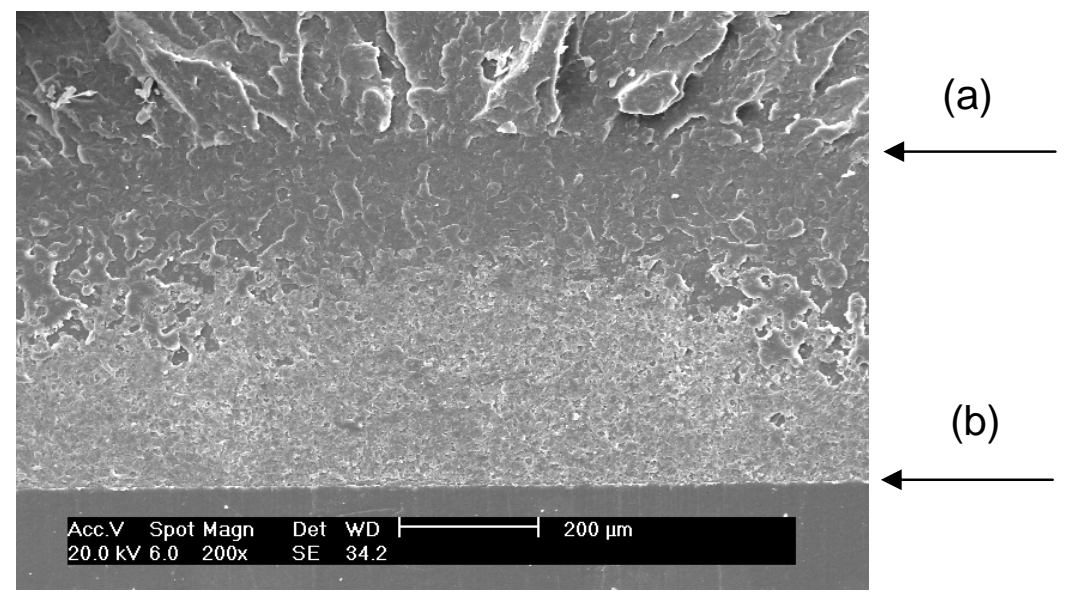

Figura 67: (a) Frente da região de crescimento estável de trinca, em ensaio de $K_{l c}$ sob condições criogênicas; (b) frente da pré-trinca introduzida por meio de pressionamento lento e controlado de uma lâmina de barbear (Material: MDPE 8818 - imagem obtida em MEV, com a superfície recoberta com ouro) 
Uma nova série de corpos de prova idênticos aos primeiros foi preparada, nos quais foram introduzidos os entalhes e pré-trincas, estas por meio de pressionamento lento e controlado, conforme procedimento já definido. A partir da análise das curvas de carregamento dos ensaios anteriores, verificou-se que a partir de $250 \mathrm{~N}$ a região não linear inicial estava terminada. Dessa forma, os novos corpos de prova foram imersos em nitrogênio líquido por um período entre 2 e 4 horas, retirados do banho e imediatamente submetidos a carregamento controlado, a 10 $\mathrm{mm} / \mathrm{min}$, até a carga máxima de $250 \mathrm{~N}$. Em seguida, os corpos de prova foram descarregados, novamente imersos em nitrogênio líquido e após 2 a 4 horas de imersão foram ensaiados. Este procedimento de carregamento e descarregamento controlado dos corpos de prova foi inspirado na norma ASTM E 1820-08 ${ }^{5}$. Em todos os corpos de prova observou-se a formação da região de crescimento estável de trinca, com formas muito semelhantes entre si. A extensão máxima de crescimento estável de trinca foi em média 0,64 mm, com desvio padrão de $0,05 \mathrm{~mm}$, o que proporciona uma idéia da reprodutibilidade da técnica. A tabela 8 apresenta os resultados dos ensaios, os quais satisfazem os critérios de validação da norma ASTM D 5045-99, enquanto que a Figura 68 ilustra uma curva de carregamento típica observada, predominantemente linear. O comprimento inicial da pré-trinca em cada corpo de prova foi obtido por meio do mesmo método da média envolvendo as medidas de cinco pontos.

Tabela 8: Resultados dos ensaios de $K_{I c-s c G}$ em que, após a introdução das pré-trincas por meio de pressionamento lento e controlado da lâmina, os corpos de prova sofreram carregamento e descarregamento para provocar o prévio crescimento estável da trinca. Material: MDPE 8818

\begin{tabular}{ccccccccc}
\hline $\begin{array}{c}\text { Corpo } \\
\text { de prova }\end{array}$ & $\begin{array}{c}\mathrm{W} \\
(\mathrm{mm})\end{array}$ & $\begin{array}{c}\mathrm{B} \\
(\mathrm{mm})\end{array}$ & $\begin{array}{c}\mathrm{a} \\
(\mathrm{mm})\end{array}$ & $\begin{array}{c}\mathrm{P}_{\mathrm{Q}} \\
(\mathrm{N})\end{array}$ & $\begin{array}{c}\mathrm{K}_{\mathrm{Q}} \\
\left(\mathrm{MPa} \mathrm{m}^{1 / 2}\right)\end{array}$ & $\begin{array}{c}2,5\left(\mathrm{~K}_{\mathrm{Q}} / \sigma_{\mathrm{y}}\right)^{2} \\
(\mathrm{~mm})\end{array}$ & $\begin{array}{c}\mathrm{K}_{\mathrm{Ic}-\mathrm{ScG}}-\text { média } \\
\left(\mathrm{MPa} \mathrm{m}^{1 / 2}\right)\end{array}$ & $\begin{array}{c}\text { Desvio } \\
\text { padrão }\end{array}$ \\
\hline 1 & 28,4 & 14,0 & 14,18 & 932,9 & 4,18 & $<8,91$ & & \\
2 & 28,4 & 14,2 & 14,19 & 1007,7 & 4,48 & $<10,24$ & & \\
3 & 28,3 & 14,0 & 14,19 & 893,7 & 4,07 & $<8,45$ & 4,29 & 0,22 \\
4 & 28,2 & 14,2 & 14,12 & 928,0 & 4,17 & $<8,87$ & & \\
5 & 28,3 & 14,1 & 14,21 & 1010,1 & 4,57 & $<10,66$ & & \\
\hline
\end{tabular}

\footnotetext{
${ }^{5}$ Vide: Note A5.1
} 


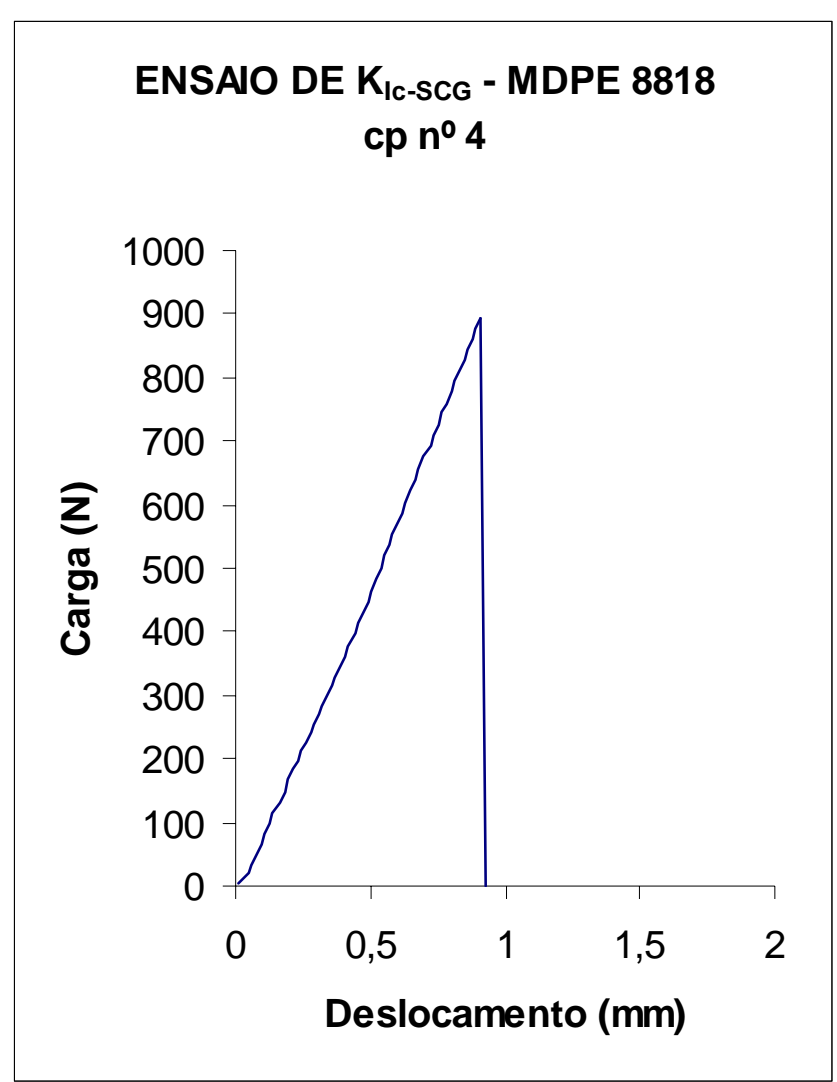

Figura 68: curva carga - deslocamento em ensaio de $K_{l c-s c G}$ de um corpo de prova de MDPE 8818 sob condições criogênicas. A pré-trinca foi introduzida por meio de pressionamento lento e controlado de uma lâmina de barbear, seguido de carregamento e subsequente descarregamento controlado, para provocar uma região de crescimento estável da trinca.

Comparando-se os resultados das tabelas 7 e 8 , verifica-se que os valores de

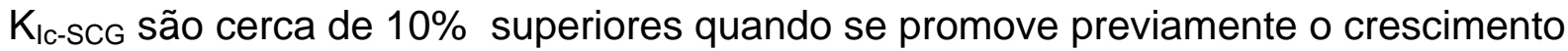
estável da trinca. De fato, assumindo-se que não há diferença nas variâncias, que as populações são normalmente distribuídos, que estamos tratando dados nãoemparelhados, e considerando-se o nível de significância de 5\%, pode-se rejeitar a hipótese nula (de que as médias dos valores de $K_{l c-S C G}$ são iguais) porque o valor da estatística-teste $\left(t_{\text {treste }}=3,57\right)$ é maior que o valor da variável $t\left(t_{8 ; 2,5}=2,306\right)$ para o teste bi-caudal, ou seja, está dentro da região de rejeição da hipótese nula (de que as médias são iguais). Pode-se assumir, então, que há evidências suficientes, ao nível de significância de 5\%, de que os valores de tenacidade à fratura no estado plano de deformação do polietileno sob condições criogênicas são mais elevados quando o método de ensaio envolve a reativação de um defeito previamente introduzido no corpo de prova, com características naturais, provocado pelo 
crescimento lento de uma trinca, tendo o corpo de prova sido descarregado após a formação do defeito.

O resultado mais elevado de tenacidade do material quando o corpo de prova é descarregado e posteriormente ensaiado vem do fato de determinados mecanismos viscoelásticos e de recomposição da região deformada atuarem na região da ponta da trinca. Os polímeros podem ser vistos como um tipo de "mola entrópica" (RODRIGUEZ, 1989; RUDIN, 1999), ou seja, quando deformados as macromoléculas que os compõem tendem a ser esticadas, com uma redução da entropia. Isto provoca o surgimento de forças de retração nos terminais das cadeias, de forma a restaurar a conformação mais estável, o que resulta em elasticidade do material. Por outro lado, mesmo em um corpo em temperatura inferior à temperatura de transição vítrea do polímero, certos fenômenos de difusão de segmentos de cadeia em uma interface polímero-polímero (como em uma trinca muito aguda, por exemplo) podem promover um tipo de "cura" (no sentido de reabilitação) natural e espontânea do material, aumentando a sua tenacidade (BOIKO; BACH; JØRGENSEN, 2004). O aprofundamento desta discussão foge ao escopo do presente estudo, mas propõe-se a sua continuidade em trabalhos futuros. Outra sugestão interessante é a de se introduzir entalhes laterais (side-grooves) e verificar como a região de crescimento estável evolui.

Em vista dos resultados obtidos e das análises realizadas, pode-se perceber que a interpretação dos ensaios de tenacidade à fratura em polietileno de média densidade pode ser bastante controversa. Em particular, sua utilidade depende da forma como um defeito é nucleado na prática operacional e do regime de carregamento do componente. Por outro lado, por razões de segurança, é geralmente mais conveniente adotar o valor mais crítico ou conservador da propriedade do material para efeito de projeto de componentes e análise de integridade estrutural. Nesse sentido, ensaios de $K_{/ c}$ conforme a norma ASTM 504599, em corpos de prova contendo pré-trincas introduzidas por meio de pressionamento lento e controlado de uma lâmina de barbear nova na raiz de um entalhe fornecem os valores mais baixos.

Como consideração final, o crescimento estável de trinca observado no início do carregamento em ensaios de $K_{l c}$ de PEMD sob condições criogênicas não deve ser ignorado. Este avanço não catastrófico da frente da trinca no material possui significado físico relevante e pode proporcionar a obtenção de valores diferentes de 
tenacidade à fratura do material, dependendo do valor do comprimento da trinca inicial adotado. Além disso, a extensão de pré-trincas por meio de crescimento estável sob carregamento controlado pode constituir uma nova técnica para a introdução de um defeito com características mais naturais em ensaios de mecânica da fratura. Esta sugestão desvia da orientação das principais normas e protocolos atualmente vigentes e precisa ser melhor avaliada.

\subsubsection{CURVAS J-R}

A construção da curva J-R pelo método dos corpos de prova múltiplos requer alguma experiência prévia. Detalhes importantes para a validação dos resultados, como a necessidade de entalhes laterais (side grooves) e o valor das deflexões aplicadas em cada corpo de prova só podem ser definidos com a prática.

Dessa forma, numa série preliminar de ensaios com a resina GM 5010 T2, três corpos de prova foram carregados a $10 \mathrm{~mm} / \mathrm{min}$ com diferentes deflexões, de forma a se verificar a adequação das dimensões e da geometria do corpo de prova e estimar os valores das deflexões nos ensaios principais.

A Figura 69 apresenta uma superfície de fratura típica dos ensaios preliminares, após o crescimento estável da trinca, seguido de resfriamento em nitrogênio líquido e ruptura final por impacto. Na parte superior da imagem pode-se observar que é bem definida a região de fratura frágil. Por outro lado, na superfície correspondente ao avanço estável da fratura a distinção dos diferentes mecanismos de deformação e de fratura é difícil. Em particular, o processo de fratura do polietileno de alta densidade está intimamente relacionado com o processo de crazing, à frente da trinca (DUAN \& WILLIAMS, 1998). Dessa forma, não é simples diferenciar a verdadeira ponta da trinca da ponta do craze e esta é uma questão delicada porque os cálculos de $\mathrm{J}$ dependem do valor do comprimento da trinca. Definiu-se neste trabalho que o avanço da trinca $(\Delta a)$ corresponde à distância entre a ponta da pré-trinca e a maior extensão da frente de dano no material em cada ponto medido, conforme adotado por Chan \& Williams (1983), ainda que esta seja presumivelmente a ponta do craze e não a ponta da trinca verdadeira.

Nota-se ainda na Figura 69 a acentuada curvatura da frente da trinca, fator que determinou a adoção dos entalhes laterais nas demais séries de ensaios. 


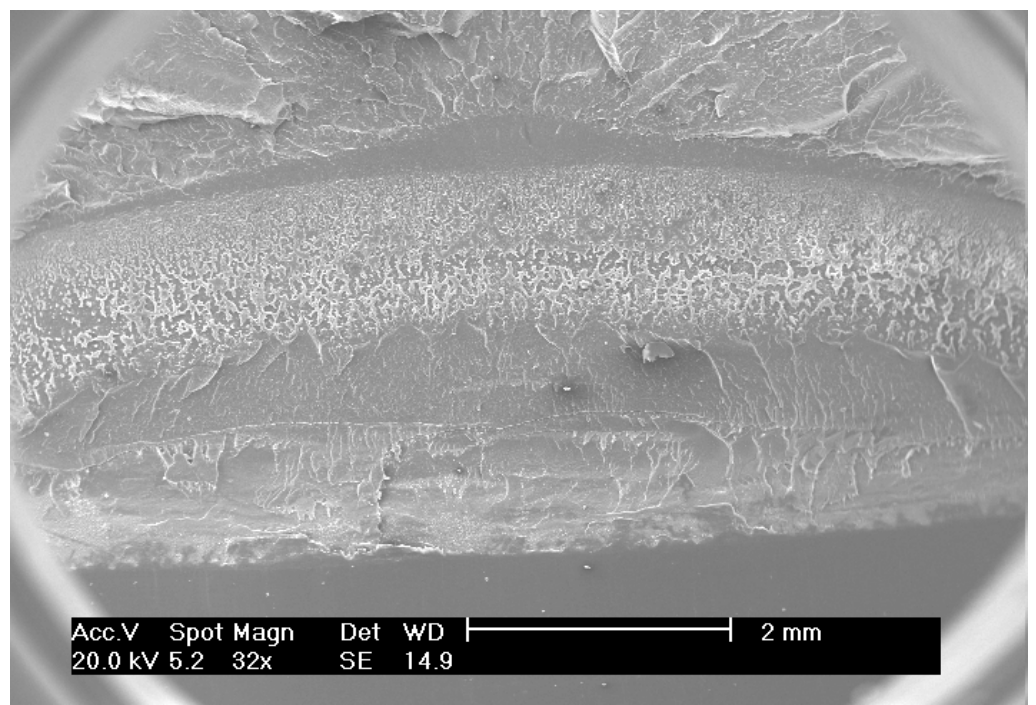

Figura 69: superfície de fratura, observada em microscópio eletrônico de varredura. Material: GM 5010T2.

A tabela 9 apresenta os resultados individuais da série preliminar de ensaios, com a resina GM 5010T2, bem como as dimensões importantes de cada corpo de prova. Os valores do avanço da trinca indicados, $\Delta a$, representam a média de cinco valores, distribuídos entre uma borda e outra do corpo de prova, conforme instrução da norma ASTM 6068-96. A Figura 70 é a representação gráfica dos pontos da tabela 9.

Tabela 9: Resultados da série preliminar de ensaios de J (material: GM 5010T2)

\begin{tabular}{ccccccccc}
\hline $\begin{array}{c}\text { Corpo } \\
\text { de prova }\end{array}$ & $\begin{array}{c}\mathrm{B} \\
(\mathrm{mm})\end{array}$ & $\begin{array}{c}\mathrm{W} \\
(\mathrm{mm})\end{array}$ & $\begin{array}{c}\mathrm{S} \\
(\mathrm{mm})\end{array}$ & $\begin{array}{c}\Delta \text { aplicado } \\
(\mathrm{mm})\end{array}$ & $\mathrm{U}(\mathrm{J})$ & $\begin{array}{c}\mathrm{a}_{0} \\
(\mathrm{~mm})\end{array}$ & $\begin{array}{c}\mathrm{J} \\
\left(\mathrm{KJ} / \mathrm{m}^{2}\right)\end{array}$ & $\begin{array}{c}\Delta \mathrm{a} \\
(\mathrm{mm})\end{array}$ \\
\hline 1 & 14,9 & 28,4 & 120 & 5,7 & 1,157 & 13,92 & 10,7 & 1,77 \\
2 & 15,1 & 29,2 & 120 & 6,6 & 2,120 & 17,49 & 24,0 & 2,66 \\
3 & 15,0 & 30,0 & 120 & 8,5 & 3,707 & 16,10 & 35,6 & 3,50 \\
\hline
\end{tabular}




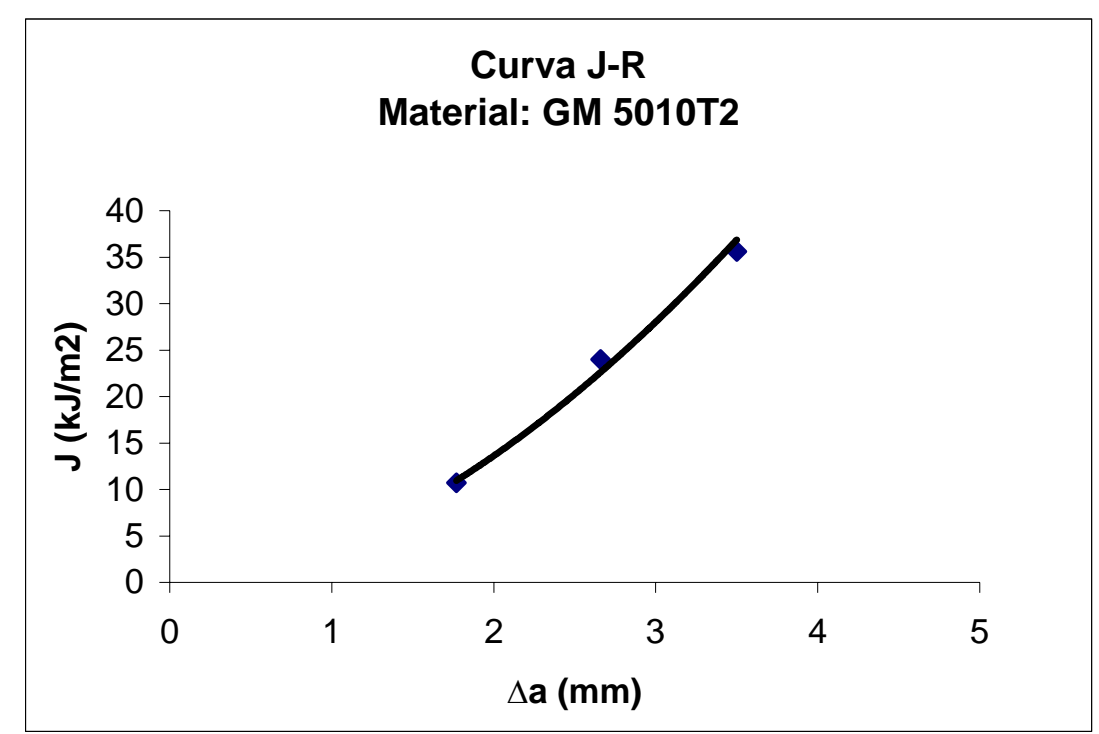

Figura 70: Curva J-R preliminar. Material: GM 5010T2

Os pontos da Figura 70 podem ser aproximados e pela seguinte relação de potência:

$$
J=4,0 \Delta a^{1,78} \quad\left(k J / m^{2}\right)
$$

para $\Delta a$ em milímetros.

De acordo com a norma ASTM D 6068-96 a máxima extensão de trinca admissível é $10 \%$ do comprimento do ligamento original $\left(W-a_{0}\right)$. Dessa forma os resultados da série preliminar de ensaios (tabela 9) prestaram-se unicamente para orientar as séries seguintes, para efeito de definição da deflexão aplicada.

Na Figura 71 são mostradas as imagens da região central das superfícies de fratura correspondentes aos ensaios da segunda série de ensaios de $\mathrm{J}$. 


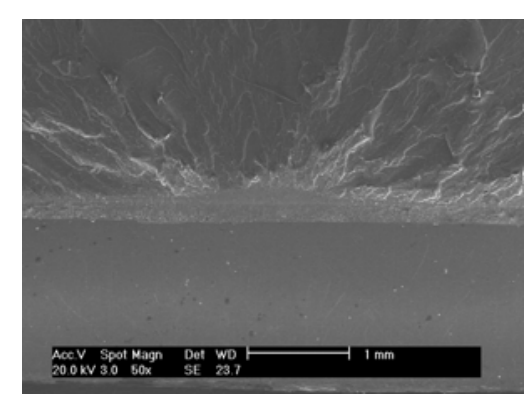

$\left(\mathrm{cp} \mathrm{n}^{\circ} 1\right)$

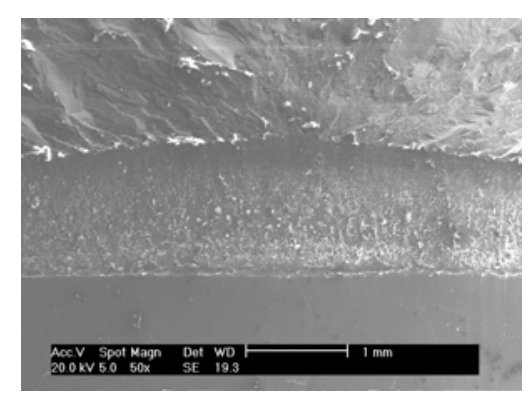

$\left(\mathrm{cp} \mathrm{n} \mathrm{n}^{\circ}\right)$

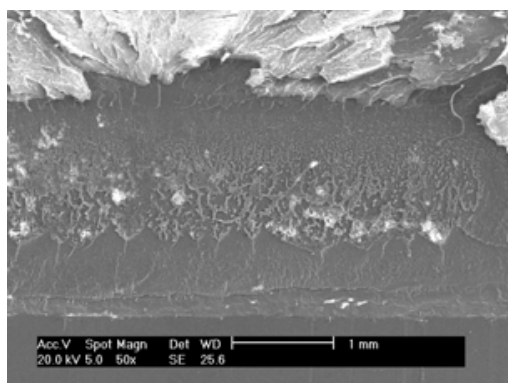

$\left(\mathrm{cp} \mathrm{n} \mathrm{n}^{07}\right)$

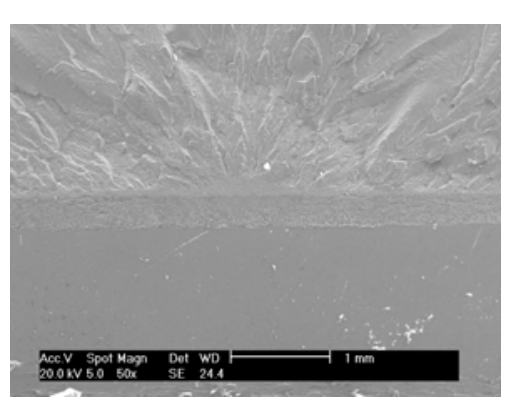

$(\mathrm{cp} \mathrm{n} 2)$

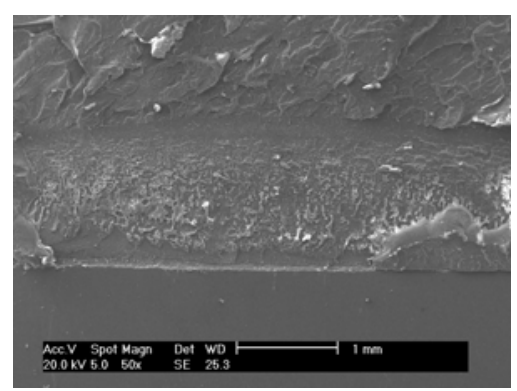

$\left(\mathrm{cp} \mathrm{n} \mathrm{n}^{0}\right)$

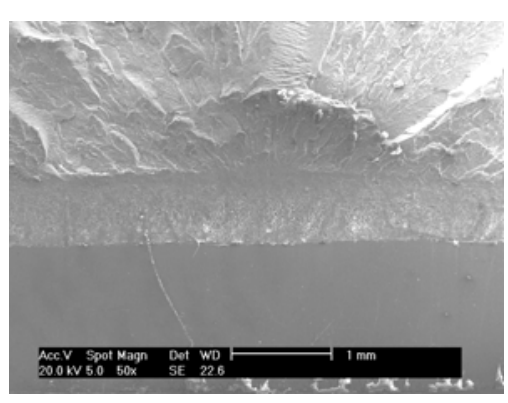

$\left(\mathrm{cp} \mathrm{n} \mathrm{n}^{\circ}\right)$

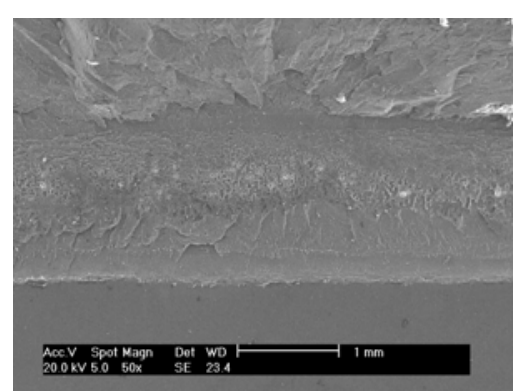

$\left(\mathrm{cp} \mathrm{n} \mathrm{n}^{\circ} 6\right)$

Figura 71: micrografias da região central das superfícies de fratura da $2^{\mathrm{a}}$ série de ensaios de $\mathrm{J}$. MEV, amostras revestidas com ouro. (Material: MDPE 8818).

Na maior parte dos casos foi difícil a interpretação das regiões da frente da trinca próximas às bordas do corpo de prova, prejudicando a leitura do avanço da trinca nestes pontos. Esta dificuldade pode ser verificada na Figura 72, onde são mostradas as extremidades da frente da trinca em um dos corpos de prova da série (сp $\mathrm{n}^{07}$ ), após o crescimento estável da trinca. Desta forma, os valores de $\Delta \mathrm{a}$ indicados representam a média dos valores lidos nas posições $B_{N} / 4, B_{N} / 2$ e $3 B_{N} / 4$ de cada corpo de prova, onde $B_{N}$ é a espessura final do corpo de prova (descontado o entalhe lateral). Ou seja, não foram consideradas as leituras próximas às bordas dos corpos de prova. 


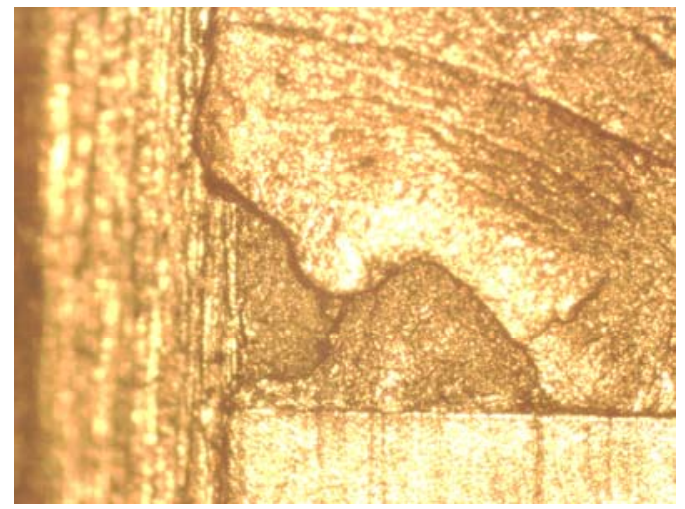

(a)

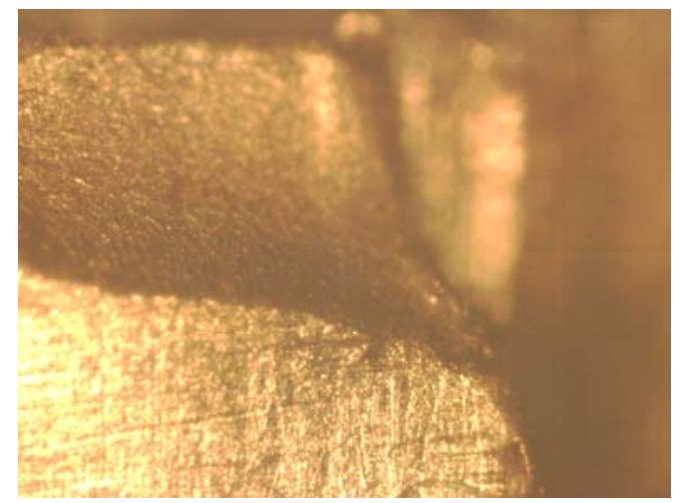

(b)

Figura 72: Regiões das extremidades esquerda (a) e direita (b) da frente da trinca, em corpo de prova de ensaio de J. Microscópio ótico em campo claro, amostras revestidas com ouro aumento 50x (Material: MDPE 8818).

$\mathrm{Na}$ tabela 10 estão apresentados, os resultados e as dimensões principais dos corpos de prova da segunda série de ensaios, com a resina MDPE 8818. Aplicando-se aos dados os critérios de validação estabelecidos na norma ASTM 6068-96, verifica-se que os corpos de prova $\mathrm{n}^{0} \mathrm{~s} 6$ e 7 não devem ser considerados porque os valores de $\Delta a$ ultrapassaram o limite de $10 \%(\approx 1,5 \mathrm{~mm})$ do ligamento original. Por outro lado, os pontos remanescentes apresentam-se corretamente posicionados nas faixas de espaçamento dos dados, conforme estabelecido na norma, faltando apenas um ponto na primeira faixa e um ponto na segunda. A Figura 73 é a representação gráfica dos pontos válidos da tabela 10.

Tabela 10: Resultados da segunda série de ensaios para construção da curva J-R (material: MDPE 8818)

\begin{tabular}{cccccccccc}
\hline $\begin{array}{c}\text { Corpo } \\
\text { de prova }\end{array}$ & $\begin{array}{c}\mathrm{B}_{\mathrm{N}} \\
(\mathrm{mm})\end{array}$ & $\begin{array}{c}\mathrm{W} \\
(\mathrm{mm})\end{array}$ & $\begin{array}{c}\mathrm{S} \\
(\mathrm{mm})\end{array}$ & $\begin{array}{c}\Delta \text { aplicado } \\
(\mathrm{mm})\end{array}$ & $\mathrm{U}(\mathrm{J})$ & $\begin{array}{c}\mathrm{a}_{0} \\
(\mathrm{~mm})\end{array}$ & $\begin{array}{c}\mathrm{J} \\
\left(\mathrm{kJ} / \mathrm{m}^{2}\right)\end{array}$ & $\begin{array}{c}\Delta \mathrm{a} \\
(\mathrm{mm})\end{array}$ \\
\hline 1 & 12,3 & 28,1 & 120 & 1,12 & 0,061 & 12,99 & 0,66 & 0,15 \\
2 & 12,7 & 28,0 & 120 & 1,51 & 0,128 & 13,48 & 1,39 & 0,31 \\
3 & 12,1 & 28,3 & 120 & 1,97 & 0,243 & 13,91 & 2,77 & 0,65 \\
4 & 13,01 & 28,0 & 120 & 2,65 & 0,446 & 13,65 & 4,78 & 1,06 \\
5 & 12,04 & 28,2 & 120 & 3,04 & 0,578 & 13,61 & 6,58 & 1,31 \\
6 & 12,05 & 28,1 & 120 & 3,43 & 0,730 & 13,70 & 8,41 & 1,56 \\
7 & 11,91 & 28,0 & 120 & 4,36 & 1,028 & 13,45 & 11,86 & 1,93 \\
\hline
\end{tabular}




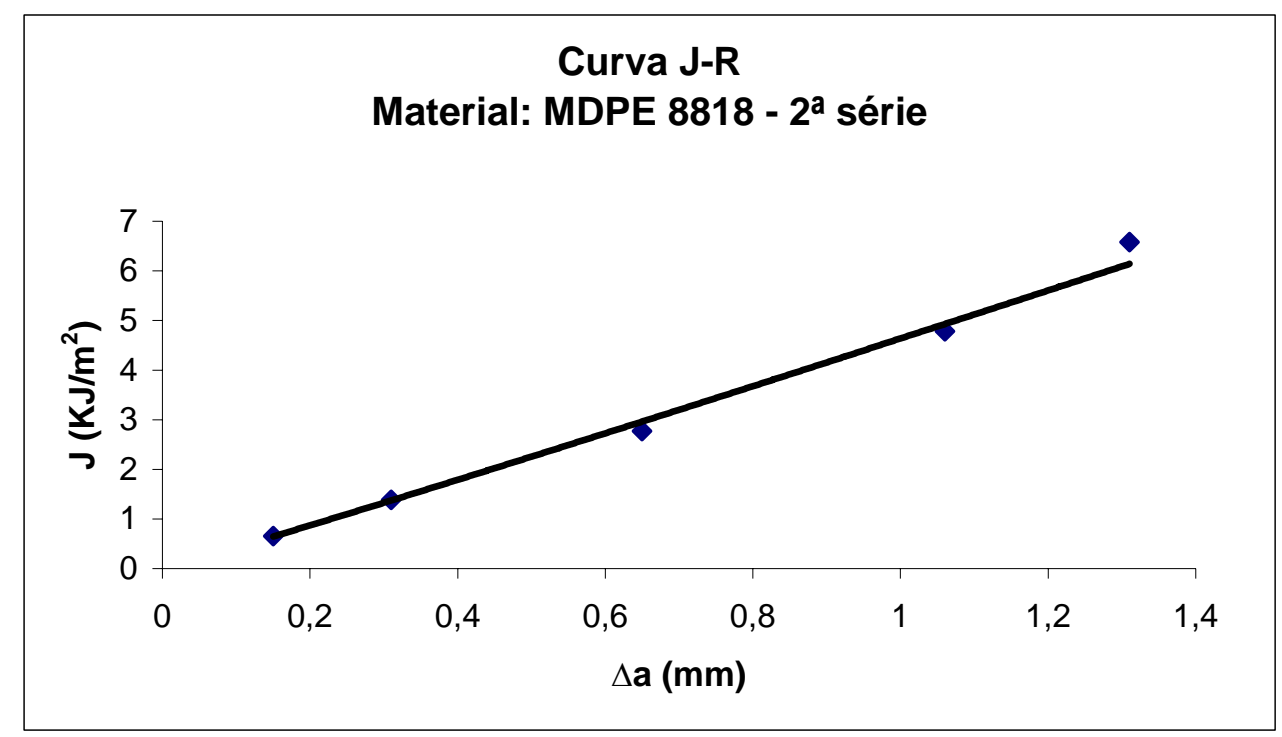

Figura 73: Curva J-R. Material: MDPE $8818-2^{\mathrm{a}}$ série

Os pontos da Figura 73 podem ser aproximados pela seguinte relação de potência:

$$
J=4,6 \Delta a^{1,04} \quad\left(k J / m^{2}\right)
$$

para $\Delta a$ em milímetros.

$\mathrm{Na}$ tabela 11 estão apresentados, os resultados e as dimensões principais dos corpos de prova da terceira série de ensaios, com a resina MDPE 8818. Como na segunda série, na maior parte dos casos foi difícil a interpretação das regiões da frente da trinca próximas às bordas do copo de prova, prejudicando a leitura do avanço da trinca nestes pontos. Desta forma, os valores de $\Delta a$ indicados representam novamente a média dos valores lidos nas posições $B_{N} / 4, B_{N} / 2$ e $3 B_{N} / 4$ de cada corpo de prova, ou seja, não foram consideradas as leituras próximas às bordas dos corpos de prova. Aplicando-se aos dados os critérios de validação estabelecidos na norma ASTM 6068-96, verifica-se que nenhum corpo de prova apresentou avanço de trinca superior a $10 \%(\approx 1,2 \mathrm{~mm})$ do ligamento original. Os pontos apresentam-se aproximadamente distribuídos nas faixas de espaçamento dos dados, conforme a norma ASTM D 6068-96, sendo que um ponto ficou ligeiramente deslocado da primeira para a segunda faixa e um ponto da quarta para a terceira. A Figura 74 é a representação gráfica dos pontos válidos da tabela 11, 
enquanto que na Figura 75 são mostradas as imagens da região central das superfícies de fratura dos corpos de prova correspondentes.

Tabela 11: Resultados da terceira série de ensaios para construção da curva J-R (material: MDPE 8818)

\begin{tabular}{ccccccccc}
\hline $\begin{array}{c}\text { Corpo } \\
\text { de prova }\end{array}$ & $\begin{array}{c}\mathrm{B}_{\mathrm{N}} \\
(\mathrm{mm})\end{array}$ & $\begin{array}{c}\mathrm{W} \\
(\mathrm{mm})\end{array}$ & $\begin{array}{c}\mathrm{S} \\
(\mathrm{mm})\end{array}$ & $\begin{array}{c}\Delta \text { aplicado } \\
(\mathrm{mm})\end{array}$ & $\mathrm{U}(\mathrm{J})$ & $\begin{array}{c}\mathrm{a}_{0} \\
(\mathrm{~mm})\end{array}$ & $\begin{array}{c}\mathrm{J} \\
\left(\mathrm{kJ} / \mathrm{m}^{2}\right)\end{array}$ & $\begin{array}{c}\Delta \mathrm{a} \\
(\mathrm{mm})\end{array}$ \\
\hline 1 & 13,1 & 27,9 & 112 & 0,90 & 0,027 & 15,32 & 0,33 & 0,13 \\
2 & 12,0 & 27,9 & 112 & 1,20 & 0,063 & 15,60 & 0,85 & 0,23 \\
3 & 13,0 & 27,8 & 112 & 1,50 & 0,094 & 15,61 & 1,19 & 0,35 \\
4 & 12,1 & 27,8 & 112 & 1,50 & 0,115 & 15,58 & 1,56 & 0,43 \\
5 & 12,6 & 27,9 & 112 & 1,70 & 0,125 & 15,99 & 1,67 & 0,43 \\
6 & 12,8 & 27,9 & 112 & 1,90 & 0,157 & 16,00 & 2,06 & 0,51 \\
7 & 12,1 & 27,8 & 112 & 2,20 & 0,240 & 15,23 & 3,16 & 0,74 \\
8 & 12,1 & 27,9 & 112 & 2,50 & 0,311 & 15,27 & 4,08 & 0,89 \\
\hline
\end{tabular}

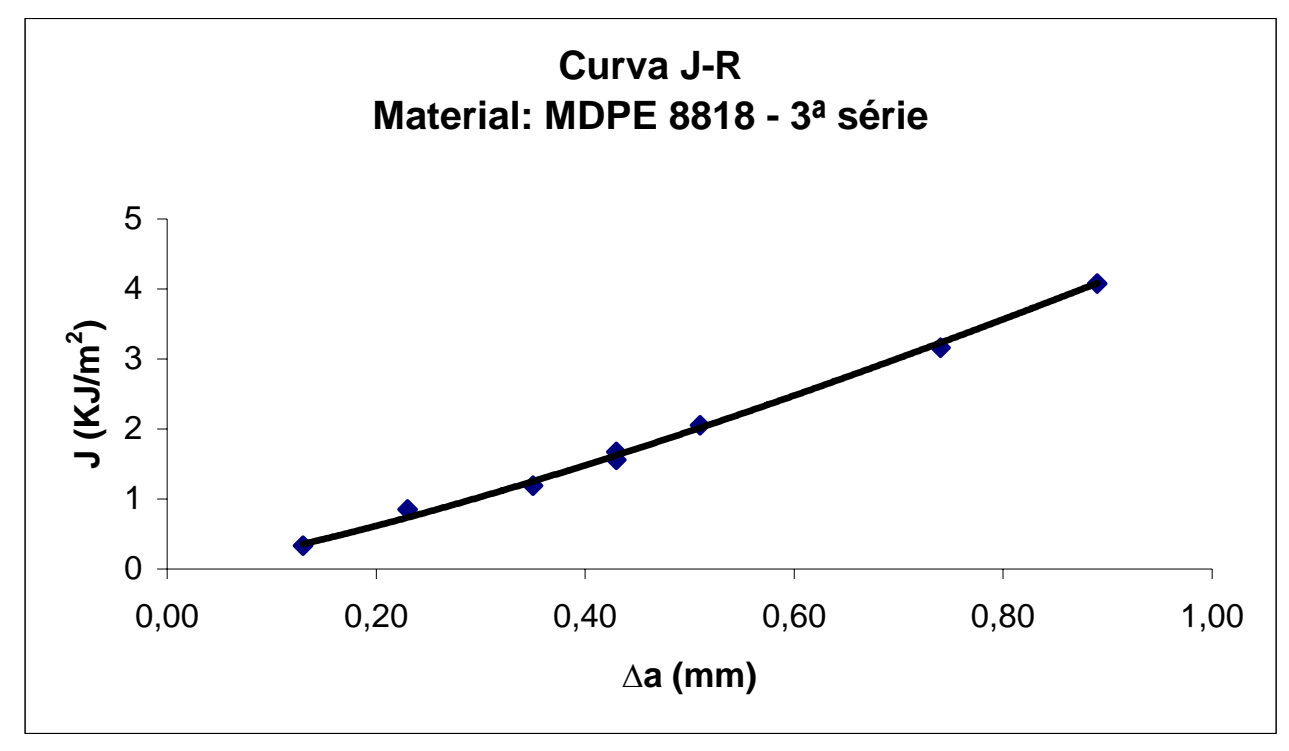

Figura 74: Curva J-R. Material: MDPE 8818 - $3^{\mathrm{a}}$ série

Os pontos da Figura 74 podem ser aproximados pela seguinte relação de potência:

$$
J=4,7 \Delta a^{1,27} \quad\left(k J / m^{2}\right)
$$

para $\Delta a$ em milímetros. 


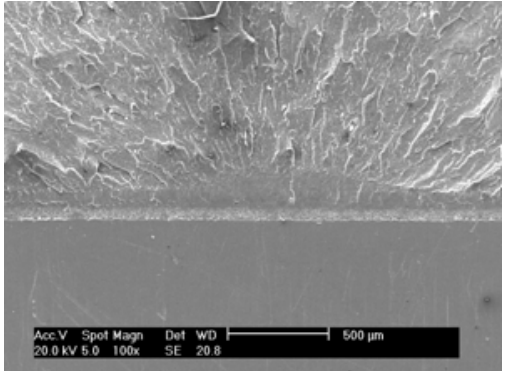

$\left(\mathrm{cp} \mathrm{n}^{0} 1\right)$

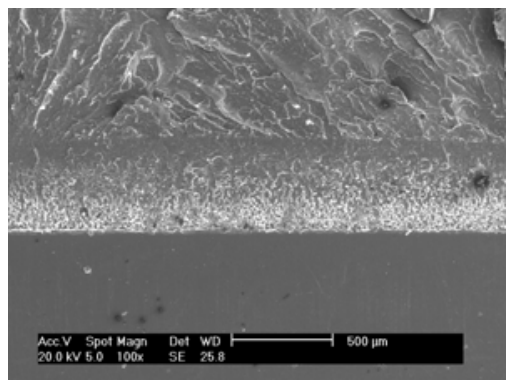

$\left(\mathrm{cp} \mathrm{n} \mathrm{n}^{\circ}\right)$

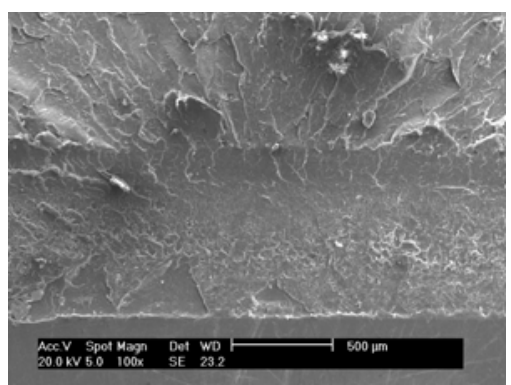

$\left(\mathrm{cp} \mathrm{n}^{07}\right)$

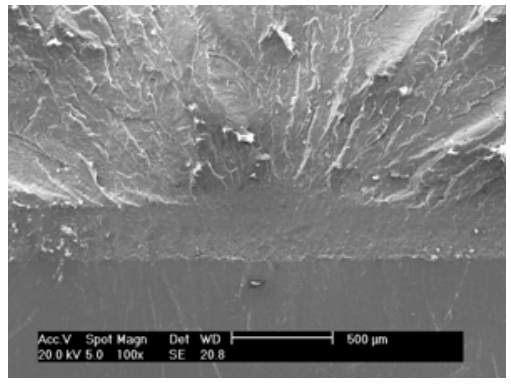

$\left(\mathrm{cp} \mathrm{n}^{0} 2\right)$

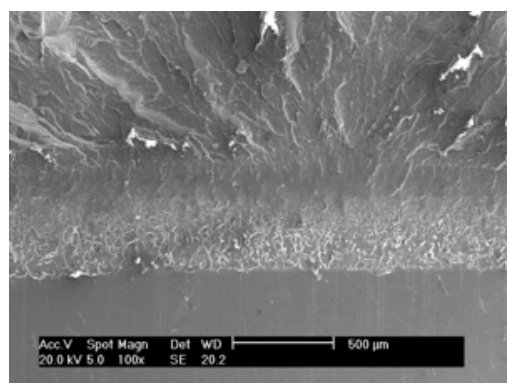

$\left(\mathrm{cp} \mathrm{n} \mathrm{n}^{0}\right)$

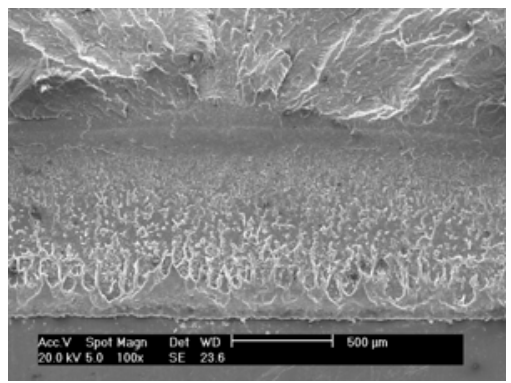

(cp n०8)

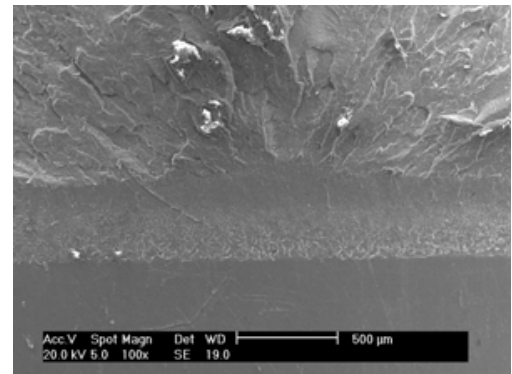

$(\mathrm{cp} \mathrm{n} 03)$

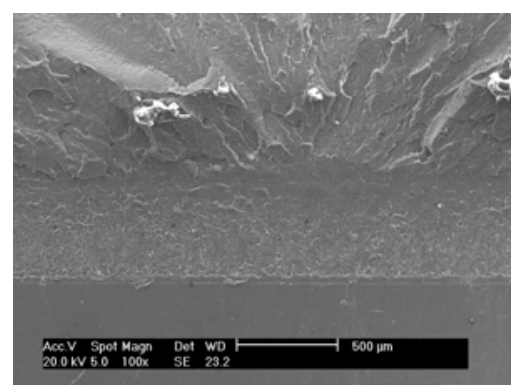

$\left(\mathrm{cp} \mathrm{n}^{\circ} 6\right)$

Figura 75: micrografias da região central das superfícies de fratura da $3^{\mathrm{a}}$ série de ensaios de $\mathrm{J}$. MEV, amostras revestidas com ouro. (Material: MDPE 8818).

Nas três séries de ensaios observa-se que o expoente das relações de potência que melhor aproximam os dados - equações (130), (131) e (132) - é maior do que 1, o que contraria a exigência da norma ASTM 6068-96 e o comportamento previsto na literatura (HALE e RAMSTEINER, 2001). É possível que a causa deste desvio esteja na interpretação da superfície de fratura, particularmente na medição da ponta da trinca verdadeira. A Figura 76 apresenta detalhadamente a região de crescimento estável de trinca na superfície de fratura de um corpo de prova da terceira série de ensaios ( $c p n^{0} 6$ ), onde se notam os tocos de fibrilas deixados no rastro da fratura em propagação. 


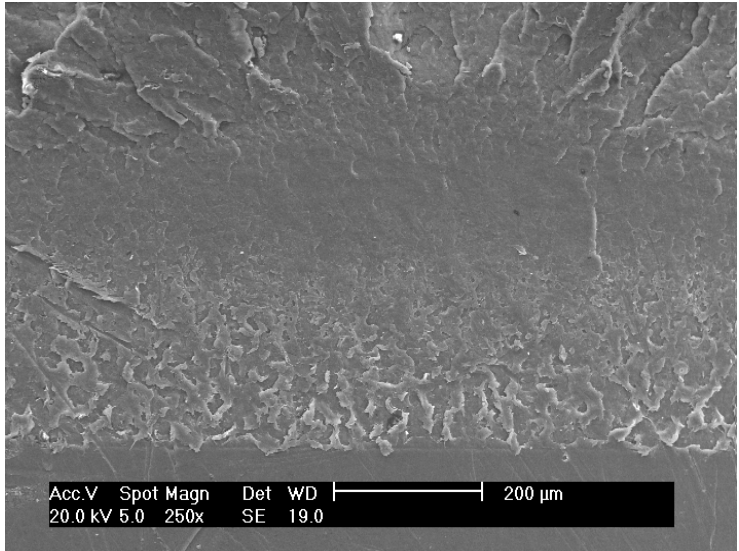

(a)

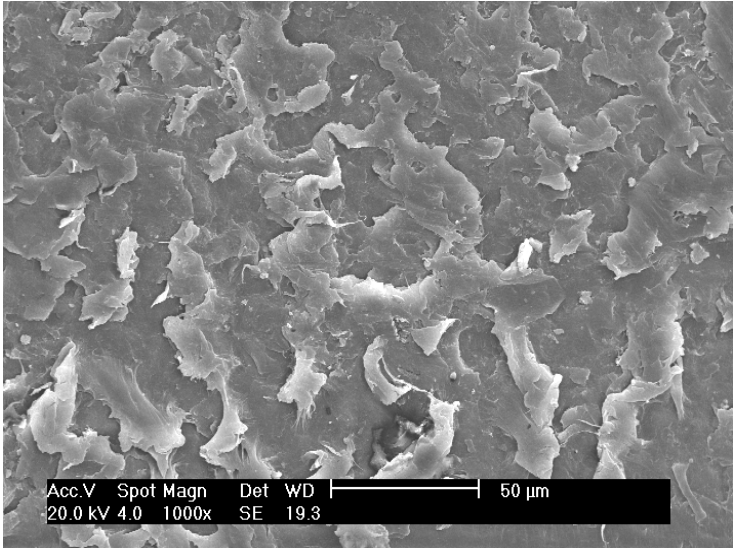

(b)

Figura 76: (a) superfície de fratura de corpo de prova de ensaio de J, após crescimento estável de trinca e resfriamento em nitrogênio líquido seguido de ruptura por impacto; (b) detalhe da região de crescimento estável da trinca.

É provável que a existência de crazing na zona de processo do polietileno (vide Figuras 4 e 5), além da própria natureza viscoelástica do material, viole importantes considerações do método da Integral-J, como o princípio da conservação de energia, uma vez que na zona de crazing há consideráveis termos de energia envolvidos na deformação das fibrilas e na formação dos microvazios, e a assunção de que as condições de plasticidade na ponta da trinca se ajustam razoavelmente à suposição de carregamento proporcional (afinal, há uma infinidade de vazios na região). Desta forma, pode ser que a aplicação do conceito de integral $\mathrm{J}$ a polímeros cujo comportamento em fratura seja semelhante ao PEMD necessite ser revisto, sugerindo-se este estudo em trabalhos futuros. Importantes autores, como J.G.Williams, também tem considerado que o método da Integral-J não se aplica muito bem ao polietileno ${ }^{6}$.

\subsubsection{TRABALHO ESSENCIAL DE FRATURA}

A Figura 77 mostra a curva carga-deslocamento, sob tração, de um corpo de prova com espessura nominal de 0,2 $\mathrm{mm}$ e comprimento do ligamento de $12 \mathrm{~mm}$. $\mathrm{O}$ comportamento da curva é típico dos materiais estudados neste trabalho e servirá como exemplo para ilustrar alguns pontos notáveis nos ensaios de EWF do

\footnotetext{
${ }^{6}$ Opinião fornecida pessoalmente ao Prof. Dr. C.G.Schön, durante o ECF-17, realizado em Brno, República Tcheca, 2008.
} 
composto Rigidex PC 002-50R968. Neste exemplo a pré-trinca foi produzida com uma lâmina de barbear nova, em corte reto. A partir do início do carregamento (a) a carga aplicada aumenta até atingir um máximo em (b). Neste ponto inicia-se o escoamento do material, formando-se uma região esbranquiçada nas pontas das pré-trincas. O escoamento do material se propaga através do ligamento do corpo de prova (c) até que as zonas de deformação em expansão se encontram no ponto (d). Inicia-se então o rasgamento na linha central do ligamento totalmente deformado, o qual evolui (e) até a ruptura final (f). Pôde-se verificar visualmente que em todos os ensaios realizados ocorreu o escoamento total do ligamento antes do rasgamento ou propagação da fratura, o que é uma exigência para aplicação do método.

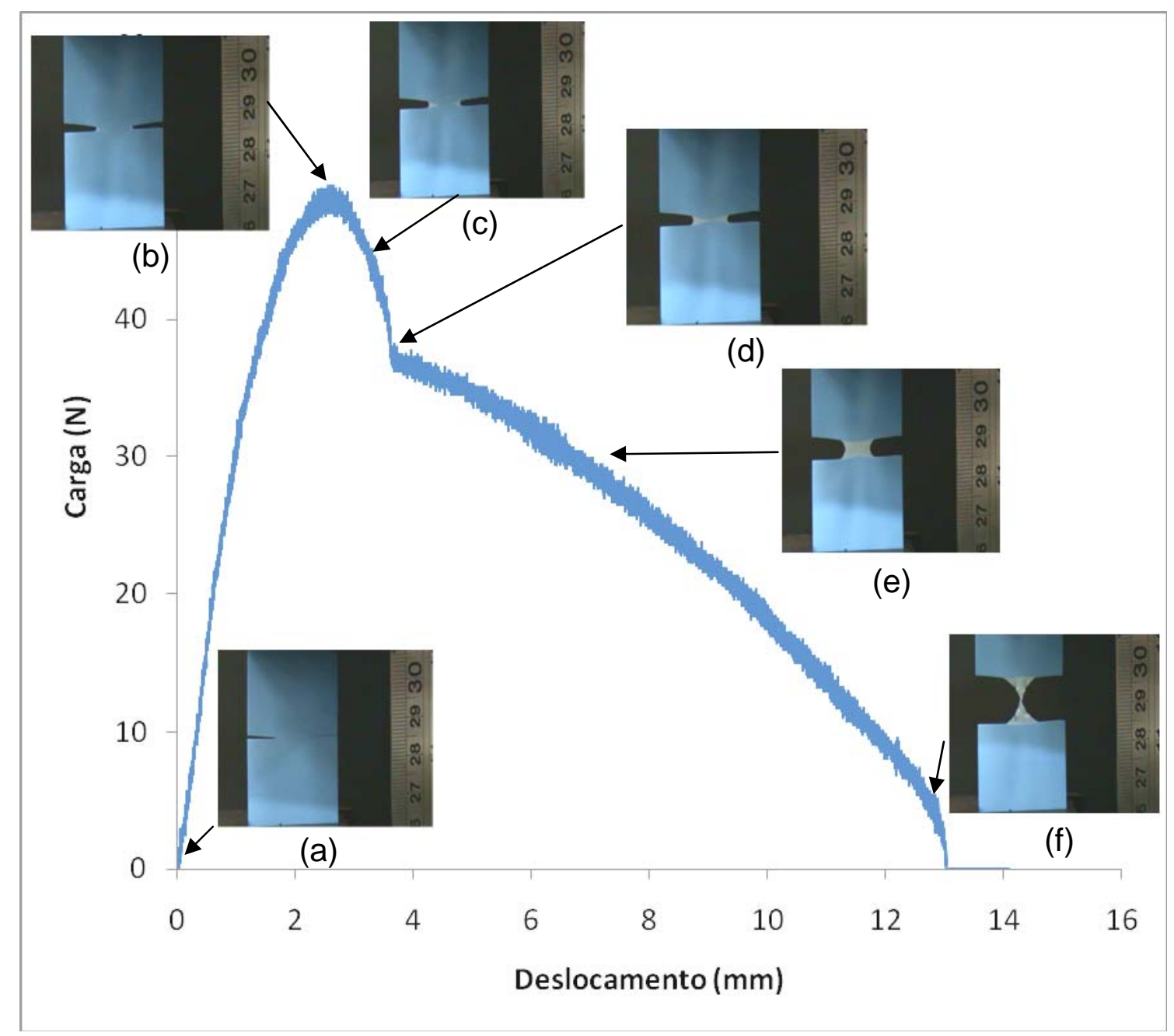

Figura 77: curva carga x deslocamento em ensaio típico de EWF do composto Rigidex PC $002-$ 50R968. Espessura do cp: 0,2 $\mathrm{mm}$; comprimento do ligamento: $12 \mathrm{~mm}$; pré-trinca introduzida por corte reto com lâmina de barbear 
A ruptura final do ligamento ocorre praticamente por colapso plástico, quando a seção resistente reduz-se a um ponto. A Figura 78 mostra imagens da região da ruptura de um corpo de prova em ensaio de EWF, tomadas em microscópio eletrônico de varredura, sendo que zona apontada em (a) é a região de fronteira entre o material deformado (esbranquiçado) e a matriz do material.

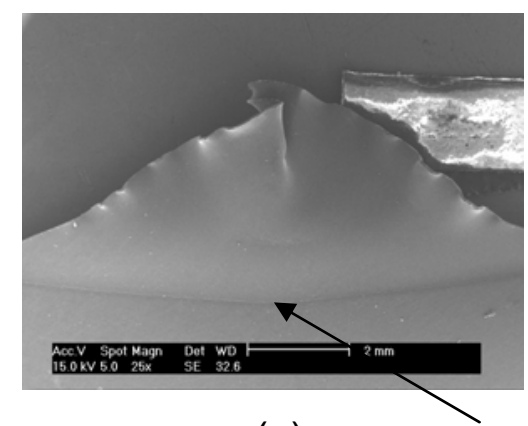

(a)

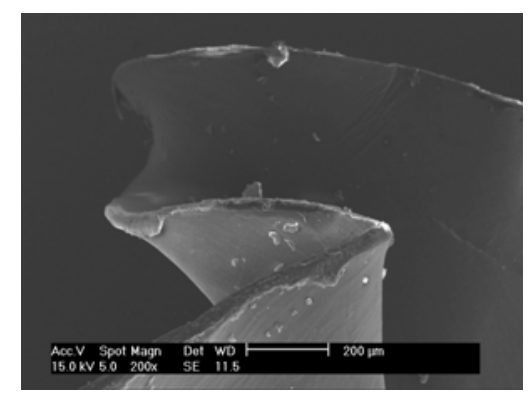

(b)

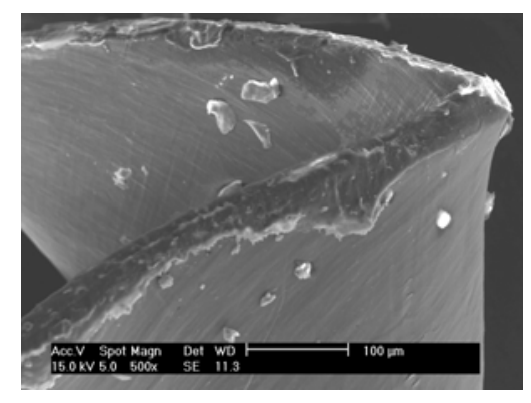

(c)

Figura 78: Região da fratura de um corpo de prova em ensaio de EWF. Material: Rigidex PC 002-50R968. (a) 25x; (b) 200x; (c) 500x. MEV, amostras recobertas com ouro.

O esbranquiçamento sob tensão de tração (stress-whitening) é um fenômeno que ocorre em muitos polímeros parcialmente cristalinos, como o MDPE, após o limite de escoamento do material ser atingido. Os autores geralmente atribuem a sua ocorrência à alteração do índice de refração local do meio, em decorrência da formação de microtrincas, crazes ou microvazios (OGORKIEWICZ, 1974; PROGELHOF; THRONE, 1993; PAE et al, 2000). A Figura 79 mostra ampliações da zona de fronteira entre a zona esbranquiçada e a matriz, apontada na Figura 78a, onde não se nota a presença de crazes ou trincas, pelo menos até 500X.

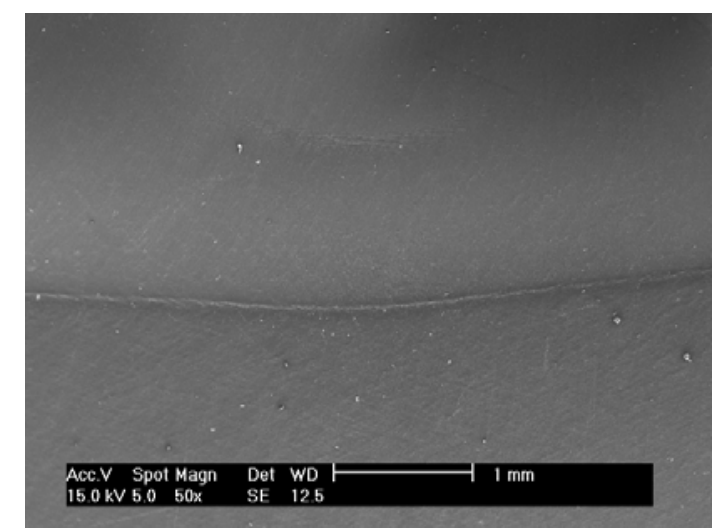

(a)

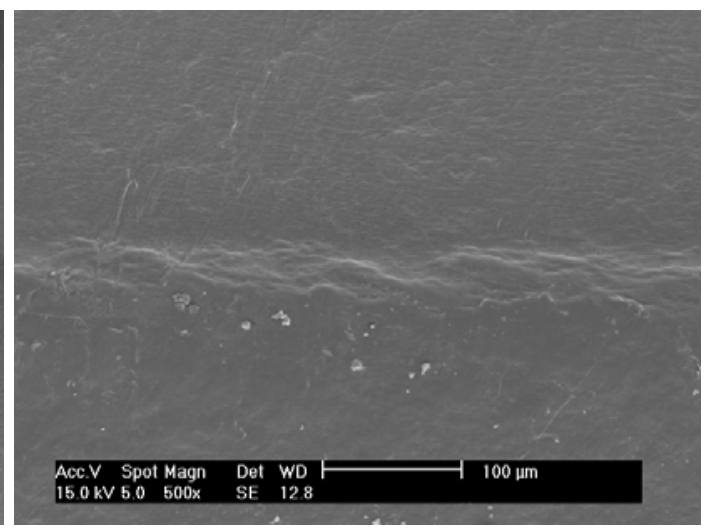

(b)

Figura 79: Região de fronteira entre a região plasticamente deformada e a matriz do material (vide Figura 78(a)), observada com aumentos de (a) 50X e (b) 500X. Material: Rigidex PC 00250R968. MEV, amostras recobertas com ouro. 
Embora possa ser útil para efeito de delimitação da zona plástica em corpos de prova de pequena espessura do material estudado, uma discussão mais aprofundada do fenômeno de esbranquiçamento foge ao escopo do presente trabalho.

As Figuras 80 a 84 apresentam, para cada série, uma família de curvas de ensaios de EWF com uma representante de cada classe de ligamento. Os gráficos estão dispostos aos pares para facilitar a comparação entre as séries, levando-se em conta pelo menos uma das classificações, com exceção da série S-0, cujos resultados foram aproveitados de um trabalho anterior do autor. Assim, na Figura 80 é possível comparar as curvas correspondentes às pré-trincas introduzidas por lâmina de barbear (a) com aquelas por estilete (b), em corte reto, na espessura nominal de $0,2 \mathrm{~mm}$, com ligamento orientado perpendicularmente à direção principal de extrusão. Na Figura 81 a diferença em relação à anterior é que a orientação do ligamento é paralela à direção principal de extrusão do filme. É interessante comparar também a Figura 80(a) com a Figura 81(a) e a Figura 80(b) com a Figura 81(b), podendo-se observar o forte efeito da diferença de orientação do ligamento (em relação à direção principal de extrusão) sobre as formas das curvas. As Figuras 82 e 83 também propõem a comparação direta entre diferentes ferramentas utilizadas na introdução de pré-trincas, mas em corpos de prova extraídos de placas moldadas por compressão.

Por outro lado, em todas as situações mostradas nas Figuras 80 a 84 pode-se observar o comportamento auto-similar das curvas, o que é um requisito para o funcionamento do método EWF. A auto-similaridade indica que o processo desenvolvido é o mesmo quando observado em diferentes escalas, ou seja, que o trabalho específico de fratura guarda uma dependência linear do comprimento do ligamento. 


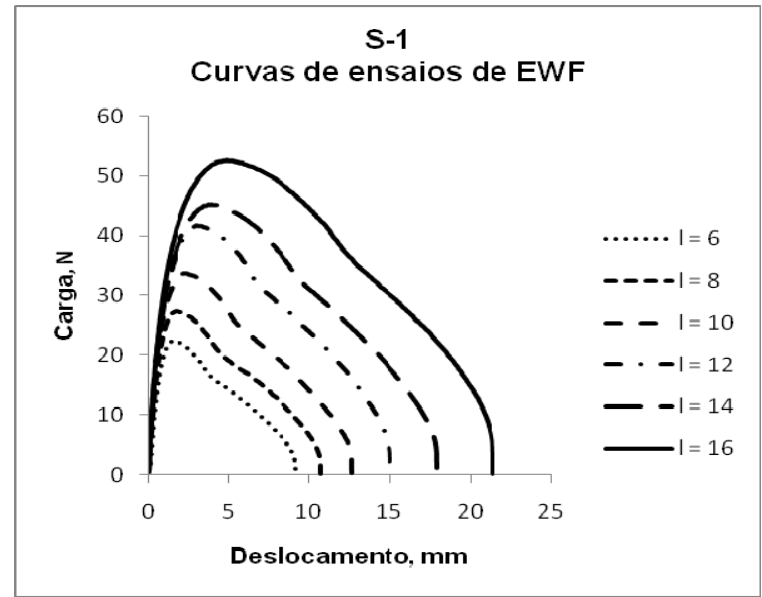

(a)

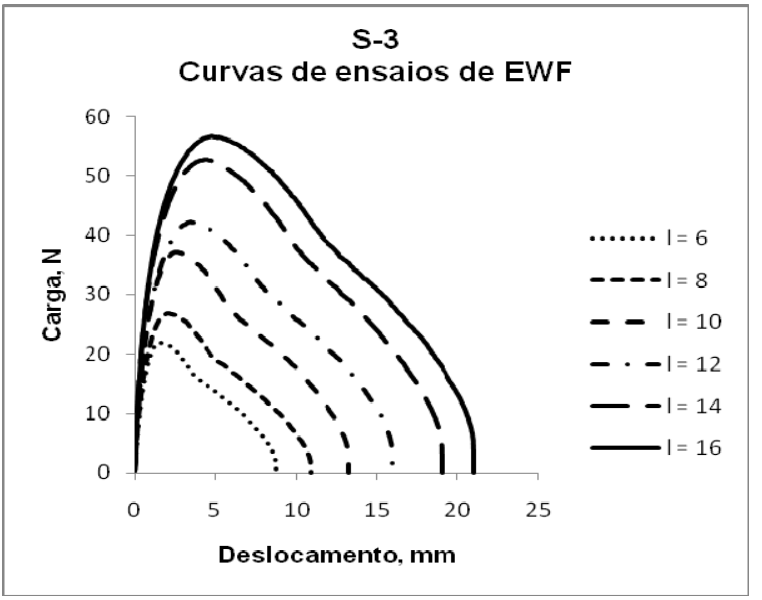

(b)

Figura 80: Curvas típicas dos ensaios de EWF das séries (a) S-1 (pré-trincas introduzidas por corte reto com lâmina de barbear) e (b) S-3 (pré-trincas introduzidas por corte reto com estilete). Espessura nominal: $0,2 \mathrm{~mm}$. Orientação do ligamento: perpendicular à direção principal de extrusão. Nas legendas, a classe de comprimento nominal do ligamento (I) é dado em milímetros.

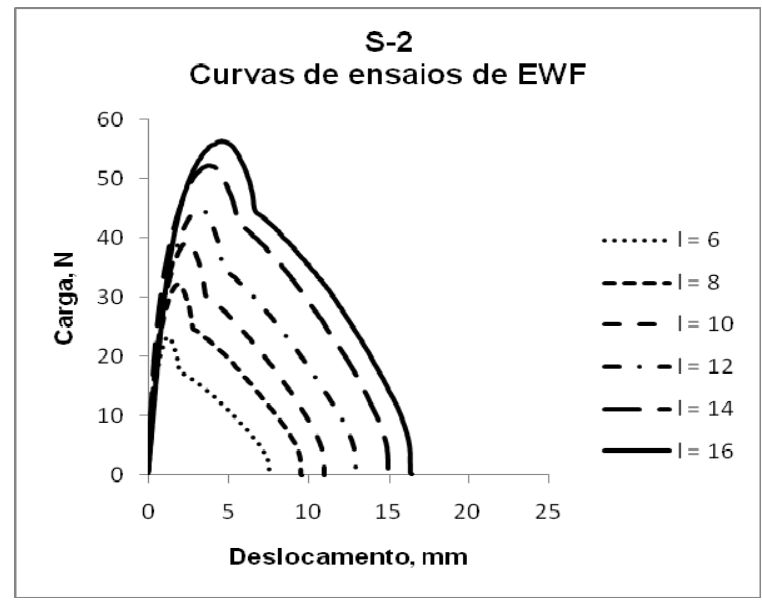

(a)

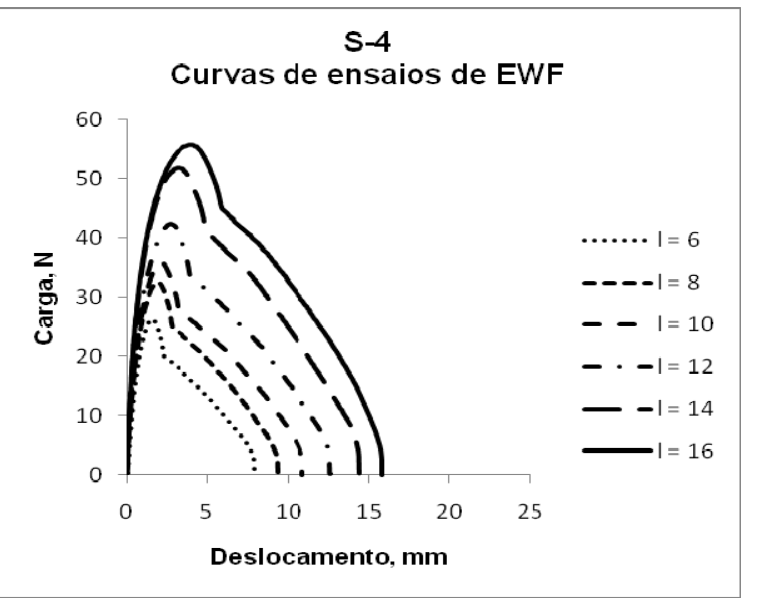

(b)

Figura 81: Curvas típicas dos ensaios de EWF das séries (a) S-2 (pré-trincas introduzidas por corte reto com lâmina de barbear) e (b) S-4 (pré-trincas introduzidas por corte reto com estilete). Espessura nominal: $0,2 \mathrm{~mm}$. Orientação do ligamento: paralela à direção principal de extrusão. Nas legendas, a classe de comprimento nominal do ligamento (I) é dado em milímetros. 


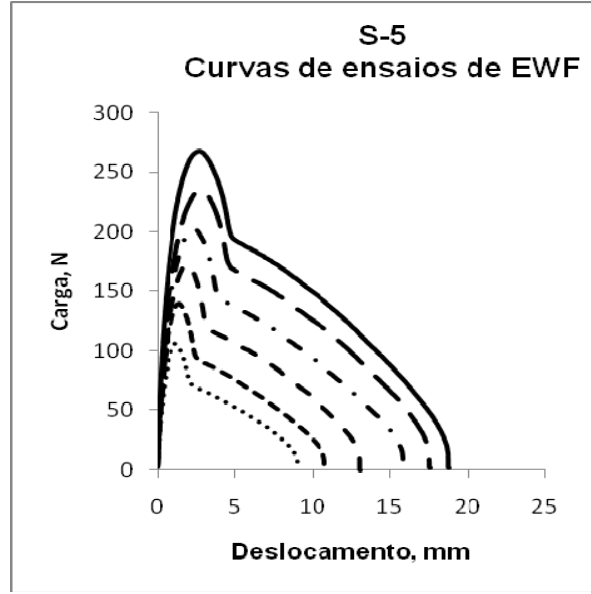

(a)

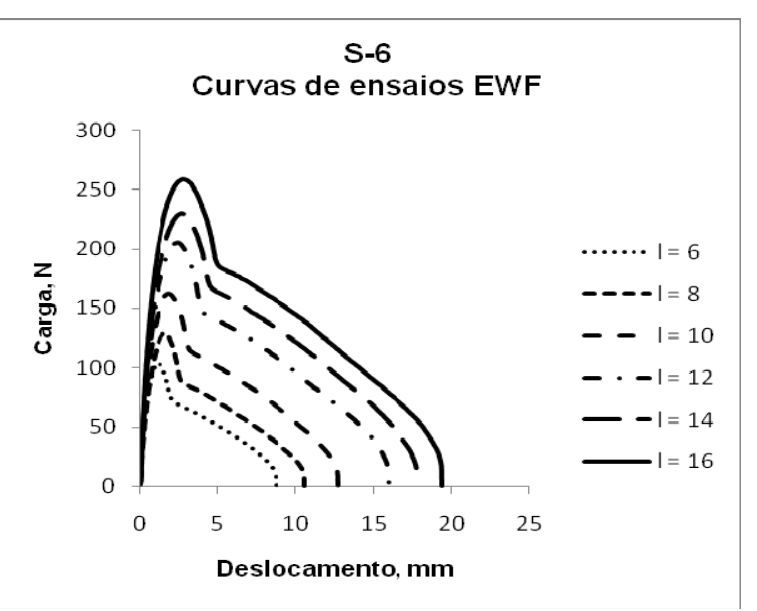

(b)

Figura 82: Curvas típicas dos ensaios de EWF das séries (a) S-5 (pré-trincas introduzidas por corte reto com lâmina de barbear) e (b) S-6 (pré-trincas introduzidas por corte reto com estilete). Espessura nominal: $1 \mathrm{~mm}$. Nas legendas, a classe de comprimento nominal do ligamento (I) é dado em milímetros.

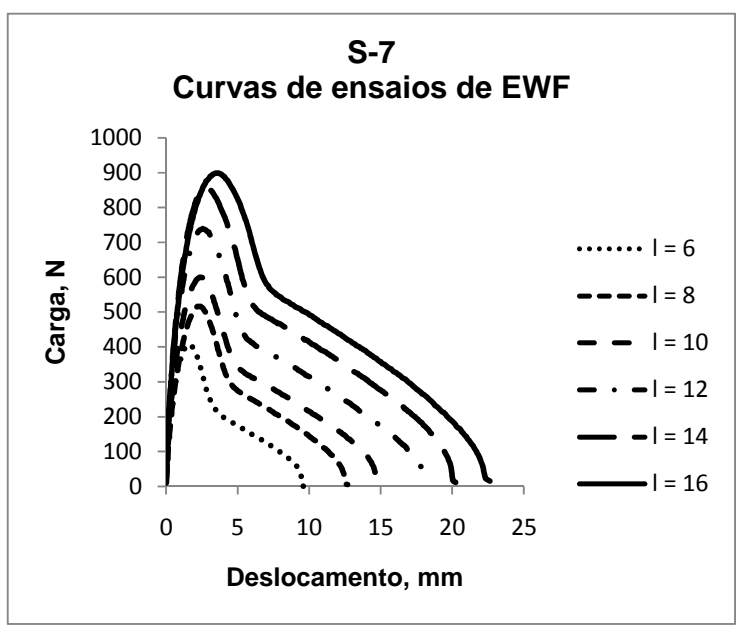

(a)

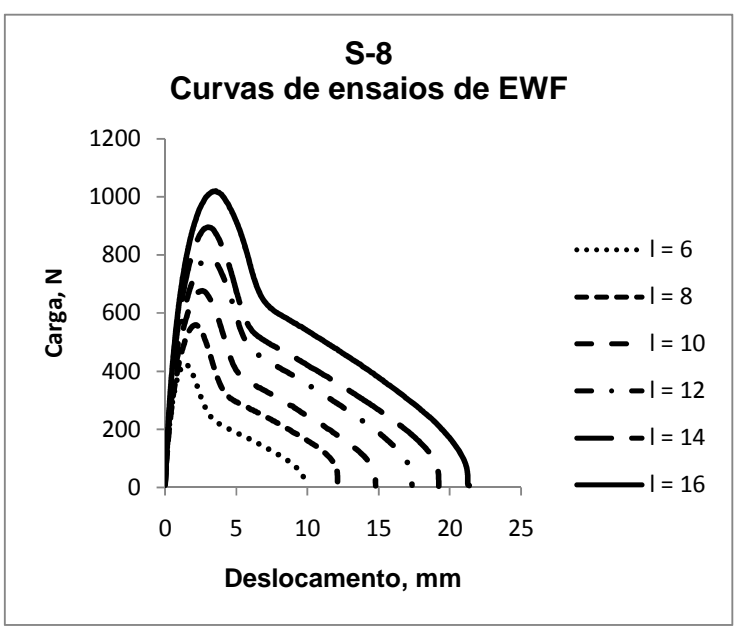

(b)

Figura 83: Curvas típicas dos ensaios de EWF das séries (a) S-7 (pré-trincas introduzidas por corte reto com lâmina de barbear) e (b) S-8 (pré-trincas introduzidas por corte reto com estilete). Espessura nominal: $3 \mathrm{~mm}$. Nas legendas, a classe de comprimento nominal do ligamento (I) é dado em milímetros. 


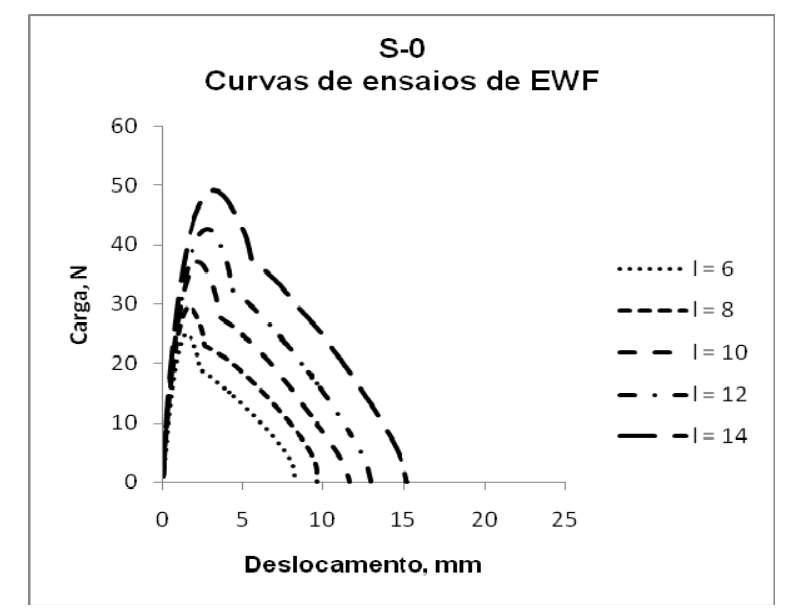

Figura 84: Curvas típicas dos ensaios de EWF da séries S-0. Pré-trincas introduzidas por pungimento da ponta de estilete. Espessura nominal: $0,2 \mathrm{~mm}$. Orientação do ligamento: paralela à orientação principal de extrusão. Na legenda, a classe de comprimento nominal do ligamento (I) é dado em milímetros.

A tabela 12 apresenta os resultados globais dos ensaios de EWF, sendo que os valores de $w_{e}$ e $\beta w_{p}$ são dados com os respectivos intervalos de $95 \%$ de confiança. O leitor interessado poderá consultar os resultados individuais dos ensaios, disponibilizados no Apêndice A.

Tabela 12: Resultados globais dos ensaios de EWF

\begin{tabular}{cccccccc}
\hline Série & $\mathrm{n}$ & $\begin{array}{c}\mathrm{W}_{\mathrm{e}} \pm \mathrm{IC} \\
\left(\mathrm{KJ} / \mathrm{m}^{2}\right)\end{array}$ & $\mathrm{S}_{\mathrm{we}}$ & $\begin{array}{c}\mathrm{CV}_{\mathrm{we}} \\
(\%)\end{array}$ & $\begin{array}{c}\beta \mathrm{w}_{\mathrm{p}} \pm \mathrm{IC} \\
\left(\mathrm{MJ} / \mathrm{m}^{3}\right)\end{array}$ & $\mathrm{S}_{\beta \mathrm{wp}}$ & $\begin{array}{c}\mathrm{CV}_{\beta w p} \\
(\%)\end{array}$ \\
\hline $\mathrm{S}-0$ & 19 & $37,57 \pm 15,37$ & 7,28 & 19,4 & $7,31 \pm 1,46$ & 0,69 & 9,4 \\
$\mathrm{~S}-1$ & 28 & $8,56 \pm 8,03$ & 3,90 & 45,6 & $14,00 \pm 0,70$ & 0,34 & 2,4 \\
S-2 & 26 & $24,40 \pm 4,86$ & 2,35 & 9,6 & $9,27 \pm 0,44$ & 0,21 & 2,3 \\
S-3 & 28 & $9,61 \pm 6,52$ & 3,17 & 33,0 & $15,04 \pm 0,57$ & 0,28 & 1,9 \\
S-4 & 22 & $32,10 \pm 5,32$ & 2,55 & 7,9 & $8,89 \pm 0,50$ & 0,24 & 2,7 \\
S-5 & 27 & $43,44 \pm 7,98$ & 3,87 & 8,9 & $10,21 \pm 0,69$ & 0,33 & 3,2 \\
S-6 & 26 & $35,18 \pm 4,68$ & 2,27 & 6,5 & $11,36 \pm 0,42$ & 0,21 & 1,8 \\
S-7 & 25 & $39,59 \pm 8,99$ & 4,34 & 11,0 & $11,20 \pm 0,81$ & 0,39 & 3,5 \\
S-8 & 28 & $41,79 \pm 10,63$ & 5,17 & 12,4 & $12,40 \pm 0,93$ & 0,45 & 3,6 \\
\hline
\end{tabular}

n: número de ensaios válidos

IC: intervalo de confiança

S: desvio padrão

$\mathrm{CV}$ : coeficiente de variação de Pearson 
A Figura 85 ilustra graficamente os dados de $w_{e}$ da Tabela 12, incluindo os respectivos intervalos de $95 \%$ de confiança. Para facilitar ao leitor a comparação dos resultados, as séries foram convenientemente agrupadas, havendo também uma rápida informação das respectivas técnicas de introdução de pré-trincas e da orientação do ligamento em relação à direção principal de extrusão. De forma semelhante, a Figura 86 contempla os dados de $\beta w_{p}$ da Tabela 12.

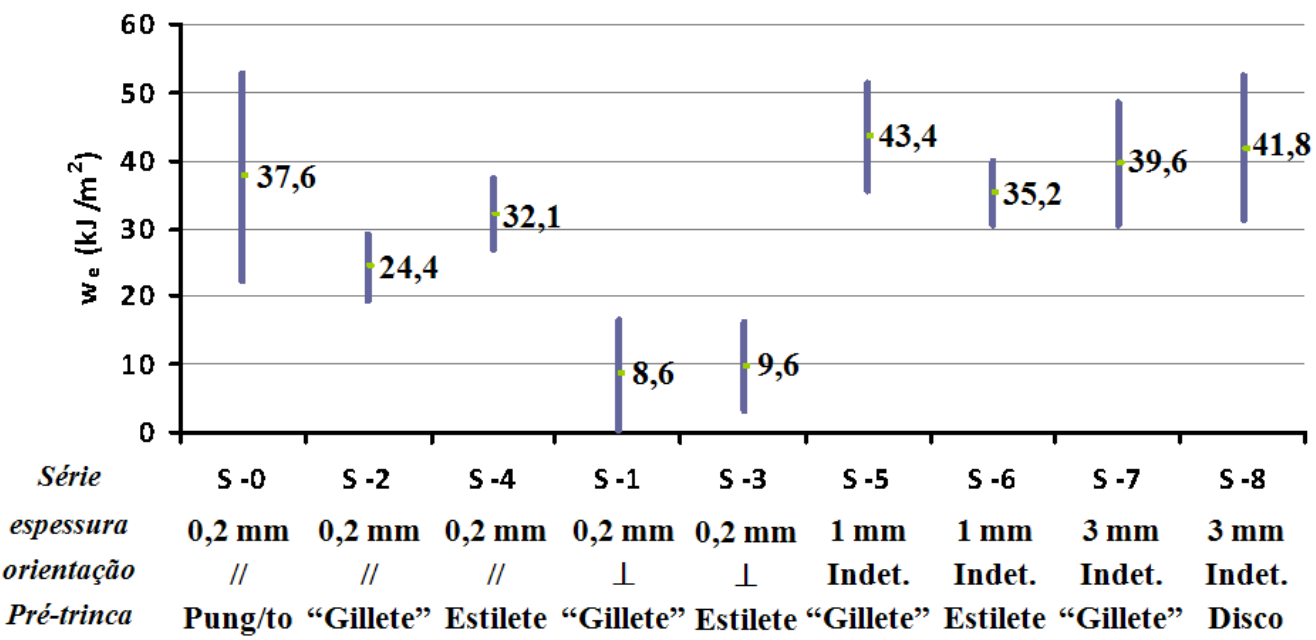

Figura 85: Representação gráfica dos resultados de $w_{e}$ da Tabela 12. Para maior facilidade de apresentação das informações, alguns termos foram adaptados: pungimento foi substituído pela expressão "pung/to"; lâmina de barbear é representada por Gillete ${ }^{\circledR}$; indeterminada foi abreviada para indet.; disco representa a expressão disco de corte. Os símbolos $/ /$ e $\perp$ representam, respectivamente, paralelo e perpendicular à orientação principal de extrusão.

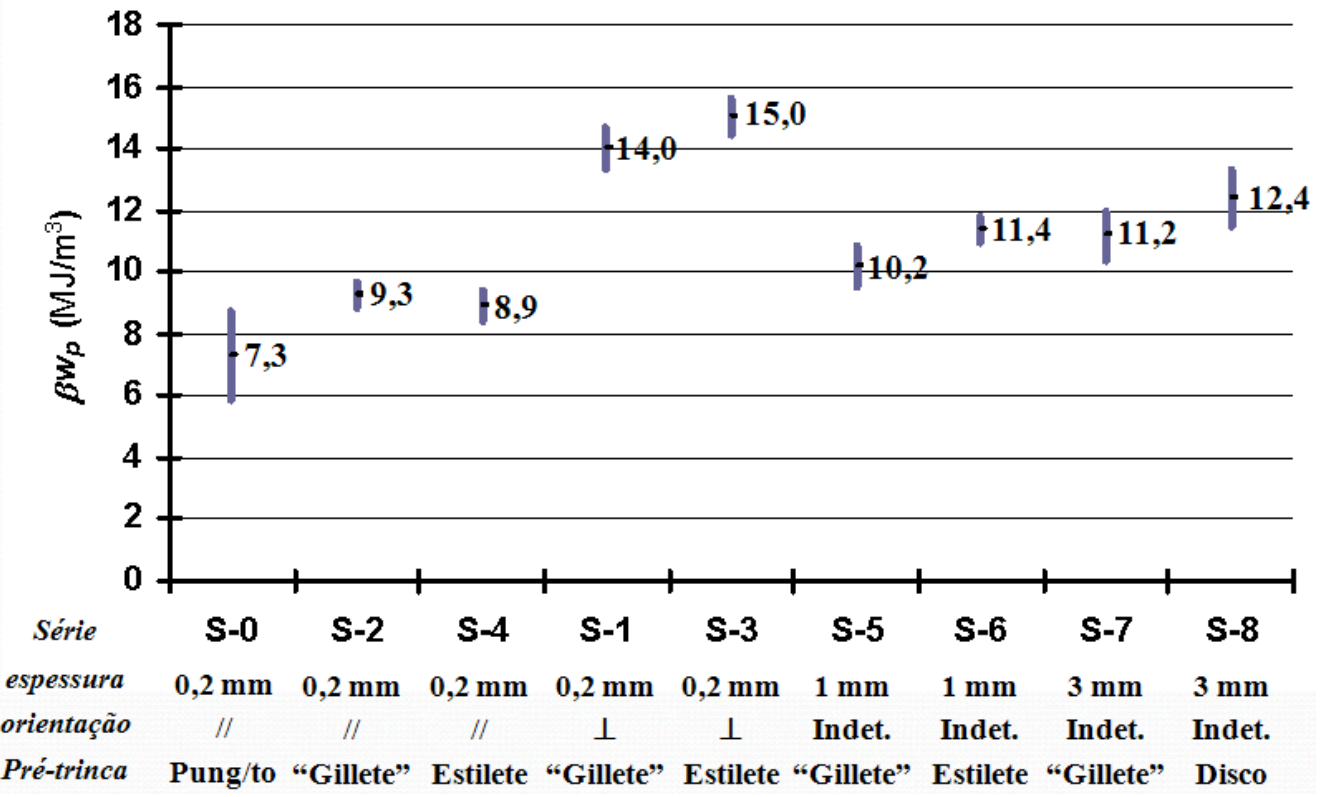

Figura 86: Representação gráfica dos resultados de $\beta w p$ da Tabela 12. Para maior facilidade de apresentação das informações, alguns termos foram adaptados: pungimento foi substituído pela expressão "pung/to"; lâmina de barbear é representada por Gillete ${ }^{\circledR}$; indeterminada foi abreviada para indet.; disco representa a expressão disco de corte. Os símbolos $/ /$ e $\perp$ representam, respectivamente, paralelo e perpendicular à orientação principal de extrusão. 
Para verificar os efeitos dos diferentes fatores estudados, os dados da tabela 12 foram comparados, com o apoio dos testes estatísticos citados na seção 2.8 (sub-seções 2.8.1 e 2.8.3), e os resultados são apresentados a seguir:

\subsubsection{Efeito do método de pré-trincamento sobre a variância de $w_{e}$}

Tabela 13: Resumo dos testes estatísticos para a verificação do efeito do método de prétrincamento sobre as variâncias de $w_{e}$

\begin{tabular}{cccccc}
$\begin{array}{c}\text { Séries } \\
\text { comparadas }\end{array}$ & $\begin{array}{c}\text { Parâmetro } \\
\text { estudado }\end{array}$ & $\begin{array}{c}\text { Significância } \\
\text { do teste }\end{array}$ & $\begin{array}{c}\text { Estatística } \\
\text { teste }\end{array}$ & $\begin{array}{c}\text { Estatística } \\
\text { crítica }\end{array}$ & Resultado \\
\hline S-0; S-2; S-4 & $S_{w_{e}}^{2}$ & $5 \%$ & $\chi_{\text {teste }}^{2}=34,9$ & $\chi_{2 ; 5 \%}^{2}=5,99$ & Rejeitar $\mathrm{H}_{0}^{7}$ \\
S-0; S-2; S-4 & $S_{w_{e}}^{2}$ & $1 \%$ & $\chi_{\text {teste }}^{2}=34,9$ & $\chi_{2 ; 1 \%}^{2}=9,21$ & Rejeitar $\mathrm{H}_{0}$ \\
S-2; S-4 & $S_{w_{e}}^{2}$ & $5 \%$ & $F_{\text {teste }}=1,18$ & $F_{21 ; 25 ; 2,5 \%} \approx 2,27$ & Não rejeitar $\mathrm{H}_{0}$ \\
S-2; S-4 & $S_{w_{e}}^{2}$ & $1 \%$ & $F_{\text {teste }}=1,18$ & $F_{21 ; 25 ; 0,5 \%} \approx 3,01$ & Não rejeitar $\mathrm{H}_{0}$ \\
S-1; S-3 & $S_{w_{e}}^{2}$ & $5 \%$ & $F_{\text {teste }}=1,51$ & $F_{27 ; 27 ; 2,5 \%} \approx 2,16$ & Não rejeitar $\mathrm{H}_{0}$ \\
S-1; S-3 & $S_{w_{e}}^{2}$ & $1 \%$ & $F_{\text {teste }}=1,51$ & $F_{27 ; 27 ; 0,5 \%} \approx 2,78$ & Não rejeitar $\mathrm{H}_{0}$ \\
S-5; S-6 & $S_{w_{e}}^{2}$ & $5 \%$ & $F_{\text {teste }}=2,91$ & $F_{26 ; 25 ; 2,5 \%} \approx 2,21$ & Rejeitar $\mathrm{H}_{0}$ \\
S-5; S-6 & $S_{w_{e}}^{2}$ & $1 \%$ & $F_{\text {teste }}=2,91$ & $F_{26 ; 25 ; 0,5 \%} \approx 2,92$ & Não rejeitar $\mathrm{H}_{0}$ \\
S-7; S-8 & $S_{w_{e}}^{2}$ & $5 \%$ & $F_{\text {teste }}=1,42$ & $F_{27 ; 24 ; 2,5 \%} \approx 2,24$ & Não rejeitar $\mathrm{H}_{0}$ \\
S-7; S-8 & $S_{w_{e}}^{2}$ & $1 \%$ & $F_{\text {teste }}=1,42$ & $F_{27 ; 24 ; 0,5 \%} \approx 2,92$ & Não rejeitar $\mathrm{H}_{0}$
\end{tabular}

Os resultados da tabela 13 indicam que, aos níveis de significância de 1\% e $5 \%$, o emprego de métodos mais grosseiros como pungimento da ponta de um estilete aumentam a dispersão dos resultados de $w_{e}$ do material estudado. Aos mesmos níveis de significância, os resultados não demonstram evidência de que métodos mais refinados, como a utilização de lâminas afiadas, aumentam o grau de dispersão.

\footnotetext{
${ }^{7}$ A hipótese nula $\left(\mathrm{H}_{0}\right)$ nos testes estatísticos será sempre a de igualdade dos parâmetros estudados
} 
3.3.3.2 Efeito do método de pré-trincamento sobre a variância de $\beta w_{p}$

Tabela 14: Resumo dos testes estatísticos para a verificação do efeito do método de prétrincamento sobre as variâncias de $\beta w_{p}$

\begin{tabular}{cccccc}
$\begin{array}{c}\text { Séries } \\
\text { comparadas }\end{array}$ & $\begin{array}{c}\text { Parâmetro } \\
\text { estudado }\end{array}$ & $\begin{array}{c}\text { Significância } \\
\text { do teste }\end{array}$ & $\begin{array}{c}\text { Estatística } \\
\text { teste }\end{array}$ & $\begin{array}{c}\text { Estatística } \\
\text { crítica }\end{array}$ & Resultado \\
\hline S-0; S-2; S-4 & $S_{\beta w_{p}}^{2}$ & $5 \%$ & $\chi_{\text {teste }}^{2}=38,7$ & $\chi_{2 ; 5 \%}^{2}=5,99$ & Rejeitar $\mathrm{H}_{0}$ \\
S-0; S-2; S-4 & $S_{\beta w_{p}}^{2}$ & $1 \%$ & $\chi_{\text {teste }}^{2}=38,7$ & $\chi_{2 ; 1 \%}^{2}=9,21$ & Rejeitar $\mathrm{H}_{0}$ \\
S-2; S-4 & $S_{\beta w_{p}}^{2}$ & $5 \%$ & $F_{\text {teste }}=1,32$ & $F_{21 ; 25 ; 2,5 \%} \approx 2,27$ & Não rejeitar $\mathrm{H}_{0}$ \\
S-2; S-4 & $S_{\beta w_{p}}^{2}$ & $1 \%$ & $F_{\text {teste }}=1,32$ & $F_{21 ; 25 ; 0,5 \%} \approx 3,01$ & Não rejeitar $\mathrm{H}_{0}$ \\
S-1; S-3 & $S_{\beta w_{p}}^{2}$ & $5 \%$ & $F_{\text {teste }}=1,49$ & $F_{27 ; 27 ; 2,5 \%} \approx 2,16$ & Não rejeitar $\mathrm{H}_{0}$ \\
S-1; S-3 & $S_{\beta w_{p}}^{2}$ & $1 \%$ & $F_{\text {teste }}=1,49$ & $F_{27 ; 27 ; 0,5 \%} \approx 2,78$ & Não rejeitar $\mathrm{H}_{0}$ \\
S-5; S-6 & $S_{\beta w_{p}}^{2}$ & $5 \%$ & $F_{\text {teste }}=2,48$ & $F_{26 ; 25 ; 2,5 \%} \approx 2,21$ & Rejeitar $\mathrm{H}_{0}$ \\
S-5; S-6 & $S_{\beta w_{p}}^{2}$ & $1 \%$ & $F_{\text {teste }}=2,48$ & $F_{26 ; 25 ; 0,5 \%} \approx 2,92$ & Não rejeitar $\mathrm{H}_{0}$ \\
S-7; S-8 & $S_{\beta w_{p}}^{2}$ & $5 \%$ & $F_{\text {teste }}=1,34$ & $F_{27 ; 24 ; 2,5 \%} \approx 2,24$ & Não rejeitar $\mathrm{H}_{0}$ \\
S-7; S-8 & $S_{\beta w_{p}}^{2}$ & $1 \%$ & $F_{\text {teste }}=1,34$ & $F_{27 ; 24 ; 0,5 \%} \approx 2,92$ & Não rejeitar $\mathrm{H}_{0}$
\end{tabular}

Os resultados da tabela 14 indicam que, aos níveis de significância de $1 \%$ e $5 \%$, o emprego de métodos mais grosseiros, como o pungimento da ponta de um estilete, aumentam a dispersão dos resultados de $\beta w_{p}$. Aos mesmos níveis de significância, os resultados não demonstram evidência de que métodos mais refinados, como a utilização de lâminas afiadas, aumentam o grau de dispersão.

\subsubsection{Efeito do pré-trincamento sobre as médias de $w_{e}$}

Os testes para comparação das médias de $w_{e}$ dependem de considerações sobre a igualdade das variâncias. Desta forma, os testes desta seção basearam-se nos resultados do item 3.3.3.1. Nos casos em que as variâncias podem ser tomadas como diferentes, em função dos resultados anteriores, aplicou-se o método de Aspin Welch. Estes casos estão indicados na tabela 15, juntamente com o nível de significância do teste. 
Tabela 15: Resumo dos testes estatísticos para a verificação do efeito do método de prétrincamento sobre as médias de $w_{e}$

\begin{tabular}{cccccc}
$\begin{array}{c}\text { Séries } \\
\text { comparadas }\end{array}$ & $\begin{array}{c}\text { Parâmetro } \\
\text { estudado }\end{array}$ & $\begin{array}{c}\text { Significância } \\
\text { do teste }\end{array}$ & $\begin{array}{c}\text { Estatística } \\
\text { teste }\end{array}$ & $\begin{array}{c}\text { Estatística } \\
\text { crítica }\end{array}$ & Resultado \\
\hline S-0; S-2 & $w_{e}$ & $5 \%($ A. Welch) & $t_{\text {teste }}=7,6$ & $t_{21 ; 2,5 \%}=2,08$ & Rejeitar $\mathrm{H}_{0}$ \\
S-0; S-4 & $w_{e}$ & $5 \%($ A. Welch) & $t_{\text {teste }}=3,11$ & $t_{22 ; 2,5 \%}=2,07$ & Rejeitar $\mathrm{H}_{0}$ \\
S-2; S-4 & $w_{e}$ & $5 \%$ & $t_{\text {teste }}=10,88$ & $t_{46 ; 2,5 \%} \approx 2,01$ & Rejeitar $\mathrm{H}_{0}$ \\
S-1; S-3 & $w_{e}$ & $5 \%$ & $t_{\text {teste }}=1,11$ & $t_{54 ; 2,5 \%} \approx 2,01$ & Não rejeitar $\mathrm{H}_{0}$ \\
S-5; S-6 & $w_{e}$ & $5 \%$ & $t_{\text {teste }}=9,43$ & $t_{51 ; 2,5 \%} \approx 2,01$ & Rejeitar $\mathrm{H}_{0}$ \\
S-5; S-6 & $w_{e}$ & $5 \%(\mathrm{~A}$. Welch) & $t_{\text {teste }}=9,52$ & $t_{51 ; 2,5 \%} \approx 2,01$ & Rejeitar $\mathrm{H}_{0}$ \\
S-7; S-8 & $w_{e}$ & $5 \%$ & $t_{\text {teste }}=1,67$ & $t_{51 ; 2,5 \%}=2,01$ & Não rejeitar $\mathrm{H}_{0}$ \\
\hline
\end{tabular}

Os resultados da tabela 15 não permitem concluir se diferentes técnicas de introdução de pré-trincas afetam os resultados de $w_{e}$ do material estudado. Parece que as espessuras menores são mais sensíveis aos métodos de pré-trincamento, entretanto, o autor entende que são necessárias mais evidências experimentais.

\subsubsection{Efeito do método de pré-trincamento sobre as médias de $\beta w_{p}$}

Os testes para comparação das médias de $\beta w_{p}$ dependem de considerações sobre a igualdade das variâncias. Desta forma, os testes desta seção basearam-se nos resultados do item 3.3.3.2. Nos casos em que as variâncias podem ser tomadas como diferentes, em função dos resultados anteriores, aplicou-se o método de Aspin Welch. Estes casos estão indicados na tabela 16, juntamente com o nível de significância do teste. 
Tabela 16: Resumo dos testes estatísticos para a verificação do efeito do método de prétrincamento sobre as médias de $\beta w_{p}$

\begin{tabular}{cccccl}
$\begin{array}{c}\text { Séries } \\
\text { comparadas }\end{array}$ & $\begin{array}{c}\text { Parâmetro } \\
\text { estudado }\end{array}$ & $\begin{array}{c}\text { Significância } \\
\text { do teste }\end{array}$ & $\begin{array}{c}\text { Estatística } \\
\text { teste }\end{array}$ & $\begin{array}{c}\text { Estatística } \\
\text { crítica }\end{array}$ & Resultado \\
\hline S-0; S-2 & $\beta w_{p}$ & $5 \%($ A.Welch) & $t_{\text {teste }}=11,98$ & $t_{21 ; 2,5 \%}=2,08$ & Rejeitar $\mathrm{H}_{0}$ \\
S-0; S-4 & $\beta w_{p}$ & $5 \%$ (A.Welch) & $t_{\text {teste }}=9,50$ & $t_{22 ; 2,5 \%}=2,07$ & Rejeitar $\mathrm{H}_{0}$ \\
S-2; S-4 & $\beta w_{p}$ & $5 \%$ & $t_{\text {teste }}=5,85$ & $t_{46 ; 2,5 \%} \approx 2,01$ & Rejeitar $\mathrm{H}_{0}$ \\
S-1; S-3 & $\beta w_{p}$ & $5 \%$ & $t_{\text {teste }}=12,5$ & $t_{54 ; 2,5 \%} \approx 2,01$ & Rejeitar $\mathrm{H}_{0}$ \\
S-5; S-6 & $\beta w_{p}$ & $5 \%$ & $t_{\text {teste }}=15,07$ & $t_{51 ; 2,5 \%} \approx 2,01$ & Rejeitar $\mathrm{H}_{0}$ \\
S-5; S-6 & $\beta w_{p}$ & $5 \%(\mathrm{~A} . \mathrm{Welch})$ & $t_{\text {teste }}=15,19$ & $t_{51 ; 2,5 \%} \approx 2,01$ & Rejeitar $\mathrm{H}_{0}$ \\
S-7; S-8 & $\beta w_{p}$ & $5 \%$ & $t_{\text {teste }}=10,31$ & $t_{51 ; 2,5 \%}=2,01$ & Rejeitar $\mathrm{H}_{0}$ \\
\hline
\end{tabular}

De acordo com os resultados da tabela 16, há evidências experimentais suficientes, ao nível de significância de 5\%, para se permitir afirmar que o método de introdução das pré-trincas afeta os resultados de $\beta w_{p}$ do material estudado.

Yamakawa e al (2004) também verificaram que método de pré-trincamento afeta os resultados do método EWF, porém, em um material bastante sensível a entalhes (poliamida 6).

\subsubsection{Efeito da espessura do corpo de prova sobre as médias de $w_{e}$}

Os testes para comparação das médias de $w_{e}$ dependem de considerações sobre a igualdade das variâncias. Como as variâncias de $w_{e}$ das séries neste item não foram comparadas antes, o teste correspondente também está incluído na tabela 17.

Tabela 17: Resumo dos testes estatísticos para a verificação do efeito da espessura do corpo de prova sobre as variâncias e sobre as médias de $w_{e}$

\begin{tabular}{cccccc}
\hline $\begin{array}{c}\text { Séries } \\
\text { comparadas }\end{array}$ & $\begin{array}{c}\text { Parâmetro } \\
\text { estudado }\end{array}$ & $\begin{array}{c}\text { Significância } \\
\text { do teste }\end{array}$ & $\begin{array}{c}\text { Estatística } \\
\text { teste }\end{array}$ & $\begin{array}{c}\text { Estatística } \\
\text { crítica }\end{array}$ & Resultado \\
\hline S-5; S-7 & $S_{w_{e}}$ & $5 \%$ & $F_{\text {teste }}=1,26$ & $F_{24 ; 26 ; 2,5 \%}=2,22$ & Não rejeitar $\mathrm{H}_{0}$ \\
S-5; S-7 & $w_{e}$ & $5 \%$ & $t_{\text {teste }}=3,38$ & $t_{50 ; 2,5 \%}=2,01$ & Rejeitar $\mathrm{H}_{0}$ \\
\hline
\end{tabular}


De acordo com os resultados da tabela 17, há evidências experimentais suficientes, ao nível de significância de 5\%, de que a espessura do corpo de prova afeta os resultados de $w_{e}$.

\subsubsection{Efeito da espessura do corpo de prova sobre as médias de $\beta w_{p}$}

Os testes para comparação das médias de $\beta w_{p}$ dependem de considerações sobre a igualdade das variâncias. Como as variâncias de $\beta w_{p}$ das séries neste item não foram comparadas antes, o teste correspondente também está incluído na tabela 18.

Tabela 18: Resumo dos testes estatísticos para a verificação do efeito da espessura do corpo de prova sobre as variâncias e sobre as médias de $\beta w_{p}$

\begin{tabular}{cccccc}
$\begin{array}{c}\text { Séries } \\
\text { comparadas }\end{array}$ & $\begin{array}{c}\text { Parâmetro } \\
\text { estudado }\end{array}$ & $\begin{array}{c}\text { Significância } \\
\text { do teste }\end{array}$ & $\begin{array}{c}\text { Estatística } \\
\text { teste }\end{array}$ & $\begin{array}{c}\text { Estatística } \\
\text { crítica }\end{array}$ & Resultado \\
\hline S-5; S-7 & $S_{\beta w_{p}}$ & $5 \%$ & $F_{\text {teste }}=1,39$ & $F_{24 ; 26 ; 2,5 \%}=2,22$ & Não rejeitar $\mathrm{H}_{0}$ \\
S-5; S-7 & $\beta w_{p}$ & $5 \%$ & $t_{\text {teste }}=9,91$ & $t_{50 ; 2,5 \%}=2,01$ & Rejeitar $\mathrm{H}_{0}$ \\
\hline
\end{tabular}

De acordo com os resultados da tabela 18, há evidências experimentais suficientes, ao nível de significância de 5\%, de que a espessura do corpo de prova afeta os resultados de $\beta w_{p}$.

A questão da influência da espessura sobre os resultados do método EWF, abordada neste item e no anterior, é controversa em polímeros. Segundo Sallemi e Nairn (1990), $w_{e}$ é independente da espessura em polímeros dúcteis. Karger-Koksis; Czigány e Moskala (1997), estudando um copoliéster amorfo, também sugerem que $w_{e}$ é independente da espessura, mas alertam que o material deve ser tal que o ligamento escoe integralmente antes da trinca avançar, o que foi verificado no material estudado neste trabalho. Já Maspoch et al (1999) verificaram que no polipropileno isotático o trabalho específico de fratura $\left(w_{f}\right)$ cai à medida que a espessura aumenta, sendo que o parâmetro mais influenciado é $w_{e}$. Por outro lado, Pardoen; Marchal e Delannay (2002) observaram que, em uma liga de alumínio, $w_{e}$ diminui com a redução da espessura, lembrando que a tenacidade varia linearmente no mesmo sentido com a espessura, no estado plano de tensão puro. Porém, segundo estes últimos autores, $\beta w_{p}$ seria independente da espessura. 
O estudo do efeito da espessura neste trabalho é pouco abrangente, sendo que uma das espessuras adotadas não deve ser comparada com as outras duas, em virtude da evidente influência causada pelas diferentes técnicas de processamento, que foi observada nos resultados (próximos itens). De qualquer forma, os resultados contribuem com dados adicionais para esta importante questão, salientando-se que o objetivo principal deste trabalho, em relação ao método EWF, é o de investigar o efeito do emprego de diferentes técnicas de pré-trincamento dos corpos de prova.

\subsubsection{Efeito do processamento sobre as médias de $w_{e}$}

Os testes para comparação das médias de $w_{e}$ dependem de considerações sobre a igualdade das variâncias. Como as variâncias de $w_{e}$ das séries neste item não foram comparadas antes, o teste correspondente também está incluído na tabela 19.

Tabela 19: Resumo dos testes estatísticos para a verificação do efeito do processamento sobre as variâncias e sobre as médias de $w_{e}$

\begin{tabular}{cccccc}
$\begin{array}{c}\text { Séries } \\
\text { comparadas }\end{array}$ & $\begin{array}{c}\text { Parâmetro } \\
\text { estudado }\end{array}$ & $\begin{array}{c}\text { Significância } \\
\text { do teste }\end{array}$ & $\begin{array}{c}\text { Estatística } \\
\text { teste }\end{array}$ & $\begin{array}{c}\text { Estatística } \\
\text { crítica }\end{array}$ & Resultado \\
\hline S-1; S-2 & $S_{w_{e}}$ & $5 \%$ & $F_{\text {teste }}=2,75$ & $F_{27 ; 25 ; 2,5 \%} \approx 2,21$ & Rejeitar $\mathrm{H}_{0}$ \\
S-1; S-2 & $w_{e}$ & $5 \%($ A.Welch) $)$ & $t_{\text {teste }}=18,22$ & $t_{46 ; 2,5 \%}=2,01$ & Rejeitar $\mathrm{H}_{0}$ \\
S-3; S-4 & $S_{w_{e}}$ & $5 \%$ & $F_{\text {teste }}=1,55$ & $F_{27 ; 21 ; 2,5 \%} \approx 2,34$ & Não rejeitar $\mathrm{H}_{0}$ \\
S-3; S-4 & $w_{e}$ & $5 \%$ & $t_{\text {teste }}=27,10$ & $t_{48 ; 2,5 \%}=2,01$ & Rejeitar $\mathrm{H}_{0}$ \\
\hline
\end{tabular}

Como indicado na tabela 19, a comparação das médias entre as séries S-1 e S-2 foi feita por meio do método de Aspin Welch, em função do resultado do teste das respectivas variâncias.

De acordo com os resultados da tabela 19, há evidências experimentais suficientes, ao nível de significância de $5 \%$, de que o processamento do material afeta os resultados de $w_{e}$. 
3.3.3.8 Efeito do processamento sobre as médias de $\beta w_{p}$

Os testes para comparação das médias de $\beta w_{p}$ dependem de considerações sobre a igualdade das variâncias. Como as variâncias de $\beta w_{p}$ das séries neste item não foram comparadas antes, o teste correspondente também está incluído na tabela 20.

Tabela 20: Resumo dos testes estatísticos para a verificação do processamento sobre as variâncias e sobre as médias de $\beta w_{p}$

\begin{tabular}{cccccc}
$\begin{array}{c}\text { Séries } \\
\text { comparadas }\end{array}$ & $\begin{array}{c}\text { Parâmetro } \\
\text { estudado }\end{array}$ & $\begin{array}{c}\text { Significância } \\
\text { do teste }\end{array}$ & $\begin{array}{c}\text { Estatística } \\
\text { teste }\end{array}$ & $\begin{array}{c}\text { Estatística } \\
\text { crítica }\end{array}$ & Resultado \\
\hline S-1; S-2 & $S_{\beta w_{p}}$ & $5 \%$ & $F_{\text {teste }}=2,64$ & $F_{27 ; 25 ; 2,5 \%}=2,21$ & Rejeitar $\mathrm{H}_{0}$ \\
S-1; S-2 & $\beta w_{p}$ & $5 \%(A . W e l c h)$ & $t_{\text {teste }}=62,0$ & $t_{47 ; 2,5 \%}=2,01$ & Rejeitar $\mathrm{H}_{0}$ \\
S-3; S-4 & $S_{\beta w_{p}}$ & $5 \%$ & $F_{\text {teste }}=1,34$ & $F_{27 ; 22 ; 2,5 \%}=2,3$ & Não rejeitar $\mathrm{H}_{0}$ \\
S-3; S-4 & $\beta w_{p}$ & $5 \%$ & $t_{\text {teste }}=82,0$ & $t_{48 ; 2,5 \%}=2,01$ & Rejeitar $\mathrm{H}_{0}$ \\
\hline
\end{tabular}

Como indicado na tabela 20, a comparação das médias entre as séries S-1 e S-2 foi feita por meio do método de Aspin Welch, em função do resultado do teste das respectivas variâncias.

De acordo com os resultados da tabela 20, há evidências experimentais suficientes, ao nível de significância de $5 \%$, de que o processamento do material afeta os resultados de $\beta w_{p}$. Os resultados deste item e do item anterior já eram anunciados pela acentuada diferença entre as curvas de carregamento observadas nas Figuras 80 e 81 . Tipicamente o processo de extrusão proporciona anisotropia ao material em relação à tenacidade, o que ficou demonstrado neste estudo pelos diferentes valores dos parâmetros do método EWF quando a orientação do corpo de prova é alterada em relação à direção principal de extrusão. Além disso, Maspoch et al (1999) lembram que diferentes formas de processamento podem levar a diferentes graus de cristalinidade, com efeitos sobre os resultados de EWF de polímeros parcialmente cristalinos. Também Yamakawa e al (2004) verificaram que o processamento interfere nos resultados de EWF da poliamida 6.

Considerando-se os resultados das diversas comparações realizadas, podese verificar que o método de introdução de pré-trincas altera os resultados dos ensaios de EWF no material testado, sendo que o parâmetro mais sensível é $\beta w_{p}$. 
Este resultado é importante porque $\beta w_{p}$ pode ser o melhor parâmetro para se estudar os efeitos estruturais sobre a tenacidade do polietileno, conforme salientam Fayolle e Verdu (2005).

Com base nas evidências encontradas, pode-se inferir que diferenças nas estruturas de deformação na região da ponta das pré-trincas, conforme se pode observar nas Figuras 62, 63 e 64, interferem no processo de fratura do polietileno, principalmente na formação da zona plástica sob estado plano de tensão.

Deve-se observar que todas as classes de ligamento estabelecidas foram consideradas nos cálculos, inclusive a classe de comprimento nominal igual a $6 \mathrm{~mm}$ para as espessuras de $3 \mathrm{~mm}$. Segundo Mai e Cotterell (1986) e Saleemi e Nairn (1990) a relação linear entre $w_{f}$ e $/$ pode ser prejudicada quando a relação $I / t$ (ligamento/espessura) é menor que $\approx 3$, em função do risco de proximidade da transição entre o estado plano de tensão e o estado plano de deformação. Entretanto, todos os pontos foram submetidos ao critério de tensão, concebido para justamente prevenir que haja alguma importante diferença no estado de tensão entre os diversos corpos de prova da série. De fato, a tensão máxima em três pontos da série S-7, na classe de ligamentos de $6 \mathrm{~mm}$, excedeu ligeiramente o limite superior de 10\%, mas nenhum deles excedeu a média das tensões máximas em mais que $12 \%$. Se os pontos da classe de ligamento nominal de $6 \mathrm{~mm}$ forem excluídos da regressão, os novos valores de $w_{e}$ e $\beta w_{p}$ passam a ser, respectivamente, 40,21 \pm $14,09 \mathrm{~kJ} / \mathrm{m}^{2}$ e $11,15 \pm 1,17 \mathrm{MJ} / \mathrm{m}^{3}$, praticamente iguais aos valores que são obtidos quando todos os pontos são considerados. Como o limite de 10\% em torno da média das tensões máximas é um tanto arbitrária, os pontos com ligamento nominal de 6 $\mathrm{mm}$ foram considerados em função do benefício obtido com a menor dispersão. Na série S-8, nenhum ponto ficou fora da faixa de validade de 10\% em torno da média das tensões máximas. Neste caso, se forem excluídos os pontos da classe de ligamento $6 \mathrm{~mm}$ há ligeira variação nos parâmetros do método EWF e na dispersão dos resultados, mas que não altera as conclusões gerais deste estudo.

A questão do comprimento do ligamento é delicada no método EWF. O ligamento deve ser suficientemente longo para prevenir uma transição no estado de tensão e garantir que todos os ligamentos estejam sobre predomínio de estado plano de tensão. Por outro lado, o ligamento deve ser suficientemente curto para garantir o escoamento integral do material ao longo do ligamento e prevenir 
indesejáveis efeitos da borda do corpo de prova (MAl; COTTERELL, 1986; SALEEMI; NAIRN, 1990; MAI; POWELL, 1991). Ao mesmo tempo, a faixa de variação do comprimento do ligamento deve ser tal que proporcione dados suficientes para a análise de regressão. Neste trabalho, pode-se verificar que todos esses requisitos foram atendidos.

Os princípios gerais do método EWF se aplicam muito bem ao PEMD. Especialmente, saliente-se que, na faixa de comprimentos de ligamento estudada, o ligamento do corpo de prova escoa totalmente antes da propagação da fratura, que não se observa alteração no estado de tensão e que se observa forte correlação linear positiva entre o trabalho específico de fratura, $w_{f}$, e o comprimento do ligamento, I. Por outro lado, embora se reconhecendo que o método funciona, a evolução da zona plástica durante o ensaio de EWF ainda é pouco conhecida e a dependência linear de $w_{f}$ com o comprimento do ligamento ainda precisa ser fisicamente melhor justificada. Desta forma, sugere-se o desenvolvimento deste estudo em trabalhos futuros.

\subsubsection{ENSAIOS CONVENCIONAIS DE TRAÇÃO}

A título de complementação da caracterização dos materiais estudados, a tabela 21 apresenta os resultados dos ensaios convencionais de tração.

Tabela 21: Resultados dos ensaios convencionais de tração

\begin{tabular}{ccc}
\hline MATERIAL & LIMITE DE ESCOAMENTO (MPa) & DESVIO PADRÃo \\
\hline Rigidex PC002-50R968 & 16,4 & 0,32 \\
MDPE 8818 & 15,5 & 0,41 \\
GM 5010T2 & 17,8 & 0,32 \\
\hline
\end{tabular}




\section{CONCLUSÕES}

As principais conclusões extraídas deste estudo são:

\subsection{ENSAIOS DE $K_{l C}$}

> Congelar o polietileno de média densidade por imersão em nitrogênio líquido é uma estratégia satisfatória para a obtenção de valores válidos de tenacidade à fratura no estado plano de deformação do material;

> Diferentes técnicas de introdução de pré-trincas em corpos de prova produzem diferentes estruturas de deformação na matriz do material na ponta da trinca e afetam os resultados dos ensaios de mecânica da fratura em polietileno de média densidade, realizados conforme a norma ASTM D 504599, sob condições criogênicas;

> Técnicas de introdução de pré-trincas que produzem maior grau de deformação na matriz do material na região da ponta da trinca proporcionam valores mais elevados de tenacidade à fratura no estado plano de deformação, sob condições criogênicas;

> Técnicas de introdução de pré-trincas mais controladas e refinadas, como o pressionamento lento de uma lâmina de barbear na raiz de um entalhe previamente produzido proporcionam resultados mais homogêneos em ensaios de $K_{l c}$ de polietileno de média densidade, sob condições criogênicas;

$>$ Os valores de tenacidade à fratura no estado plano de deformação do polietileno de média densidade estudado - MDPE 8818, quando congelado por imersão em nitrogênio líquido, obtidos a partir de ensaios realizados conforme a norma ASTM D 5045-99 são 4,23 MPam ${ }^{1 / 2}$, quando a pré-trinca é introduzida por meio de "batidinhas" sobre uma lâmina de barbear, e 3,74 $\mathrm{MPam}^{1 / 2}$, quando a pré-trinca é introduzida por meio do pressionamento lento e controlado da lâmina de barbear. 


\subsection{ENSAIOS DE INTEGRAL-J}

Ensaios de Integral-J realizados em PEMD, conforme a norma ASTM D 606896 ou conforme o protocolo de ensaios do ESIS levam a resultados inesperados. Determinados mecanismos de deformação e de fratura típicos do material e que atuam na zona de processo podem violar princípios do método da Integral-J, requerendo uma revisão mais profunda do conceito em relação ao material estudado.

\subsection{ENSAIOS DE EWF}

$>$ O método EWF se aplica bem ao polietileno de média densidade, sendo que o trabalho específico de fratura escala linearmente com o comprimento do ligamento do corpo de prova.

$>$ Diferentes técnicas de introdução de pré-trincas em corpos de prova para ensaios de EWF em polietileno de média densidade, conforme o protocolo de ensaios do ESIS, produzem diferentes estruturas de deformação na matriz do material na ponta da trinca e afetam os resultados;

> O parâmetro do método EWF mais sensível à técnica de introdução de prétrincas em PEMD é $\beta w_{p}$, o que sugere que o dano provocado na raiz da trinca inicial influencia a formação da zona plástica no processo de fratura.

$>$ Métodos mais grosseiros de pré-trincamento aumentam a dispersão dos resultados de ensaios de EWF em polietileno de média densidade;

$>\mathrm{O}$ processamento afeta os resultados do método EWF em polietileno de média densidade;

> Os valores dos parâmetros do método EWF para o polietileno de média densidade estudado - Rigidex PC 002-50R968, obtidos de acordo com o protocolo de ensaio do ESIS, a partir de corpos de prova com espessura de 1 $\mathrm{mm}$, extraídos de placas moldadas por compressão, contendo pré-trinca introduzidas por meio de corte reto com lâmina de barbear são: (i) $w_{e}: 43,44 \pm$ $7,98 \mathrm{~kJ} / \mathrm{m}^{2}$; (ii) $\beta w_{p}: 10,21 \pm 0,69 \mathrm{MJ} / \mathrm{m}^{3}$. 


\section{APÊNDICE A: RESULTADOS INDIVIDUAIS DOS ENSAIOS DE EWF}

A1 RESULTADOS INDIVIDUAIS DE EWF DA SÉRIE S-0

\begin{tabular}{|c|c|c|c|c|c|}
\hline $\begin{array}{c}\mathrm{I} \\
(\mathrm{mm})\end{array}$ & $\begin{array}{c}\mathrm{t} \\
(\mathrm{mm})\end{array}$ & $\begin{array}{c}W_{f} \\
(m J)\end{array}$ & $\begin{array}{c}w_{f} \\
(k J / m 2)\end{array}$ & $\begin{array}{r}\sigma_{\max } \\
(\mathrm{MPa})\end{array}$ & $\begin{array}{c}\text { dados } \\
\text { inválidos }\end{array}$ \\
\hline 5,5 & 0,20 & 99,6 & 90,6 & 20,6 & critério de tensão \\
\hline 6,0 & 0,20 & 116,8 & 97,3 & 21,3 & critério de tensão \\
\hline 6,3 & 0,20 & 113,2 & 89,8 & 19,8 & critério de tensão \\
\hline 6,3 & 0,20 & 112,9 & 89,6 & 19,1 & \\
\hline 6,3 & 0,20 & 106,8 & 84,8 & 18,3 & \\
\hline 8,0 & 0,20 & 143,6 & 89,7 & 16,9 & \\
\hline 8,1 & 0,20 & 172,6 & 106,6 & 18,3 & \\
\hline 8,2 & 0,20 & 148,6 & 90,6 & 17,0 & \\
\hline 8,3 & 0,20 & 164,6 & 99,2 & 17,9 & \\
\hline 8,3 & 0,20 & 172,8 & 104,1 & 17,9 & \\
\hline 9,7 & 0,20 & 230,1 & 118,6 & 19,2 & \\
\hline 10,0 & 0,20 & 202,9 & 101,4 & 16,8 & \\
\hline 10,2 & 0,20 & 211,8 & 103,8 & 17,1 & \\
\hline 10,2 & 0,20 & 235,2 & 115,3 & 18,2 & \\
\hline 10,3 & 0,20 & 210,0 & 101,9 & 16,4 & \\
\hline 12,0 & 0,20 & 311,1 & 130,2 & 17,9 & \\
\hline 12,1 & 0,20 & 305,9 & 126,4 & 17,2 & \\
\hline 12,2 & 0,20 & 377,7 & 154,8 & 19,4 & análise de resíduos \\
\hline 12,3 & 0,20 & 298,2 & 121,2 & 16,9 & \\
\hline 12,5 & 0,20 & 302,9 & 121,2 & 16,2 & \\
\hline 13,9 & 0,20 & 377,5 & 135,8 & 16,2 & \\
\hline 14,1 & 0,20 & 354,1 & 125,6 & 15,4 & critério de tensão \\
\hline 14,1 & 0,20 & 355,8 & 126,2 & 15,7 & critério de tensão \\
\hline 14,3 & 0,20 & 432,3 & 151,2 & 17,3 & \\
\hline 14,4 & 0,20 & 435,3 & 151,1 & 17,1 & \\
\hline
\end{tabular}

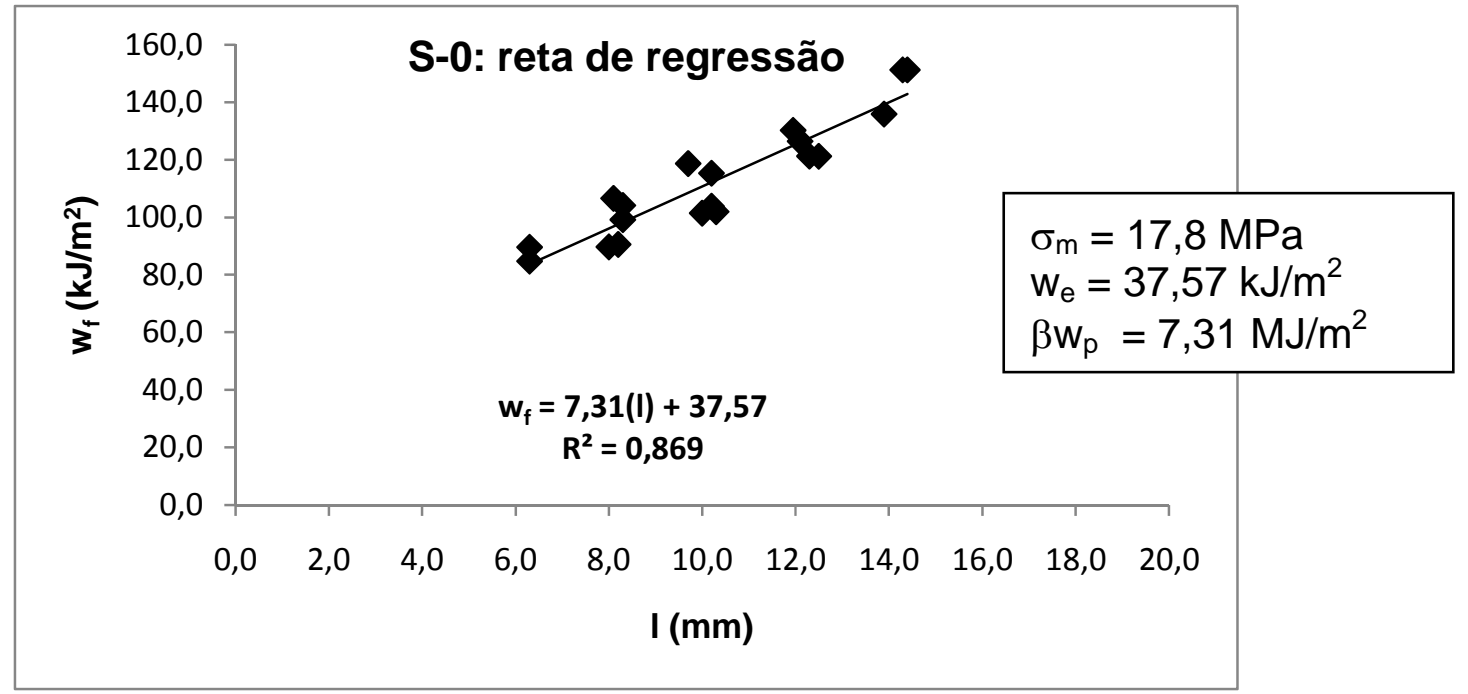

Figura 87: Reta de regressão da série S-0 (ensaios de EWF) 
A2 RESULTADOS INDIVIDUAIS DE EWF DA SÉRIE S-1

\begin{tabular}{|c|c|c|c|c|c|}
\hline $\begin{array}{c}\mathrm{I} \\
(\mathrm{mm})\end{array}$ & $\begin{array}{c}\mathrm{t} \\
(\mathrm{mm})\end{array}$ & $\begin{array}{c}W_{f} \\
(m J)\end{array}$ & $\begin{array}{c}w_{f} \\
\left(k J / m^{2}\right)\end{array}$ & $\begin{array}{c}\sigma_{\max } \\
(\mathrm{MPa})\end{array}$ & $\begin{array}{c}\text { dados } \\
\text { inválidos }\end{array}$ \\
\hline 6,15 & 0,199 & 126,8 & 103,5951 & 18,73024 & \\
\hline 5,30 & 0,193 & 85,0 & 83,09514 & 17,73683 & \\
\hline 6,59 & 0,221 & 157,8 & 108,3375 & 18,68593 & \\
\hline 6,45 & 0,194 & 125,8 & 100,4992 & 17,92776 & \\
\hline 6,04 & 0,195 & 115,9 & 98,42653 & 18,42248 & \\
\hline 7,65 & 0,190 & 183,8 & 126,4643 & 19,0602 & critério de tensão \\
\hline 7,97 & 0,188 & 183,1 & 122,2323 & 18,24395 & \\
\hline 8,22 & 0,187 & 156,3 & 101,6744 & 15,63098 & análise de resíduos \\
\hline 7,96 & 0,197 & 175,3 & 111,8006 & 15,94712 & \\
\hline 8,15 & 0,201 & 180,0 & 109,8517 & 16,23844 & \\
\hline 9,36 & 0,204 & 238,7 & 125,036 & 16,11415 & \\
\hline 9,56 & 0,204 & 265,4 & 136,0751 & 16,46823 & \\
\hline 9,54 & 0,201 & 280,0 & 146,024 & 17,45257 & \\
\hline 9,91 & 0,204 & 299,9 & 148,3369 & 17,28151 & \\
\hline 9,55 & 0,203 & 271,7 & 140,1517 & 17,3889 & \\
\hline 12,27 & 0,203 & 450,7 & 180,9345 & 16,83147 & \\
\hline 11,55 & 0,207 & 407,0 & 170,2137 & 17,43271 & \\
\hline 11,16 & 0,195 & 363,8 & 167,1518 & 17,46209 & \\
\hline 11,88 & 0,192 & 395,5 & 173,3803 & 17,1441 & \\
\hline 11,88 & 0,197 & 415,7 & 177,6281 & 17,12771 & \\
\hline 13,64 & 0,196 & 538,1 & 201,2748 & 16,91977 & \\
\hline 13,48 & 0,195 & 529,4 & 201,3918 & 16,9284 & \\
\hline 13,75 & 0,206 & 561,1 & 198,1092 & 16,61889 & \\
\hline 13,69 & 0,206 & 575,3 & 203,9921 & 16,64811 & \\
\hline 13,73 & 0,203 & 565,1 & 202,7569 & 16,66912 & \\
\hline 15,93 & 0,203 & 771,8 & 238,6617 & 16,30038 & \\
\hline 15,37 & 0,204 & 704,4 & 224,6619 & 16,45936 & \\
\hline 16,18 & 0,203 & 772,2 & 235,0996 & 16,04852 & \\
\hline 15,95 & 0,206 & 778,9 & 237,0468 & 16,45312 & \\
\hline 16,24 & 0,212 & 772,9 & 224,4994 & 15,80886 & \\
\hline
\end{tabular}

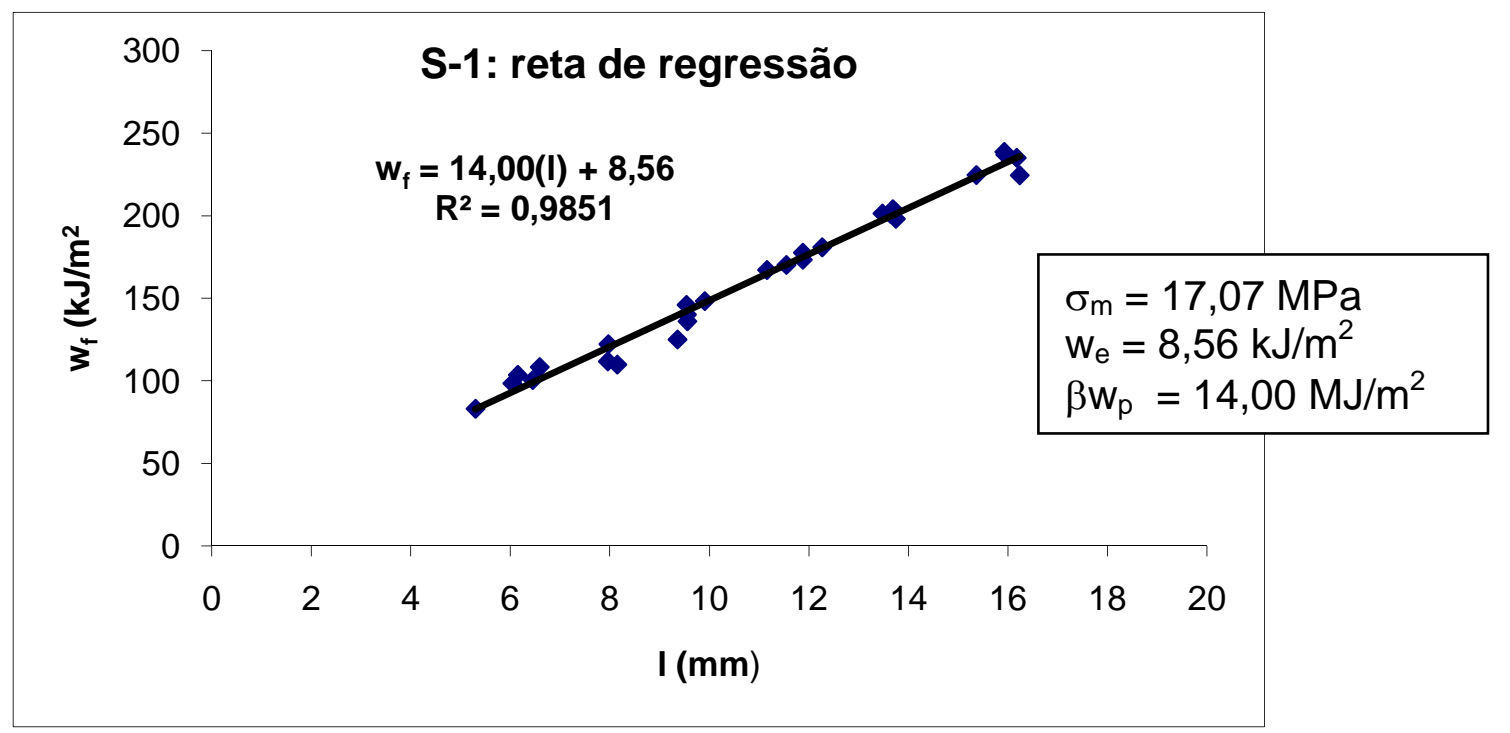

Figura 88: Reta de regressão da série S-1 (ensaios de EWF) 
A3 RESULTADOS INDIVIDUAIS DE EWF DA SÉRIE S-2

\begin{tabular}{|c|c|c|c|c|c|}
\hline $\begin{array}{c}\mathrm{I} \\
(\mathrm{mm})\end{array}$ & $\begin{array}{c}\mathrm{t} \\
(\mathrm{mm})\end{array}$ & $\begin{array}{c}W_{f} \\
(m J)\end{array}$ & $\begin{array}{c}W_{f} \\
\left(k J / m^{2}\right)\end{array}$ & $\begin{array}{c}\sigma_{\max } \\
(\mathrm{MPa})\end{array}$ & $\begin{array}{c}\text { dados } \\
\text { inválidos }\end{array}$ \\
\hline 5,93 & 0,212 & 102,10 & 81,22 & 19,40 & \\
\hline 5,16 & 0,208 & 76,29 & 71,08 & 19,53 & \\
\hline 5,66 & 0,213 & 100,34 & 83,23 & 19,73 & \\
\hline 6,13 & 0,205 & 95,39 & 75,91 & 18,14 & \\
\hline 6,26 & 0,208 & 97,90 & 75,19 & 17,89 & \\
\hline 7,96 & 0,200 & 154,71 & 97,18 & 18,94 & \\
\hline 7,95 & 0,199 & 151,24 & 95,60 & 18,21 & \\
\hline 8,09 & 0,214 & 176,34 & 101,86 & 18,62 & \\
\hline 8,05 & 0,214 & 173,44 & 100,68 & 18,15 & \\
\hline 8,03 & 0,209 & 168,04 & 100,13 & 18,41 & \\
\hline 9,74 & 0,210 & 239,46 & 117,07 & 18,52 & \\
\hline 9,99 & 0,209 & 246,66 & 118,14 & 18,38 & \\
\hline 9,73 & 0,206 & 231,57 & 115,53 & 18,10 & \\
\hline 10,13 & 0,213 & 250,59 & 116,14 & 18,18 & \\
\hline 9,98 & 0,214 & 253,71 & 118,79 & 18,19 & \\
\hline 12,00 & 0,211 & 343,61 & 135,71 & 17,82 & \\
\hline 12,19 & 0,209 & 346,13 & 135,86 & 17,61 & \\
\hline 12,06 & 0,209 & 343,82 & 136,41 & 17,22 & \\
\hline 12,09 & 0,209 & 354,92 & 140,46 & 17,56 & \\
\hline 14,17 & 0,207 & 445,09 & 151,74 & 17,43 & \\
\hline 14,02 & 0,215 & 492,61 & 163,42 & 17,32 & \\
\hline 14,27 & 0,214 & 486,22 & 159,22 & 17,58 & \\
\hline 13,81 & 0,211 & 488,34 & 167,59 & 17,08 & análise de resíduos \\
\hline 13,64 & 0,206 & 408,29 & 145,31 & 17,45 & \\
\hline 16,02 & 0,206 & 561,05 & 170,01 & 17,09 & \\
\hline 15,85 & 0,205 & 554,41 & 170,63 & 17,17 & \\
\hline 16,07 & 0,212 & 661,69 & 194,22 & 16,62 & análise de resíduos \\
\hline 16,01 & 0,209 & 574,29 & 171,63 & 16,82 & \\
\hline
\end{tabular}

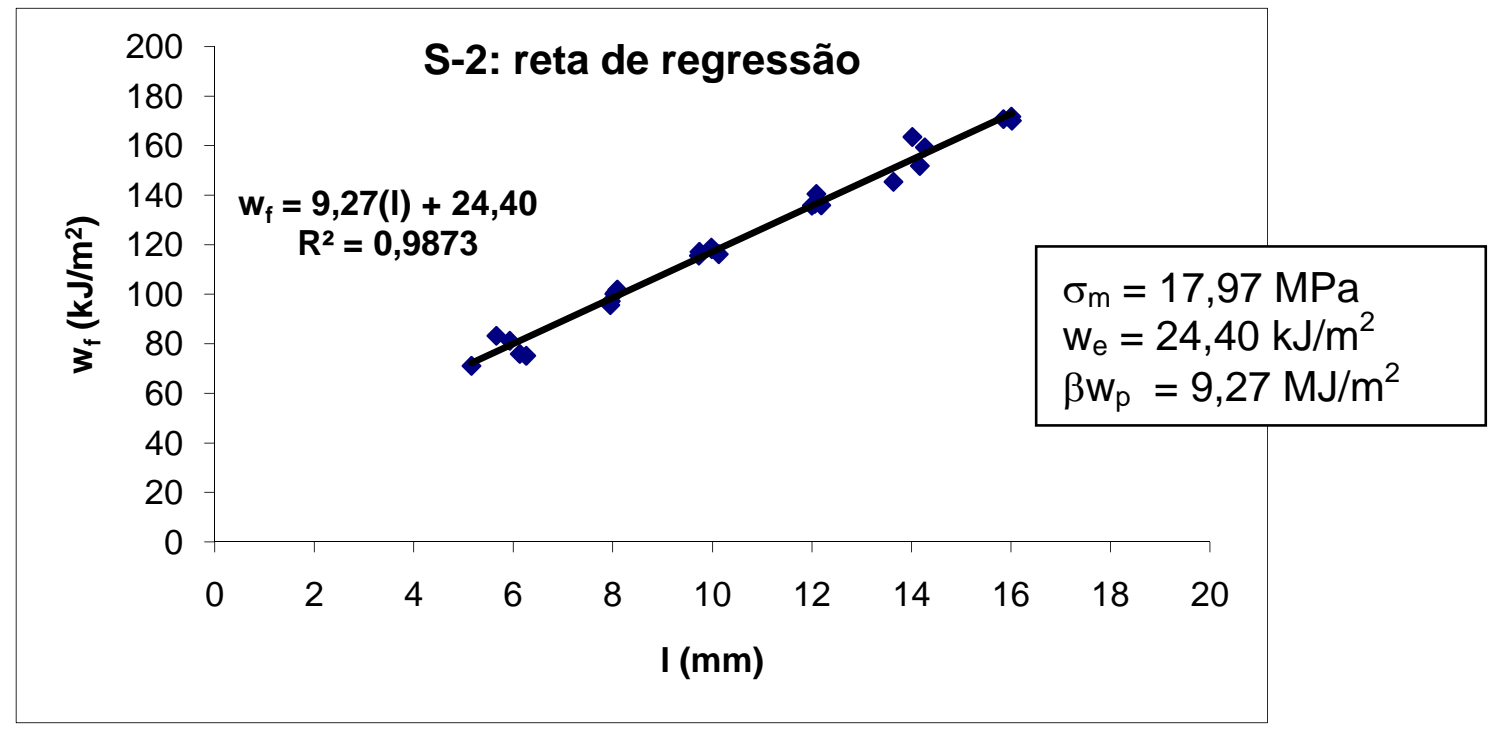

Figura 89: Reta de regressão da série S-2 (ensaios de EWF) 
A4 RESULTADOS INDIVIDUAIS DE EWF DA SÉRIE S-3

\begin{tabular}{|c|c|c|c|c|c|}
\hline $\begin{array}{c}\mathrm{I} \\
(\mathrm{mm})\end{array}$ & $\begin{array}{c}\mathrm{t} \\
(\mathrm{mm})\end{array}$ & $\begin{array}{c}W_{f} \\
(\mathrm{~mJ})\end{array}$ & $\begin{array}{c}W_{f} \\
\left(k J / m^{2}\right)\end{array}$ & $\begin{array}{c}\sigma_{\max } \\
(\mathrm{MPa})\end{array}$ & $\begin{array}{c}\text { dados } \\
\text { inválidos }\end{array}$ \\
\hline 5,30 & 0,198 & 0,11 & 101,76 & 19,98 & análise de resíduos \\
\hline 6,12 & 0,194 & 0,12 & 101,40 & 18,58 & \\
\hline 5,84 & 0,201 & 0,12 & 105,09 & 18,90 & \\
\hline 5,85 & 0,192 & 0,11 & 96,85 & 18,34 & \\
\hline 5,60 & 0,192 & 0,10 & 97,18 & 18,81 & \\
\hline 5,88 & 0,195 & 0,11 & 95,74 & 18,50 & \\
\hline 8,11 & 0,185 & 0,18 & 118,66 & 17,24 & análise de resíduos \\
\hline 7,61 & 0,193 & 0,18 & 120,38 & 18,28 & \\
\hline 7,86 & 0,191 & 0,18 & 121,22 & 17,88 & \\
\hline 7,96 & 0,195 & 0,20 & 131,29 & 18,40 & \\
\hline 10,01 & 0,200 & 0,31 & 155,92 & 18,55 & \\
\hline 9,91 & 0,213 & 0,34 & 161,14 & 18,93 & \\
\hline 9,56 & 0,193 & 0,28 & 149,98 & 18,34 & \\
\hline 10,19 & 0,197 & 0,33 & 165,49 & 19,05 & \\
\hline 9,97 & 0,188 & 0,30 & 159,50 & 18,57 & \\
\hline 11,71 & 0,200 & 0,44 & 186,03 & 18,63 & \\
\hline 12,05 & 0,197 & 0,44 & 186,46 & 17,76 & \\
\hline 11,55 & 0,191 & 0,42 & 190,84 & 19,28 & \\
\hline 11,61 & 0,194 & 0,41 & 182,30 & 17,96 & \\
\hline 11,64 & 0,187 & 0,41 & 187,48 & 18,64 & \\
\hline 14,61 & 0,193 & 0,67 & 236,87 & 18,74 & \\
\hline 13,41 & 0,198 & 0,54 & 201,91 & 18,14 & \\
\hline 13,38 & 0,182 & 0,53 & 215,86 & 18,68 & \\
\hline 14,17 & 0,213 & 0,66 & 217,24 & 18,20 & \\
\hline 12,96 & 0,213 & 0,56 & 202,52 & 18,52 & \\
\hline 16,17 & 0,198 & 0,80 & 249,64 & 17,69 & \\
\hline 15,21 & 0,188 & 0,71 & 247,37 & 18,39 & \\
\hline 15,62 & 0,199 & 0,74 & 239,33 & 17,79 & \\
\hline 15,61 & 0,192 & 0,75 & 250,43 & 18,04 & \\
\hline 15,69 & 0,213 & 0,81 & 243,31 & 18,34 & \\
\hline
\end{tabular}

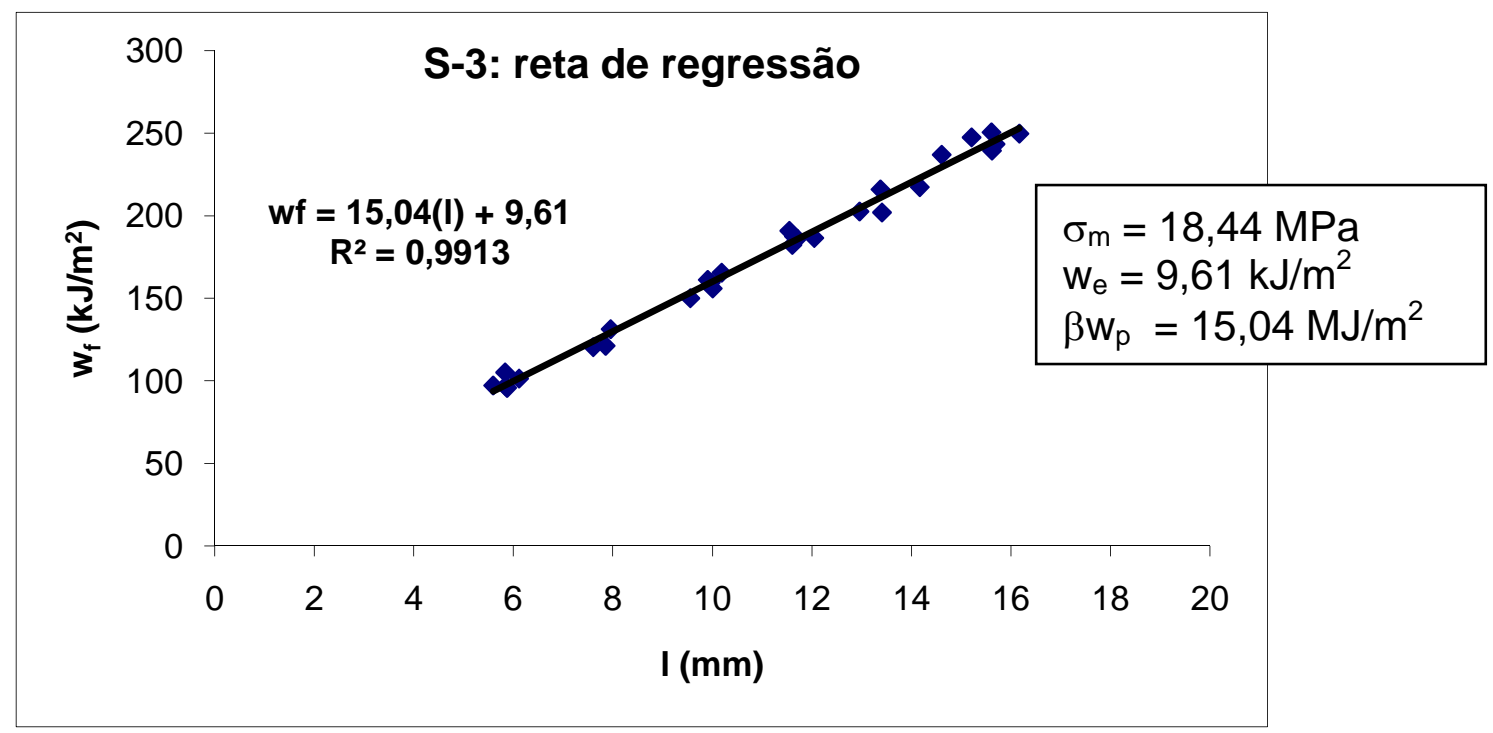

Figura 90: Reta de regressão da série S-3 (ensaios de EWF) 
A5 RESULTADOS INDIVIDUAIS DE EWF DA SÉRIE S-4

\begin{tabular}{|c|c|c|c|c|c|}
\hline $\begin{array}{c}\mathrm{I} \\
(\mathrm{mm})\end{array}$ & $\begin{array}{c}\mathrm{t} \\
(\mathrm{mm})\end{array}$ & $\begin{array}{c}W_{f} \\
(\mathrm{~mJ})\end{array}$ & $\begin{array}{c}\mathrm{W}_{\mathrm{f}} \\
\left(\mathrm{kJ} / \mathrm{m}^{2}\right)\end{array}$ & $\begin{array}{c}\sigma_{\max } \\
(\mathrm{MPa})\end{array}$ & $\begin{array}{c}\text { dados } \\
\text { inválidos }\end{array}$ \\
\hline 5,39 & 0,206 & 95,30 & 85,83 & 19,54 & \\
\hline 5,34 & 0,206 & 85,38 & 77,61 & 19,06 & \\
\hline 5,74 & 0,206 & 97,94 & 82,83 & 19,08 & \\
\hline 6,43 & 0,206 & 113,76 & 85,89 & 19,43 & \\
\hline 6,20 & 0,213 & 116,62 & 88,31 & 19,96 & \\
\hline 7,87 & 0,215 & 171,99 & 101,65 & 19,20 & \\
\hline 7,96 & 0,192 & 178,28 & 116,65 & 20,48 & análise de resíduos \\
\hline 8,37 & 0,195 & 173,82 & 106,50 & 18,85 & \\
\hline 10,11 & 0,191 & 230,15 & 119,19 & 18,54 & \\
\hline 9,89 & 0,205 & 239,97 & 118,36 & 17,96 & \\
\hline 9,56 & 0,201 & 225,14 & 117,16 & 18,69 & \\
\hline 9,68 & 0,203 & 220,51 & 112,22 & 18,47 & \\
\hline 10,12 & 0,214 & 266,82 & 123,20 & 18,28 & \\
\hline 11,34 & 0,210 & 336,37 & 141,25 & 18,74 & \\
\hline 10,98 & 0,211 & 314,36 & 135,69 & 18,68 & \\
\hline 10,82 & 0,213 & 295,60 & 128,26 & 18,35 & \\
\hline 11,90 & 0,195 & 311,50 & 134,24 & 18,28 & \\
\hline 11,61 & 0,199 & 307,85 & 133,24 & 18,09 & \\
\hline 13,94 & 0,207 & 449,04 & 155,62 & 17,93 & \\
\hline 14,02 & 0,207 & 501,20 & 172,70 & 17,83 & análise de resíduos \\
\hline 13,91 & 0,200 & 425,04 & 152,78 & 17,93 & \\
\hline 14,06 & 0,201 & 451,62 & 159,80 & 17,91 & \\
\hline 15,49 & 0,204 & 587,47 & 185,91 & 17,15 & análise de resíduos \\
\hline 15,84 & 0,203 & 550,71 & 171,27 & 17,35 & \\
\hline 15,15 & 0,203 & 519,38 & 168,88 & 17,66 & \\
\hline
\end{tabular}

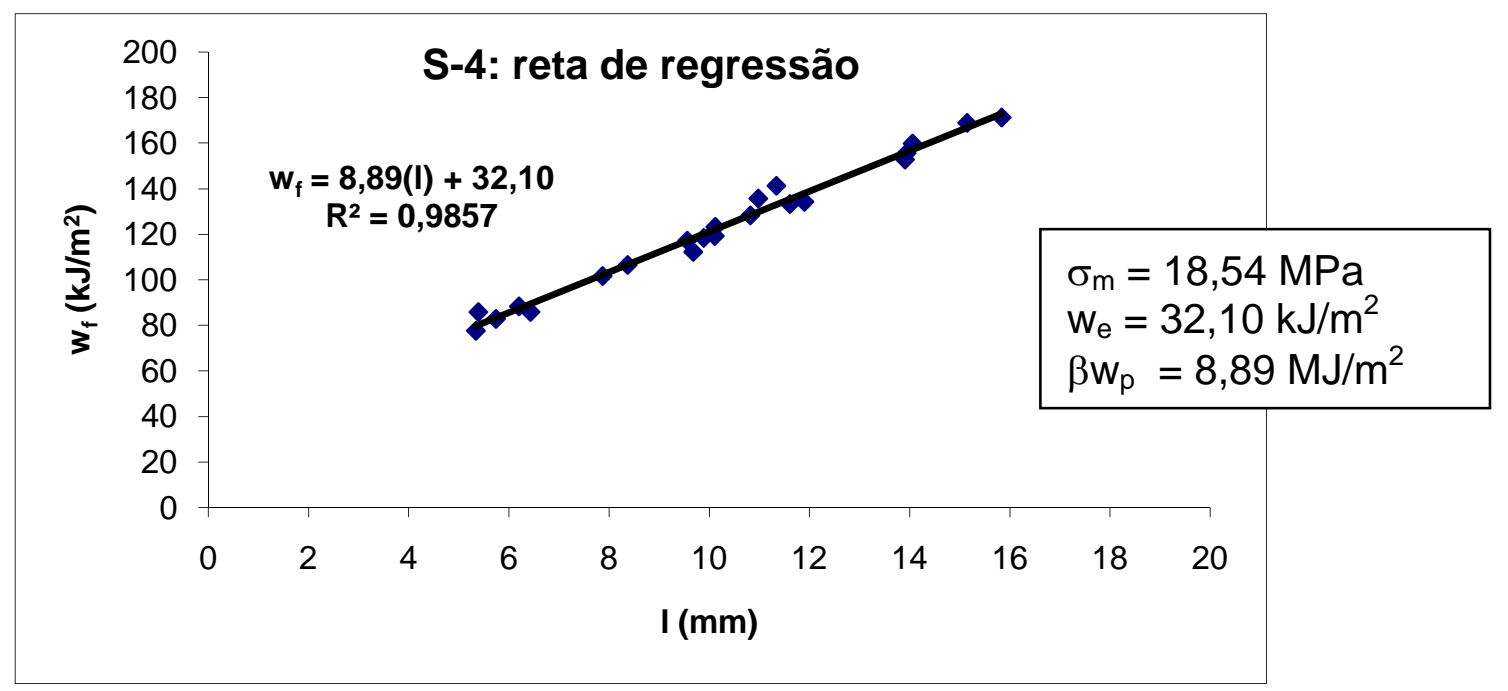

Figura 91: Reta de regressão da série S-4 (ensaios de EWF) 
A6 RESULTADOS INDIVIDUAIS DE EWF DA SÉRIE S-5

\begin{tabular}{cccccc}
\hline $\begin{array}{c}\mathbf{I} \\
\mathbf{( m m})\end{array}$ & $\begin{array}{c}\mathbf{t} \\
\mathbf{( m m})\end{array}$ & $\begin{array}{c}\mathbf{W}_{\mathbf{f}} \\
\mathbf{( m )})\end{array}$ & $\begin{array}{c}\mathbf{W}_{\mathbf{f}} \\
\mathbf{( k J / \mathbf { m } ^ { 2 }} \mathbf{)}\end{array}$ & $\begin{array}{c}\sigma_{\mathbf{m a x}} \\
\mathbf{( M P a})\end{array}$ & $\begin{array}{c}\text { dados } \\
\text { inválidos }\end{array}$ \\
\hline 5,92 & 0,832 & 499,54 & 101,42 & 21,65 & \\
5,67 & 0,824 & 469,31 & 100,45 & 22,93 & \\
6,40 & 0,792 & 571,86 & 112,82 & 22,20 & \\
5,60 & 0,795 & 446,63 & 100,32 & 21,86 & \\
8,04 & 0,825 & 845,01 & 127,39 & 21,14 & \\
8,04 & 0,803 & 769,13 & 119,13 & 21,65 & \\
7,59 & 0,790 & 708,72 & 118,20 & 21,43 & \\
8,76 & 0,854 & 924,50 & 123,58 & 20,78 & \\
8,56 & 0,811 & 867,49 & 124,96 & 20,94 & \\
10,14 & 0,831 & 1256,25 & 149,09 & 20,19 & \\
9,92 & 0,812 & 1185,48 & 147,17 & 21,37 & \\
10,38 & 0,822 & 1240,15 & 145,35 & 19,70 & \\
9,45 & 0,784 & 1101,12 & 148,62 & 21,39 & \\
11,69 & 0,831 & 1640,06 & 168,83 & 20,61 & \\
11,77 & 0,831 & 1671,61 & 170,91 & 20,30 & \\
12,14 & 0,831 & 1628,04 & 161,38 & 21,29 & \\
12,11 & 0,813 & 1762,04 & 178,97 & 20,15 & \\
12,34 & 0,798 & 1721,58 & 174,83 & 20,52 & \\
14,01 & 0,821 & 2132,29 & 185,38 & 20,89 & \\
14,27 & 0,802 & 2146,78 & 187,58 & 20,22 & \\
14,21 & 0,783 & 2122,47 & 190,76 & 20,71 & \\
13,99 & 0,805 & 2121,06 & 188,34 & 20,22 & \\
14,36 & 0,827 & 2290,74 & 192,89 & 19,80 & \\
16,34 & 0,818 & 2733,27 & 204,49 & 20,40 & \\
16,21 & 0,808 & 2840,84 & 216,90 & 19,77 & \\
16,02 & 0,810 & 2555,73 & 196,96 & 20,67 & \\
16,32 & 0,840 & 2777,42 & 202,60 & 19,49 & \\
16,21 & 0,846 & 3219,73 & 234,78 & 21,56 & análise de resíduos \\
\hline & & & & & \\
& & & & & \\
& &
\end{tabular}

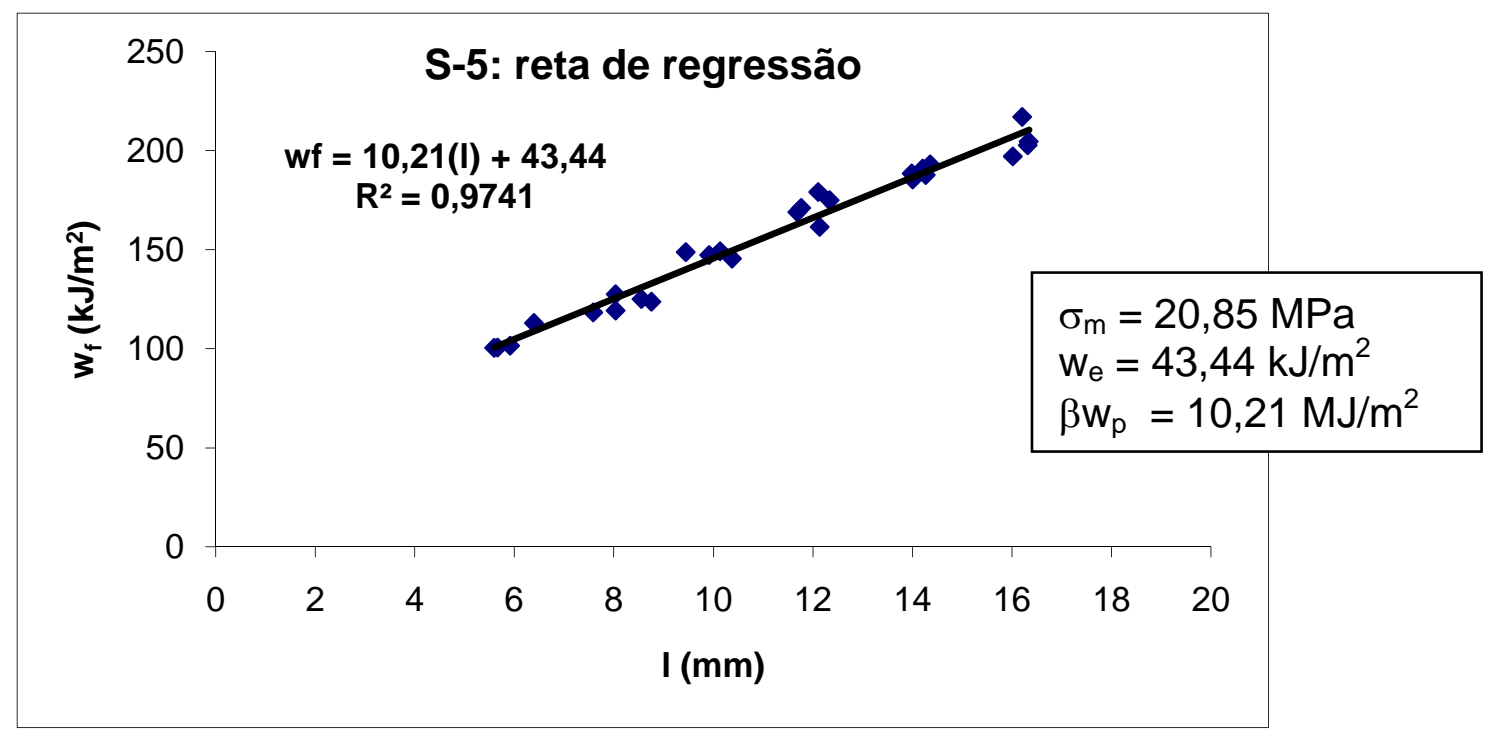

Figura 92: Reta de regressão da série S-5 (ensaios de EWF) 
A7 RESULTADOS INDIVIDUAIS DE EWF DA SÉRIE S-6

\begin{tabular}{|c|c|c|c|c|c|}
\hline $\begin{array}{c}\mathrm{I} \\
(\mathrm{mm})\end{array}$ & $\begin{array}{c}\mathrm{t} \\
(\mathrm{mm})\end{array}$ & $\begin{array}{c}W_{f} \\
(\mathrm{~mJ})\end{array}$ & $\begin{array}{c}W_{f} \\
\left(k J / m^{2}\right)\end{array}$ & $\begin{array}{c}\sigma_{\max } \\
(\mathrm{MPa})\end{array}$ & $\begin{array}{c}\text { dados } \\
\text { inválidos }\end{array}$ \\
\hline 5,70 & 0,845 & 479,48 & 99,55 & 21,68 & \\
\hline 5,84 & 0,810 & 482,60 & 102,02 & 22,80 & \\
\hline 6,36 & 0,848 & 559,61 & 103,76 & 21,41 & \\
\hline 5,89 & 0,836 & 496,96 & 100,92 & 22,06 & \\
\hline 7,62 & 0,818 & 751,51 & 120,57 & 21,28 & \\
\hline 8,05 & 0,802 & 815,18 & 126,27 & 21,68 & \\
\hline 8,11 & 0,810 & 867,70 & 132,09 & 21,46 & \\
\hline 7,66 & 0,774 & 703,67 & 118,69 & 21,88 & \\
\hline 8,34 & 0,813 & 890,26 & 131,30 & 21,59 & \\
\hline 9,54 & 0,803 & 1128,78 & 147,35 & 20,74 & \\
\hline 10,14 & 0,809 & 1178,37 & 143,65 & 21,31 & \\
\hline 9,79 & 0,801 & 1170,97 & 149,32 & 21,01 & \\
\hline 9,68 & 0,801 & 1106,36 & 142,69 & 21,15 & \\
\hline 9,08 & 0,837 & 1101,01 & 144,87 & 21,32 & \\
\hline 11,65 & 0,791 & 1496,63 & 162,41 & 21,20 & \\
\hline 12,08 & 0,827 & 1767,36 & 176,91 & 20,61 & \\
\hline 12,27 & 0,816 & 1742,31 & 174,02 & 20,40 & \\
\hline 11,70 & 0,835 & 1636,64 & 167,53 & 20,20 & \\
\hline 11,62 & 0,815 & 1593,48 & 168,26 & 20,87 & \\
\hline 14,00 & 0,822 & 2288,98 & 198,90 & 20,15 & \\
\hline 13,69 & 0,842 & 2203,04 & 191,12 & 20,87 & \\
\hline 14,00 & 0,813 & 2245,45 & 197,28 & 20,25 & \\
\hline 13,96 & 0,832 & 2052,17 & 176,69 & 20,88 & análise de resíduos \\
\hline 15,84 & 0,811 & 2739,60 & 213,26 & 20,17 & \\
\hline 16,06 & 0,819 & 3007,84 & 228,68 & 19,01 & análise de resíduos \\
\hline 15,04 & 0,803 & 2479,89 & 205,34 & 19,69 & \\
\hline 15,71 & 0,807 & 2660,42 & 209,85 & 19,76 & \\
\hline 15,60 & 0,815 & 2687,91 & 211,41 & 19,98 & \\
\hline
\end{tabular}

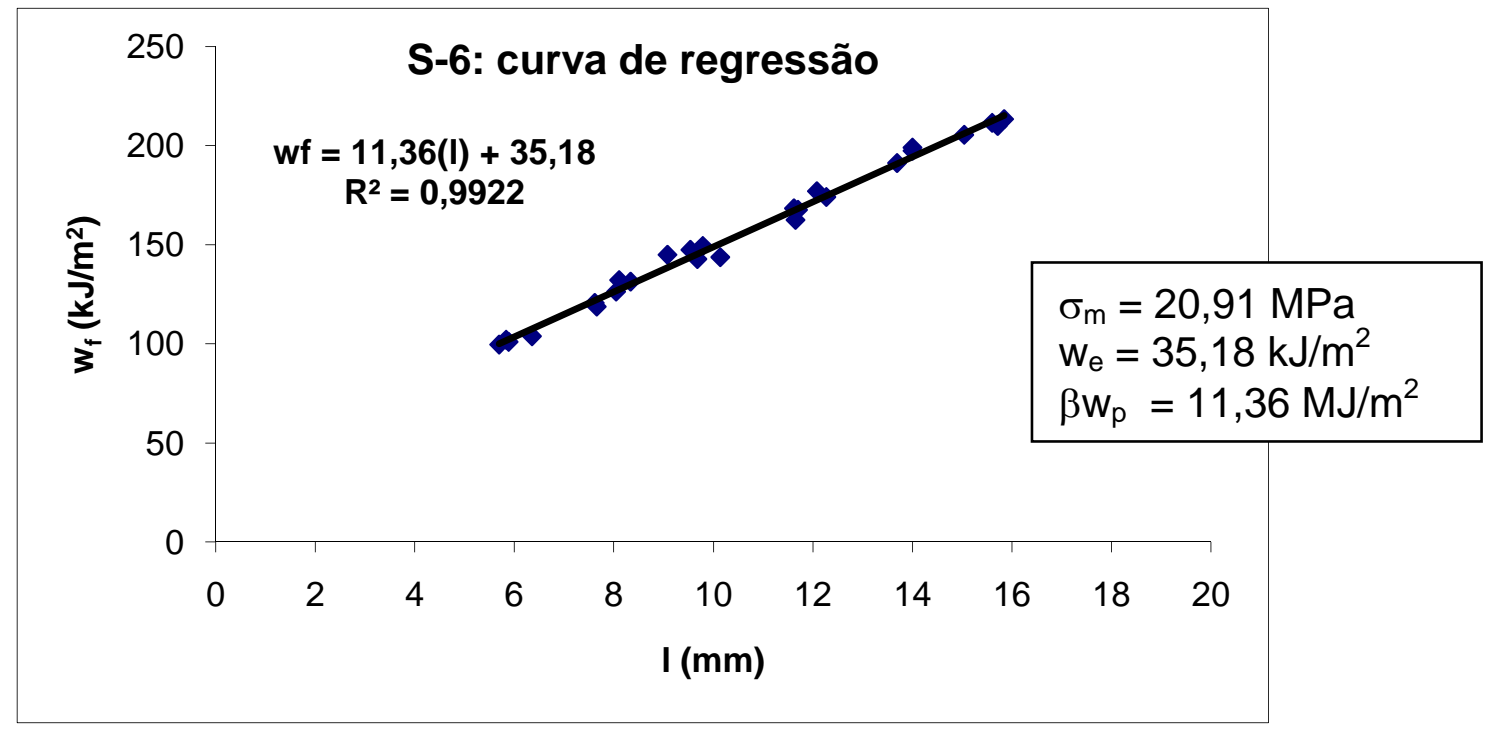

Figura 93: Reta de regressão da série S-6 (ensaios de EWF) 
A8 RESULTADOS INDIVIDUAIS DE EWF DA SÉRIE S-7

\begin{tabular}{|c|c|c|c|c|c|}
\hline $\begin{array}{c}\mathrm{I} \\
(\mathrm{mm})\end{array}$ & $\begin{array}{c}\mathrm{t} \\
(\mathrm{mm})\end{array}$ & $\begin{array}{c}W_{f} \\
(m J)\end{array}$ & $\begin{array}{c}W_{f} \\
\left(k J / m^{2}\right)\end{array}$ & $\begin{array}{c}\sigma_{\max } \\
(\mathrm{MPa})\end{array}$ & $\begin{array}{c}\text { dados } \\
\text { inválidos }\end{array}$ \\
\hline 5,76 & 3,09 & 1875,36 & 105,37 & 22,87 & \\
\hline 7,31 & 2,99 & 2797,09 & 127,97 & 22,43 & \\
\hline 6,28 & 3,10 & 2023,07 & 103,92 & 22,48 & \\
\hline 5,99 & 3,05 & 1945,01 & 106,46 & 22,61 & \\
\hline 5,86 & 3,05 & 1848,48 & 103,42 & 21,74 & \\
\hline 7,95 & 2,99 & 3208,18 & 134,96 & 21,71 & \\
\hline 8,28 & 3,09 & 3420,47 & 133,69 & 21,51 & \\
\hline 7,62 & 3,10 & 2972,27 & 125,83 & 21,33 & \\
\hline 7,64 & 3,06 & 3053,74 & 130,62 & 21,81 & \\
\hline 7,79 & 3,01 & 3224,59 & 137,52 & 20,96 & \\
\hline 9,57 & 3,04 & 4349,84 & 149,52 & 20,60 & \\
\hline 9,78 & 3,04 & 4074,74 & 137,05 & 18,93 & \\
\hline 9,96 & 2,98 & 4207,96 & 141,77 & 19,96 & \\
\hline 12,94 & 2,98 & 6722,59 & 174,34 & 20,14 & \\
\hline 13,47 & 3,18 & 8066,19 & 188,31 & 19,74 & \\
\hline 11,76 & 3,10 & 5914,17 & 162,23 & 19,10 & \\
\hline 12,23 & 3,01 & 6505,97 & 176,73 & 19,34 & \\
\hline 12,49 & 3,02 & 6432,08 & 170,52 & 19,60 & \\
\hline 13,60 & 3,06 & 7300,85 & 175,43 & 19,32 & análise de resíduos \\
\hline 13,31 & 3,03 & 7681,97 & 190,48 & 19,55 & \\
\hline 12,76 & 3,00 & 7298,49 & 190,66 & 19,52 & \\
\hline 14,39 & 3,05 & 8587,84 & 195,67 & 19,53 & \\
\hline 16,02 & 3,02 & 10977,99 & 226,91 & 18,89 & \\
\hline 15,44 & 3,06 & 10254,94 & 217,05 & 18,47 & \\
\hline 15,35 & 2,95 & 9634,21 & 212,76 & 19,19 & \\
\hline 15,77 & 3,00 & 10513,75 & 222,23 & 18,99 & \\
\hline
\end{tabular}

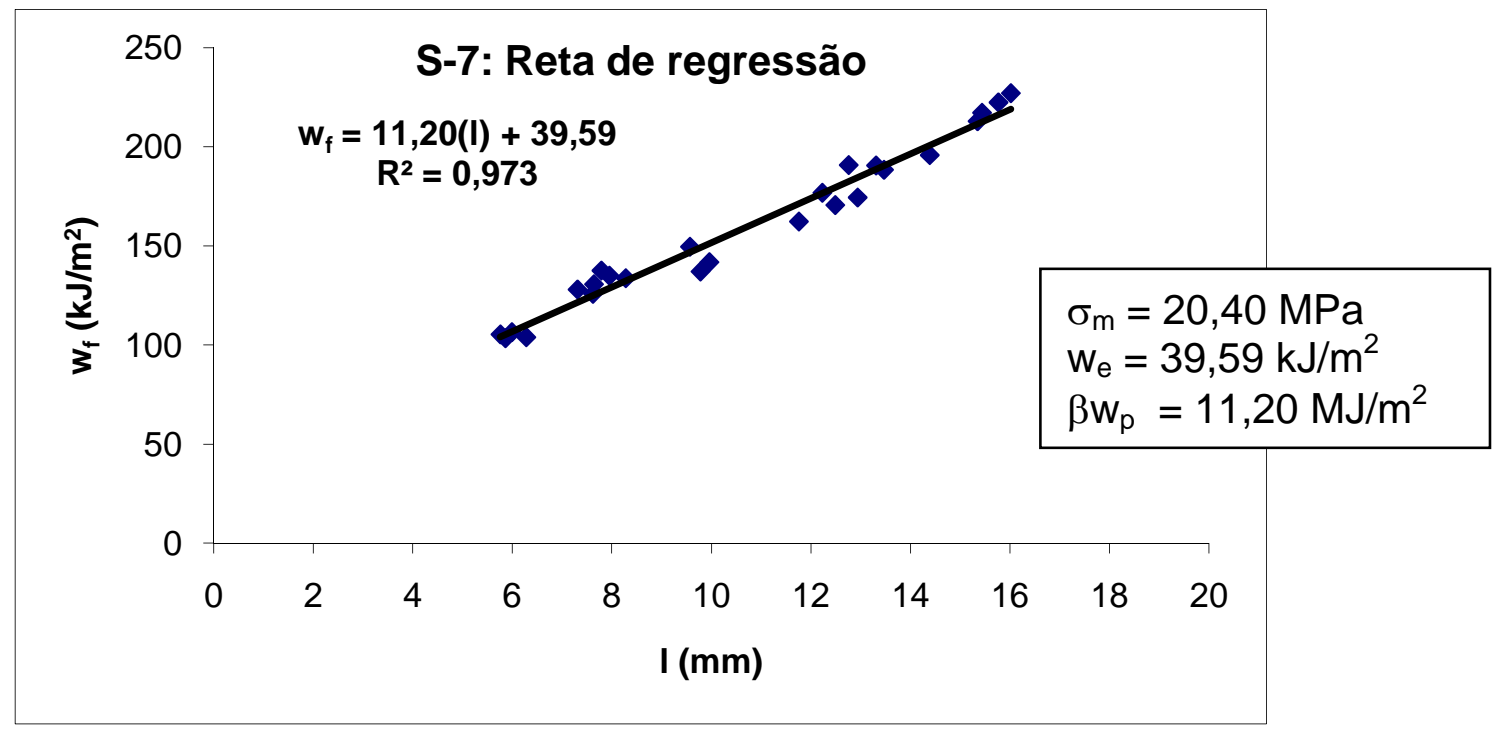

Figura 94: Reta de regressão da série S-7 (ensaios de EWF) 
A9 RESULTADOS INDIVIDUAIS DE EWF DA SÉRIE S-8

\begin{tabular}{|c|c|c|c|c|c|}
\hline $\begin{array}{c}\mathrm{I} \\
(\mathrm{mm})\end{array}$ & $\begin{array}{c}\mathrm{t} \\
(\mathrm{mm})\end{array}$ & $\begin{array}{c}W_{f} \\
(\mathrm{~mJ})\end{array}$ & $\begin{array}{c}\mathrm{W}_{\mathrm{f}} \\
\left(\mathrm{kJ} / \mathrm{m}^{2}\right)\end{array}$ & $\begin{array}{c}\sigma_{\max } \\
(\mathrm{MPa})\end{array}$ & $\begin{array}{c}\text { dados } \\
\text { inválidos }\end{array}$ \\
\hline 6,05 & 3,07 & 2016,56 & 108,64 & 22,92 & \\
\hline 5,98 & 3,07 & 2169,38 & 118,21 & 23,85 & \\
\hline 6,09 & 3,09 & 2105,40 & 111,88 & 23,26 & \\
\hline 5,99 & 3,05 & 2117,16 & 115,77 & 24,13 & \\
\hline 6,00 & 3,10 & 1969,13 & 105,90 & 22,35 & \\
\hline 7,88 & 3,06 & 3131,81 & 129,75 & 22,30 & \\
\hline 7,90 & 3,04 & 3454,91 & 144,00 & 22,43 & \\
\hline 7,70 & 3,07 & 3440,61 & 145,74 & 23,68 & \\
\hline 7,79 & 3,03 & 3406,62 & 144,56 & 23,25 & \\
\hline 10,15 & 3,08 & 5642,09 & 180,30 & 22,21 & \\
\hline 9,83 & 3,04 & 5092,93 & 170,26 & 23,07 & \\
\hline 9,84 & 3,01 & 4997,24 & 168,50 & 21,95 & \\
\hline 9,81 & 3,07 & 4997,01 & 166,19 & 22,50 & \\
\hline 10,22 & 2,99 & 4924,33 & 161,42 & 22,06 & \\
\hline 11,87 & 3,05 & 6667,18 & 184,10 & 22,14 & \\
\hline 11,78 & 2,99 & 7307,69 & 207,40 & 21,08 & \\
\hline 11,90 & 3,05 & 7197,07 & 198,10 & 21,05 & \\
\hline 11,85 & 3,12 & 7009,28 & 189,52 & 21,41 & \\
\hline 12,06 & 3,08 & 5718,76 & 153,81 & 21,53 & análise de resíduos \\
\hline 13,58 & 3,09 & 8586,37 & 204,69 & 21,36 & \\
\hline 14,06 & 2,99 & 8692,98 & 206,51 & 21,67 & \\
\hline 13,96 & 3,03 & 8963,95 & 211,85 & 21,87 & \\
\hline 13,93 & 3,14 & 8724,76 & 199,28 & 21,45 & \\
\hline 13,86 & 3,07 & 9029,76 & 211,94 & 22,18 & \\
\hline 15,93 & 3,01 & 11855,25 & 247,00 & 20,41 & \\
\hline 15,74 & 3,08 & 11482,19 & 237,23 & 21,65 & \\
\hline 15,78 & 3,09 & 11960,87 & 245,22 & 21,59 & \\
\hline 15,73 & 2,99 & 10893,93 & 231,39 & 21,17 & \\
\hline 15,78 & 3,07 & 11254,35 & 232,69 & 21,09 & \\
\hline
\end{tabular}

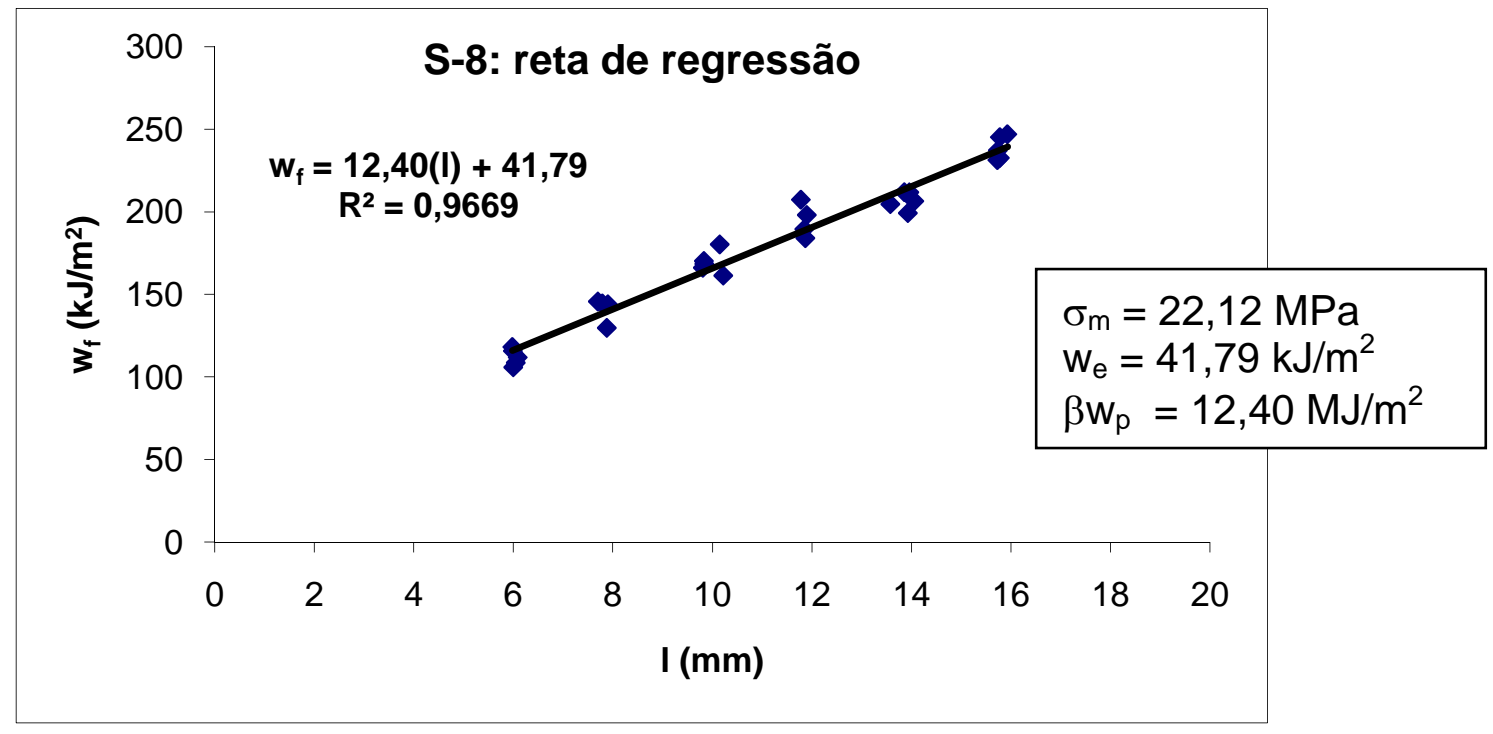

Figura 95: Reta de regressão da série S-8 (ensaios de EWF) 


\section{APÊNDICE B: CURVAS DE REGRESSÃO DOS MATERIAIS}

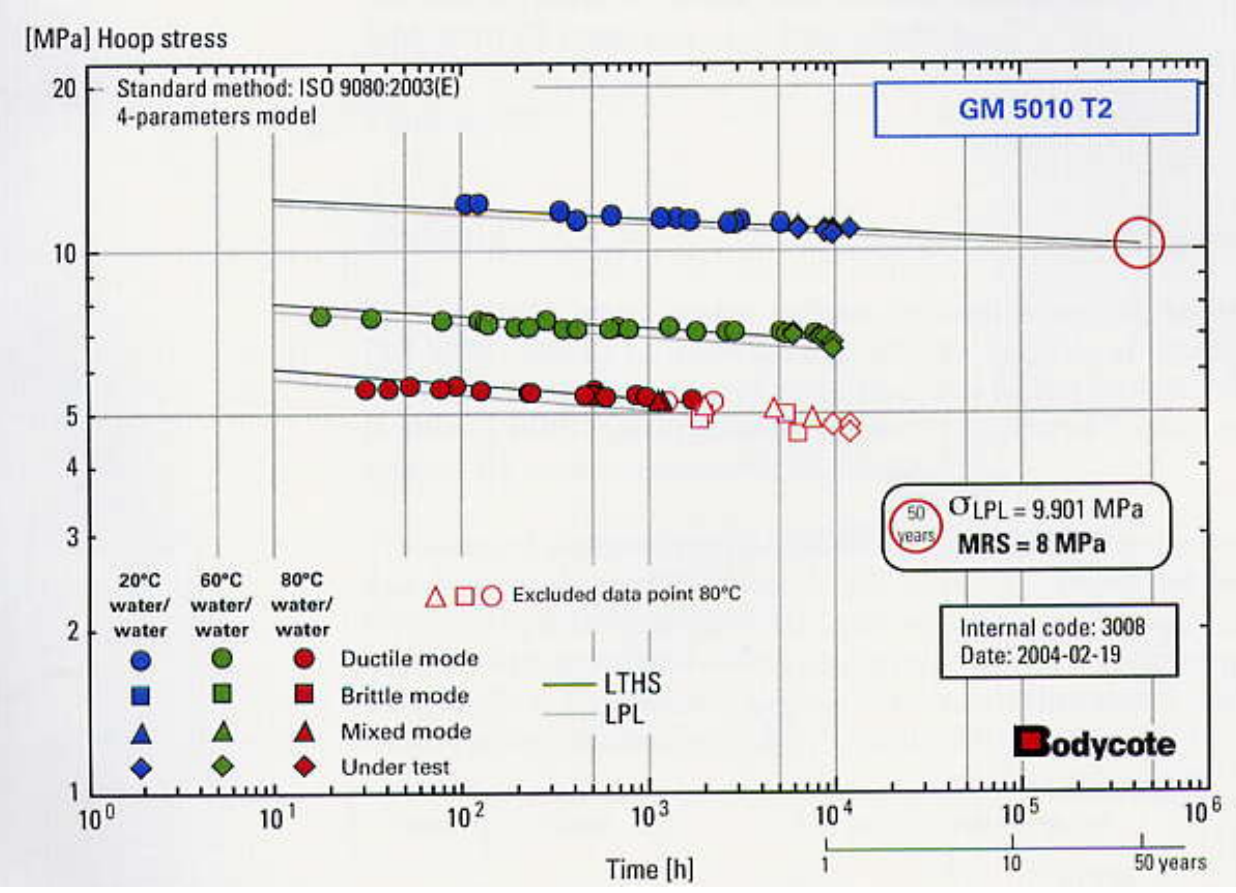

Figura 96 - "Curva de regressão" da resina GM 5010 T2, fornecida pelo fabricante.

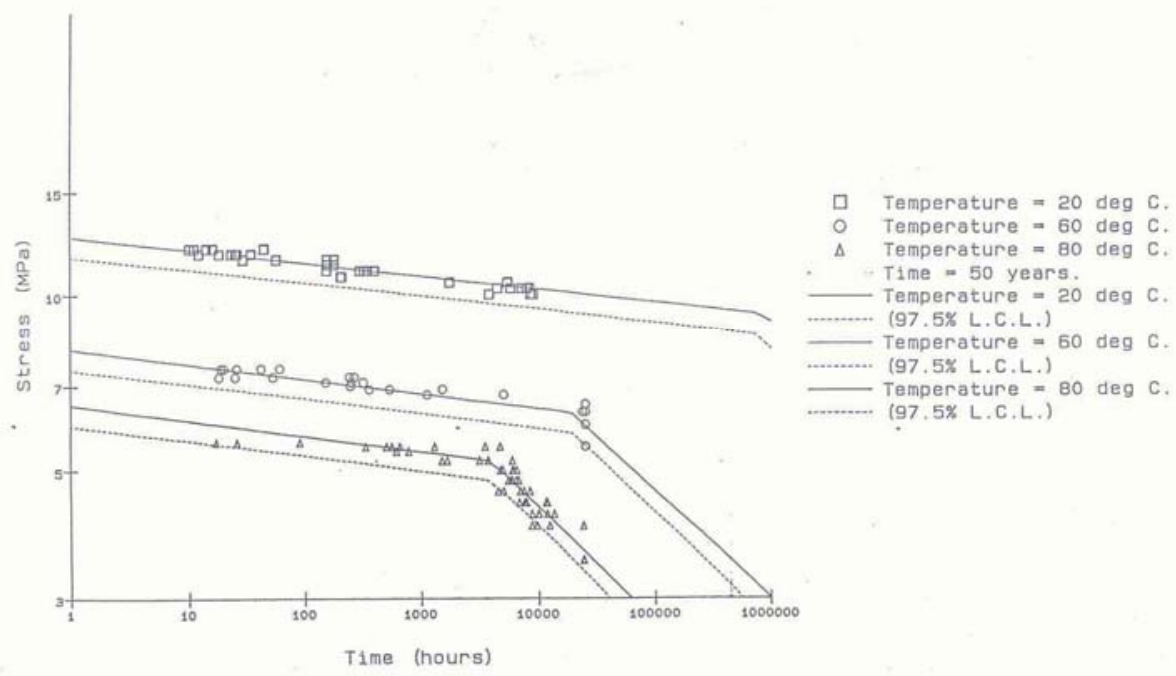

ISO DP9080 SEM 50YA LTHS - $9.38 \mathrm{MPa}$

Figura 97 - "Curva de regressão" da resina Rigidex PC 002-50R968, fornecida pelo fabricante. 


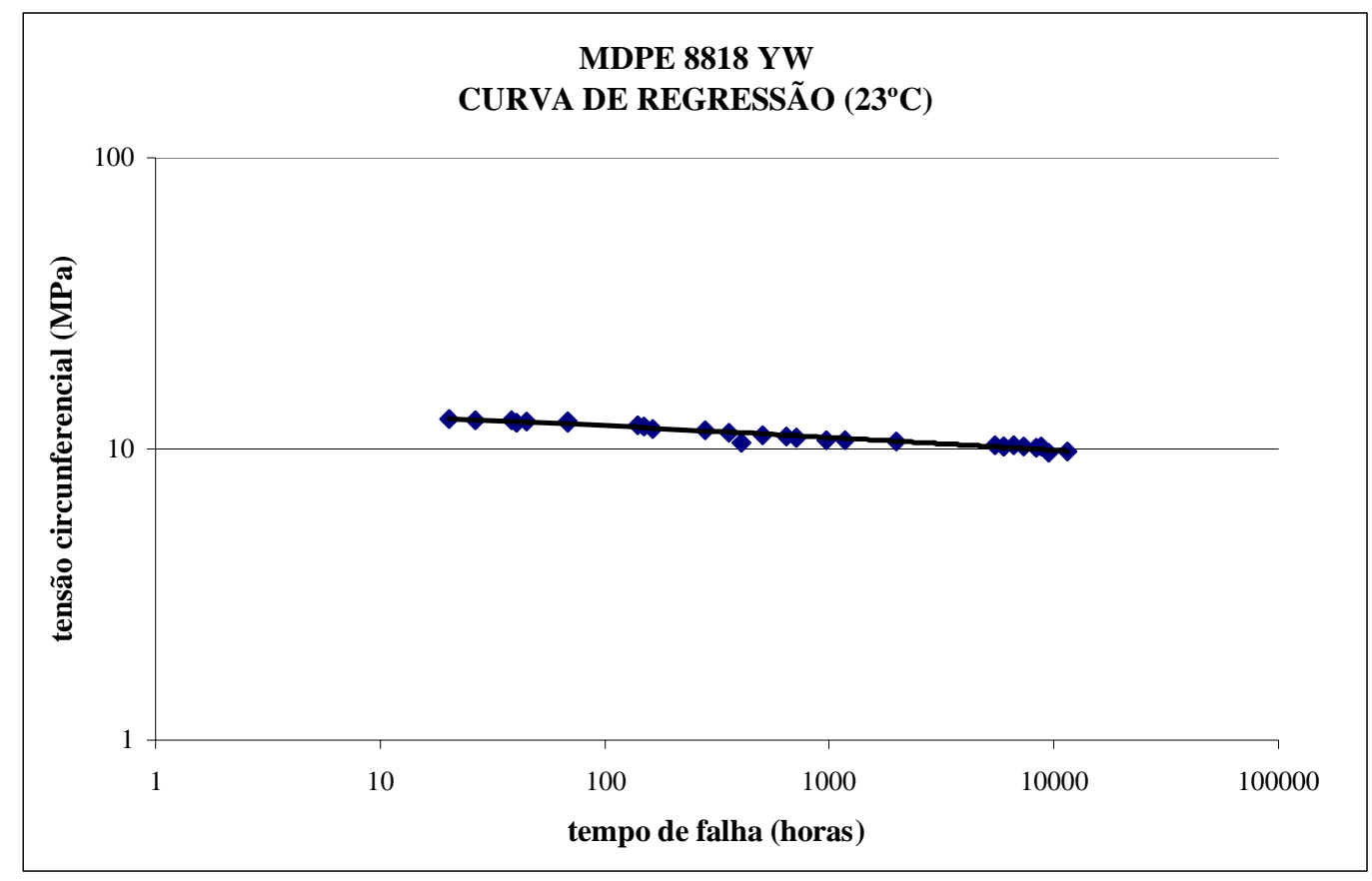

Figura 98 - "Curva de regressão" da resina MDPE 8818 YW. . A Figura é uma adaptação extraída do relatório fornecido à PBBPolisur S.A. pela Gastec N.V. - The Netherlands, referente ao material indicado na curva de regressão. 


\section{REFERÊNCIAS BIBLIOGRÁFICAS}

ASTM INTERNATIONAL. D 638-08: Standard Test Method for Tensile Properties of Plastics. West Conshohocken, 2008, 16p.

ASTM INTERNATIONAL. D 4703-03: Standard Practice for Compression Molding Thermoplastic Materials into Test Specimens, Plaques, or Sheets. West Conshohocken, 2007, 12p

ASTM INTERNATIONAL. D 5045 - 99: Standard Test Method for Plane-Strain Fracture Toughness and Strain Energy Release Rate of Plastic Materials. West Conshohocken, 1999, 9p

ASTM INTERNATIONAL. D 6068 - 96 (Reapproved 2002): Standard Test Method for Determining J-R Curves of Plastic Materials. West Conshohocken, 2002, 8p

ASTM INTERNATIONAL. E 813-89: Standard Test Methods for $\mathbf{J}_{\mathrm{lc}}-\mathbf{A}$ Measure of Fracture Toughness. West Conshohocken, 1989, 15p.

ASTM INTERNATIONAL. E 1737: Standard Test Method for J-Integral Characterization of Fracture Toughness.

ASTM INTERNATIONAL. E 1820-08: Standard Test Method for Measurement of Fracture Toughness. West Conshohocken, 2008, 48p

A ARQUITETURA da água. Pesquisa Fapesp, ed. 159, maio 2009, p.34.

ANDERSON, T.L. Fracture mechanics: fundamentals and applications. Boca Raton: CRC Press, $2^{\text {nd }} E d .$, 1995, 688p.

ANDRIANOPOULOS, N.P; PIKRAKIS, A. A new technique for the machining of natural cracks. In European Conference on Fracture, 16., 2006, Alexandropoulis, Geece. Proceedings of $16^{\text {th }}$ European Conference on Fracture - ECF 16. Dordrecht: Springer, 2006.

BARROS, I.Q. Introdução ao cálculo numérico. São Paulo: Edgard Blücher, 1972.

BARRY, D.B. and DELATYCKI, O., The Strain Rate Dependency of Fracture In Polyethylene: Fracture Initiation, Journal of Applied Polymer Science, v. 38, n. 2, p. 339-350, 1989.

BEGLEY, J.A.; LANDES, J.D. The $\mathbf{J}$ integral as a Fracture Criterion. In: National Symposium on Fracture Mechanics, 1971. Fracture Toughness, Proceedings of the 1971 National Symposium on Fracture Mechanics, Part II, ASTM 514, American Society for Testing and Materials, 1972, pp. 1-20.

BEGLEY, J.A.; LANDES, J.D. A comparison of the J-Integral fracture criterion with the equivalent energy concept. Progress in Flaw Growth and Fracture Toughness Testing, ASTM STP 536, American Society for Testing and Materials, $p$. 246-263, 1973. 
BOIKO, Y;M.; BACH, A.; JØRGENSEN, J.L. Self-bonding in a amorphous polymer below the glass transition: a T-Peel test investigation. Journal of Polymer Science: Part B: Polymer Physics, V. 42, p. 1861-1867, 2004.

BROBERG, K.B. Critical review of some theories in fracture mechanics. International Journal of Fracture Mechanics, 4, p. 11-18, 1968.

BROBERG, K.B. On the stable crack growth. Journal of the Mechanics and Physics of Solids, v. 23, p. 215-237,1975.

BROBERG, K.B. Critical review of some methods in non linear fracture mechanics. Engineering Fracture Mechanics, vl. 50, n. 2, p. 157-164, 1995.

BROEK, D. Elementary Engineering Fracture Mechanics. Dordrecht, The Netherlands: Kluwer Academic Publishers, $4^{\text {th }}$ ed., $5^{\text {th }}$ printing, 1991, 516p.

BROOKS, N.W.J.; DUCKETT, R.A.; WARD, I.M. Temperature and strain-rate dependence of yield stress of polyethylene. Journal of Polymer Science: Part B: Polymer Physics, v. 35, p. 2177-2189, 1998.

BROWN, N; LU, X; HUANG, Y-L; QIAN, R. Slow crack growth in polyethylene - a review. Makromol. Chem, Macromol. Symp, v. 41, p. 55-67, 1991.

CANEVAROLO JR, S.V. Ciência dos polímeros: um texto básico para tecnólogos e engenheiros. São Paulo: Artliber, 2002, 183p.

CAWOOD, M.J.; CHANNELL, A.D.; CAPACCIO, G. Crack initiation and fibre creep in polyethylene. Polymer, v. 34, n. 2, p. 423-425, 1993.

CHAN, M.K.V; WILLIAMS, J.G. Slow stable crack growth in high density polyethylenes. Polymer, vol. 24, pp. 234-244, 1983.

CHAN, M.K.V.; WILLIAMS, J.G. J-integral studies of crack initiation of a tough high density polyethylene. International Journal of Fracture, v.23, n. 2, p.145-159, 1983b.

CHAN, W.Y.F.; WILLIAMS, J.G. Determination of the fracture toughness of polymeric films by the essential work method. Polymer, v. 35, n. 8, pp. 16661672, 1994.

CHUDNOVSKY, A.; SHULKIN, Y. Application of the crack layer theory to modeling of slow crack growth in polyethylene. International Journal of Fracture, v. 97, p. 83-102, 1999.

CLARKE, G.A.; ANDREWS, W.R.; PARIS, P.C; SCHMIDT, D.W. Single specimen tests for $J_{l c}$ determination, in Mechanics of Crack Growth, ASTM STP 590, American Society for Testing and Materials, pp. 27-42, 1976. 
CLUTTON, E.. Essential work of fracture, in MOORE, D.R; PAVAN, A.; WILLIAMS, J.G. - Editors: Fracture mechanics testing methods for polymers, adhesives and composites. Amsterdam: Elsevier, ESIS Publication 28, 2001, p. 177-195.

COSTA NETO, P.L.O. Estatística. São Paulo: Edgard Blücher, 1977, 264p.

COTTERELL, B.; REDDEL, J.K. The essential work of plane stress ductile fracture. International Journal of Fracture, v. 13, n. 3, p. 267-277, 1977.

COTTERELL, B.; ATKINS, A.G. A review of the $\mathbf{J}$ and $\mathbf{I}$ integrals and their implications for crack growth resistance and toughness in ductile fracture. International Journal of Fracture, vl. 81, p. 357-372, 1996.

DAPP, E.K.; RIMNAC, C.M. Effect of precracking method on the static (JIntegral) fracture resistance of ultra high molecular weight polyethylene. BEDVol.39, Advances in Bioengineering, ASME 1998, p. 349-350,1998.

DOWLING, N.E. Mechanical behavior of materials - engineering methods for deformation, fracture, and fatigue. New Jersey: Prentice-Hall, $2^{\text {nd }}$ Ed., 1999, 830p.

DUAN, D.M.; WILLIAMS, J.G. Craze testing for tough polyethylene. Journal of Materials Science, 33, p. 625-638, 1998.

DUGDALE, D.S. Yielding of steel sheets containing slits. Journal of Mechanics and Physics of Solids, v. 8, p. 100-104, 1960.

EWALDS, H.L.; WANHILL, R.J.H. Fracture Mechanics. Delft, The Netherlands: Edward Arnold \& Delftse Uitgevers Maatschappij, 1986, 304p.

FAYOLE, B; VERDU, J. EWF method to study long term fracture properties of cross-linked polyethylene. Polymer Engineering and Science, v 45, n. 3, p. 424431, 2005.

GERE, J.M.; TIMOCHENKO, S.P. Mechanics of materials. Chap 6. London, UK: Chapman \& Hall, p 411, 1991

GRAICE, I.M.; YOUNAN, M.Y.A.; NAGA, S.A.R. Experimental investigation into the fracture toughness of polyethylene pipe material. Journal of Pressure Vessel Technology, v. 127, p.70-75, 2006.

GUZ, A.N. Constructing the non linear small-deformation theory in the mechanics of deformable bodies. International Applied Mechanics, v. 37, n. 8, 2001.

HAMOUDA, H.B., SIMOES-BETBEDER, M., GRILLON, F., BLOUET, P., BILLON, N. and PIQUES, R., Creep Damage Mechanisms in Polyethylene Gas Pipes. Polymer, 42, p. 5425-5437, 2001.

HALE, G.E.; RAMSTEINER, F.. J-Fracture toughness of polymers at slow speed, in MOORE, D.R.; PAVAN, A.; WILLIAMS, J.G. - Editors: Fracture mechanics 
testing methods for polymers, adhesives and composites. Amsterdam: Elsevier, ESIS Publication 28, 2001, p. 123-157.

HASHEMI, S. Fracture toughness evaluation of ductile polymeric films. Journal of Materials Science, v. 32, n. 6, p. 1563-1573, 1997.

HERTZBERG, R.W. Deformation and fracture mechanics of engineering materials. John Wiley \& Sons, 4.ed, 1995, 786p.

HUANG, Y-L; BROWN, N. The effect of molecular weight on slow crack growth in linear polyethylene homopolymers. Journal of Materials Science, v. 23, p. 3648, 1988.

HUTCHINSON, J.W. Singular behavior at the end of a tensile crack in a hardening material. Journal of Mechanics and Physics of Solids, v. 16, p.13-131, 1968.

HUTCHINSON, J.W. Plastic stress and strain fields at a crack tip. Journal of Mechanics and Physics of Solids, v. 16, p. 337-347, 1968b.

HUTCHINSON, J.W.; PARIS, P.C. Stability analysis of J-controlled crack-growth. Elastic-Plastic Fracture, ASTM STP 668, American Society for Testing and Materials, pp. 37-64, 1979.

INTERNATIONAL ORGANIZATION FOR STANDARDIZATION. ISO 9080: 2003. Plastic-piping and ducting systems - Determination of the long-term hydrostatic strength of thermoplastics materials in pipe form by extrapolation. 2003, 24p.

INTERNATIONAL ORGANIZATION FOR STANDARDIZATION. ISO 12162: 1995. Thermoplastics materials for pipes and fittings for pressure applications Classification and designation - Overall service (design) coefficient. 1995, 3p.

JANSON, L-E. Plastic pipes for water supply and sewage disposal. Stockholm: VBB/SWECO INTERNATIONAL, 2003. 404p.

KAPLAN, W.; LEWIS, D.J. Cálculo e álgebra linear - vol.4. Rio de Janeiro: Livros Técnicos e Científicos, 1974.

KARGER-KOCSIS, J; CZIGÁNY, T.; MOSKALA, E.J. Thickness dependence of work of fracture parameters of an amorphous copolyester. Polymer, v. 38, n. 18, p. 4587-4593, 1997.

KINLOCH, A.J.; YOUNG, R.J. Fracture behaviour of polymers. London: Chapman \& Hall, 1995. 496p.

KRISHNASWAMY, R.K. Analysis of ductile and brittle failures from creep rupture testing of high-density polyethylene (HDPE) pipes. Polymer, 46, p. 11664-11672, 2005. 
KRISHNASWAMY, R.K.; LAMBORN, M.J. The influence of process history on the ductile failure of polyethylene pipes subject to continuous hydrostatic pressure. Advances in Polymer Technology, v. 24, n. 3, p. 226-232, 2005.

LACH, R.; SCHNEIDER, K.; WEIDISCH, R.; JANKE, A.; KNOLL, K. Application of the essential work of fracture concept to nanostructured polymer materials. European Polymer Journal, 41, p. 383-392, 2005.

LANDES, J.D.; BEGLEY, J.A. The effect of specimen geometry on $\mathbf{J}_{\mathrm{Ic}}$. Fracture Toughness, Proceedings of the a971 National Symposium on Fracture Mechanics, Part II, ASTM STP 514, American Society for Testing and Materials, pp. 24-39, 1972.

LANDES, J.D.; BEGLEY, J.A. Test results from J-Integral studies: an attempt to stabklish a $J_{I c}$ testing procedure. Fracture analysis, ASTM STP 560, American Society for Testing and Materials, pp. 170-186, 1974.

LANDES, J.D.; BEGLEY, J.A. Recent Developments in $J_{\mathbf{l c}}$ testing, in BROWN, W,F.; KAUFMAN, J.G. - editors: Developments in Fracture Mechanics Test Methods Standardization. ASTM STP 632, American Society for Testing and Materials, pp. 58-81, 1977.

LANG, R.W.; STERN, A.; DOERNER, G. Applicability and limitations of current lifetime prediction models for thermoplastics pipes under internal pressure. Die Angewandte Makromolekulare Chemie, v. 247, p.131-145, 1997.

LAWN, B. Fracture of brittle solids. Cambridge, New York: Cambridge University Press, $2^{\text {nd }}$ ed., 1993, 378p.

LJUNGBERG, L.Y. Materials selection and design for structural polymers. Materials and Design, v. 24, n. 5, p. 383-390, 2003.

$\mathrm{LU}, \mathrm{X}$.; BROWN, N. The transition from ductile to slow crack growth failure in a copolymer of polyethylene. Journal of Materials Science, 25, p.411-416, 1990a.

$\mathrm{LU}, \mathrm{X}$;; BROWN, N. The ductile-brittle transition in a polyethylene copolymer. Journal of Materials Science, 25, p.29-34, 1990b.

LU, X; QIAN, R.; BROWN, N. Discontinuous crack growth in polyethylene under a constant load. Journal of Materials Science, v. 26, p. 917-924, 1991a.

LU, X; QIAN, R.; BROWN, N. Notchology - the effect of the notching method on the slow crack growth failure in a tough polyethylene. Journal of Materials Science, Vol. 26, pp. 881-888, 1991b.

$\mathrm{LU}, \mathrm{X}$; ZHOU, Z.; BROWN, N. The anisotropy of slow crack growth in polyethylene pipes. Polymer Engineering and Science, v. 34, n. 2, 1994.

MAI, Y.-W; COTTERELL, B. On the essential work of ductile fracture in polymers. International Journal of Fracture, v. 32, p. 105-125, 1986. 
MAI; Y.-W; COTTERELL, B.; HORLYCK, R.; VIGNA, G. The essential work of plane stress ductile fracture of linear polyethylenes. Polymer Engineering and Science, vol. 27, n. 11, p.804-809, 1987.

MAI, Y-W; POWELL, P. Essential work of fracture and J-Integral measurements for ductile polymers. Journal of Polymer Science: Part B: Polymer Physics, v. 29, p. 785-793, 1991.

MANO, E.B. Polímeros como materiais de engenharia. São Paulo: Edgard Blücher, 2001, 197p.

MARCHAL, Y.; WALHIN, J., DELANNAY, F. Statistical procedure for improving the precision of the measurement of the essential work of fracture of thin sheets. International Journal of Fracture, v. 87, p. 189-199, 1997.

MARTINS, G.A. Estatística Geral e Aplicada. São Paulo: Atlas, $2^{\mathrm{a}}$ Ed., 2002, 424p.

MASPOCH, M.L.; FERRER, D.; GORDILLO, A.; SANTANA, O.O.; MARTINEZ, A.B. Effect of the specimen dimensions and the test speed on the fracture toughness of iPP by essential work of fracture (EWF) method. Journal of Applied Polymer Science, v. 73, p.177-187, 1999.

MCCLINTOCK, F.A. Plasticity Aspects of Fracture, in LIEBOWITZ, H., editor: Fracture - an advanced treatise - Vol.3. New York: Academic Press, 1971, p. 47255.

MEGUID, S.A. Engineering Fracture Mechanics. London: Elsevier Applied Science, 1989, 397p.

MCMEEKING, R.M.; PARKS, D.M. On criterion for J-dominance of crack tip fields in large-scale yielding. Elastic-Plastic Fracture, ASTM STP 668, American Society for Testing and Materials, pp. 175-194, 1979.

MEYERS, M.A.; CHAWLA, K.K. Mechanical behavior of materials. John Wiley \& Sons, 1999, 680p.

MILLS, N.J. Plastics: microestructure \& engineering applications. London: Edward Arnold, $2^{\text {nd }}$ ed., 1993, 377 p.

MOORE, D.R.; PAVAN, A.; WILLIAMS, J.G. - Editors. Fracture mechanics testing methods for polymers, adhesives and composites. Amsterdam: Elsevier, ESIS Publication 28, 2001, 375p.

MOSKALA, E.J. A fracture mechanics approach to environmental stress cracking in poly(ethyleneterephthalate). Polymer, vol. 39, n. 3, p. 675-680, 1998.

NATIONAL TRANSPORTATION SAFETY BOARD - NTSB. NTSB/SIR-98/01: Special investigation report: brittle-like cracking in plastic pipe for gas service. 1998. Disponível em <http://www.ntsb.gov/publictn>. Acesso em 18/06/2003. 
NEWMAN JUNIOR, J.C. The merging of fatigue and fracture mechanics concepts: a historical perspective. Progress in Aerospace Sciences, vol. 34, p. 347-390, 1998.

NISHIMURA, H; KAWAGUCHI, T. Evaluation method of slow crack growth on polyethylene pipes for gas distribution. In: Plastic-Pipes, XII, 2004, Milão. Proceendings of Plastic-Pipes XII, 2004 [1 CD-ROM].

OGORKIEWICZ, R.M (ed). Thermoplastics: properties and design. London: John Wiley \& Sons, 1974, 248p.

PAE, K.-D; CHU, H.-C; LEE, J.K; KIM, J.-H. Healing of stress-whitening in polyethylene and polypropylene at or below room temperature. Polymer Engineering and Science, v. 40, n. 8, p. 1783-1795, 2000.

PARDOEN, T; MARCHAL, Y.; DELANNAY, F. Essential work of fracture compared to fracture mechanics - towards a thickness independent plane stress toughness. Engineering Fracture Mechanics, v. 69, p. 617-631, 2002.

PEGORETTI, A.; MARCHI, A.; RICCÒ, T. Determination of the fracture toughness of thermoformed polypropylene cups by the essential work method. Polymer Engineering and Science, v. 37, n. 6, p. 1045-1052, 1997.

PERES, F.M. Desenvolvimento de métodos alternativos para a avaliação da resistência à fratura por fluência de resinas de polietileno utilizadas para a extrusão de tubos de água. Dissertação (Mestrado) - Escola Politécnica, Universidade de São Paulo, São Paulo, 2005.

PERES, F.M.; SCHÖN, C.G. Application of fracture mechanics to failure of high density polyethylene pipes used in service line of water distribution systems. In: PPS-2004: Americas Regional Meeting, Florianópolis, 2004. Proceedings of PPS2004 Americas Regional Meeting, The Polymer Processing Society, Florianópolis, [1 CD-ROM], 2004.

PERES, F.M.; SCHÖN, C.G. Evaluation methods of slow crack resistance in polyethylene. In European Conference on Fracture, 16., 2006, Alexandropoulis, Geece. Proceedings of $16^{\text {th }}$ European Conference on Fracture - ECF 16. Dordrecht: Springer, 2006.

PERES, F.M.; SCHÖN, C.G. An alternative approach to the evaluation of the slow crack growth resistance of polyethylene resins used for water pipe extrusion. Journal of Polymer Research, 14, p. 181-189, 2007.

PERES, F.M.; SCHÖN, C.G. Application of the essential work of fracture method in ranking the performance in service of high-density polyethylene resins employed in pressure pipes. Journal of Materials Science, 43, p. 1844-1850, 2008.

PLASTIC PIPE INSTITUTE. Handbook of polyethylene pipe. $1^{\text {st }}$ ed., 2006. Disponível em <http://www.plasticpipe.org/publications>, acesso em 09/01/2009. 
PROGELHOF, R.C.; THRONE, J.L. Polymer Engineering Principles. Munich: Hanser, 1993, 918p.

QIAN, R.; LU, X.; BROWN, N. Investigating the existence of a threshold stress intensity for slow crack growth in high-density polyethylene. Journal of Materials Science, 24, p. 2467-2472, 1989.

RICE, J.R. A path independent integral and the approximate analysis of strain concentration by notches and cracks. Journal of Applied Mechanics, Transactions of the ASME, v. 35, p. 379-1968.

RICE, J.R.; ROSENGREN, G.F. Plane strain deformation near a crack tip in a power-law hardening material. Journal of Mechanics and Physics of Solids, vol. 16, p. 1-12, 1968.

RICE, J.R.; PARIS, P.C.; MERKLE, J.G. Some further results of J-integral analysis and estimates. Progress in Flaw Growth and Fracture Testing, ASTM STP 536, American Society for Testing and Materials, Philadelphia, Pa., p. 231-245, 1973.

RODRIGUEZ, F. Principles of polymer systems. Taylor \& Francis, $3^{\text {rd }}$ ed., 1989, $640 \mathrm{p}$.

ROSE, L.J.; CHANNELL, A.D.; FRYE, C.J.; CAPACCIO, G. Slow crack growth in polyethylene: a novel predictive model based on the creep of craze fibrils. Journal of Applied Polymer Science, v. 54, p. 2119-2124, 1994.

RUDIN, A. The elements of polymer science and engineering. San Diego: Academic Press, $2^{\text {nd }}$ ed., 1999., 509p.

SALEEMI, A.S.; NAIRN, J.A. The plain-strain essential work of fracture as a measure of the fracture toughness of ductile polymers. Polymer Engineering and Science, v. 30, n. 4, p. 211, 1990.

SAXENA, A. Nonlinear fracture mechanics for engineers. Boca Raton, Florida: CRC Press, 1998, 472p.

SCHÖN, C.G. Mecânica dos Materiais. São Paulo: Epusp, 2008. 359p. Apostila para disciplinas de graduação e de pós-graduação do Departamento de Engenharia Metalúrgica e de Materiais, PMT-2405 - Mecânica dos Materiais, PMT-2406 Mecânica dos Materiais Metálicos, PMT-5857 - Tópicos Avançados em Fadiga dos Materiais e PMT-5860 - Teoria da Plasticidade e da Fratura dos Materiais.

SHIH, C.F.; GERMAN, M.D. Requirements for a one parameters characterization of crack tip fields in large-scale yielding. Elastic-Plastic Fracture, ASTM STP 668, American Society for Testing and Materials, pp. 175-194, 1979.

SCHÜTZ, W. A history of fatigue. Engineering Fracture Mechanics, v. 54, n. 2, p.263-300, 1996. 
SOUZA, J.M.; PERES, F.M.; SCHÖN, C.G. Methods for introducing pre-cracks in fracture mechanics testing of polymers. In: $17^{\text {th }}$ European Conference on Fracture, Brno, Czech, 2008. Proceedings of $17^{\text {th }}$ European Conference on Fracture - ECF-17, 2008.

TARPANI, J.R. Avaliação da estabilidade de trincas em componentes estruturais por meio do parâmetro elasto-plástico Integral-J e comparação com resultados obtidos via mecânica da fratura elástica linear. Tese (Doutorado) Escola de Engenharia de São Carlos, Universidade de São Paulo, São Carlos, 1995.

TJONG, S.C.; XU, S.A.; LI, R.K.Y. Work of fracture of polystyrene/high density polyethylene blends compatibilized by triblock copolymer. Journal of Applied Polymer Science, v. 77, p. 2074-2081, 2000.

WIEBECK, H.; HARADA, J. Plásticos de engenharia: tecnologia e aplicações. São Paulo: Artliber, 2005, 349p.

WILLIAMS, J.G. $\mathbf{K}_{\mathrm{c}}$ and $\mathbf{G}_{\mathrm{c}}$ at slow speeds for polymers, in MOORE, D.R.; PAVAN, A.; WILLIAMS, J.G. (ed.): Fracture mechanics testing methods for polymers, adhesives and composites. Amsterdam: Elsevier, ESIS Publication 28, 2001a, p. 11-26.

WILLIAMS, J.G. Introduction to elastic-plastic fracture mechanics, in MOORE, D.R.; PAVAN, A.; WILLIAMS, J.G. (ed): Fracture mechanics testing methods for polymers, adhesives and composites. Amsterdam: Elsevier, ESIS Publication 28, 2001b, p.119-122.

WILLIAMS, J.G.; RINK, M. The standardisation of the EWF test. Engineering Fracture Mechanics, 74, p. 1009-1017, 2007.

WU, J; MAI, Y.W. The essential fracture work concept for toughness measurement of ductile polymers. Polymer Engineering and Science, v. 36, n. 18, p.2275, 1996.

YAMAKAWA, R.S.; RAZZINO, C.A.; CORREA, C.A.; HAGE JR, E. Influence of notching and molding conditions on determination of EWF parameters in polyamide 6. Polymer Testing, v. 23, p. 195-202, 2004. 